

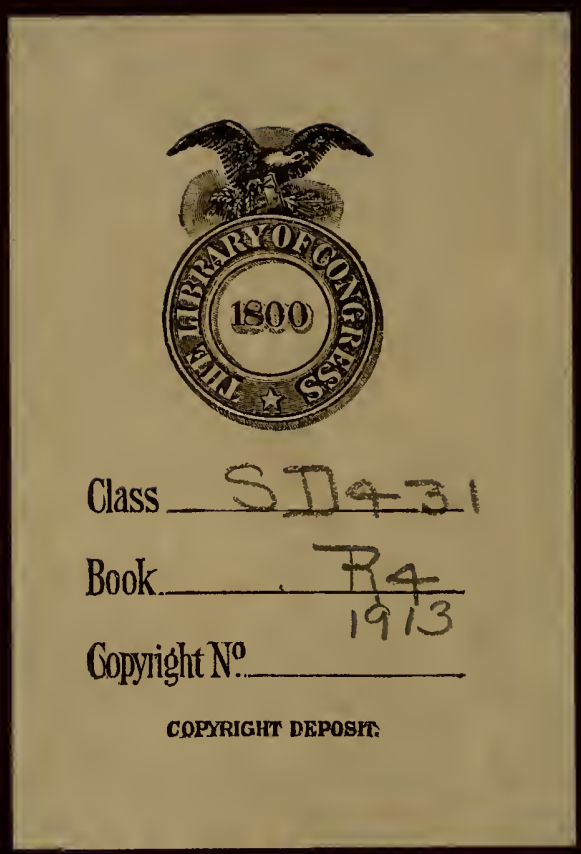








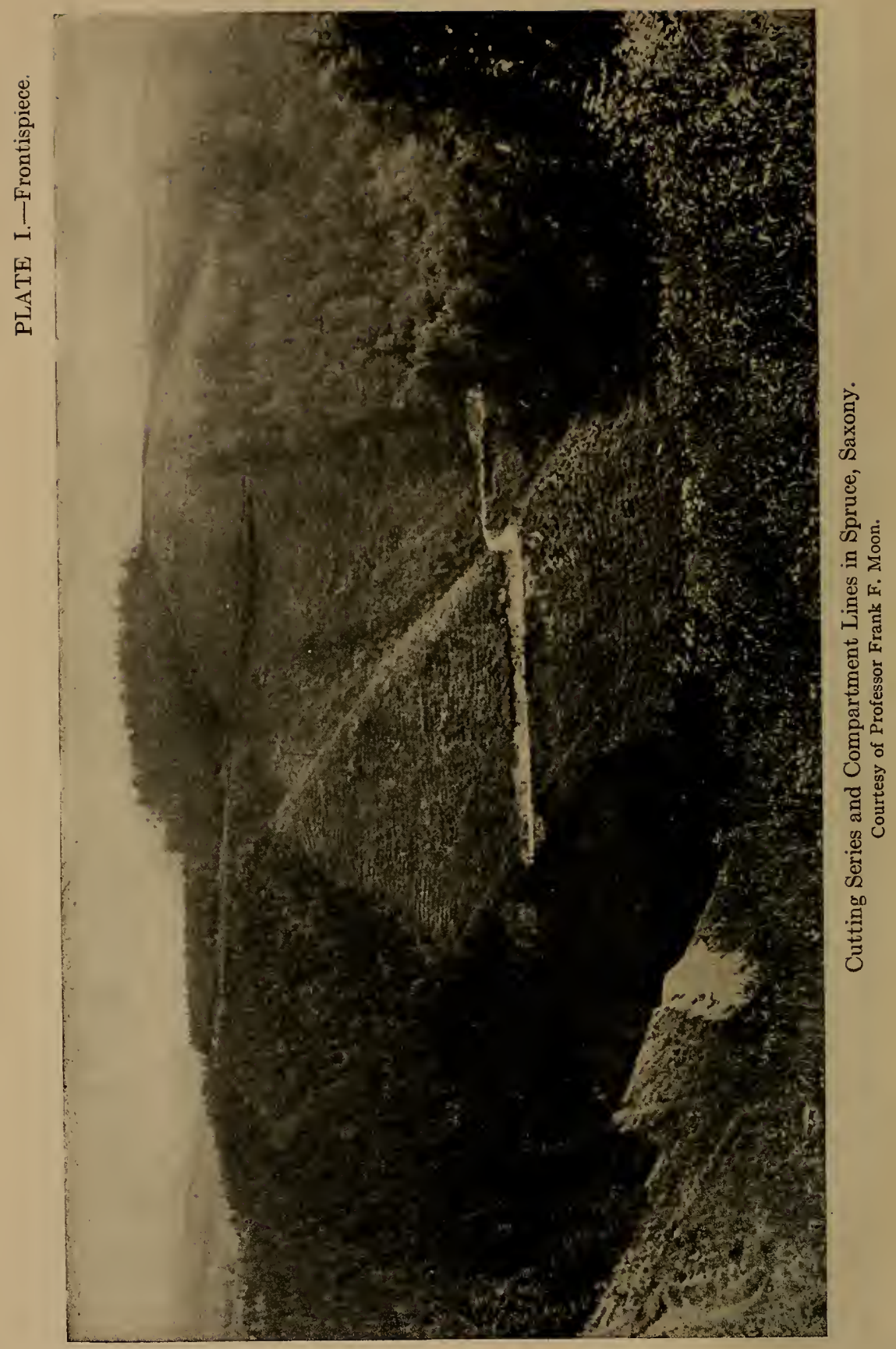




\title{
The
}

\section{Theory and Practice}

OF

\section{Working Plans (FOREST ORGANIZATION)}

BY

A. B. RECKNAGEL, B.A., M.F.

"Professor of Forestry

CoRnell University

FIRST EDITION

FIRST THOUSAND

\author{
NEW YORK \\ JOHN WILEY \& SONS \\ LONDON: CHAPMAN \& HALL, LIMITED
}


Copyright 1913 by

A. B. RECKNAGEL

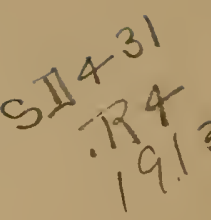

3

3 


\section{PREFACE}

THIs book does not pretend to present any original theories of Forest Organization, but merely the best of European efforts along this line adapted to the present needs of American forestry. The necessary data were gathered in the course of a year's study abroad, and, in their application, the experience gained in five years of similar work for the forest service in various parts of the United States was constantly kept in mind. The theoretical part has, therefore, been reduced to the minimum; similarly, the description of such intensive methods of regulating the yield as that by area and volume in periods has been merely sketched for the sake of completeness, since its application to America is of the far distant future, if ever. In a word, while sacrificing nothing to the completeness necessary in a textbook, the aim has been to make the book of value not only to the student, but also to the practising forester, and hence theory has in each case been subordinated to practice.

It will be ample reward for the time and labor spent, if this book takes its humble place in the growing list of American text-books on forestry.

Grateful acknowledgment is made to those who so unselfishly assisted in the collection of the subject-matter.

\section{A. B. RECKNAGEL.}

DRESDEN, SePtember, I9I2. 



\section{CONTENTS}

InTRODUCTION, - . . . . . . . . . . . . . . . . . . . xi

Value and Need of Working Plans, . . . . . . . . . . xi

Scope of Working Plans, . . . . . . . . . . . . xi

Sphere of Working Plans, . . . . . . . . . . . xii

\section{PART ONE}

\section{Foundations of Working Plans}

\section{CHAPTER I}

\section{Preliminary Basis}

Section I. The Normal Forest and its Attributes,

The Increment,

The Growing Stock, .

Section 2. Collection of Data.-Reconnaissance, . . . . . . . 8

Preliminary Work, . . . . . . . . . . . . . 8

Survey of Area, . . . . . . . . . . . . . . . 9

Timber Estimates, . . . . . . . . . . . . . . . . 10

Requisites, . . . . . . . . . . . . . 10

Base Lines, . . . . . . . . . . . . . . . I0

The Strips, . . . . . . . . . . . . . . . 12

Reconnaissance Estimates, . . . . . . . . . . I4

Topographic Notes, . . . . . . . . . . . . 16

Time of Survey and Estimate, . . . . . . . . . 16

Use of Yield Tables, . . . . . . . . . . . . I7

Cost, . . : . . . . . . . . . . . . 17

Forest Description . . . . . . . . . . . . . 17

Division of Area, . . . . . . . . . . . . . . 20

Designations of Divisions, . . . . . . . . . 23

Boundaries of Divisions, . . . . . . . . . . 23

Maps and Tables, . . . . . . . . . . . . 26

General Stand Table, . . . . . . . . . . 20

Age Class Table, . . . . . . . . . . . . . $3 \mathrm{I}$ 
Governing Conditions, . . . . . . . . . . . . 33

The Unit of Regulation, . . . . . . . . . . . . 33

Silvicultural Method of Management, . . . • . . . 35

Object of Management, . . . . . . . . . . . 37

The Rotation, . . . . . . . . . . . . . 38

\section{CHAPTER II}

Regulation OF Yield

Definition, . . . . . . . . . . . . , 42

Section I. Determination of Yield, . . . . . . . . . 43

By Area (I), . . . . . . . . . . . . . . . . . 44

By volume. Von Mantel's Method (2), . . . . . . . . 47

Méthode de Masson (3), . . . . . . . . . 49

By Current Annual Increment (4), . . . . . . 49

Formula Methods: Austrian Formula (5), . . . 52

Karl's Method (6), . . . . 55

Hundeshagen's Method (7), . . 59

Breymann's Method (8), . . 6I

Heyer's Method (9), . . . . 63

Summary and Comparison of the Formula Methods, . 65

French Method (10), . . . . . . . . 66

Indian Method (II), . . . . . . . . 72

Diameter Class Method (I2), . . . . . 75

By Area and Volume. Russian Method (13), . . . . . 78

Direct Method (I4), . . . . . 8I

Hufnagl's Method (15), . . . . 82

The Stand Method (16), . . . . . 84

The Period Methods (17), . . . . 89

Review of the Methods of Determining the Yield, . . . . . 94

Section 2. Distribution of Yield, . . . . . . . . . . . . . 96

Selection of Stands to be Cut, . . . . . . . . . . 97

Mapping of Stands to be Cut, . . . . . . . . . . . 98

Cutting Series, . . . . . . . . . . . . . . . . . . 99

Plan of Cutting, . . . . . . . . . . . . . . 100

General Cutting Plan, . . . . . . . . . . . . Iог

Annual Cutting Plan, . . . . . . . . . . . 103

Section 3. Regulation of Yield in Special Cases, . . . . . . . . 104

I. Regulation of Abnormal Forests, . . . . . . . . . 104

II. Regulation of Transition Forests, . . . . . . . . . . I06

III. Regulation of Wood-lots, . . . . . . . . . . . I08

IV. Regulation of Turpentine Forests, . . . . . . . . . . 108 


\section{CHAPTER III}

\section{The Working-Plan Document}

Section I. Contents and Form,

r. Orientation,

2. Foundations, . . . . . . . . . . . . . . . II6

3. Recommendations, . . . . . . . . . . . . . . . II9

4. Regulation, . . . . . . . . . . . . . . . . . . I2 I

Section 2. Outlines for Working Plan, . . . . . . . . . . . I22

A. Prussian Outline, . . . . . . . . . . . . . . I22

B. Saxon Outline, . . . . . . . . . . . . . . . . 124

C. American Outline (suggested). Complete Forest Plan, . . . I24

Section 3. The Planting Plan, . . . . . . . . . . . . . 128

Annual Planting Plan, . . . . . . . . . . . . . . . I30

General Planting Plan, . . . . . . . . . . . . . . . I32

Section 4. Control and Revision of Working Plan, . . . . . . . . I33

Control Book, . . . . . . . . . . . . . . . . . 134

\section{PAR'T TWO}

\section{Practice of Working Plans}

\section{CHAPTER I}

IN Europe

Section I. Germany, PAGE

I. Prussia, . . . . . . . . . . . . . . . . . . . I 137

II. Bavaria, . . . . . . . . . . . . . . . . . . I47

III Saxony, . . . . . . . . . . . . . . . . . . I59

IV. Württemberg, . . . . . . . . . . . . . . . . I63

V. Baden, . . . . . . . . . . . . . . . . . I64

VI. Alsace-Lorraine, . . . . . . . . . . . . : . 167

Section 2. France, . . . . . . . . . . . . . . . . . . . I7I

Division of Area, . . . . . . . . . . . . . . . . . 172

Method of Determining the Yield, . . . . . . . . . 173

Distribution of the Periodic Cutting Areas, . . . . . . . 175

Determination of the Allowed Annual Cut, . . . . . . . I76

Section 3. Austria, . . . . . . . . . . . . . . . . . I77

Division of Area, . . . . . . . . . . . . . . . I 80

Estimates and Forest Description, . . . . . . . . . . I82

Determination of the Yield, . . . . . . . . . . . . I85

Control and Revision of the Working Plan, . . . . . . . I86

Section 4. Résumé, . . . . . . . . . . . . . . . . . I87 


\section{CHAPTER II}

\section{IN AMERICA}

Section I. Early Beginnings, PAGE

Section 2. The New Reconnaissance, . . . . . . . . . . . . I9I

Current Outline for Forest Working Plans, . . . . . . . . . I92

Section 3. Present Procedure, . . . . . . . . . . . . . . $20 \mathrm{I}$

Forest Plans, . . . . . . . . . . . . . . 202

Preliminary Plans, . . . . . . . . . . . . 203

Working Plans, . . . . . . . . . . . . . . . . 208

Annual Plans, . . . . . . . . . . . . . . . . . . . 211

Outline for the Plan of Silvicultural Management, . . . . . 2 I3

Timber Estimates, . . . . . . . . . . . . . . . 213

Forest Types, . . . . . . . . . . . . . . . . . 214

Object of Management, . . . . . . . . . . . . .215

Silvicultural System, . . . . . . . . . . . . . . 215

Regulation Yield, . . . . . . . . . . . . 216

Regulation of Cut, . . . . . . . . . . . . . 216

Policy, . . . . . . . . . . . . . . . . . . . 217

Stumpage Rates, . . . . . . . . . . . . . . . 217

Utilization, . . . . . . . . . . . . . . . 218

Timber Business Statistics, . . . . . . . . . 220

Planting, . . . . . . . . . . . . . . . . . . 224

Timber Reconnaissance, . . . . . . . . . . . . 226

Investigations, . . . . . . . . . . . . 226 


\section{ILLUSTRATIONS}

Plate I.-Cutting Series and Compartment Lines in Spruce, Saxony.

Frontispiece

Plate II.-A Reconnaissance Survey Party, Florida, . . . . . . Io $^{\text {PAge }}$

Plate III.-A Reconnaissance Survey Camp, Florida, . . . ‘ . I6

Plate IV.-Fig. I. A Compartment Regenerated by Shelterwood Cutting, Baden. Fig. 2. A Compartment Regenerated by Border

Cutting, Württemberg, . . . . . . . . . . 36

Plate V.-Road Forming a Compartment Boundary Line, Saxony, . I6o

Plate VI. - A Burned Area, Forming a Subcompartment, Arizona, . . $208 \mathrm{~V}$

FIG. 1.-Sketch Map of part of a Block, showing Compartments, Subcompartments, Age Classes, and Cutting Series, . . . . 27

Fig. 2.-Turpentine Regulation: Number of Crops Operative Annually, . . . . . . . . . . . . . . . II 2 



\section{INTRODUCTION}

\section{VALUE AND NEED OF WORKING PLANS}

SystemaTIC forest management demands that the yield in timber or other forest products be regulated according to time and place. This apportioning of the yield is the sphere of Forest Organization through its instrument, the Working Plan.

Forest Organization is co-ordinate in importance with Silviculture, Forest Protection, and all the other major branches of the science of Forestry. It makes use of them all and combines their several teachings into a harmonious whole-the forest properly adjusted.

\section{SCOPE OF WORKING PLANS}

In its broadest sense a complete Forest Plan deals not only with Silvicultural Management of the timber resources. but may cover any or all of the following subjects:

I. General administration.

2. Silvicultural management.

3. Grazing management.

4. Permanent improvements.

5. Forest protection.

6. Uses of forest land.

Since the prime object of any forest is the growing of timber, the silvicultural management is the most important; it is also the most difficult. The present work will, therefore, confine itself to this phase of the complete forest plan. The French call this phase "Amenagement"_-"Management"; the Germans call it "Forsteinrichtung"— "Forest Adjustment" or "Forest Organization." The latter title seems preferable since "management" 
is commonly considered to include Mensuration, Valuation, etc.* Unfortunately the title "Working Plan" has been long used in America to designate not only the document, but the whole subject of Forest Organization. However, as Dr. Fernow says:i "It is difficult to eradicate poor terms once in the world," yet "we must admit also the use of synonyms, for, after all, language is partly a matter of taste and only partly of rule." The word "Working Plan" has, therefore, been retained for the present, but "Forest Organization" is used synonymously with it to designate the subject of regulated Silvicultural Management.

\section{SPHERE OF WORKING PLANS}

The working plan is not confined to such forests as are managed with the idea of a sustained yield, but is equally adapted to the exploitation forest; i.e. forests which are to be logged within the next ten or twenty years. As in every other business the adrantages of systematization are obrious; the working plan secures these adrantages. At the same time it is usually to the interest of the owner to leave the tract in as favorable a condition as possible for future growth without the undue expenditure of time, timber, or money. The rorking plan secures this by so organizing the logging operations that the natural reproductive powers of the forest are brought into full play instead of being nullified by the fortuities of haphazard and often unnecessarily destructive logging.

The sphere of Forest Organization therefore embraces all forests and is applicable to all classes of omners, large and small. letin I, I9I2.

"A Classification for Forestry Literature," Yale Forest School, Bul-

† "F. Q.," Vol. IX., No. 3, p. 427. 
PART ONE

FOUNDATIONS OF WORKING PLANS 



\title{
FOUNDATIONS OF WORKING PLANS
}

\author{
CHAPTER I \\ PRELIMINARY BASIS \\ SECTION ONE
}

\section{THE NORMAL FOREST AND ITS ATTRIBUTES}

AT the very root of Forest Organization lies the idea of a Normal Forest; that is, one which has a normal distribution of the age classes and a normal increment; these two factors will, of themselves, result in a normal growing stock. Such a forest probably does not exist; it is merely a theoretical ideal towards which to strive.

Assuming, therefore, that every forest is more or less abnormal, it is necessary to determine the degree of abnormality in the following directions:

r. Increment.

2. Growing Stock.

3. Distribution of the Age Classes.

In this connection it should be noted that while normality in I and 3 of themselves result in normality in 2, the reverse is by no means the case. A normal growing stock may exist in a forest with only a single age class. Valuable as its determination is, therefore, it should never be used as the sole criterion of regulating the yield.

\section{The INCREMENT}

The determination of the increment is the province of Forest Mensuration; without trespassing on this subject, so admirably 
covered in Mr. Graves' textbook, ${ }^{*}$ it is worth while to consider the matter solely in its relation to Forest Organization.

Not every method of regulating the yield requires the determination of the volume increment; e.g., the Method of Von Mantel or the Méthode de Masson. Again, it is possible to regulate the yield by increment alone (Hufnagl's Method). But, as is pointed out in Chapter II, most methods of regulating the yield require a determination of the increment.

The normal increment is that given in yield tables: this is required for several of the "formula methods." Where the real increment is to be taken from yield tables, the values given in the table must be reduced by the actual factor of density, since yield tables are always for fully stocked stands.

Where yield tables are not available, the incremen. must be determined on the ground, either by applying the increment per cent of representative trees of the stand, or else by calipering sample areas and figuring their increment by means of diametergrowth and diameter-volume tables. The former (and yield tables) is better for nearly even-aged stands; the latter method for all-aged stands.

Where diameter-growth tables are lacking, stump analyses can be made.

For determining current annual increment the use of an increment borer is deserving of wider popularity than it has heretofore enjoyed in America. Where no increment borer is obtainable, the representative trees, selected according to any of the standard methods (Draudt, Urich, etc.) can be cut into at breast height and the rings on the last inch of radius counted on the horizontal under-cut.

Schneider's formula then applies:

$p=\frac{400}{n d}$ (or 450 or 500 according as the height-growth of the tree is poor, average, or good), $\&$ Sons.

* "Forest Mensuration," Henry Solon Graves. New York, John Wiley 
where $n=$ number of rings of annual growth in the last inch and $d=$ diameter breast high, in inches.

The growth per cent must always be translated into figures of actual volume. For example:

A spruce tree 28 inches in diameter at breast height, of average height-growth, shows 8 rings in the last inch, bored at breast height. The increment per cent according to Schneider's formula is

$$
p=\frac{450}{28 \times 8}=2 \%
$$

Assuming a stand of 2,400 feet board measure per acre, the volume increment (current annual) would be, if this were a sample tree:

$$
\frac{2,400 \times 2}{100}=48 \text { board feet per acre per annum. }
$$

Whether the current annual or the mean annual increment is to be determined depends on the Method of Regulating the Yield which is to be adopted (Chapter II). However, in general it may be said:

The "formulæ methods" usually require the determination of the mean annual increment. Methods by Area and Volume usually employ the current annual increment pro-rated for the next decade or two decades. Indeed, for the "Period" Methods it usually suffices to determine the increment of only such stands whose age is more than half the rotation $\left(\frac{r}{2}\right)$ or even only those of the two highest age classes of, say, 20 years each. In either case it is not usually necessary to determine painstakingly the exact increment of each stand, but rather to correctly approximate the increment in each Working Figure-i.e., the unit area for which the yield is to be regulated; for it is evident that in comparison with the volume of merchantable timber the increment is a relatively small amount. It is a useful fact that in stands approaching maturity (not overmature) the mean annual and current annual increment remains virtually the same 
for about ten years; since the former is simply the volume divided by the age $\left(\frac{V a}{a}\right)$, a simple way is thereby opened to approximate the current annual increment in mature, evenaged stands.

\section{The Growing Stock}

The normal growing stock is expressed by the formula:

$$
n v=\frac{r i}{2}
$$

where $n v=$ normal volume of growing stock, $r=$ rotation, and $i=$ the normal increment. $n v$ can also be determined directly from yield tables constructed by measurements of fully stocked stands. That the normal volume is possible even with abnormal arrangement of the age classes is clear if one considers a unit of area covered with a normal steplike gradation of the age classes, the same area half bare and half stocked with trees whose age equals $r$ (the rotation), or again, the whole area stocked with trees whose age equals $1 / 2 r$. In each case by the formula $n v=\frac{r i}{2}$ the growing stock would be apparently normal, yet true normality exists only in the first case.

\section{Distribution of the Age Classes}

The correct distribution of the age classes is theoretically like a series of equal sized steps, growing higher towards the prevailing storm direction. However, this theoretical ideal is never achieved; it suffices that each age class has an approximately equal representation on the area which is to have a sustained yield; in fact, without a fairly even distribution of the age classes sustained yield on a given area is impossible.

Twenty years is commonly taken as one age class, though sometimes ro and sometimes 36 years is used. In any case the rotation must be a simple multiple of the age class. It is customary to number the age classes from I up, beginning with 
the youngest.* Thus for an 80-year rotation there are four age classes of twenty years each; a fifth age class would contain all stands older than $r$ (the rotation).

Where stands are fairly even-aged, but conditions are too extensive to permit the exact assignment to definite age classes, the general classification into:

merchantable

near merchantable

intermediate

young growth

will serve the purpose. It is of the utmost importance to get some conception of how the age classes are distributed. If it is possible, the age should be determined by counting the annual rings on recent stumps, but in default of this it is useful to note the age class roughly as:

$O$ overmature (more than rotation age)

$M$ mature (of rotation age down to $1 / 2$ thereof)

$Y$ young (from lowest age to $1 / 2$ rotation)

The perfect selection forest is, of course, all aged and hence has no age classes, or rather all age classes are inextricably intermingled. But where the age differences are not to exceed $1 / 3$ or $1 / 4$ of the rotation, the stand can be classified according to its average age, or, more exactly, according to the proportion of space each age occupies. For example: 320 acres of spruce might contain 160 acres of trees 70 years old, Ioo of trees 60 years old, and 60 acres of trees only 40 years old. The average age here would be $6 \mathrm{I}$ years; for:

$$
\frac{160 \times 70+100 \times 60+60 \times 40}{320}=61 \text { years. }
$$

Where, in uneven-aged forest, the age classes are so intermingled that they cannot be distinguished by area but only by volume (from the diameter-classes in the estimates, see

* In Prussia this is reversed, I. is the oldest age class. 
Section 2), the average age $=$ the $\frac{\text { volume }}{\text { increment }} ;$ e.g., if the unevenaged forest has three main age classes:

I00 year class with 2,000 feet board measure

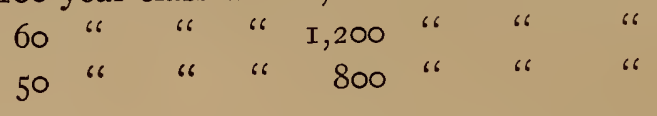

then the average age would be $\frac{2000+\mathrm{r} 200+\frac{800}{2000}}{\frac{100}{100}+\frac{1200}{60}+\frac{800}{50}}=71.4$ years.

The ordinary selection forest would show the following distribution of ages by area:

E.g., 900 acres of selection forest with a rotation of $I_{5} \circ$ years and a cutting cycle of 30 years would normally contain $\frac{I 50}{30}=5$ age classes, not distinct in space but in area, as follows:

$$
\begin{aligned}
& \text { Trees I- } 30 \text { years old } \frac{900 \times 30}{I_{50}}=I 80 \text { acres }
\end{aligned}
$$

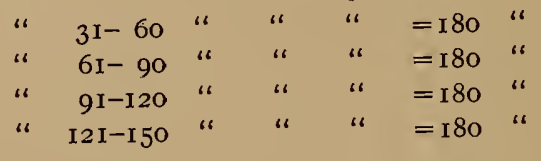

A convenient way to express the age limits and average age in an uneven-aged stand is by the expression $\frac{50-100}{7 \mathrm{I}}$ where, in the example above, the age varies from 50 to Ioo years and the average has been determined as $7 \mathrm{I}$ years (strictly $7 \mathrm{I} .4$ years). Where the average age has not been arithmetically determined the approximate age figures will, at least, serve as a valuable guide. Or even the letters $O, Y, M$ may be used, e.g., $\frac{O-M}{O}$ would be a stand Mature to Overmature with the average Overmature, i.e., in excess of the rotation age. 
Nor should it be forgotten that certain species, such as fir and spruce, often withstand decades of suppression during which their growth is almost nil. In determining their age this "core of suppression" should, therefore, be disregarded.

Areas that are being regenerated by shelterwood methods fall into two age classes, divided according to the per cent of density of the original stand. For example, a shelterwood cutting in a 90-year-old stand covering 200 acres of which only 40 per cent of the stand remained uncut would be apportioned: 80 acres to the higher-age class and 120 acres to the lowest or to the "blanks" if no reproduction was on the ground. Where less than 20 per cent of the original stand remains on a cutting area or burn and the density of stocking is less than .3 (Section 2) and there is no reproduction the area is, temporarily at least, classed with the "blanks."

The age classes are differentiated by species only if there is a marked difference in their value.

There are two graphic ways of comparing the actual with the normal distribution of the age classes. One is by plotting the normal and the actual area of each age class on cross-section paper, using the co-ordinates for age and the abcissæ for area. The normal distribution will, of course, be a straight line; the actual a zigzag, now rising above, now falling below the horizontal line of normality.

The other method is that of rectangular blocks, the normal age classes being equal-sized and placed next to the unequal blocks showing the actual size of the various age classes.

It is always of advantage to compare the real and the normal age-class distribution; for it is a criterion of a sustained yield and, in conjunction with the increment, determines the degree of approach toward a normal forest. 


\section{SECTION TWO}

\section{COLLECTION OF DATA-RECONNAISSANCE.}

Here again Forest Organization touches upon the domain of Forest Mensuration and, in part, of Engineering. Hence only the salient points affecting the Working Plan will be treated.

\section{Preliminary Work}

Before the field work is begun, all available data should be gathered from the records, along the following lines:

I. Area and boundaries of forest.

2. Best existing estimates of timber.

3. Approximate distribution of species.

4. Salient topographic features.

5. Past cuttings and their results; stumpage prices.

6. Classes of material utilized; prices obtained; market conditions.

7. Previous working plan or previous silvical studies; volume, growth, or yield tables.

8. Best maps available.

Armed with these data, the Forest Organizer should then make a preliminary trip over the forest so as to gain a general familiarity therewith and the better to formulate his plan of campaign. Wherever possible, he should be accompanied by the owner, the administrator, or both.

A conference should always be had between the owner or administrator, or both, and the Forest Organizer. The wishes and objects of the owner are basic in outlining a plan of silvicultural management and determine what data are requisite and what degree of detail is necessary in securing these data. The permissible cost of field work should also be decided. It is well if the results of this conference are put in writing and the document signed by each of the participants. 


\section{SuRVEY OF AREA}

A good map is an essential part of every Working Plan. The map need not be elaborate, but it must be accurate.

Where the land involved has not been surveyed, this must form a part of the field work, though it can often be done in conjunction with the estimating. In every case, reconnaissance involves at least the retracement of the principal land lines and their fixation on the ground and on the map. Especial attention must be given to the boundary lines.

It is very serviceable to post boundary and interior corners with fire warnings or similar placards, in pathless forests. These are most helpful in indicating the position of corners, especially if they are stamped with rubber stencils and indelible ink to show what corner it is. Thus where the land is sectionized, the section corner would be posted and perhaps also where an important section or township line crossed a much-traveled road or trail. The object is to make the results of field surveys or retracement of old survey lines available not only on the map, but on the ground.

The extent to which topography should be shown depends on the uses of the map. Where a detailed plan of logging is to be included, the topography must be shown in detail. For purposes of ordinary forest organization it suffices to show all drainage, all roads and trails, all houses, barns, and other "culture," and the topography in contours of roo-foot interval sketched in from aneroid barometer traverses. In level country contours serve no useful purpose. In the matter of topography the object is to get a good working medium for orientation and for the subsequent division of the area.

The scale of the map must depend on the size of the area, the wealth of detail, and the intensity of the proposed management. Ordinarily a scale of $\mathbf{I}$ or 2 inches to the mile for the general map is quite sufficient. Where the forest is very large it is well to have a small scale location map, and then larger scale maps showing the various parts of the forest in greater detail. 
No survey of the area-and no forest map-is complete which does not include a delineation of the forest types. This is usually done in conjunction with the estimating, but its importance must be emphasized here. Simplicity in type distinctions is essential for clearness. Only those type differences should be recognized which are sufficiently striking as to be recognized instantly by every trained eye. Ordinarily, permanent types alone should be regarded, but often transitory types-e.g., aspen on old burns-must be recognized, since they demand a different treatment. Minor differences should never, for the purposes of a Working Plan, be made the basis of type distinction.

The mapping of all cut-over or burned areas, of swamps, barrens, etc., is a part of every forest survey.

\section{Timber Estrmates}

Requisites.-Without encroaching on the subject of forest mensuration, the requisites of the timber estimates for purposes of the Working Plan are:

I. Amount and species of timber.

2. Class of timber (saw timber, cordwood, etc.).

3. Condition of timber (soundness).

4. Approximate age of timber.

For purposes of combining the survey with the timber estimate, the strip method of estimating is undoubtedly the best. From a definite base line-such as a section boundary or, if in unsurveyed or very rough country, a base line previously run out-the strips are run out at right angles, at definite intervals.

Base Lines.-The section line serves as an excellent base, especially in fairly level country. Rough topography or the lack of suitable survey lines as a base make it necessary to establish base lines in advance of the actual estimating. They should be located in valley bottoms, along roads, or elsewhere so that they can be easily re-traced; at the same time they give a preliminary 
PLATE II.

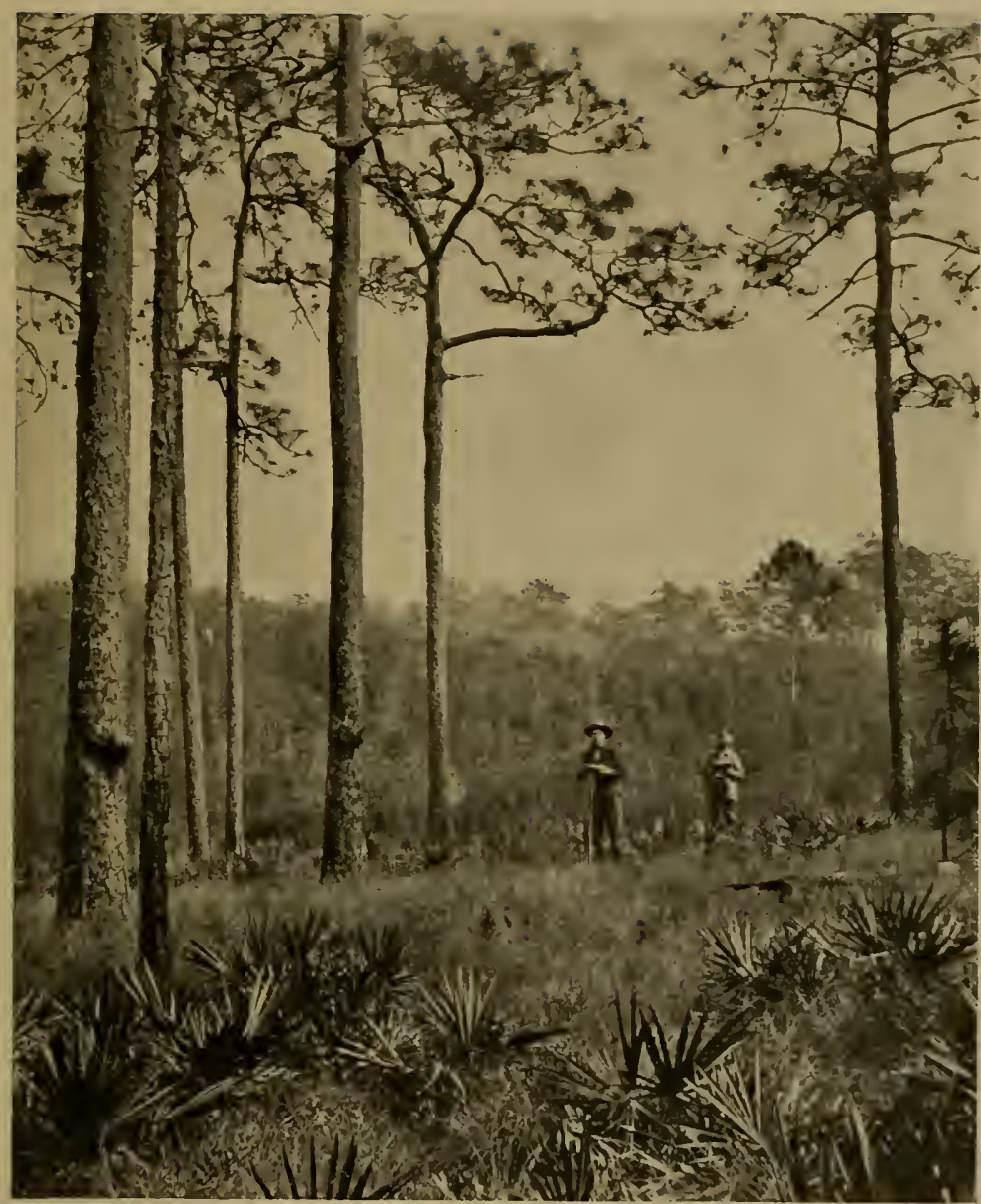

A Reconnaissance Survey Party, Florida. 

topographic control. The distances must of course be measured accurately either by chain or tape or by stadiæ. The use of stadia-involving a mountain transit or a telescopic alidadeis advisable only in fairly open country or for the primary base lines. The chain or tape is much handier in timbered country; pacing is not accurate enough for this purpose.

Beginning at some known point, or at least tied thereto by definite triangulation, the base line system is developed over the whole forest like the stem and branches of a tree. The number of base lines must depend on the intensity of the work ; better fewer and accurate than many and slipshod.

A traverse board and open sight alidade are excellent for base-line work unless the timber is too dense; then chaining alone is possible, and the notes must be plotted not only upon return to camp, but immediately, in the rough, so as to determine where the equidistant survey stations are to be established. For the base line traverse will necessarily be a zig-zag and the survey stations must be exactly equidistant. They are usually marked with a stake and a pile of stones or a blaze, scribed or blue-penciled with the number and the elevation of the station. For purposes of identification it is well to place the station close to some road, trail, stream, or other topographic feature. The elevation is determined by aneroid barometer readings carried from some point of known elevation. Where transit or telescopic alidade are used it can also be determined by the vertical angles. The crossings of all roads and trails, of creeks, etc., are noted, either directly plotted on the traverse table or else entered in the note-book; the elevation at these crossings is also noted.

If the forest is so large that the estimating will require several seasons, only so much of the base-line work need be completed in advance as will be used in that season. However, base-line work can often be done to advantage several months before the detailed estimates are begun.

Wherever possible, the Forest Organizer should himself be in charge of the base-line work. Three men constitute the ordinary base-line crew; two will suffice at a pinch, though it is 
better to have two to chain and one for the traverse board or to enter notes, take aneroid readings, etc..

The Strips.-The estimate strips should always run across the topography; only in that way will average conditions be secured. The size of the crew depends on the method of estimating employed. The ordinary valuation survey crew consists of two caljper men, and a head and a rear chainman. The former runs the compass, the last named takes notes on topography and elevation and enters the diameters breast high as called out by the caliper men. Each strip is usually one chain wide.

Where the strip is not chained, the crew can be reduced to three, or even two, the compassman to pace and keep notes, two (or one) to caliper.

Where trained men are used, calipering is seldom necessary; here two men-one to pace and keep notes, one to estimate diameters-suffice.

In open timber the strips can be widened to one chain on each side of the line.

One man can run a strip, but he can scarcely manage compass, aneroid, note-book, and estimate all at the same time. Either he must make an ocular estimate of the whole stand or else confine himself to quarter-acre (or similar sized) sample areas at definite intervals. Only in cases of need is this samplearea method advised; it is usually better economy to use a two or more man crew. The work goes better, the men check each other's judgment and, finally, in case of accident, the single man is not left helpless.

The strips must gridiron the forest. The interval between the grids depends on the purpose of the work. For a reliable estimate 5 to ro per cent of the area should be covered. This means:

For 5 per cent of area: chain wide strips 20 chains apart.

" 5 " " " strips two chains wide, 40 chains apart.

" 5 " " " Four I/4-acre sample areas, 21/2 chains apart on strips 20 chains apart 
For to per cent of area chain wide strips ro chains apart.

" Io " " " strips two chains wide 20 chains apart.

" 10 " " $"$ Four $1 / 4$-acre sample areas, 21/2 chains apart on strips ro chains apart.

A very practical way of recording the estimates is by 3 -inch diameter classes, beginning with the smallest merchantable diameter, supposing this to be II inches, as follows:

\begin{tabular}{|c|c|c|c|c|}
\hline \multirow{2}{*}{$\begin{array}{l}\text { D. B. H. } \\
\text { inches }\end{array}$} & \multicolumn{4}{|c|}{ SPECIES } \\
\hline & Pine & Spruce & Fir & Etc. \\
\hline $12 \ldots \ldots \ldots \ldots$ & & & & \\
\hline I $5 \ldots \ldots \ldots \ldots$ & & & & \\
\hline $18 \ldots \ldots \ldots$ & & & & \\
\hline $21 \ldots \ldots \ldots \ldots$ & & & & \\
\hline 24 , etc........ & & & & \\
\hline Poles......... & & & & \\
\hline Saplings....... . & & & & \\
\hline Seedlings...... & & & & \\
\hline
\end{tabular}

Seedlings are all trees under 5 feet in height; these are usually counted on a quarter-acre circle at the end of every ten chains or so, to supplement the notes on reproduction (see below).

Saplings are from 5 feet in height to, say, 6 inches diameter breast high.

Poles are over, say, 6 inches diameter breast high up to the minimum merchantable diameter. Poles and saplings are counted and tallied just like the larger timber.

While the strip estimates, in combination with volume tables, usually give more accurate results than an ocular estimate, the greater expense of the former and the longer time required to cover a given area often decide in favor of the latter, expecially where a rough estimate suffices and data on diameter classes are not requisite.

Various methods of ocular estimating have been devised; for rurposes of Forest Organization the Method of Reconnaissance 
Estimating practised by the Federal Forest Service since I 907 is probably the best.*

Reconnaissance Estimates.-This method is briefly as follows: Beginning at a known point, the estimator paces ro chains, compass in hand, in a straight N., S., E., or W. line. This places him in the centre of a 40-acre square. For example, if the initial point were to chains west of the southeast corner of Section 6, the estimator would pace to chains due north and thereby be in the exact centre of the S.E. $1 / 4$ of the S.E. $1 / 4$ of Section 6.

Here the estimator glances carefully around and "sizes up" the timber to the best of his ability. However, he makes no permanent entry in his note-book until, having gone a further ro chains in the same direction, the boundary of the 40-acre square is reached. The last ro chains may have revealed conditions necessitating a change in the original estimate; the estimator now sets down the estimate by species for the entire forty directly in $\mathrm{M}$. feet board measure or cords or other unit. A diagrammatic blank is provided for the purpose. He also notes the general age of the timber and designates it for the forty by the letters:

$O$ for overmature-older than the rotation age.

$M$ for mature -more than half the rotation age.

$Y$ for young - -less than half the rotation age.

The intermediate grades $O-M$ and $Y-M$ are also used.

This classification and the estimates are for timber above the minimum merchantable diameter; below this diameter, the "young growth" or "reproduction" is designated for the forty by the letters:

$G$ for good-enough to fully restock the area.

$F$ for fair -enough to half restock the area.

$P$ for poor-practically nothing wherewith to restock the area.

The intermediate grades $G-F$ and $P-F$ are also used.

* For detailed description see "Proceedings Society of American Foresters," Vol. IV., No. I. Reprinted Yale Publishing Association, 1909. See also, for practical workings, cost, etc., "F. Q.," Vol. VIII., No. 4, pp. 4I5 to 4I 8. 
This process repeats itself for each forty. For purposes of checking, the estimator ties his line to any known points. E.g., in the above example, after having run 40 chains or to the middle of the Section, the estimator ties to the E. $1 / 4$ corner thereof; again, after having run 80 chains or to the northern section line, the estimator ties to the N.E. section corner. Similarly baseline corners are tied to, and the aneroid elevations checked.

In tying to surveyed section corners Mr. J. H: Allison of the Forest Service has, from many years of field experience, evolved an excellent shortcut. E.g., in the example cited above, the estimator starts directly from the S.E. section corner and runs I4.I chains N. $45^{\circ} \mathrm{W}$., which places him in the centre of the S.E. $1 / 4$ of the S.E. $1 / 4$. Thence he runs due north Io chains at a time. The twentieth chain places him in the centre of the N.E. $1 / 4$ of the S.E. $1 / 4$. Thence he runs I4.I chains N. $45^{\circ}$ E. to the E. I/4 corner and ties thereto. Thence again I4.I chains N. $45^{\circ} \mathrm{W}$. to the centre of the S.E. $1 / 4$ of the N.E. $1 / 4$, thence Io and again ro chains due north to the centre of the N.E. $1 / 4$ of the N.E. I $/ 4$, thence I4.I chains N. $45^{\circ}$ E. to the N.E. section corner. To go back southward through the section-from the N.E. section corner the estimator runs 20 chains due W., thence S. $45^{\circ}$ W. I4.I chains to the centre of the N.W. $1 / 4$ of the N.E. I $/ 4$, thence due south, reversing the process previously described (except that there is no centre corner to tie to), and so reaching after 60 chains due south, the centre of the S.W. $1 / 4$ of the S.E. $1 / 4$, and thence $14 . I$ chains S. $45^{\circ} \mathrm{W}$. to the south $1 / 4$ corner of the section.

Obviously, the distance between the strips must be varied according to the character of the timber traversed. Very open stands may permit strips 40 instead of 20 chains apart and estimates by quarter sections; in dense stands the distance may have to be shortened to to chains and the estimate made by Io-acre units. The method remains the same. The criterion is the area which can be looked over by the estimator without slighting any important part.

In this method the estirnator should be an experienced judge 
of timber; in any case he should check his judgment by frequent sample areas whose contents have been accurately determined by calipering each tree; thorough drills, monthly, on sample "forties" will serve to test and bring up to standard the judgment of each man in an estimating crew.

Topographic Notes.-Besides the timber estimating, it is a valuable feature of all strip systems that the opportunity is offered to get excellent data on topographic features.

The estimator or tally man carries an aneroid barometer and notes the elevation at each stream, divide, or similar feature; also at each corner to which he ties. Streams, ridges, roads, trails, etc., are sketched by him in a suitable note-book so as to show the exact point at which these features were crossed and their trend for a short distance to either side of the survey line. The same method applies to burned and cut-over areas. The boundaries of these and of the forest types should be noted where they are crossed and their trend for a short distance to either side of the survey line. These data should be sketched in on blanks or note-books provided for the purpose.

Time of Survey and Estimate.-The "field season"-i.e., that season when field work can be accomplished with the minimum of climatic difficulties - is usually the best for the work of estimating and mapping. In mountainous countries and in northern latitudes, this means the summer months; in southern latitudes winter is often preferable because of the excessive summer heat. Even in mountain regions the winter season may sometimes be chosen because the forest personnel is usually less heavily burdened with work in winter than in summer. That winter work is entirely feasible, if snowshoes or skis are used, is demonstrated by the winter reconnaissance in certain mountain forests of California.* One advantage of winter work is the ease with which the compassman's tracks can be followed by the cruisers and used by them as a check on the width of the estimating strips.

* See "Winter Reconnaissance in Californian Mountains," R. F. Hammatt, "F. Q.," Vol. IX., No. 4, pp. 557-562. 
PLATE III.

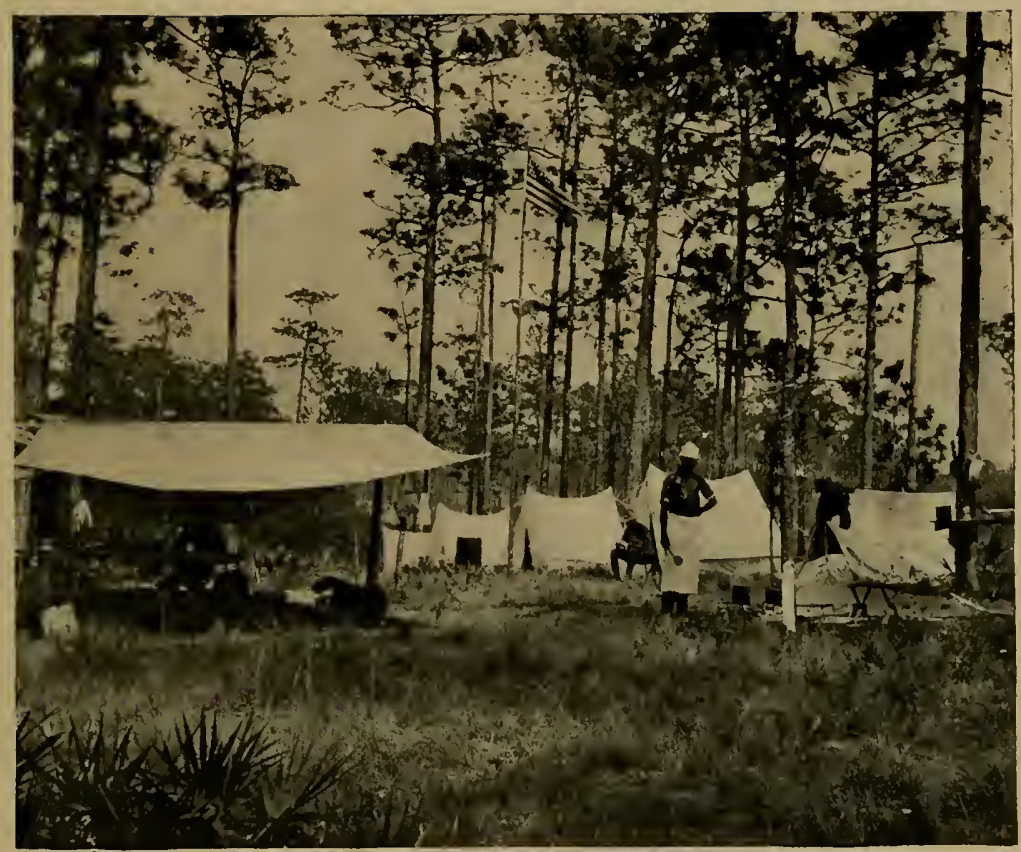

A Reconnaissance Survey Camp, Florida. 

Use of Yield Tables.-The estimating of timber by means of yield tables unfortunately finds little or no application in America because of the lack of suitable tables. Yield tables are constructed for even-aged fully stocked stands of a single species for various site qualities. The age is usually given in five- or ten-year intervals. European yield tables are separated for final and intermediate yield (thinnings) and total. Normal yield tables preponderate, but real (empirical) yield tables are used as makeshifts. The methods of making yield tables is the province of Forest Mensuration, but for purposes of Forest Organization the data should comprise at least: Age, Yield, Current and Mean Annual Increment for each Site Quality (I to V, see "Forest Description," below).

The use of Yield Tables requires the determination in the field of the following data (presupposing nearly even-aged stands): Age, Site Quality, Density of Stocking. The corresponding value for the age and site quality is read directly from the yield table and this multiplied by the factor of density (I.o to 0.०)-see "Forest Description," below. Where there are several species in the stand, the percentage of each is determined and the corresponding value in the various yield tables multiplied thereby; these values are then added and their sum multiplied by the factor of density ( 1.0 to 0.0 ).

Cost.--The cost of estimating by the strip methods averages between the following figures:

Summer work.......... r.5 to 6 cents per acre Winter work........... to 6 cents per acre

\section{Forest DESCRIPTION}

It is of the utmost importance for the Working Plan that the silvical data secured in gridironing a forest be made a matter of record. In order that the observer may put down his observations while they are fresh in his mind it is well to provide a notebook or blanks with appropriate headings, such as:

Character of Forest.-Even-aged, all-aged, even-aged in 2 
groups, etc., average age. Component species in percentages of chief timber trees.

Average Site Quality.-(I to $\mathrm{V}$ of which $\mathrm{I}$ is the best, $\mathrm{V}$ the poorest; intermediate grades are expressed thus: I/II, IV/V, etc. The usual criterion for determining site quality is the height growth; tables of height growth serve as a useful guide in this respect. Until the eye is trained, some hypsometer measurements are advisable. Comparative volume growth is also a useful guide to Site Quality.

Density of Stocking.-(I.O to 0.0 in decimals, of which I.o is the fully stocked stand, 0.0 is the vacant or barren area.) The density is usually determined by the crown cover, although this varies with the species. For example, a fully-stocked stand of Western yellow pine has an altogether different crown density from the fully stocked stand of spruce. The best judgment of the observer is required in this and every other phase of forest description, if the data are to be of real value and use and not merely "guesswork."

Both Site Quality and Density of Stocking have their explanation in natural causes which the observer should try to determine and to place under one or several of the following headings:

Cuttings.- Apparent date, purpose, silvicultural method used, if any, present condition with especial regard to whether the cutting area is restocking satisfactorily.

Burns.-Apparent date, cause, present condition with especial regard to whether the cutting area is restocking satisfactorily.

Rock.-The determining characteristics, such as "granite," "shale," etc.

Soil.-The simple name- "sandy loam," "clay," etc.

Ground Cover.-Weeds, grass sods, etc. Whether sufficient to prevent natural reproduction.

Undergrowth.-Character of undergrowth, brush, etc. Whether sufficient to prevent natural regeneration.

-Young Growth.-Seedlings, saplings, poles, approximate proportion of each, whether they occur scattered uniformly 
over area, or patchy and groupwise. Is the young growth now present sufficient to restock the area. "This does not mean," as Mr. Zon points out,* "a few seedlings or even a few hundred seedlings to the acre, but a reproduction which is sufficient to produce a hundred years hence a merchantable stand of timber. Allowing for the natural thinning out of the young growth, there must be at least between fifteen hundred and two thousand seedlings to the acre in order to produce a merchantable stand at the time of maturity. A few hundred seedlings per acre may be capable of growing up and producing a large amount of seed, but cannot produce a merchantable stand of timber."

Size and Quality of Timber.-The average diameter breasthigh of all timber of merchantable size. If saw timber, the number of sawlogs (I6 feet long) per tree and per M. feet board measure. The character, i.e., if unusually clear boled, or limby, etc. Approximate per cent of clear lumber.

Condition of Timber.-Soundness, rot or insect attack, etc.

These subjects need not be treated exhaustively; the forest description must, above all, be practical and brief.

The unit of area in forest description depends, of course, on the degree of intensity possible in the Working Plan. The ideal unit of description is the Stand. The stand is that portion of the forest which is so essentially different in forest type, in method of management, in component species, in age, in density of stocking, or in site, that it is clearly distinct from the surrounding forest. The stand as a unit of forest description is ideal, since it is at the same time the true unit of Forest Management and Forest Organization (see "Division of Area" below). But the necessity of pushing the reconnaissance work and the size of the Working Plan area often makes it more feasible to confine the description to the survey unit-such as the sectionor to an entire watershed (in unsurveyed and very mountainous country), leaving it to the Forest Organizer to combine the various descriptions and smooth out their differences and dis-

* "Results of Cuttings on Minnesota National Forest," R. Zon, "Proceedings of the Society of American Foresters," Vol. VII., No. I, p. IO3. 
crepancies into a General Forest Description for the Working Plan (see Chap. III). At the same time the Forest Organizer is helpless if these Specific Forest Descriptions are inadequate or inaccurate. Nor need the description contain many words; for mere stereotyped repetition is both tiresome and futile.

\section{Division of AREa}

The Division of Area for purposes of Forest Organization is in Europe considered the prerequisite of any Working Plan. For the extensive conditions prevailing in many parts of America the elaborate divisions of area used in Europe can well be waived. Indeed it is conceivable that a useful Working Plan could be constructed without any systematic division of the area. The need for these divisions grows with the refinements in management, and while it would be mere play in most American forests to mark each compartment and subcompartment in the map or on the ground, a skeleton outline of the salient divisions will often serve to facilitate and to systematize the working of a forest. Unnecessary divisions must be avoided.

For these divisions topographic features, roads, trails, etc., should be made the boundaries; even in flat country the hewing through of compartment lines is justified only under most intensive conditions.

The customary subdivisions of a forest are:

The working figure (syn. working block, working circle, Betriebsklasse).

The block.

The compartment.

The subcompartment or stand.

The Working Figure is that unit which is to be managed with the idea of a sustained yield. It may be only a part of a single administrative unit (e.g., National Forest), or it may comprise several such units. This is discussed in detail in the next section, "Determination of Method of Treatment." 
The Block is a convenient subdivision of the Working Figure, made to assist in the regulation of the yield. The Block comprises a logging unit or group of logging units. Since the division of a Block is entirely topographic, a suitable local name can generally be taken from some salient topographic or cultural feature contained therein.

The Compartment is a convenient subdivision of the Block, wherever conditions are sufficiently intensive to warrant it. It is created for purposes of easier orientation in the woods and for facilitating and systematizing the keeping of detailed forest records. Where the boundaries of compartments are hewn out or made into roads, these serve the additional purposes of fire lines, logging roads, points of attack in cutting series, and as convenient units where game is beaten from cover.*

The "ultima ratio" of division of area is the Stand or Subcompartment. The distinction is a silvicultural one, i.e., the Stand is that part of the area which through reasons of difference in forest type, in component species, in age, in density of stocking, and in site clearly demands a different method of treatment. It is really, therefore, an independent unit of cutting. It may be large or it may be small; but it must be of sufficient size to warrant the division, and of the right shape-i.e., a long, narrow strip might have sufficient area, but would nevertheless be unsuitable. Minor differences should be disregarded in creating subcompartments- "de minimis non curat lex!" Even under the most intensive European conditions the average minimum size of a Subcompartment is $1 / 4$ to $21 / 2$ acres. The size of the Subcompartment is in direct ratio to that of the forest. With decreasing size of the latter one would finally reach the single tree-as is actually the case in the small wood lot managed by the Selection (or Single Tree) System. Conversely, as the forest increases in size and the conditions become more extensive, the subcompartment also increases in area until, for forests of

* Hence in the plains, e.g., in the Prussian pineries, the Compartment is called a "Jagen"-i.e., a "Hunting." The average size in Prussia is 25 hectares $=6 \mathrm{I} 3 / 4$ acres. 
100,000 to $1,000,000$ acres, the minimum size of the subcompartment would be about 40 to I60 acres.

The degree of difference between two adjacent forest areas necessary to warrant their division into separate stands must be gauged along the following lines:

Forest Type.-Differences in forest type always determine differences in stands. Permanent forest types alone are to be regarded in this respect.

Component Species.-Minor differences in percentage of mixture or presence of subsidiary species should be disregarded. Only where the component species necessitate a different silvicultural method of management or a different rotation, or where there is a marked difference in their market value, should separate stands be recognized. These differences are seldom regarded in young growth-i.e., under one-quarter of the rotation; a mere note in the stand table suffices to indicate the difference and whether the component species are intermingled singly or groupwise.

Age is determinative of stand differences especially where the regulation is to be by age classes (Chap. II), and where the forest is essentially even-aged. In the younger growth, i.e., under one-half of the rotation age, differences of $20-35$ years can be disregarded; a mere note in the stand table suffices to indicate the difference. Stands over half the rotation age demand a closer classification; not over 20 years difference for the third quarter of the rotation, not over ro years for the last quarter. Over-mature stands, i.e., over ro years more than the rotation age, should be segregated as they are the especial objects of an early cutting.

In this as in all cases of stand differentiation, the degree of refinement varies with the size of the forest and the intensity of the management.

Density of Stocking and Site Quality determine stand differences where they are sufficiently striking to necessitate a different method of management (e.g., protection forest on upper slopes). 
In general it is this Necessity for a Different Method of Management which is determinative of stand distinction. Where no striking differences in type, species, age, density, or site occur the same method of management applies, and there is no occasion to differentiate into separate stands. Where the methods of management are different the stands are, ipso facto, different. Hence it is impossible within the same subcompartment to have High Forest, Coppice with Standards, and Straight Coppice. Furthermore, even-aged and uneven-aged areas of High Forest are always separated into separate stands.

Designation of Divisions.-Working figures and blocks are given names; compartments are numbered; subcompartments (stands) are lettered. E.g., a paper-birch thicket in midst of spruce compartments on the lower slopes of Mount Tecumseh block in the Waterville, N. H., basin, would be designated as $29 a$, Tecumseh Block, Waterville Figure.

Boundaries of Divisions.-Before designating the boundaries of any working-plan divisions, either in the field or on the map, the Forest Organizer, in consultation with the owner and the administrator of the forest, or both, should decide just what divisions are to be made and on what basis. The determination of working figures is a sine qua non, but whether blocks, compartments, and subcompartments are also to be segregated depends entirely on the specific needs of the forest. Large forests should almost always be divided into blocks. The further subdivision into compartments and subcompartments is necessary only where intensive working plans are practicable.

Having decided just how far to go in the matter of divisions, the Forest Organizer keeps this in mind during his preliminary reconnaissance and during the entire progress of the field work. The detail of forest description and the unit described depend on the extent of subdivisions. That is, if blocks are the mirimum divisions possible, the organizer needs only the briefest descriptions by sections or other survey unit and a mere detailed general description by watersheds or other appropriate logging units, for these are the future blocks. If, on the other hand, the 
refinements of compartments and subcompartments are possible the unit of description must be the stand, and the forest description of each stand must be sufficiently detailed so that the Forest Organizer can determine therefrom whether to make it a subcompartment, and its function in regulating the yield.

Obviously, therefore, the provisional boundaries of the minimum unit of division decided upon must be noted in the progress of the survey and estimate and noted on the map.

As the work of gathering the data progresses, the Forest Organizer keeps always in mind the possible division of the forest and, map in hand, goes through the area to determine its most advantageous arrangement. His task will be the easier if the forest description data are well and carefully gathered.

Stands (subcompartments) are combined into compartments. The boundaries of the former are silvical (see above), of the latter, topographic and natural just as far as possible. Oftentimes the compartment and the stand coincide (which is especially convenient), or a stand stretches partly or wholly over several compartments. Streams, ditches, ridges, landslides, rock barrens, roads, trails, alienated areas, all form natural boundaries for compartments. Only where these natural boundaries are lacking, or insufficient, is the cutting through of artificial lines permissible.

The compartment varies in size from 50 to 250 acres; it is, as far as possible, rectangular or at least trapezoidal in shape, the boundary lines running with or at right angles to the prevailing local storm direction. Where artificial lines are cut through, those running with the prevailing storm direction are called "Haupt-Gestell" (Main Frame) or "Wirtschafts streifen" (Management Stripe), those running at right angles thereto, "Neben-Gestell" (Accessory Frame) or "Schneussen" or "Schneisen" (Glades [sic!]).* The former average ${ }_{5} 5$ to 30 feet in width, the latter $61 / 2$ feet to $5_{5}$ feet; in this way they serve as a network of logging roads and fire lines. The "Schneisen"

* In Prussia the "Hauptgestelle" are 700 to 800 yards apart; the "Nebengestelle" are 350 to 400 yards apart. 
serve also to strengthen the stand against windfall; for along them develops the "Waldmantel" or "Windmantel"--i.e., the crowns of the trees on the border form an impenetrable mantle and protect the interior of the stand from windfall. This is especially important in spruce and similar shallow-rooted species. As the lower branches show signs of dying off, the strip is widened so as to let in the necessary additional light and keep the forest mantle intact, until it reaches a maximum width of 30 or 40 fect. These "Schneisen" are then made the points of attack for the cutting series, since the stand to leeward of then has through its forest mantle ample protection against the storms (Chapter II, Section 2).

But, ordinarily, artificial division lines are not necessary. As main lines can be chosen the crests of ridges, the valleys and creeks; as secondary lines the spurs and hogbacks and smaller tributary creeks.

Block divisions are always natural and are chosen on a large scale-watersheds, drainage basins, are suitable units. The single block may contain many thousand acres; its shape is immaterial; the governing considerations are logging and market conditions. The block is essentially a logging unit. Its segregation requires a complete knowledge of such matters as present market conditions, lines of transportation, outlets for the timber, and the probable changes and developments in all three.

How far, if at all, the blocks should coincide with the administrative divisions such as ranger districts, must depend on local conditions. It is often convenient to have block and ranger district coincide, and in level country, such as the Prussian pineries, this is entirely feasible. But the purposes of administrative division are so different from those of the Working Plan that the coincidence should never be secured at a sacrifice of either Forest Administration or Forest Organization.

The boundaries of blocks and stands (subcompartments) need not be marked on the ground. Compartments must be designated, either by numbered stakes or stones or both, or by 
stencilling the number of the compartment in white paint on the bark of a tree nearest to the corner thereof. Where the lines are not actually cut through, their intersections with roads, trails, streams, etc., should be similarly designated. Where road or trail or stream itself serves as the boundary, this is not necessary, but merely corner monuments or occasional guidemonuments are placed.

On the map the boundary of the Working Figure is marked by heavy dot and dash - . - . . . - ; the blocks by dashes - _ _ _ _ - . . . . . . . . .; and the subcompartment or stand by a thin, unbroken line

\section{MaPs AND TABles}

The various data collected in the field should, as far as possible, be entered on maps and summarized in tables. In this way they are made available at a glance.

Maps, or, at least, some map of the forest, however crude, are indispensable in Forest Organization. The forest map should contain:

(a) Essential topographic features; contours are seldom necessary in level country; hachures are not ordinarily advisable.

(b) Roads and trails, railroads, houses, barns, and other "culture."

(c) Boundary (exterior) of the forest; also all other interior holdings by other owners.

(d) The forest types; also all burns and cut-over areas; all barrens and all land under cultivation or pasturage (nonforest land) within the exterior boundaries.

$A, b, c$, and $d$ may form one base map, or they may be made into separate maps as the wealth of detail necessitates or convenience dictates. Where the area is too large to be shown completely on one map of ordinary scale ( $1 / 2$ or I inch to the mile), a small scale location map can be made and as many large scale detail maps as are desired. In surveyed country a separate map 


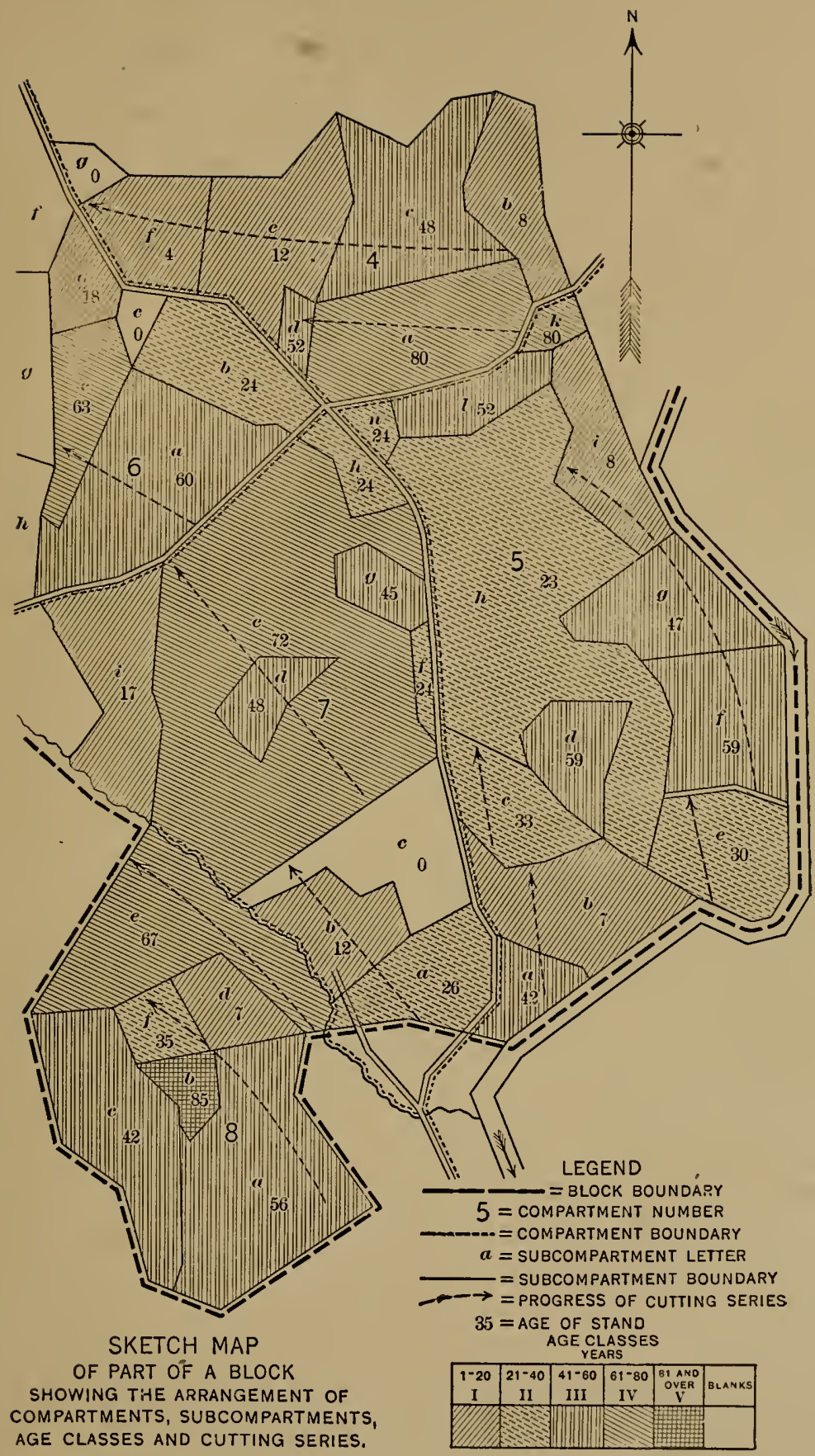

FIG. 1. 
of each township, compiled from section sketches, is advisable.

Armed with this base map the Forest Organizer sketches in from survey notes, detail sketches, and forest description the following additional points:

(e) Provisional division of area into

Blocks,

Compartments,

Subcompartments or Stands,

all depending on the divisions previously decided upon. The stands are always irregular in shape and must be combined into compartments of suitable size and shape. Where the forest is approximately even-aged and the method of regulation is to consider age classes, these should be entered on the map by writing the age class of the subcompartment in Roman numerals (see Section I), and coloring or shading it accordingly. Barrens and treeless land are left blank. The blocks are also outlined provisionally. Often the Organizer must go over the area, map in hand, in order to settle some uncertainty on the ground. The boundaries had best be sketched only in pencil. If the original maps are made on tracing linen or on thin bond paper, blue-prints, or, still better, Van Dyke copies can be used for this provisional division of the area.

This provisional map quite suffices until the final workingplan document is prepared, when the maps may be elaborated as much as is desired. E.g., the age classes can be shaded or colored, the types colored or symbolized, etc. (see Chapter III).

The prevailing local storm direction is entered (where it is not known already it must be determined; in a mountainous region the storms often follow the direction of the main drainage) by means of long dotted arrows (see Fig. I).

The next step is to obtain the areas of the various divisions, types, alienations, etc. This is most easily done by means of a planimeter. One decimal place usually suffices. The larger areas are always measured first-e.g., the blocks before the compartments - the sum of the smaller divisions, e.g., of compart- 

GENERAL STAND TABLE, $\ldots \ldots \ldots \ldots \ldots \ldots \ldots \ldots \ldots \ldots$ WO

\begin{tabular}{|c|c|c|c|c|c|c|c|c|c|c|c|c|c|}
\hline 1 & 2 & 3 & 4 & 5 & 6 & 7 & 8 & 9 & 10 & 11 & 12 & 13 & 14 \\
\hline \multicolumn{3}{|c|}{ DIVISION } & \multicolumn{11}{|c|}{ AREA } \\
\hline \multirow[b]{3}{*}{$\begin{array}{c}\text { Block } \\
\text { (name) }\end{array}$} & \multirow[b]{3}{*}{$\begin{array}{l}\text { Compt. } \\
\text { (No.) }\end{array}$} & \multirow[b]{3}{*}{$\begin{array}{l}\text { Sub- } \\
\text { compt. } \\
\text { (ltr.) }\end{array}$} & \multirow{2}{*}{$\begin{array}{l}\text { Total } \\
\text { Area }\end{array}$} & \multirow{2}{*}{\multicolumn{2}{|c|}{ Even Aged }} & \multirow{2}{*}{\multicolumn{2}{|c|}{ All Aged }} & \multicolumn{4}{|c|}{ Cut Over } & \multirow{2}{*}{\multicolumn{2}{|c|}{ Burnt }} \\
\hline & & & & & & & & \multicolumn{2}{|c|}{ Regulated } & \multicolumn{2}{|c|}{ Unregulated } & & \\
\hline & & & Acres & Area & $\begin{array}{l}\text { Average } \\
\text { and Age } \\
\text { Limits }\end{array}$ & Area & $\begin{array}{c}\text { Age } \\
\text { Limits }\end{array}$ & Area & \begin{tabular}{|c|} 
Silvi- \\
cult. \\
Method \\
Date \\
and \% \\
Left
\end{tabular} & Area & $\begin{array}{l}\text { Date } \\
\text { and } \\
\% \\
\text { Left }\end{array}$ & Area & $\begin{array}{c}\text { Date } \\
\text { and } \\
\% \\
\text { Left }\end{array}$ \\
\hline Tecumseh & I & .. & 104.27 & I04 & $20-40$ & . & . & .. & . & . & . & .. & . \\
\hline$\ldots \ldots$ & 2 & . & 96. & 96 & $60-80$ & . & . & .. & .. & .. & .. & .. & . \\
\hline$\cdots \cdots$ & 3 & . & 93.73 & . & $\ldots$ & 94 & I-I 5O & . & . & . & . & .. & . \\
\hline$\ldots \ldots$ & 4 & . & Io6. & I06 & $100-120$ & .. & . & . & . & . & $\cdots$ & . & . \\
\hline$\ldots \ldots$ & 5 & . & 99.20 & $\cdots$ & $\cdots$ & 90 & $I-I 50$ & . & . & . & $\cdots$ & . & $\cdots$ \\
\hline$\ldots \ldots$ & 6 & . & Io3. & 100 & $140-160$ & .. & . & . & . & 3 & $\begin{array}{l}1900 \\
\text { clean }\end{array}$ & .. & . \\
\hline$\cdots \cdots$ & 7 & $\cdots$ & & $\cdots$ & $\cdots$ & 80 & $I-x 50$ & $\cdots$ & $\cdots$ & $\cdots$ & . & .. & $\cdots$ \\
\hline$\cdots \cdots$ & 8 & . & 99.50 & 100 & $\{$ I-IO & .. & . & 100 & $\begin{array}{c}\text { Sh. 'o2 } \\
40 \%\end{array}$ & . & . & . & . \\
\hline$\cdots \cdots$ & 9 & $\begin{array}{l}a \\
b\end{array}$ & \begin{tabular}{|l|}
40. \\
$6 \mathrm{I}$.
\end{tabular} & $\begin{array}{l}40 \\
6 I\end{array}$ & $\begin{array}{c}740-160 \\
160-200\end{array}$ & $\begin{array}{l}. \\
\ldots\end{array}$ & $\begin{array}{l}\cdots \\
\ldots\end{array}$ & $\begin{array}{l}\cdots \\
\ldots\end{array}$ & $\begin{array}{l}\cdots \\
\cdots\end{array}$ & $\begin{array}{l}\cdots \\
\cdots\end{array}$ & $\begin{array}{l}\cdots \\
\cdots\end{array}$ & $\begin{array}{l}\cdots \\
\ldots\end{array}$ & $\begin{array}{l}\cdots \\
\ldots\end{array}$ \\
\hline ...... & IO & $\cdots$ & 100.30 & . & $(160-200)$ & . & . & . & . & 50 & $\begin{array}{l}\text { I } 895 \\
\text { ro\% } \\
\text { Culls. }\end{array}$ & 50 & $\begin{array}{l}\text { I906 } \\
\text { None }\end{array}$ \\
\hline Totals.. & . & .. & I,, 000. & 607 & $\ldots$ & 264 & . & See & Col. 5 & 53 & $\ldots$ & 50 & . \\
\hline $\begin{array}{l}\text { * The silvicu } \\
\text { may be des } \\
\text { symbols: }\end{array}$ & $\begin{array}{l}\text { ural me } \\
\text { gnated }\end{array}$ & $\begin{array}{l}\text { ethods } \\
\text { by the }\end{array}$ & $\begin{array}{l}C \\
C \text { str } \\
C p \\
C \text { ss } \\
S h \\
S \\
S h-S \\
S h-G \\
S h-S t r \\
S h-B\end{array}$ & $\begin{array}{l}=\mathrm{C} \\
=\mathrm{C} \\
=\mathrm{C} \\
=\mathrm{C} \\
=\mathrm{S} \\
=\mathrm{S} \\
=\mathrm{S} \\
= \\
= \\
=\end{array}$ & $\begin{array}{l}\text { lear cutting } \\
\text { lear cutting } \\
\text { lear cutting } \\
\text { lear cutting } \\
\text { helterwood } \\
\text { election cut } \\
\text { helterwood } \\
\text { ". } \\
\text { ". }\end{array}$ & $\begin{array}{l}\text { gin p } \\
\text { cutti } \\
\text { tting. } \\
\text { selec } \\
\text { grou } \\
\text { strip } \\
\text { bord }\end{array}$ & $\begin{array}{l}\text { trips. } \\
\text { atches (" } \\
\text { scatter } \\
\text { ng. } \\
\text { tion cut } \\
\text { p } \\
\text { er }\end{array}$ & $\begin{array}{l}\text { "'Wel } \\
\text { ered s } \\
\text { tting. } \\
\text { ". } \\
\text { " }\end{array}$ & $\begin{array}{l}\text { 1" meth) } \\
\text { eed trees }\end{array}$ & & & & \\
\hline
\end{tabular}

$\dagger \mathrm{M} .=$ thousand feet, board measure. 


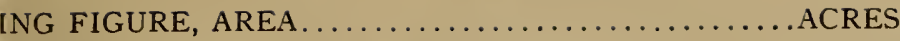

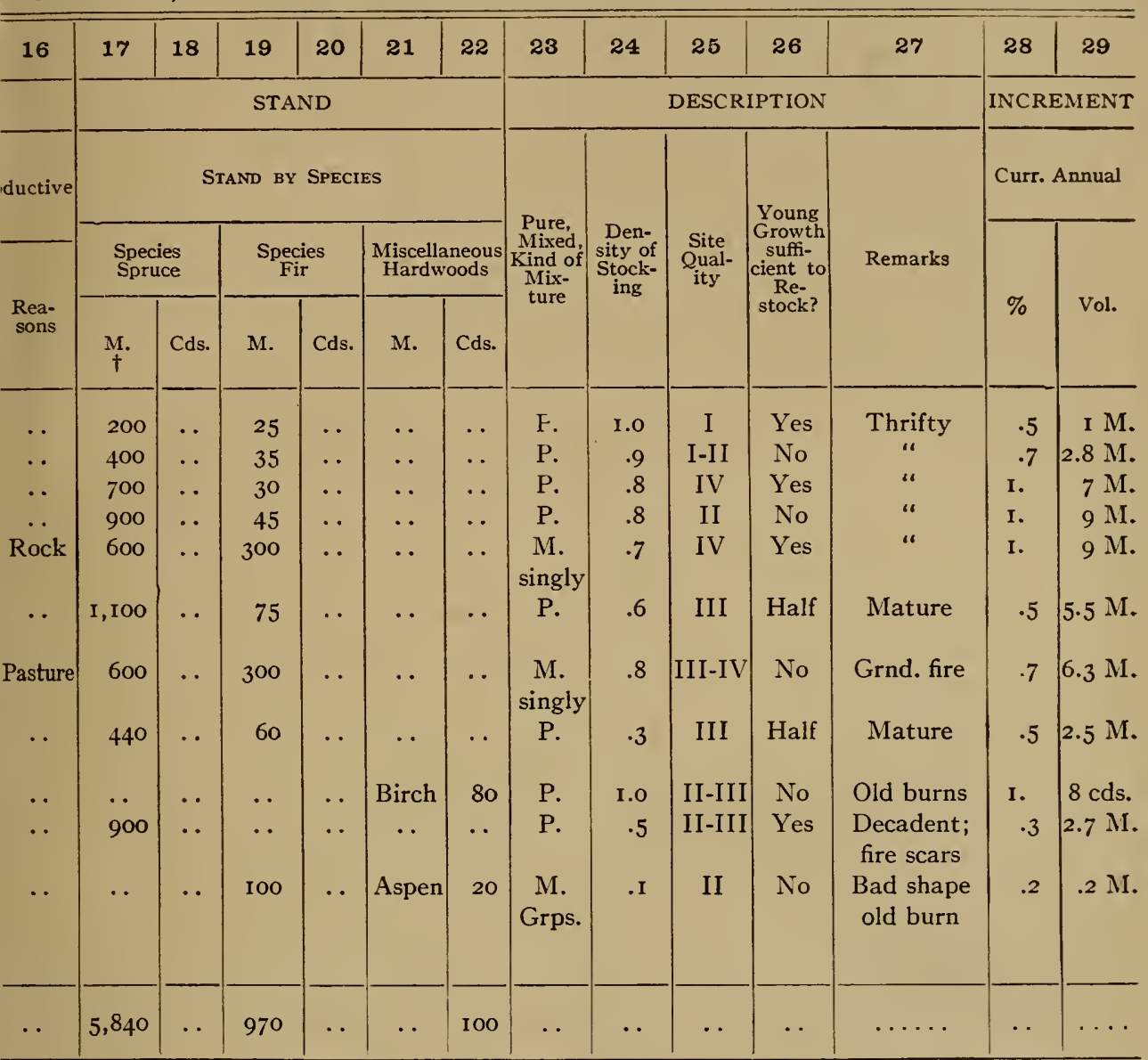



ments, should check with the area of the larger unit (block) containing them. Minor errors can be proportioned. Roads, streams, boundary lines which have been cut through, etc., are seldom calculated as separate areas unless they are excessively wide, e.g., more than 20 feet.

Tables are now drawn up to contain these and other data which can be summarized. These may be:

(a) Alienation tables (status).

(b) Stand tables (volume by species, classes of timber, units of area, etc.).

(c) Area tables (by types, by divisions of area).

(d) Age-class table (comparison with the normal). Any or all of these tables may be constructed as the data warrant and as there is occasion for them. An alienation table is necessary only where there are many interior holdings, or where the status is complicated. Stand tables are practically a necessity. Area tables are also almost indispensable in a well-regulated working plan. An age-class table is necessary only where the distribution of the age classes plays a part in the regulation of the yield (Chapter II). Tables $(b)$ and $(c)$, to gether with abbreviated notes on site, density, age, and salient silvical characteristics, can be combined into the following General Stand Table.

The particular form which this table takes should be varied to meet the needs of the working plan in question. The purpose is to give the essential data for the regulation of the yield; these essential data vary with the method of regulation which is chosen (Chapter II). In the appendix example the table has been made as complete as is necessary even under intensive conditions. The hypothetical data would have required a correspondingly intensive estimate and forest description. The division is by stands. In compartments $I, 2,3,4,7$, and IO the stand and the compartment coincide; compartments 6 and 8 are one stand; compartment 9 has two stands or subcompartments.

These data will be required for only those forests which permit of an intensive management. However, the same form 
of table, with minor modifications, applies to even the most extensive conditions. For example:

If the estimate and description is by survey units, e.g., by sections, quarter-sections, or even forties (reconnaissance), the arrangement of the columns would be varied so that Col. 2 would be township and section, Col. 3 the quarter-section or forty, Cols. $5,7,9, \mathrm{II}, \mathrm{I}_{3}$, and $\mathrm{I}_{5}$ would give the area, not in acres, but in per cent of total, Cols. 6, 8, I0, I2, I4, and I6 would usually indicate the age only as Over-mature $(O)$, Mature $(M)$, or Young $(Y)$ (see Section 2, above). Cols. 23-29 would usually be recorded separately for each type.

If the estimate and description are lumped for the entire area of one type within the same watershed, Col. 2 would be the name of the type, Col. 3 would be blank, Cols. 5 to 22 inclusive would be as in the paragraph above, Cols. 23 and 26 would be very general, Cols. 24 and 25 would fall away, but Cols. 28 and 29 would be retained.

From the above data, a rough age-class table can, and, for all methods of regulating yield by the distribution of the age classes (Chapter II), should be constructed. Assuming in the hypothetical data of the general stand table above that the rotation is 160 years, the form of age-class table would then be as follows: Age Class Table A.

In the above example if only the symbols " $O$," " $M$," and " $Y$ " are used, the comparison would be: Age Class Table B.

Were the intermediate steps $O / M$ and $Y / M$ used also to designate the approximate age of the stands, the table would read: Age Class Table $\mathrm{C}$. 
THE THEORY AND PRACTICE OF WORKING PLANS

\begin{tabular}{|c|c|c|c|c|c|}
\hline & $\stackrel{20}{\rightarrow}$ & 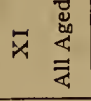 & $\vdots \vdots \vdots \vdots$ ஃ $\vdots ஃ \quad \vdots \vdots \vdots \vdots \vdots$ & \multicolumn{2}{|c|}{ 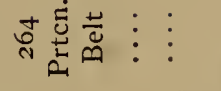 } \\
\hline \multirow{10}{*}{ 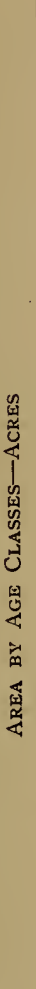 } & $\underset{-1}{\mathbb{N}}$ & 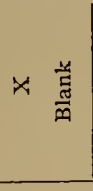 & 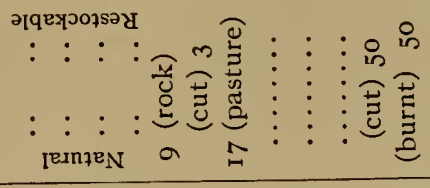 & 离 & 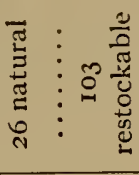 \\
\hline & $\stackrel{\infty}{\sim}$ & 崫志 & $::::::::: \not{\bullet}:$ & $\vec{b}$ & $:: \overparen{0}$ \\
\hline & $\stackrel{\propto}{\sim}$ & 志总 & $::::: \stackrel{8}{\circ}:$ : : : & 是 & $\stackrel{n}{\Re}: \stackrel{\text { n }}{\stackrel{n}{*}}$ \\
\hline & 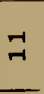 & 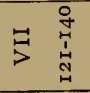 & $:::::::::$ : : & & 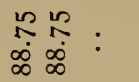 \\
\hline & 우 & 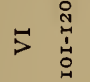 & $::: \stackrel{\circ}{\circ}::::::$ : & & $\stackrel{n}{n}: \stackrel{n}{n}$ \\
\hline & a & 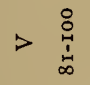 & $::: \quad: \quad: \quad: \quad: \quad:$ & & $\begin{array}{l}n: \\
\infty \\
\infty \\
\infty \\
\infty\end{array}$ \\
\hline & $\infty$ & $\geq \underset{\substack{0 \\
0 \\
\vdots}}{\vdots}$ & $: \&::::::::$ : & & $\underset{\substack{n \\
\infty}}{\mathfrak{\infty}}: \stackrel{n}{N}$ \\
\hline & $\nabla$ & 盯亭 & $:::::::$ : $:$ : : & & 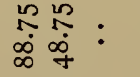 \\
\hline & 0 & $\exists \stackrel{?}{\dot{H}}$ & 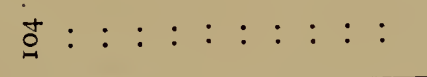 & & 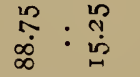 \\
\hline & 20 & $-\stackrel{\circ}{\stackrel{\leftrightarrow}{4}}$ & $::::::: 8::$ : & 8 & 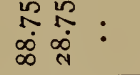 \\
\hline ङ & $H$ & 离 & ஸे श & $\frac{8}{8}$ & 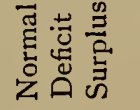 \\
\hline 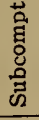 & $\infty$ & 岕 & $\vdots \vdots \vdots \vdots \vdots \vdots \vdots \vdots \vdots \propto$ & $\vdots$ & 胥 \\
\hline 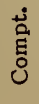 & $Q$ & $\stackrel{\circ}{z}$ & $\operatorname{matmona} a$ & $\dot{n}_{\tilde{J}}^{\dot{0}}$ & 范岁 \\
\hline 范 & -1 & 苋 & 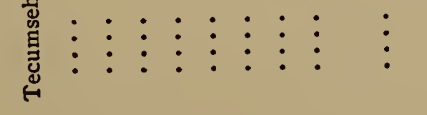 & & 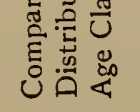 \\
\hline
\end{tabular}




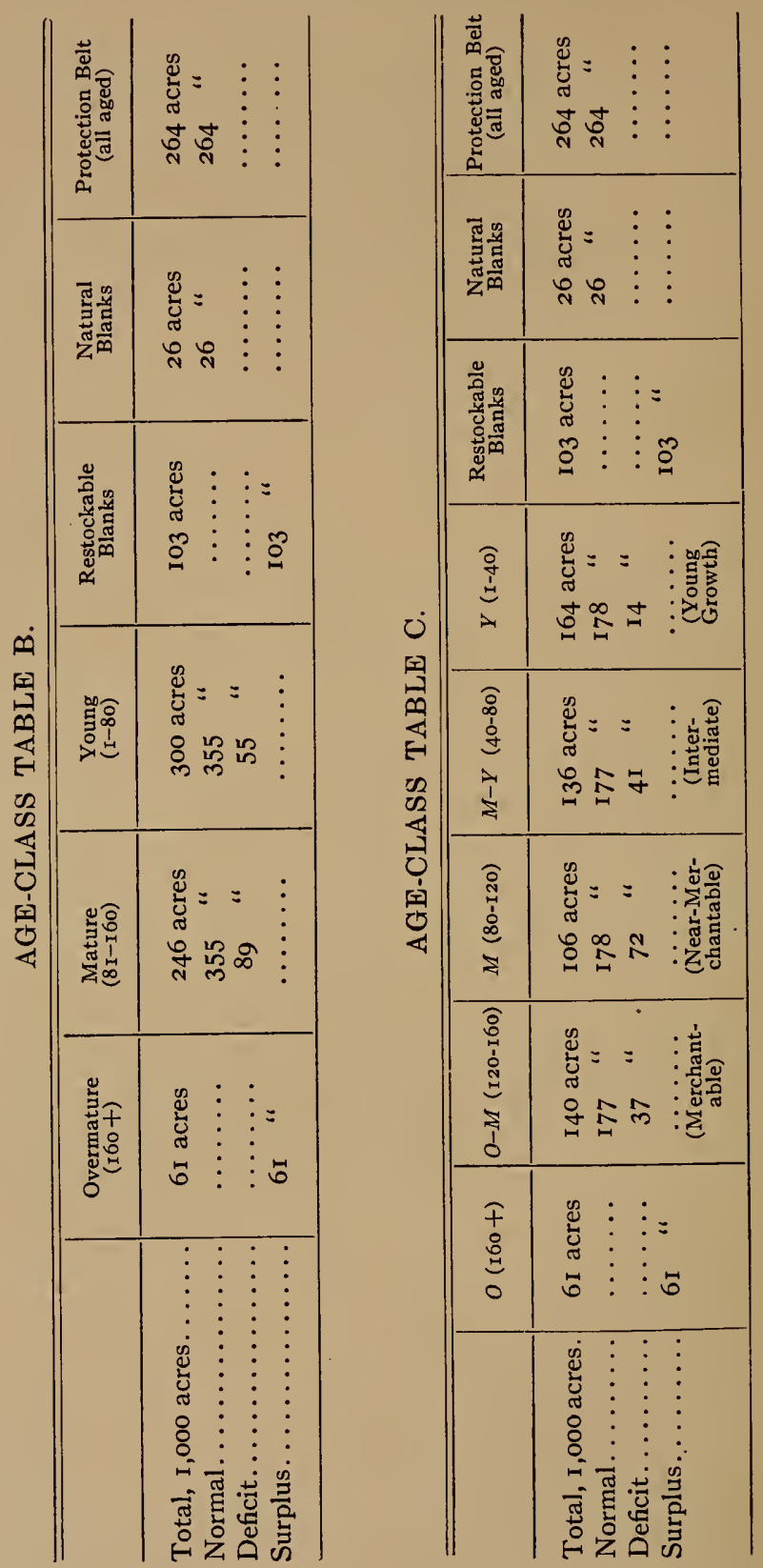


SECTION THREE

\section{DETERMINATION OF METHOD OF TREATMENT}

\section{Governing Conditions}

The method of treatment of any given forest depends on the wishes and purposes of its owner. It is very necessary that these fundamentals be decided in consultation between the owner and administrator, and the Forest Organizer, for the working plan must be arranged accordingly.

Three main issues must be decided before any complete working plan is possible:

I. The unit of regulation.

2. The silvicultural method of management.

3. Object of management.

A fourth, Rotation, is necessary to all but one method of regulating the yield (Chapter II).

\section{The Unit of Regulation}

The unit of regulation is that area which is to be managed for a sustained yield. It is usually a working figure (synonyms, working block, working circle, Betriebsklasse). The working figure may or may not coincide with the administrative unit, e.g., the single national forest. Where species, topography, and markets are similar, or even identical, the creation of separate working figures is unnecessary and undesirable. The blocks serve every purpose of subdivision.

Again, there may be several working figures within the same administrative unit-e.g., high forest and coppice should never occur in the same working figure.

The cases necessitating separate working figures are:

High forest.

Coppice with standards. 
Coppice.

Differences in ownership.

Areas far apart or of very large size.

In creating working figures, the doctrine of sustained yield must be treated broadly. A sustained yield presupposes three things:

(I) A sustained market with attendant transportation facilities rendering every part of the forest accessible now or progressively so in the near future.

(2) An area ample, under the silvicultural methods chosen, to supply this sustained market.

(3) Stable market prices for the lumber and other forest products.

These three factors do not always coincide with the administrative units. The boundary of the administrative unit is purely for convenience in the management of the forest; the boundary of the working figure is, as far as limitations of ownership permit, an economic one within which the marketing of timber is controlled by certain factors of consumption or distribution. Economic reasons may warrant the over-cutting on one administrative unit and the under-cutting on another, but if a sustained yield from the entire market unit is maintained it is of small moment if the stand on one or more of the administrative subdivisions is over-cut.

This broad construction is of course adapted to the extensive conditions existing in most parts of America. In Europe, e.g., in Prussia, it has long been customary to require a sustained yield by administrative units-i.e., for each oberförsterei or supervisor's area-recently it has been extended in Prussia to cover each ranger's district! But in America the unit of regulation, the working figure, must be practical, must be the market unit, just as the subdivision, the block, must be the logging unit.

Where administrative unit areas belonging to the same owner are far apart or exceedingly large, they are not included in the same working figures. E.g., it would be preposterous to make a single working plan for the two divisions of the Florida 
National Forest or for the whole complex of contiguous national forests in Washington and Oregon.

But it is entirely correct and logical to combine, e.g., the contiguous and similar Coconino and Tusayan National Forests in northern Arizona. The administrative boundary separating these two national forests is a purely arbitrary one; they are essentially the same in character and composition, and are parts of the same market unit.

The working figure is given some convenient local name which is simple and characteristic. It is conceivable that one working figure might be within another-e.g., a coppice of oak might be within a pine forest. If the coppice is of sufficient size to warrant the distinction, it should be made a separate working figure within the other, for it requires a different method of organization from that accorded high forest. A forest in process of conversion, e.g., from coppice to standards, is also considered a separate working figure, and requires a separate working plan. Forests or parts of forests managed chiefly for turpentine or other unique forest products require a separate working plan, and constitute distinct working figures.

\section{Silvicultural Method of Management}

Having decided upon the unit of regulation, the Organizer, in conference with owner and administrator, should decide, provisionally, upon the silvicultural method of management; for the method of regulating the yield varies with the silvicultural system.

The first point to determine is whether the forest is to be managed as:

$$
\begin{aligned}
& \text { High forest, } \\
& \text { Coppice with standards, } \\
& \text { or Coppice, }
\end{aligned}
$$

or is to be converted from one of these forms to another. If high forest is chosen, the method of regeneration must be determined provisionally as: 
I. Artificial (sowing or planting) $=$ Clear Cutting.

II. Natural.

(A) Natural re-seeding from shelterwood.

(B) Natural re-seeding from adjacent stands.

In (A) the re-seeding is by means of seed trees left more or less equally distributed over the cutting area. Where these seed trees are of all ages, i.e., where all trees of seed-bearing age take part in regenerating the stand (as in virgin forest), the method is called that of Selection Cutting. Where the seed trees left are approximately even-aged and the merchantable timber is removed in successive cuttings at relatively short intervals, the method is that of Shelterwood Cutting. In the Selection Cutting, the period of regeneration stretches over the entire rotation, the resulting stand is all-aged; in the Shelterwood Cutting the period of regeneration is definite, theoretically not to exceed IO-I5 years, the resulting stand is approximately even-aged.

In practice the two methods (Selection and Shelterwood) are often combined for greater flexibility, and then the period of regeneration may be 30 to 50 years. This is called the Shelterwood-Selection Cutting.

Modifications of the Shelterwood system are the Shelterwood Group Cutting, the Shelterwood Strip Cutting, and the Shelterwood Border Cutting.*

In (B) the re-seeding is by seed from adjacent stands (often supplemented by isolated seed trees of windfirm species), which presupposes species with a light seed of great carrying power. The cutting is either Clear Cutting in Strips or Clear Cutting in Patches ("Well" method) or Clear Cutting with Scattered Seed Trees.

The various systems grade into each other, and even the two extremes-Clear Cutting and Selection Cutting-touch each other; for as the clear cut area grows smaller and smaller (Clear Cutting in Patches or "Well" method), the point is finally

* See "Proceedings Society of American Foresters," Vol. VII., No. 2;

"Border Cuttings: A Suggested Departure in American Silviculture." 
PLATE IV.

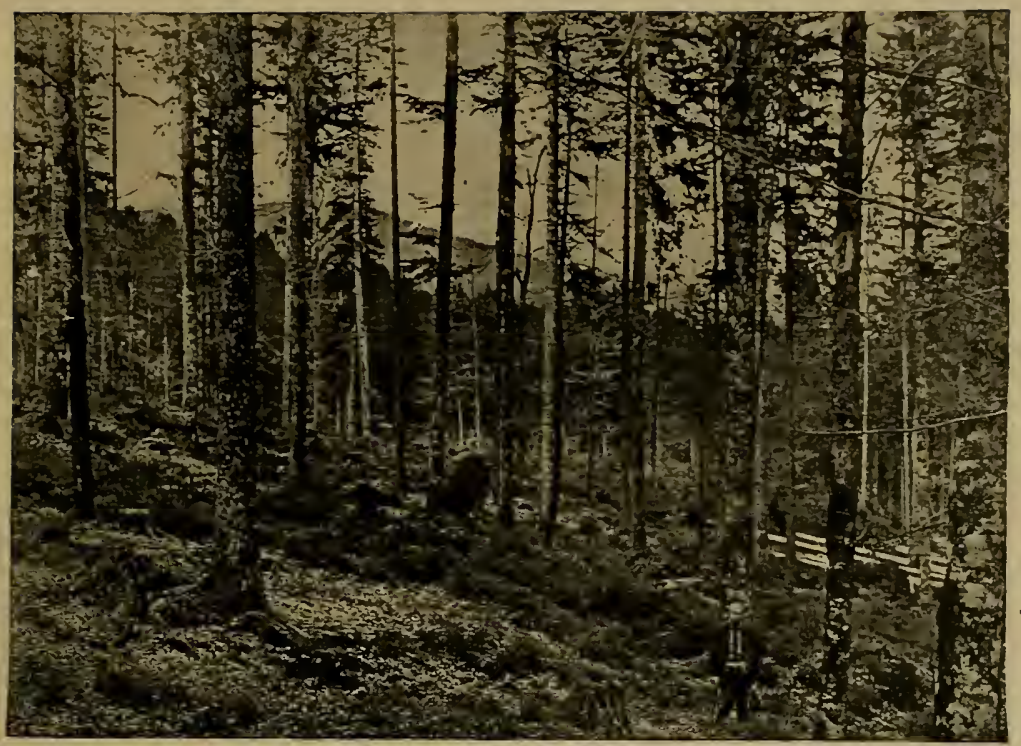

Fig. 1.-A Compartment Regenerated by Shelterwood Cutting, Baden. Courtesy of Mr. Lincoln Crowell.

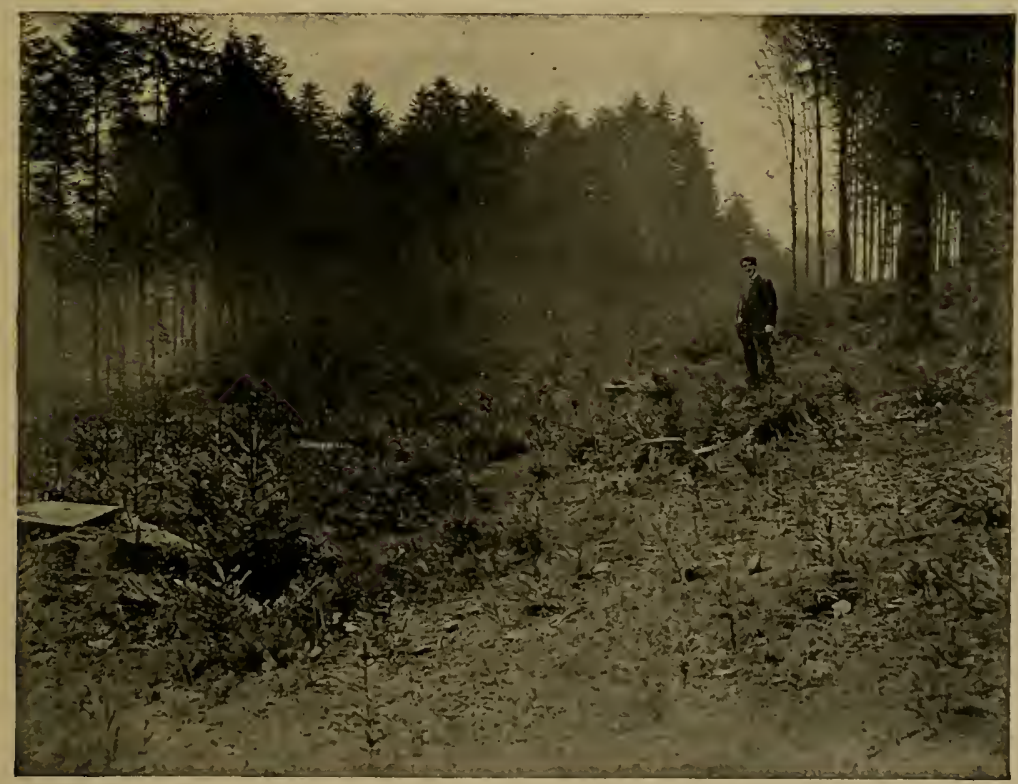

Fig. 2.-A Compartment Regenerated by Border Cutting, Wurttemberg. Courtesy of Mr. Lincoln Crowell. 

reached where the clear cut area is that occupied by a single tree-the Selection Cutting. Thus the snake bites its own tail!

The determination of the silvicultural method to be practised will require the best judgment and experience of the Forest Organizer. The regulation of the yield will vary accordingly. Large regular areas, clear cut or regenerated by shelterwood system, permit of a working plan by area-i.e., where the annual cut is determined by the area-whereas the small, irregular areas demand a working plan by volume and increment (see Chapter II). Complete forest descriptions and frequent observations within the forest will assist greatly in determining the best silvicultural system to pursue.

\section{Object of Management}

At the working-plan conference between owner, administrator, and Organizer, the object for which the forest is to be managed must be decided, i.e., whether

I. For maximum productivity in timber (forest rent theory),

2. For maximum productivity in money (soil rent theory),

3. For protection,

4. For æsthetic purposes, or for the chase,

5. For local needs,

or how far each or all of these considerations is to govern.

If the forest is to be a productive one, the next point to decide is the class of product desired:

I. Sawtimber,

2. Cordwood,

3. Mining timber,

4. Turpentine, etc.

It must also be decided whether the yield is to be sustained, and, if so, whether periodic or annual, or the forest managed on a purely exploitation basis.

The satisfactory solution of all these questions demands a thorough knowledge of forest policy on the part of the Organizer. 


\section{The Rotation}

In determining the rotation age, the considerations of greatest moment are the silvicultural methods chosen and the objects of management decided upon. The conception of a rotation is essential to a sustained yield. This rotation age may be only a tentative figure or it may be definitely determined; indeed, as shown in Chapter II, it is quite possible to regulate the yield without having determined the rotation, by increment and ageclass distribution alone (Hufnagl's method), but the feeling of a rotation underlies in all cases.

Various kinds of rotations are distinguished as follows:

I. Physical,

2. Greatest volume,

3. Technical,

4. Greatest income,

5. Financial,

6. Latent.

Without trespassing too far on the domain of Forest Mensuration, it should be noted that:

I. The Physical Rotation is either that which is best suited for the natural regeneration of a species on given site conditions, and for certain silvicultural systems; or that which coincides with the natural span of life for the stand. In practice the physical rotation is restricted to protection forests, luxury forests (for æsthetic and hunting purposes), and, occasionally, to coppice.

2. The Rotation of Greatest Volume (syn. Silvicultural Rotation, Economic Rotation) coincides with the age of the maximum mean annual increment. This maximum corresponds to the point where the plotted curves of current annual increment and mean annual increment cross.

3. The Technical Rotation is that at which the stand has produced the timber or other material best suited for certain purposes-e.g., the rotation for turpentine production is a technical one. Its application is necessarily limited. 
4. The Rotation of Greatest Income or that of highest forest rent is that age at which the stand yields the largest income calculated by the arithmetical mean. In contradistinction to (5) the financial or highest soil-rent rotation, the soil is not considered as interest-bearing capital, but as a necessary presupposition for any forest (Waldreinertrag). The income per cent is determined by the formula:

$$
\frac{\text { Forest Income less Forest Expense }}{\text { Value of Forest Capital }} \times \text { roo }=\begin{gathered}
\text { Income } \\
\text { per cent. }
\end{gathered}
$$

This is figured for various tentative rotations; that rotation which shows the highest income per cent is then finally adopted.

5. The Financial Rotation is that of highest net income, or that of highest soil rent. Herein (in contradistinction to 4, the rotation of highest forest rent) the soil is considered as interestbearing capital. The rate of interest must be determined according to local requirements, wishes of owner, etc. Then the index per cent, $W$, is determined by the formula

$$
W=(a+b \text { or } c) \frac{A}{A+S}
$$

where $a=$ volume increment, $b=$ quality increment, $c=$ value increment or depreciation, $A=$ the arithmetical mean of present and future yield, and $S$ the soil capital with interest thereon.* That rotationage is then adopted where $W$ is at a maximum.

6. The Latent Rotation. For every distribution of the age classes there exists a certain rotation which is normal in so far that by its adoption the normal annual cut $\frac{A}{r}$ (area $\div$ by rotation) can be utilized without disturbing the sustained character of the yield. This latent rotation is just double the average age of the working figure. For example, if the stand shows the following distribution of the age classes:

* For further details see Schlich: "Manual of Forestry," Vol. III., 3rd edition, pp. 194-201. London: Bradbury, Agnew \& Co., Ltd. Since this method of calculating the rotation is suitable only to very intensive conditions, it would serve no useful purpose to elaborate it at this point. 


\begin{tabular}{c||c|c|c|c|c|c}
\hline \hline $\begin{array}{c}\text { Total Area } \\
\text { acres }\end{array}$ & $\begin{array}{c}\text { I } \\
\text { I-20 yrs. }\end{array}$ & $\begin{array}{c}\text { II } \\
\text { 2I-40 yrs. }\end{array}$ & $\begin{array}{c}\text { III } \\
4 \mathrm{I}-60 \mathrm{yrs}\end{array}$ & $\begin{array}{c}\mathrm{IV} \\
6 \mathrm{I}-80 \mathrm{yrs}\end{array}$ & $\begin{array}{c}\mathrm{V} \\
8 \mathrm{I} \text { and over }\end{array}$ & $\begin{array}{c}\text { Blanks } \\
\text { (unst'k'd) }\end{array}$ \\
\hline $2, \mathrm{I} 60$ & $5 \mathrm{IO}$ & 496 & 465 & 443 & 214 & 32 \\
\hline
\end{tabular}

then the average age would be:

$$
\begin{array}{rl}
32 \times 0 & =0 \\
510 \times 10 & =5,100 \\
496 \times 30 & =14,880 \\
465 \times 50 & =23,250 \\
443 \times 70 & =31,010 \\
214 \times 90 & =19,260 \\
\hline \text { Total, } 2,160 & 93,500
\end{array}
$$

$93,500 \div 2,160=43$ years $=$ the average age

The latent rotation then $=43 \times 2=86$, or practically 80 to 90 years. This method fails in stands of the same age, or in entirely young or otherwise abnormal working figures. It also, of course, fails in selection forest, since this does not usually permit of the construction of an age-class table.

The kind of rotation to adopt depends on matters of policy, to wit:

I. Conditions of ownership, wishes and purpose of owner.

2. The market and logging conditions.

3. The site.

4. The character of the stand.

I. The State can afford a higher rotation than can the private owner; furthermore, it is the duty of the State to grow timber not only for profit, but to supply future demand, especially in sizes requiring long rotations.

2. The market conditions influence the rotation, inasmuch as good markets and easy accessibility permit shorter rotations, whereas forests further from market and more difficult of access necessitate a longer rotation to make logging at all profitable. The decreasing area of virgin forest and the rapidly increasing population justify the consideration of future as well as present market conditions. - It is reasonable to expect that the price of larger timber will increase proportionately more than that of 
smaller sizes, and hence it may be good economy, in view of future market prices, to adopt a longer rotation and plan to grow larger sizes of timber than present market prices would warrant.

3. The more the site is adapted to a certain species, the longer can the rotation be. Conversely the more rapid growth on good sites will often tend to shorten the rotation.

4. The character of the stands influences the rotation in respect to their quality and species. The better the quality of the stand, the longer can the rotation be; the less thrifty stands will often have to be cut before the regular rotation age. The species in mixed stands can usually be worked on the same rotation unless they mature at different ages or are markedly different in value, e.g., a mixed forest of Engelmann spruce and white fir (A. concolor) will often require a higher rotation for the spruce than for the fir; because the fir deteriorates at an earlier age and becomes almost valueless at a time when the spruce is just fully matured.

Where the species are not intermingled but form pure groups or stands in the same working figure, the rotation is determined separately for each species comprising more than one-third of the total volume, and the results are then averaged.

The customary rotations are, in Europe, for the chief species about as follows:

\begin{tabular}{|c|c|c|c|c|c|c|}
\hline \multirow{4}{*}{$\begin{array}{l}\text { Smaller } \\
\text { Tracts: }\end{array}$} & & \multicolumn{2}{|c|}{$\begin{array}{l}\text { Plains and } \\
\text { Foothills }\end{array}$} & \multicolumn{2}{|c|}{$\begin{array}{l}\text { Intermediate } \\
\text { Mountains }\end{array}$} & $\underset{\text { Mountains }}{\text { High }}$ \\
\hline & $\mathrm{Pi}$ & $60-80$ & ears & $70-90$ & ears & \\
\hline & Spru & $60-80$ & & $60-100$ & “ & 80 -100 years \\
\hline & Fir & $80-100$ & " & $80-100$ & “ & $80-120$ \\
\hline \multirow{3}{*}{$\begin{array}{l}\text { Larger } \\
\text { Tracts: }\end{array}$} & Pin & $80-120$ & “ & $80-120$ & “ & \\
\hline & $\mathrm{Sp}$ & $80-100$ & “ & $80-120$ & " & $80-$ I 20 years \\
\hline & Fir and beech & $80-120$ & “ & $100-120$ & “ & $100-140$ \\
\hline
\end{tabular}




\section{CHAPTER II}

\section{REGULATION OF YIELD}

\section{DEFINITION}

REGULATION of the yield is the determination, for some years in advance, of the allowed annual cut. This regulation is the very essence of the working plan.

The space of years for which the yield is regulated depends on the frequency of accurate revisions of the working plan. Ten years is the customary minimum period for which the yield is regulated; at the end of that time* the working plan is revised and the yield regulated for the following decade. Where period methods (see below) are used, the yield is regulated in detail for the first period-twenty years in advancet-or even for the first two periods-forty years in advance - in detail for the first period of twenty years and roughly for the second period. Despite this regulation, so far in advance, exhaustive revisions are undertaken at the end of each decade. Frequent revisions are an absolute essential, and the regulation of yield for many years in advance, or even for the whole rotation, is little better than a useless play.

The allowed annual cut is fixed: First, in respect to how much can be cut, i.e., the determination of yield; second, in respect to where it is to be cut, i.e., the distribution of yield. This chapter is accordingly divided into sections to correspond with these two divisions of the subject and a third to treat special cases of yield regulation.

* In Saxony, the revision is undertaken every five years: the plan is for ten years.

$\dagger$ Prussia. $\quad \ddagger$ Austria 


\section{SECTION ONE}

\section{DETERMINATION OF YIELD}

The determination of the yield is either by area, by volume, or by both. In this determination the bases are the foundations of working plans already considered (Chapter I), namely:

I. Increment.

2. Growing stock and distribution of the age classes.

3. Silvicultural method of management.

4. Object of management.

5. Rotation.

Of these, increment is the most important, i.e., the increment as it actually is.* No sustained yield is possible which disregards the increment.

According as the determination of yield is to be by area, by volume, or by both, the following methods have been evolved:

I. A. By area.

B. By volume.

I. Based solely on growing stock.

2. I. Von Mantel's method.

3. 2. Méthode de Masson.

II. Based solely on increment.

4. I. By current annual increment (Hufnagl).

III. Based on Growing Stock and Increment.

5. I. Austrian formula (Kameraltaxe).

6. 2. Karl's method.

7. 3. Hundeshagen's method.

8. 4. Breymann's method.

9. 5. Heyer's method.

"Formula

Methods."

* "The main task for the regulation of yield, here as well as abroad, is doubtless the determination of the annual or periodic increment-the increment as it actually is. This is under all circumstances the most important basis and standard of comparison for the yield."-Prof. Dr. Martin, Tharandt, in private letter to the writer, January 21 , I9I2. 
IV. Based on Diameter Classes.

Io. I. French method (Méthode de I883).

II. 2. Indian method.

I2. 3. Diameter class method (Hufnagl).

C. By Area and Volume.

I. For entire forest.

I3. I. Russian method.

II. Based on age classes.

I4.

I. Direct method (Hufnagl).

I5.

2. Hufnagl's method.

I6. 3. The stand method (Judeich's "Bestandswirtschaft").

III. Based on periods ("Fachwerks Methoden").

I7.

I. Area-period method ("Flächenfachwerk").

2. Volume-period method ("Massenfachwerk").

3. Area-and-volume period ("Kombiniertes Fachwerk").

These seventeen methods of determining the yield will be considered seriatim; for each will be given (a) the description of the method, (b) an example of its working, and (c) an estimate of its value and application, with especial regard to American conditions. The following symbols are used: $V=$ volume, $r=$ rotation, $A=$ area, $a=$ age, M. = thousand feet board measure, $c d s=$ cords, $i=$ increment.

\section{BY AREA.}

(a) Description of Method.-The forest or main divisions thereof (working figures, blocks) is divided into a number of cutting areas - annual or periodic-corresponding to the rotation age. These annual or periodic cutting areas are marked on the ground; annually or periodically, a cutting area is logged. The size of the cutting areas is either exactly equal or else is equal to the reduced area corresponding to the varying site qualities. In order to give more accurate expression to the distribution of the age classes, Hufnagl has suggested that each annual cutting 
area be multiplied by the factor: $\frac{\text { average age }}{\text { half the rotation }}$ or $\frac{a}{\frac{r}{2}}$ thus securing the maximum sustained annual cutting area.

(b) Example: I. Area not reduced. II. Area reduced. III. Hufnagl variation.

I. A block contains $\mathrm{I}, 000$ acres. It is to be managed on a rotation of $\mathrm{r} 60$ years. The annual cutting area $=\frac{A}{r}=62.5$ acres. If the cutting period is 20 years, then the periodic cutting area will be $62.5 \times 20=1,250$ acres.

II. BY REDUCED AREA: Each site quality produces for a fully stocked stand a varying volume at the rotation age. These volumes can either be secured empirically or by means of normal yield tables. E.g., for Scotch pine it has been determined that the maximum yield (Site I) for a roo-year rotation is $102 \mathrm{M}$. per acre, the minimum (Site V) 34 M. per acre. The intermediate grades are:

Site quality $I \ldots \ldots \ldots \ldots \ldots \ldots \ldots \ldots$ Io2 $\mathrm{M}$. per acre

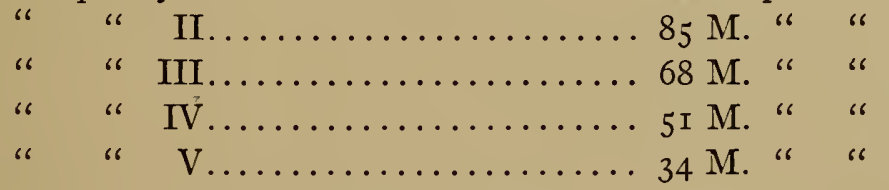

Further intermediate grades would be, e.g.:

Site quality I/II.............. 93 $93^{\mathrm{T}} / 2 \mathrm{M}$. per acre etc.

On the basis of site quality I the per cents of the other site qualities would be:

Site quality $I \ldots \ldots \ldots \ldots \ldots \ldots \ldots \ldots$

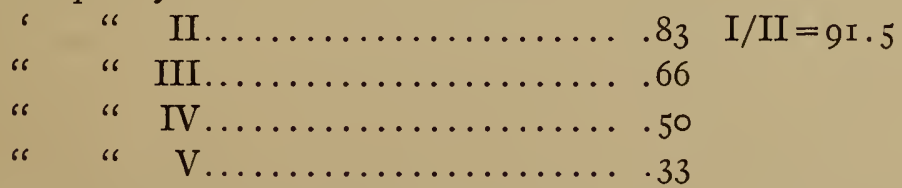

These are the factors of reduction to the common site quality (I). If, in the above instance, the actual area of $\mathrm{I}, 000$ acres was 
composed of 200 acres of each site quality ( $\mathrm{I}$ to $\mathrm{V}$ ), then the reduced area would be:

Site quality I, original 200 acres, reduced 200 acres.

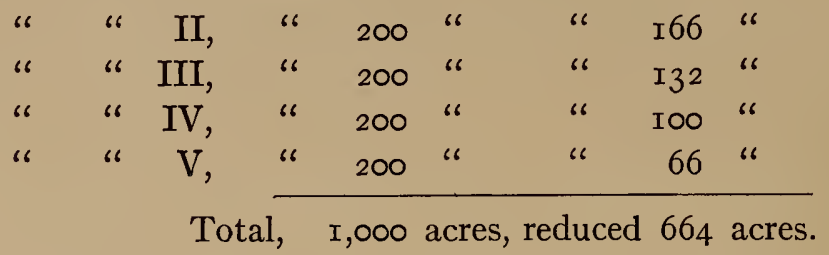

The annual or the periodic cutting area is, therefore, varied according to the site quality or qualities in the area allotted. $E . g .$, the annual cutting area $=\frac{\text { reduced area }}{\text { rotation }}=\frac{664}{\text { I00 }}=6.64$ acres. Similarly the periodic cutting area $=6.64 \times 20=I 32.8$ acres. If these 132.8 acres were all to be distributed among site quality III it would actually require:

$$
\mathrm{I} 32.8 \times \mathrm{I} .5 \mathrm{I} 5=20 \mathrm{I} \text { acres; }
$$

for, from the above table of percentages, it requires:

I.2 acres of site quality II to equal I acre of site quality I.

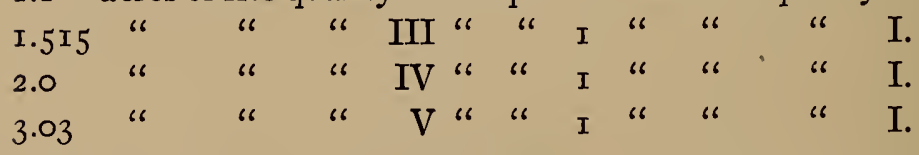

III. HUFNAGL VARIATION: Hufnagl multiplies the annual cut by the $\frac{\text { average age }}{\frac{r}{2}}$

Taking the example of age-class distribution and average age given under Latent Rotation (Chapter I, Section 3), this would. be:

Area

Rotation

Average age
$=2, \mathrm{I} 60$ acres.

$=80$ years.

$=43$ years.

$\therefore$ the annual cutting area $=\frac{2160}{80} \times \frac{43}{40}=29$ acres. 
(c) Value and Application.-The area method is the oldest of yield regulation, dating from the sixteenth century. It enables the transition from mere exploitation to a conservative management.

Its great advantage is simplicity.

Its great disadvantages are:

I. The rotation is assumed as a fixed value, whereas in reality it is a mere approximation and varies with the interior (management, accidents, etc.) and exterior (markets, desires of owner) changes to which every forest is subjected.

2. The method is too straight-laced to permit the free play necessary for the best silviculture, e.g., natural regeneration.

It is, therefore, restricted in application to forests with fairly uniform conditions, i.e., to coppice, coppice with standards, and well-developed selection forests.

\section{BY VOLUME.-BASED SOLELY ON GROWING STOCK. VON MANTEL'S METHOD.}

(a) Description of Method.-This is the simplest of the "formula methods." Indeed it is hardly to be ranked with them except in having the same underlying principle, namely, that the real yield must bear the same relation to the real growing stock as the normal yield (or, what is the same, the normal increment) bears to the normal growing stock.

Von Mantel considers that the growing stock $=$ the real increment (mean annual) multiplied by half of the rotation $\left(i \times \frac{r}{2}\right)$; for under normal conditions the half of that which grows during a rotation should be utilized and the other half remain as growing stock. This can be shown diagrammatically on next page.

The yield during a rotation therefore $=r / 2$ the total volume produced or $=$ all the volume produced during half of the rotation. The annual yield therefore equals the volume $\div$ by half the number of years in the rotation, or, as Von Mantel puts it:

$$
Y(\text { yield, annual })=\frac{V}{\frac{r}{2}}
$$


(b) Example.-A forest contains 6,810 M. feet board measure of spruce and fir to be managed on a $160-y e a r$ rotation. The annual yield $=\frac{V}{\frac{r}{2}}=\frac{6,8 \mathrm{IO}}{\frac{\mathrm{I} 6 \mathrm{O}}{2}}=\frac{6,8 \mathrm{IO}}{8 \mathrm{o}}=85 \mathrm{I}, 250$ feet board measure.

c) Value and Application.-The greatest advantage of Von Mantel's formula is its utter simplicity; for it requires only

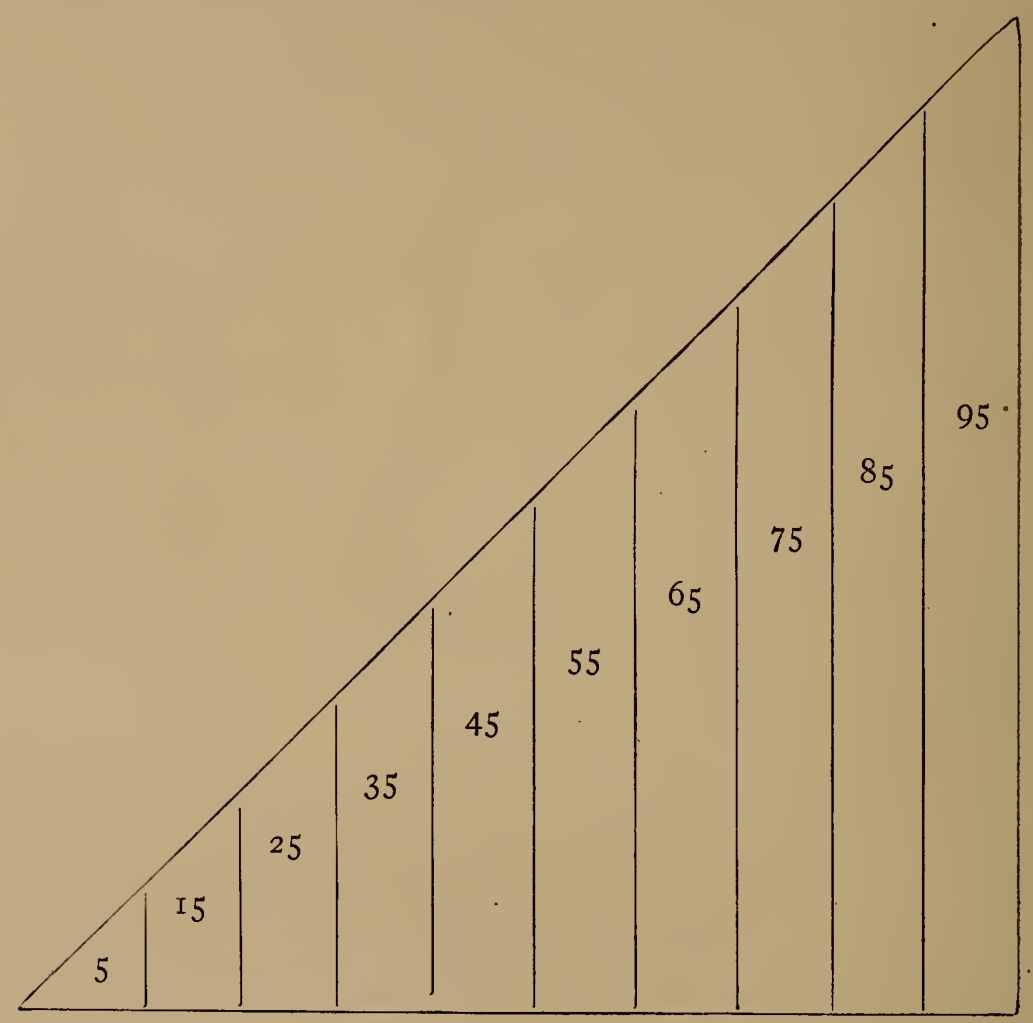

the total volume and the rotation. It is thereby adapted to the most meagre data.

Its disadvantages are: I. That it assumes a definite rotation which is altogether impossible in view of the disturbing emergencies which always arise. 2. While it does automatically 
reduce any surplus or deficit in the growing stock, it requires half the rotation to do so.

Its use is, therefore, restricted to determining the yield provisionally before detailed data can be obtained, and as a check on the results obtained by other methods.

3. BY VOLUME.-BASED SOLELY ON GROWING STOCK. METHODE DE MASSON.

(a) De.jcription of Method.-Masson's formula closely approximates that of Von Mantel, but is claimed by the French to have been developed independently, although based on the same principles. The formula is:

$$
\text { Annual yield }=\frac{2 V}{r}
$$

(b) Example.-A forest contains 6,8 זо M. feet board measure of spruce and fir to be managed on a 160 -year rotation. The annual yield $=\frac{2 V}{r}=\frac{13,620}{160}=851,250$ feet board measure.

-(c) Value and Application.-Precisely as in Von Mantel's method (No. 2).

4. BY VOLUME.-BASED SOLELY ON INCREMENT. BY CURRENT ANNUAL INCREMENT (HUFNAGL).

(a) Description of Method.-The chief data required are an exact determination of the current annual increment and an age-class table. The increment must be determined for all stands above a minimum age of, say, twenty years (corresponding to the minimum merchantable diameter). The age-class distribution must approach the normal relation. On these premises the allowed annual cut is taken directly as the sum of the annual increment for the entire working figure. It is a further essential of this method that the increment and growing stock be redetermined, by identical means, at frequent, regular intervals of not to exceed ten years. If the growing stock then shows an unintentional diminution, the yield was set at too high a figure; if, conversely, the growing stock, at the time of revision, shows an unintentional increase, the yield was set too low. 
The method can also be applied to uneven-aged forests if the diameter of all trees above the minimum merchantable be determined. Calipering is preferable, but ocular estimates in three-inch classes, as described under "Estimates," Chapter I, Section 2, will suffice in default thereof. The diameter-class data, when checked by sample plots, will determine the relative normality of the entire stand. If sufficiently normal, the annual cut is taken as directly equal to the increment; if the growing stock is excessive, more than the increment is taken; if the growing stock is deficient, less than the increment is taken.

Periodic remeasurements of the growing stock and increment are essential. This should be done every ten, or, at most, every twenty years.

(b) Example.-I Even-aged stand; II uneven-aged stand.

I. The age-class table shows a fairly normal distribution (such as that under "Rotation," Chapter I, Section 3), over I, ০০o acres of even-aged spruce forest with a rotation of 80 years, as follows:

\begin{tabular}{|c|c|c|c|c|c|c|c|}
\hline \multirow[b]{2}{*}{$\begin{array}{l}\text { Age } \\
\text { No. }\end{array}$} & \multirow[b]{2}{*}{$\begin{array}{l}\text { Class } \\
\text { years }\end{array}$} & \multirow[b]{2}{*}{$\begin{array}{c}\text { Area } \\
\text { (acres) }\end{array}$} & \multirow[b]{2}{*}{$\begin{array}{l}\text { Site } \\
\text { Quality }\end{array}$} & \multirow[b]{2}{*}{$\begin{array}{c}\text { Dens- } \\
\text { ity }\end{array}$} & \multirow[b]{2}{*}{$\begin{array}{l}\text { Increment } \\
\text { per acre* } \\
\text { ft.b.m. }\end{array}$} & \multicolumn{2}{|c|}{ Total Increment } \\
\hline & & & & & & $\begin{array}{l}\text { Fully } \\
\text { Stocked } \\
\text { ft.b.m. }\end{array}$ & $\begin{array}{l}\text { Reduced for } \\
\text { Density } \\
\text { ft.b.m. }\end{array}$ \\
\hline \multirow{2}{*}{ I } & $1-20$ & \multirow{2}{*}{510} & \multirow{2}{*}{ III } & \multirow{2}{*}{1.0} & \multirow{2}{*}{612} & \multirow{2}{*}{312,120} & \multirow{2}{*}{312,120} \\
\hline & I0 & & & & & & \\
\hline \multirow[t]{2}{*}{ II } & $2 I-40$ & 496 & III & $\cdot 7$ & $I, 360$ & \multirow[t]{2}{*}{674,560} & 472,192 \\
\hline & $\begin{array}{c}30 \\
41-60\end{array}$ & 470 & & & & & \\
\hline III & 50 & 465 & III & .4 & $\mathrm{I}, 649$ & 766,785 & $306,7 \mathrm{I} 4$ \\
\hline IV & $6 I-80$ & 443 & \multirow[t]{2}{*}{ III } & .5 & 1,309 & 579,887 & 289,944 \\
\hline & $\begin{array}{c}70 \\
81-120\end{array}$ & Tד & & & & & \\
\hline V & 100 & $2 \mathrm{I} 4$ & III & $\cdot 3$ & 782 & 167,348 & 50,204 \\
\hline Blanks & $\ldots \ldots \ldots$ & 32 & II/III & .0 & $\cdots$ & $\ldots \ldots \ldots$ & $\ldots \ldots \ldots$ \\
\hline Total & & 2,160 & & & & & $\mid \begin{array}{c}\text { I, } 43 \text { I I I I } 74 \\
=\underset{\text { annual }}{\text { cut }}\end{array}$ \\
\hline
\end{tabular}

* From yield table for spruce, Schwappach. 
II. The diameter-class distribution of a certain Ioo-acre area of pure Western yellow pine, ${ }^{*}$ uneven aged, is assumed to be as follows:

D. B. H., inches

$10-12$
$13-15$
I6-I 8
I9-2I
$22-24$
$25-27$
$28-30$
$31-33$

$\begin{array}{rc}\text { Average Volume } & \text { Number of Trees } \\ \text { 6o ft.b.m. } & 240 \\ \text { I Io ft.b.m. } & 440 \\ \text { I90 ft.b.m. } & 770 \\ \text { 3 ro ft.b.m. } & 720 \\ \text { 480 ft.b.m. } & 580 \\ \text { 7 I0 ft.b.m. } & 410 \\ \text { I,020 ft.b.m. } & 190 \\ \text { I,4 I0 ft.b.m. } & 70\end{array}$

This distribution, as determined by sample plots, is fairly normal. Hence the current annual increment per cent is applied directly to the volume of each diameter class, e.g..

$$
\begin{aligned}
& \text { I } 4,400 \text { feet b.m. } \times_{4} \quad \% \dagger=576 \text { feet b.m. } \\
& 48,400 \text { " " } \times 2.87 \%=1,389 \text { " " } \\
& \text { I 46,300 " " } \times 2.04 \%=2,985 \text { " " } \\
& 223,200 \text { " " } \times 1.49 \%=3,326 \text { " " } \\
& 278,400 \text { " " } \times 1.04 \%=2,895 \text { " " } \\
& 291,100 \text { " " } \times .84 \%=2,445 \text { " " } \\
& 193,800 \text { " " } \times .66 \%=1,279 \text { " " } \\
& 98,700 \text { " " } \times .54 \%=533 \text { " " } \\
& \text { I } 5,428 \mathrm{ft} . \mathrm{b} \cdot \mathrm{m} .=\text { annual cut. }
\end{aligned}
$$

(c) Value and Application.-This method is adapted to all classes of stands, but requires an amount and kind of data which would enable the use of a more accurate method of determining the yield. Its chief use is, therefore, as a check on other methods; for, after all, the increment is an important gauge of the correctness of the annual-or periodic-cut.

Where yield tables are wanting for even-aged stands, or increment figures for uneven-aged stands, an increment borer will give the desired data (see Chapter I, Section I, Increment) for

* Data chiefly from Bulletin I0I, Forest Service, U. S. Dept. of Agriculture.

† Adapted from European yieid tables. 
representative trees of each age class or each diameter class, and these data can then be applied directly to the entire stand.

\section{BY VOLUME.-BASED ON GROWING STOCK AND INCREMENT. AUSTRIAN FORMULA (KAMERALTAXE).}

(a) Description of Method.-This, and the other so-called "formula methods" ("Vorrats methoden"), is characterized by the fact that the allowed annual cut is determined, apart from any plan of management, by mathematical calculation based on a formula. The main factors in this calculation are the growing stock and the increment. The aim in regulating the yield is to have the actual growing stock $(V)$ and the actual increment $(i)$ approach the normal forest characterized by a normal growing stock $(n V)$ and a normal increment $(n i)$. The period of time in which the actual growing stock is to be brought to point of normality is taken as the whole rotation. This is to be accomplished by heavier cutting if the actual growing stock is greater than the normal growing stock, and lighter cutting if the actual growing stock is less than the normal growing stock.

The normal growing stock is calculated by the formula $\frac{r i}{2}$ where $i=$ the actual mean annual increment.* In even-aged stands it can also be calculated from yield tables by the formula $n\left(a+b+c+\ldots \frac{m}{2}\right)$, where $a, b, c \ldots m$ are the values

* Barrington Moore, in an article on "Methods of Regulating the Cut on National Forests," Proceedings of the Society of American Foresters, Vol. VII., No. I, has suggested that: "If, as is almost always the case, the real growing stock $(G r)$ is made up of only merchantable trees, it will be manifestly unfair to compare with this real growing stock a normal growing stock, which includes the small as well as the large trees. The result would be too small a surplus or too large a deficit. To obtain a more correct surplus or deficit a normal growing stock which includes only the merchantable trees should be used. This can be found by substituting for $R$ in the expression $\frac{I \times R}{2}$ a quantity, $R^{\prime}$, equal to the difference between the age of the merchantable trees and the rotation. For example, if the rotation is 200 years, and trees become merchantable at 60 years, the growing stock of merchantable trees necessary to leave on the area would be $\frac{I \times 140}{2}$ instead of $\frac{I \times 200}{2}$." 
given in the table for each age class, $n$ the number of age classes, and $m$ the volume at the rotation age.

The main formula then follows: $y$ (annual cut) $=i+\frac{V-n V}{r}$. Here again $i$ is the actual mean annual increment, not the normal.*

(b) Example.-An uneven-aged forest of Western yellow pine contains $3,500,000$ feet board measure of timber $\mathrm{r} 2$ inches diameter breast high and over on $\mathrm{r}, 000$ acres. The actual mean annual increment (Chapter I, Section I) is assumed as 0.7 per cent, or 49,000 feet board measure; the rotation as 200 years. The normal growing stock $\frac{r i}{2}=\frac{200 \times 24,500}{2}=2,450,000$ feet board measure. The annual cut $(y)$ then $=i+\frac{V-n V}{r}=24,500$ $+\frac{3,500,000-2,450.000}{200}=24,500+\frac{1,050,000}{200}=24,500+5,250$ $=29,750$ feet board measure. In this case there appears to be an excess growing stock. Adopting Mr. Moore's variation (see footnote), the result would be:

Normal growing stock $=\frac{r^{\prime} i}{2}=\frac{\mathrm{I} 40 \times 24,500}{2}=\mathrm{I}, 7 \mathrm{I} 5,000$ feet board measure.

The annual cut $(y)=i+\frac{V-n V}{r}=24,500+\frac{3,500,000-\mathrm{I}, 7 \mathrm{I} 5,000}{200}$ $=24,500+\mathrm{I} 7,850=42,350$ feet board measure.

This, however, is not strictly accurate, due to the failure to consider the increment per acre of young growth. "If the area of young growth below merchantable size is known, the increment can be found by determining the number of merchantable trees per acre which there would be if the stand were about normally stocked and contained no other age classes. The volume of such a stand divided by the average age of merchant-

* There has been some dispute about this, but the matter seems settled by the authoritative pronouncement of Judeich, "Forsteinrichtung," 6th Edition, p. 360, and Martin, "Forsteinrichtung," pp. 216-217. 
able trees will give the increment per acre of the young growth below merchantable size." *

E.g., area of young growth under I 2 inches diameter breast high $=6$ per cent of total area (I,000 acres) or 60 acres. A normally stocked stand of Western yellow pine 12 inches in dî̀ameter (about 60 years old) contains 5,850 board feet $\dagger ; \frac{5,850}{20}=$ 292.5 board feet $=$ the increment per acre of the young growth below merchantable size. There are 60 such acres, hence $292.5 \times 60=\mathrm{I} 7,550$ feet board measure. But the average density of stocking is only $\cdot 7$, so the real increment $=12,285$. The increment of the merchantable timber has already been figured at 24,500 feet; this + the 12,285 increment on unmerchantable timber $=36,785$. Then $\frac{\boldsymbol{r}^{\prime} i}{2}=\frac{\mathbf{I} 40 \times 36,785}{2}=2,574,950$ feet board measure.

The annual cut $(y)=i+\frac{V-n V}{r}=36,785+\frac{3,500,000-2,574,950}{200}$ $=4 \mathrm{I}, 4 \mathrm{I} O$ feet board measure.

(c) Value and Application.-Dating from a decree of the Vienna Hofkammer in 1788 (whence the name "Kameraltaxe"), this method has won the cognomen of "Austrian," although in Austria it is now used only as a check on other methods of determining the yield (see Part Two). Adapted to rather primitive conditions, especially to irregular, uneven-aged forests, the Austrian formula has grave disadvantages in that it assumes both $i$ and $n V$ as constants, whereas in consequence of cutting and unforeseen contingencies they are always changing, e.g., becoming better by correct cutting, becoming worse by storms, windfall, etc. In view of these changing constants the formula cannot secure even an approach to normal during the next rotation unless the yield is revised at least every ten years. This revision is not a part of the original Kameraltaxe any more

* Barrington Moore, ibid.

† From Tables Io and r9, Bulletin Ior, Forest Service, U. S. Dept. Agric. 
than is a plan of cutting (Distribution of Yield) so essential to a well regulated forest; for, as shown in Chapter I, Section I, no forest can be normal unless increment and age-class distribution are normal. The normal increment and normal growing stock alone do not suffice. Hence this and the other "formula methods" are all makeshifts (except as a check on other methods) and must be replaced by other and better methods as soon as conditions warrant.

Realizing these deficiencies, Huber varied the Austrian method by using the current annual instead of the mean annual increment and distributing the surplus or deficiency in growing stock over the whole rotation in a decreasing series instead of equally. This variation is, therefore, a transition to the methods of Karl and of Hundeshagen, which are considered below (6 and 7).

\section{BY VOLUME.-BASED ON GROWING STOCK AND INCREMENT. KARL'S METHOD.}

(a) Description of Method.-This method was probably suggested by the Austrian formula just described (No. 5) with Huber's modification. Karl takes the allowed annual cut as equal to the real current annual increment plus or minus the excess or deficiency of the actual growing stock when compared with the normal growing stock, distributed over a period of $A$ years instead of over the entire rotation, as in the Austrian formula. The formula for the cut for the first year therefore

$$
=i+\frac{V-n V}{A} \text {. }
$$

This formula would apply accurately to subsequent years only if $i$ were determined anew each year; for it changes constantly (see above under 5). In order to accomplish the approach to normal without an annual recalculation of $i$, a third expression is added to the formula, namely: $\frac{i-n i}{A} \times n$ where $n i=$ the normal current annual increment and $n=$ the number of years which have elapsed since the estimates were made. In the first year 
$n=O$, and hence the entire expression $=O$. In consequence of the increase of $n$ the annual cut would really have to be redetermined each year, but, for convenience, Karl presupposes the adoption of ten-year periods and makes $n=5$, i.e., the middle of the ten-year period during which the annual yield is to be equal. At the end of the ten-year period a revision of the yield takes place.

This third expression of the formula is always given the sign opposite that of the preceding expression.

The entire formula is therefore:

$$
y \text { (annual cut) }=i \pm \frac{V-n V}{A} \mp\left(\frac{i-n i}{A}\right) n .
$$

In addition a simple plan of cutting (distribution of yield) is drawn up as a guide in the management of the forest. However, this plan of cutting plays no part in the determination of the yield, which is by formula alone.

(b) Example.-An uneven-aged forest of Western yellow pine contains $3,500,000$ feet board measure of timber 12 inches and over diameter breast high, on 1,000 acres. The actual mean annual increment is assumed at .7 per cent, the rotation at 200 years. $n V$ then $=\frac{r i}{2}=2,450,000$ feet board measure. ${ }^{*}$ $A$, the period of distribution, is assumed as one-quarter of the rotation, or 50 years. $\dagger i$, the actual current annual increment, is averaged (see Chapter I, Section I) for the whole stand*and, reduced for the density of stocking, is assumed as $=\mathrm{x}$ per cent or, in volume, $=35,000$ feet board measure. The normal current annual increment is obtained from fully stocked sample plots (or from yield tables in even-aged stands), and is assumed as I.2 per cent, or 42,000 feet board measure. (With a density of .85

* It can also, in even-aged stands, be calculated from yield table (see No. 5).

$\dagger$ This period of distribution is chosen according to local exigencies; it had best be somewhat longer than seems necessary, in order to avoid possible errors and to remain on the side of conservatism. 
this would $=$ an actual increment of $\mathrm{I} .2 \times .85=\mathrm{I} .02$ or, roughly, one per cent.)

The annual cut by the formula then $=i \pm \frac{V-n V}{A} \mp\left(\frac{i-n i}{A}\right) n$ $=35,000+\frac{3,500,000-2,450,000}{50}-\left(\frac{35,000-42,000}{50}\right) 5=$ $35,000+2 \mathrm{~T}, 000-(\mathrm{I} 40) 5=55,300$ feet bcard measure equals annual cut.

Adopting Mr. Moore's variation of $r^{\prime}$ instead of $r$ in developing $n V$ (see No. 5), $n V=$ I,7 15,000 feet board measure. The annual cut then equals $i \pm \frac{V-n V}{A} \mp\left(\frac{i-n i}{A}\right) n=35,000+$ $\frac{3,500,000-\mathrm{I}, 7 \mathrm{I} 5,000}{50}-\left(\frac{35,000-42,000}{50}\right) 5=35,000+35,700$ $-700=70,000$ feet board measure equals annual cut.

Calculating the increment on the area of young growth, as was done under No. 5, the result would be: for $n V, 2,574,95^{\circ}$ feet board measure. The annual cut then equals $i \pm \frac{V-n V}{A} \mp$ $\left(\frac{i-n i}{A}\right) n=35,000+\mathrm{I} 2,285$ (the mean annual increment on the unmerchantable young growth, conservative since less than the current annual increment) $+\frac{3,500,000-2.574,950}{50}-$ $\left(\frac{35,000-42,000}{50}\right)_{5}=35,000+\mathrm{I} 2,285+\mathrm{I} 8,50 \mathrm{I}-700=65$,086 feet board measure equals annual cut.

(c) Value and Application.--Karl's method, which dates from 1838 , shows an advantage over the Austrian formula in so far as it uses the current annual instead of the mean annual increment, and in that it distributes the excess or deficit over a period adapted to local conditions instead of arbitrarily over the whole rotation. However, it is incorrect in making the third expression $\left(\frac{i-n i}{A}\right) n$ always bear a sign opposite that of the 
expression $\frac{V-n V}{A}$ directly preceding it. This would presume that an increase or decrease of the actual growing stock is always followed by an increase or decrease in the actual current annual increment. But the exact opposite can happen, e.g., if overmature stands are replaced by thrifty young growth or if, contrariwise, the overmature stock is allowed to accumulate. Karl's error probably arose through considering the volume of a forest's growing stock as comparable to a sum of money which bears more interest as it increases in size. Judeich* therefore considers the third expression $\left(\frac{i-n i}{A}\right) n$ not only incorrect, but unnecessary in view of the ten-year revisions; which would reduce the formula to $y=i \pm \frac{V-n V}{A}$ and would make the values in the above three examples, $56,000,70,700$, and 65,786 feet board measure respectively, the expression $\left(\frac{i-n i}{A}\right) n=700$ falling away in each case. The only remaining difference between Karl's formula and the Austrian formula is, then, the use of current instead of mean annual increment and of a suitable period for distributing the surplus or deficit-50 years in this case. There seems to be no reason why the latter modification can not be applied directly to the Austrian formula (No. 5) so that it reads:

$y=i+\frac{V-n V}{A}, \dagger$ whereupon the values in the three examples under (5) would become:

(I) $24,500+\frac{3,500,000-2,450,000}{50}=45,500$ feet b.m.

*Lorey's "Handbuch der Forstwissenschaft," 2d Ed., Vol. III., pp. $42 \mathrm{I}-2$.

† This is Heyer's formula as given by Martin's "Die Forsteinrichtung," 2 Ed., p. 67, but Judeich, who made a special study of this point, considers it as under 9 below, and his precedent has been followed, although the results are exactly identical. (See example under No. 9.) 
(2) $24,500+\frac{3,500,000-10,715,000}{50}=60,200$ feet b.m.

(3) $36,785+\frac{3,500,000-2,574,950}{50}=55,286$ feet b.m.

With Judeich's suggested modification, the value of Karl's formula is as a rough method in irregular stands or as a check upon other methods of regulating the yield. For this purpose either it or the just suggested modification of the Austrian formula may be used according as the current or the mean annual increment has been determined.

\section{BY VOLUME.-BASED ON GROWING STOCK AND INCREMENT.} HUNDESHAGEN'S METHOD.

(a) Description of Method.-Hundeshagen conceives of the increment or yield as the interest on the growing stock and assumes that the actual yield is to the actual growing stock as the normal yield is to the normal growing stock, or: $\frac{y}{v}=\frac{n y}{n v}$ transposed this is $y=v \frac{n y}{n v}$ which is the Hundeshagen formula.

Hundeshagen calls the factor $\frac{n y}{n v}$ the "use per cent" ("Nutzungs prozent"). If $n v$ is calculated by means of the mean annual increment $\left(n v=\frac{r i}{2}\right)$ and $n y$ is taken as $=i$, then $\frac{n y}{n v}=\frac{2}{r}$. Hundeshagen, however, calculates $n v$ by means of yield tables (see method for even-aged stands under No. 5). $v$ is the volume actually present in the forest.

Hundeshagen suggests a short-cut method wherein for calculating $n v$ and $v$ only those stands are to be considered whose age exceeds $\frac{r}{2}$ and thereby a "partial use per cent" obtained.

(b) Example.-An uneven-aged forest of Western yellow pine contains $3,500,000$ feet board measure of timber I $_{2}$ inches and over diameter breast high, on $\mathrm{I}, 000$ acres. The mean annual increment $(i)$ is assumed at .7 per cent, the rotation at 200 
years. Disregarding Hundeshagen's method of determining $n v$ by means of yield tables and taking $\frac{n y}{n v}=\frac{2}{r}=\frac{2}{200}=.0 \mathrm{I}$, the formula gives:

$y=v \frac{n y}{n v}=v \times .0 \mathrm{I}=3,500,000 \times .0 \mathrm{I}=35,000$ feet board measure equals annual cut.

This result is identical with that obtained by Von Mantel's formula (No. 4) or by the Austrian formula (No. 5) modified (as suggested under No. 6) by making the period of distribution of excess or deficit equal half the rotation, e.g.:

$$
y=i+\frac{v-n v}{\frac{r}{2}}
$$

but $n v=\frac{r i}{2}$

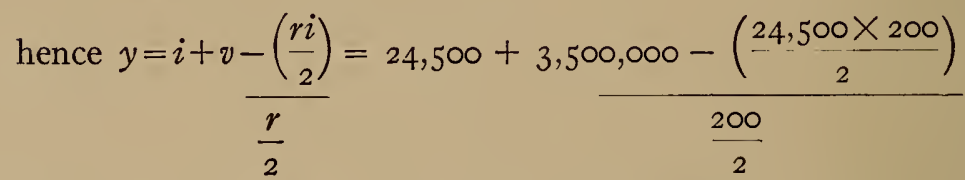

$=24,500+10,500=35,000$ feet board measure equals annual cut.

(c) Value and Application.-This method, published by Hundeshagen in I82 I, was really discovered by Paulsen in I795, though Hundeshagen never knew of the latter's work until I830. It presents no advantages over the methods already described and some very substantial disadvantages:

(I) The assumption that the actual yield is to the actual growing stock as the normal yield is to the normal growing stock is not always correct, especially not where there are overmature and deteriorating stands in the forest.

(2) The value of $v$ changes constantly, hence, to be strictly accurate, $y$ would have to be redetermined annually.

(3) The method provides no definite period for the distribution of surplus or saving of deficit in the growing stock. A 
cutting plan is permissible, but does not affect the volume of the cut as determined by the formula. Hence under the method, overmature stands can be dragged through many years if the growing stock is excessive or immature stands cut off though the growing stock is already deficient.

The only real use of the formula in irregular, uneven-aged stands is as a check on other methods. Its use in even-aged stands presupposes normal yield tables and regulated conditions, neither of which exist in America at present nor will exist for some time to come.

8. BY VOLUME.-BASED ON GROWING STOCK AND INCREMENT. BREYMANN'S METHOD.

(a) Description of Method.-Based on Hundeshagen's formula, Breymann assumed that the actual yield is to the normal yield as the actual average age is to the normal average age of a stand. Hence $y=n y \frac{a}{n a}(a=$ age). Now $n y=n i$ (mean annual increment) and $n a=\frac{r}{2}$. The average age can be determined either by area according to the formula: $a=\frac{f_{1} a_{1}+f_{2} a_{2}+f_{3} a_{3}}{f_{1}+f_{2}+f_{3}}$ wherein $f_{1}, f_{2}, f_{3}$, etc., equal the area of the various age classes and $a_{1}, a_{2}, a_{3}$, etc., equal their respective average age (see examples under "Distribution of the Age Classes," Chapter I, Section I, and under "The Latent Rotation," Chapter I, Section 3, "Rotation") or else the average age can be determined by volume according to the formula:

$a=\frac{v^{1}+v^{2}+v^{3}}{\frac{v^{1}}{a^{1}}+\frac{v^{2}}{a^{2}}+\frac{v^{3}}{a^{3}}}$ wherein $v^{1}, v^{2}, v^{3}$, etc., equal the volumes of the

various age or diameter classes and $a^{1}, a^{2}, a^{3}$, etc., their respective age (see example under "Distribution of the Age Classes," Chapter I, Section I).

(b) Example.-A forest of Western yellow pine containing $3,500,000$ feet board measure of timber I2 inches and over 
diameter breast high, on I,000 acres, is essentially uneven-aged, but shows three distinct diameter classes: I2 to 18 inches, average 14 inches ("Black Jacks"), and 20 inches and over, average 26 inches ("yellow pine"). The volume of the former is 20 per cent of the total, or 700,000 feet board measure; the volume of the latter is 80 per cent of the total, or $2,800,000$ feet board measure. The average age of a I4-inch "Black Jack" is 70.5 years, of a 26 -inch "yellow pine" 285 years.* Then by the formula,

$a=\frac{v^{1}+v^{2}}{\frac{v^{1}}{a^{1}}+\frac{v^{2}}{a^{2}}}=\frac{700,000+2,800,000}{\frac{700,000}{70}+\frac{2,800,000}{285}}=\frac{3,500,000}{10,000+9,818}=\mathrm{x} 76$ years.

The adopted rotation is, however, only 200 years, hence

$n a=\frac{r}{2}=\frac{200}{2}=100$. The current mean annual increment is placed at 0.7 per cent, or 24,500 feet board measure. By the formula

$y=n y \frac{a}{n a}=24,500\left(\frac{\mathrm{I} 76}{\mathrm{I} 00}\right)=24,500 \times x .76=43, \mathrm{I} 20$ feet board measure, equals annual cut.

(c) Value and Application.-This method, promulgated by Breymann in I854, aims in common with the other "formula methods" to secure an approach of the actual growing stock toward the normal growing stock. However, in addition to the employment of data which are difficult and subject to error in irregular stands and extensive conditions (e.g., normal increment and average age calculations), it has the strong drawback that the adjustment of the excess or deficit in the growing stock is spread over the whole rotation, whereas the exigencies of the occasion usually warrant this adjustment in a fraction of that time.

The method is, therefore, of little practical value except as a check upon other methods of regulating the yield.

* From Table 9, Bulletin IoI, Forest Service, U. S. Dept. of Agric. 


\section{BY VOLUME.-BASED ON GROWING STOCK AND INCREMENT. HEYER'S METHOD.}

(a) Description of Method.-Heyer bases his formula on the following premises:

(I) If a stand is normal, then an amount equal to the mean annual increment can be cut each year so long as the three requisites of normality are maintained, i.e., (a) normal growing stock, $(b)$ 11ormal increment, and (c) normal distribution of the age classes (see Chapter I, Section I, "The Normal Forest and Its Attributes").

(2) If normality in (a) and (b) exists, but (c) is abnormal, it can be made normal if the normal increment is cut annually or periodically, and the cut-over stands immediately regenerated.

(3) If the actual increment is less than the normal increment (the contrary can scarcely ever occur), then, even if the growing stock is normal, only the actual, not the normal, increment can be cut.

(4) If the growing stock is abnormal it can be brought toward normality by either cutting less than the actual increment if the growing stock is too small, or cutting more if it is too large.

(5) The period of distribution ( $x$ ) of excess or deficit, i.e, the time during which an abnormal stand is to approach normality, can be determined only with regard to local exigencies, it must be developed out of a general plan of management which is in consonance with the wishes of the owner. If $v<n v$ then $x$ must equal at least a period of years sufficient so that the sum of the actual increments during that period equal the difference between $v$ and $n v$; where this is exactly the case then $y$ (the annual cut) equals $o$.

On these premises Heyer develops the formula:

$$
y=\frac{v+i x-n v}{x}
$$

$i$ is the actual mean annual increment, and hence really varies from year to year. Hence as $i$ improves, the approach toward normality is accelerated to less than $x$ years, as it grows 
smaller the approach toward normality is retarded to more than $x$ years. This variation of $i$ Heyer meets by calculating $i$ not solely according to its present condition, but by conceiving of the expression $i x$ as the increment during the period of $x$ years, with regard to all the probable changes in increment during the $x$ years. This is facilitated by the drawing up of a plan of cutting (distribution of yield) as outlined in Section 2 of the present chapter.

$n v$ is found by the formula $\frac{r i}{2}$ in which Heyer takes $i$ as the normal mean annual increment, but at the same time raises the question whether taking $i$ as the actual mean annual would not be equally correct.* (It has now come to be universally considered as the correct method.)

(b) Example.-An uneven-aged forest of Western yellow pine contains $3,500,000$ feet board measure of timber I 2 inches and over diameter breast high, on 1,000 acres. The mean annual increment equals .7 per cent, equals 24,500 feet board measure. The rotation is taken at 200 years. The normal growing stock equals $\frac{r i}{2}=\frac{200 \times 24500}{2}=2,450,000$ feet. $v$ is, therefore, $>n v$ by $1,050,000$ feet. This excess is, in view of local exigencies and the wishes of the owner, to be distributed over $\frac{r}{4}$ years $=\frac{200}{4}=50$ years $=x$. By the formula:

$$
\begin{aligned}
& y=\frac{v+i x-n v}{x}=\frac{3,500,000+(24,500,50)-2,450,000}{50} \\
= & \frac{3,500,000+\mathrm{I}, 225,000-2,450,000}{50}=45,500 \text { feet board measure }
\end{aligned}
$$

equals annual cut, which is exactly the same result secured by the Austrian formula (No. 5) modified as suggested under 6, (c) , i.e., $y=i+\frac{v-n v}{x}=24,500+\frac{3,500,000-2,450,000}{50}=45,500$

* Judeich, "Forsteinrichtung" in Lorey's "Handbuch der Forstwissenschaft," 2 d edition, Vol. III., p. 425, foot-note. 
feet board measure. The only difference is if $i x$ is modified to correspond with expected changes during the next $x$ yearsas outlined above.

(c) Value and Application.-Carl Heyer's formula dates from $\mathrm{I} 84 \mathrm{I}$, and is perhaps the only one of the formula methods in active use to-day, having been adopted by the grand duchy of Baden for the determination of the volume yield; this is supplemented by a careful cutting plan (Distribution of Yield) for the next period of years (see Part Two, Chapter I). Gustav Heyer, in the revised edition of Carl Heyer's work, ${ }^{*}$ adds a complete period distribution of the yield similar to that described under No. I 7 below. However, this is possible only under regular conditions and in even-aged stands, and in no way destroys the effectiveness of Heyer's formula in irregular uneven-aged stands, although it correctly emphasizes the importance of adding to the mere volume determination of the yield a "when" and "where" by means of a careful cutting plan (distribution of yield) as described below in Section 2 of the present chapter.

With this in mind, Heyer's formula is directly applicable to the majority of American forests, especially to those where, as in virgin forests, the actual growing stock is far in excess of the normal growing stock and a reduction to normal is of prime importance.

\section{Summary and Comparison of the "Formula Method"}

The "formula methods," or, more properly, the "growing stock methods" ("vorratsmethoden"), for there are other methods employing formulæ to determine the yield, all aim to have the actual growing stock approach the normal. This is secured by a purely mathematical ratio of increment and growing stock, whereas, oftentimes, the character of the stands and other

* Carl Heyer, "Die Waldertrags-Regelung," I84I. Second and third editions edited by Gustav Heyer, I 862 and I 883 . 
conditions of management which do not admit of mathematical cxpression are of more importance.

In combination with a careful cutting plan (distribution of yield) the Heyer formula serves as a useful determinator in irregular, uneven-aged forests. It is better than the other formulæ for the reasons already detailed under (c) "Value and Application," although the other formulæ will serve as a useful check. The superiority of the Heyer formula is still further evident when the results of the examples based on identical premises are compared:

\begin{tabular}{|c|c|c|c|}
\hline \multirow[b]{2}{*}{ Current No. } & \multicolumn{3}{|c|}{$y$ (annual cut) in feet board measure } \\
\hline & If $n v=\frac{r i}{2}$ & If $n v=\frac{r^{\prime} i^{*}}{2}$ & $\begin{array}{l}\text { Including } \\
\text { young } \\
\text { growth, etc. }\end{array}$ \\
\hline 5. Austrian Formula & $29,75^{\circ}$ & 42,350 & 41,410 \\
\hline 6. Karl's Formula & 55,300 & 70,000 & 65,086 \\
\hline Karl's Formula without $\left(\frac{\imath-n \imath}{a}\right)$ & 56,000 & 70,700 & 65,786 \\
\hline 7. Hundeshagen Formula......... & 35,000 & & . \\
\hline 8. Breymann's Formula.. & 43,120 & & $\ldots$ \\
\hline 9. Heyer's Formula.. & 45,500 & 60,200 & 55,286 \\
\hline For Comparison: & & & \\
\hline $\left.\begin{array}{l}\text { 2. Von Mantel's Formula } \ldots \ldots \ldots \ldots \ldots \\
\text { 3. Méthode de Masson............. }\end{array}\right\}$ & 35,000 & & \\
\hline
\end{tabular}

1o. BY VOLUME.-BASED ON DIAMETER CLASSES. MÉTHODE DE 1883 ("FRENCH METHOD"). $\dagger$

(a) Description of Method.-Instead of constructing a stand table, the total volume of each diameter class should be determined. Some figures should also be obtained showing the number of trees of the diameter desired at the end of the rotation (exploitable diameter) which there would be per acre in a normally stocked stand, if no other age classes were present. Since

* See explanation under No. 5: (a) "Description of Method" and (b) "Example" of Austrian formula.

$\dagger$ Adapted from Barrington Moore's article "Methods of Regulating the Cut on National Forests," in Vol. VII., No. I, "Proceedings of the Society of American Foresters." 
these figures must be taken in the field, sometimes before the exploitable diameter has been decided upon, several diameters should be taken.

When the desired exploitable diameter has been decided upon, determine from the growth figures the number of years necessary to produce this diameter. This number of years, lengthened by a few years to allow for a possible delay in reproduction, will be the rotation.

Divide the trees shown by the estimates into three groups as follows:

Ist group, old trees. Those containing two-thirds of the exploitable diameter and above; e.g., if the exploitable diameter is $30^{\prime \prime}$, this group would contain trees between $20^{\prime \prime}$ and $30^{\prime \prime}$.

$2 \mathrm{~d}$ group, medium trees. Trees having a diameter falling between one-third and two-thirds of the exploitable diameter; e.g., trees between $1 \mathrm{O}^{\prime \prime}$ and $2 \mathrm{O}^{\prime \prime}$.

$3 \mathrm{~d}$ group, young trees. Everything with a diameter less than one-third of the exploitable diameter.

The calculation of the yield is based on groups I and 2, and is made in the following manner:

Find the volume of each of the first two groups. Then if the volume of the old trees is to that of the medium trees as 5 is to 3 the proportion of the two groups may be considered normal.* If the proportion is normal it will be possible to cut the group of old trees, plus their increment, during the first third of the rotation, the increment, of course, being figured for only half of the third of the rotation.

But, first of all, it is necessary to ascertain whether or not the volume as a whole is too great or too small. This is done by finding the total volume which there would be if half of the

* This ratio is based on the relative age of the old group and the medium group; it will vary with the length of the rotation, the conditions of growth, and the species. In the present instance, if the rotation age is 50 , each group covers 50 years, i.e., the old group 100-150, average 125 ; the medium group $50-100$, average 75 . Then the old group is to the medium group as 125 : $75=5: 3$. 
entire area were covered with trees of just exploitable size* (not of very large mature trees). In obtaining this volume the number of exploitable trees per acre, called for above, is used. The result should be approximately equal to the sum of the old and medium trees. If the result is less the forest contains a surplus; if more, it contains a deficit. There are five distinct possibilities:

(I) The volume of the old and volume of the medium trees may be in the proportion of $5: 3$, and sum of their volumes normal. In this case nothing further is necessary before the actual calculation of the cut.

(2) The volume of old and medium trees may be in the proportion of $5: 3$, but their sum less than normal. In this case it will be necessary to increase the growing stock. This can be done by cutting, during the first third of the rotation, only the old trees, without their increment, or, if the area is very badly understocked, by cutting less than the old trees.

(3) The volume of old and medium trees may not be in the proportion of $5: 3$, and their sum nevertheless normal. This is adjusted by transfers from the group which is too large to that which is too small.

(4) The volume of old and medium trees may not be in the proportion of $5: 3$, and their sum less than normal. This will probably mean that the volume of old trees is deficient, and must be increased by cutting less than the otherwise allowable volume of old trees.

(5) The volume of old and medium trees may not be in the proportion of $5: 3$, and their sum more than normal.

This could occur only with an excess in the old group. To correct this, find the volume of old trees necessary to make the ratio $5: 3$ with the volume of the medium trees, and which, added to the volume of medium trees, will give a normal growing stock. The difference between this volume and the actual volume of old trees is surplus. This surplus must generally

* In dealing with open stands, such as Western yellow pine in the Southwest, the area must be considered as fully stocked with exploitable trees, but due allowance must be made for natural openings and bare places. 
be removed during the first third of the rotation, for the entire area will be cut over once during that time. Even though it were desirable to distribute this surplus over a longer period, such a course would generally be impossible, because in virgin forests, most of them of difficult accessibility, the first cut must be heavy per acre to justify logging. Later cuttings may, without hardship to purchasers, be made lighter.

When several species occur in mixture all are regulated together without affecting the method. If one species has a more rapid growth and is shorter lived, requiring a shorter rotation, its exploitable diameter should be made lower than that of the other species.

The whole calculation is checked by figuring what per cent of the total volume is represented by the allowable cut. This per cent, after subtracting the surplus, should be approximately the growth per cent of the group of old trees.

The area check on this method is applied as follows:

The whole working circle (working figure) is to be gone over in one-third of the rotation. Since the rotation may be long, this third is further divided into periods during which the plan is to run without revision. If these periods are too short an unnecessary expense will be incurred by frequent reconnaissance work, whereas if they are too long there is danger that the effects of original errors may accumulate. A period of about 20 years seems reasonable. Thus if the rotation is 180 years, the whole working circle will be cut over in 60 years. If the period during which the plan is to run be 20 years, the area is divided on the basis of topography into three parts, each containing about an equal volume, and each to be cut over in 20 years. In some cases, where the working circle does not lend itself to a division into parts containing equal volumes, it may be divided into unequal parts, each part to be cut over in a period bearing the same relation to the one-third of the rotation as the part bears the whole working circle. The part containing the largest proportion of overmature and deteriorating timber should be cut during the first period. This part may be further subdivided 
for convenience into watersheds forming natural logging units or groups of units (blocks).

(b) Example.-Total area of working circle $=200,000$ acres. Minimum merchantable D. B. H. $=10^{\prime \prime}$.

Size of material desired: Sugar pine and yellow pine $=30^{\prime \prime}$. Incense cedar $=24^{\prime \prime}$.

The group of old trees will include those $20^{\prime \prime}$ and over D. B. H. The medium trees will include those between $\mathrm{IO}^{\prime \prime}$ and $2 \mathrm{O}^{\prime \prime}$ D. B. H.

The average length of time required to produce a tree $30^{\prime \prime}$ D. B. H., considering the important species, is 160 years. The period of reproduction is approximately 20 years. Hence the rotation will be $160+20$, or 180 years. Incense cedar is shorter lived and more rapid growing, hence will be considered exploitable at $24^{\prime \prime} *$

TABLE of Estimates

Medium Trees

Old Trees

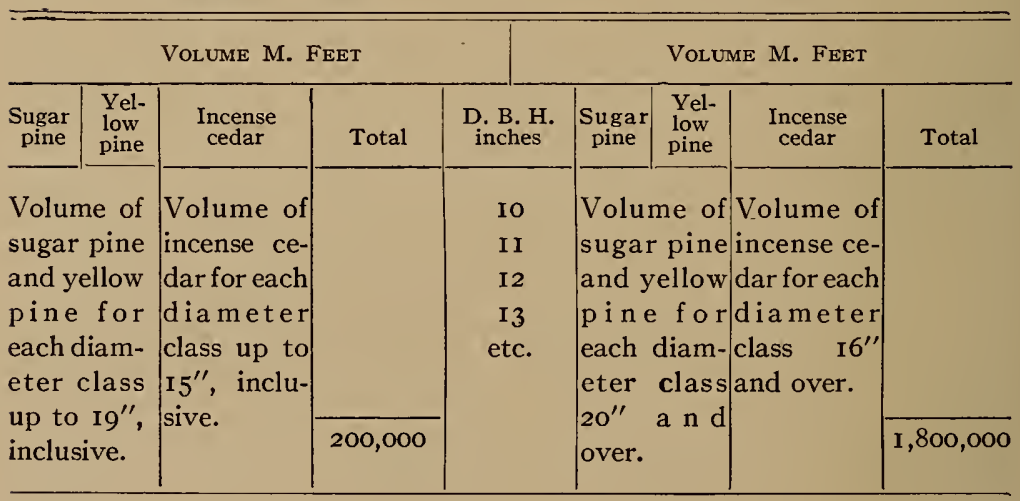

* This exploitable diameter for incense cedar will cause a slight inaccuracy in that the medium trees should be taken to $8^{\prime \prime}$ instead of $10^{\prime \prime}$ to correspond with the $24^{\prime \prime}$. On the other hand, the volume between $8^{\prime \prime}$ and $10^{\prime \prime}$ will be small, and if desired can be allowed for by sample tallies over a small percentage of the strips. The cutting of a short-lived species to a lower diameter limit is desirable in this case because the area is gone over only once in 60 years. 
From the table we find the actual proportion of old and medium trees to be:

$$
\begin{array}{r}
\text { Old trees }=1,800,000 \text { M. feet } \\
\text { Medium trees }=\frac{200,000 \text { M. feet }}{\text { Total, } 2,000,000} \text { M. feet }
\end{array}
$$

The normal proportion should be:

Old trees, $2,000,000 \times \frac{5}{8}=1,250,000$

Medium trees, $2,000,000 \times \frac{3}{8}=750,000$

But the normal growing stock over the whole area, considering half of the area stocked with $30^{\prime \prime}$ trees, should be I,I 20,000 M. This should be divided between the two groups as follows:

Old trees, $\mathrm{I}, \mathrm{1} 20,000 \times \frac{5}{8}=700,000 \mathrm{M}$. Medium trees, $1,120,000 \times \frac{3}{8}=420,000 \mathrm{M}$.

$$
\text { I,120,000 M. }
$$

Hence, although there is a surplus of $1,800,000-700,000=$ I,I00,000 M. feet of old trees, there is a deficit of $420,000-$ $200,000=220,000 \mathrm{M}$. in the medium trees. If all the old trees were cut during the first third of the rotation the growing stock would be depleted. Therefore $220,000 \mathrm{M}$. feet will be taken from the lower diameters of the large trees, chiefly from the more valuable species, and added to the medium trees. The resulting surplus will be $1,100,000-220,000=880,000 \mathrm{M}$. This surplus is to be removed during the first third of the rotation. The cut for the first third of the rotation will therefore be the $880,000 \mathrm{M}$. surplus and the 700,000 M. normal volume of old trees, plus the increment on their sum. This increment will be I 2,000 M. per annum, or $12,000 \times 30=360,000$ for the 60 -year period.* Therefore the annual cut for the first third of the rotation will be:

$$
Y=\frac{800,000+700,000+360,000}{60}=32,333 \text { M. feet. }
$$

This amounts to I.6r per cent of the total volume. Not counting the surplus or increment on the surplus, there will be .going on.

* The increment is taken for only half of the period because cutting is 
a cut of only $853,000 \mathrm{M}$. feet for the 60 -year period, or an annual cut of only I4,2 I $6 \mathrm{M}$. feet. This is but .7 I per cent of the total volume, or approximately the increment on the group of old trees.

In carrying out this method, site qualities producing very marked differences in growth must be distinguished in the field work and kept separate in the computations. For instance, in some of the very dry limestone soils of the Western yellow-pine belt of the Southwest the trees are small and stunted, and even when mature hardly reach the diameter of poles on ordinary sites. Such areas if small and unimportant may be thrown out and ignored; but if of some extent they should generally receive a separate calculation of yield and proper consideration in the final allotment of the cut.

(c) Value and Application.-A disadvantage of the French system is that it requires the tallying of trees down to onethird of exploitable diameter. This means that if the exploitable diameter is $24^{\prime \prime}$ everything above $8^{\prime \prime}$ must be tallied. It is, therefore, best adapted to a high diameter limit and long rotations, which is, however, generally the case in many of our selection forests. The advantages of the method are elasticity and a degree of accuracy not attainable with formulæ.

\section{BY VOLUME.-BASED ON DIAMETER CLASSES. INDIAN METHOD.*}

(a) Description of Method.-This method is based on the principle that a certain number of trees reach a size suitable for cutting every year or period of years. The aim of the method is to cut just this number of trees.

The data required are:

r. A careful enumeration of the growing stock. For this purpose five or six broad classes are made fr mm seedlings up to mature trees.

* Adapted from Barrington Moore's article, "Methods of Regulating the Cut on National Forests," in Vol. VII., No. I, "Proceedings of the Society of American Foresters." 
2. Growth figures, particularly showing the number of years required to pass through each class.

3. Figures showing the percentage of mortality suffered by each class as it passes into the next class above and into the final or mature class.

The rotation is generally the sum of the number of years required to pass through each age class till the exploitable size is reached, with generally a few years added on to make it conservative. The felling period is a convenient subdivision of the rotation and should be at least the length of time required to produce enough material to justify the next cut.

The annual cut is calculated in the following manner: The number of trees in each class is multiplied by the percentage which will survive till maturity. The results are added and then divided by the rotation plus one-half of the felling period.*

In order to find the growing stock of Class I trees the average annual yield as found above is multiplied by half of the felling period. In order to allow for mortality this number is raised by multiplying by

$$
\text { I } \times\left(\frac{\text { Mortality per cent }}{2}\right) \text {. }
$$

The growing stock thus found is compared with the actual growing stock to find whether there is a surplus or deficit. The annual cut is allotted accordingly, distributing this surplus or deficit over a certain period according to the proportion of lower classes and reproduction.

The area check is applied by prescribing the order of the fellings through the different subdivisions (compartments) of the working circle. A table is drawn up showing for each year the subdivision on which the cut is to be located and number of trees to be removed.

* Half of the felling period is added to the rotation to allow for the number of Class I trees (the largest class) which should always be on the ground, because there should always be a number of Class I trees equal to the Felling period $\times$ average annual yield. 
(b) Example.-

Total Growing Stock

Class

\begin{tabular}{|c|c|c|c|c|c|c|}
\hline Species & $\begin{array}{c}\text { I } \\
28^{\prime \prime} \text { and } \\
\text { over } \\
\text { D.B.H. }\end{array}$ & $\begin{array}{c}\text { II } \\
24^{\prime \prime} \text { to } 28^{\prime \prime}\end{array}$ & $\begin{array}{c}\text { III } \\
\text { I } 8^{\prime \prime} \text { to } 24^{\prime \prime}\end{array}$ & $\begin{array}{c}\mathrm{IV} \\
\mathrm{I} 2^{\prime \prime} \text { to } 18^{\prime \prime}\end{array}$ & $\begin{array}{c}\mathrm{V} \\
6^{\prime \prime} \text { to } 12^{\prime \prime}\end{array}$ & $\begin{array}{c}\text { VI } \\
\text { Below } \\
\text { 6" D.B.H. }\end{array}$ \\
\hline Yellow pine.... & $\mathrm{I} 3, \mathrm{I} 78$ & I I,366 & 19,770 & 42,577 & I I 7,590 & 215,667 \\
\hline
\end{tabular}

Rotation $=I 50$ years

Felling period $=15$ years

From a table showing per cent of each class, reaching Class I, and the per cent of Class I surviving ${ }_{5} 5$ years, the following calculation is made: Average annual yield $=$

$$
\begin{aligned}
& \underline{(13178 \times .95)+(\text { I } 1366 \times .83)+(19770 \times .66)+(42577 \times} \\
& \mathrm{I} 5 \mathrm{O}+\frac{13}{2} \\
& \frac{.50)+(117590 \times .30)+(215667 \times .10)}{150+1 \frac{5}{2}} \\
& =\frac{\mathrm{I}_{25} \mathrm{I}_{9}+9472+\mathrm{I} 3 \mathrm{I} 80+2 \mathrm{I} 288+35^{277}+2 \mathrm{I}_{567}}{\mathrm{I}_{57.5}} \\
& \frac{\text { II } 3303}{I 57 \cdot 5}=7 \text { I9 trees per annum. }
\end{aligned}
$$

The growing stock of Class I trees, which there should always be, is therefore $7 \mathrm{I} 9 \times \frac{15}{2} \times 1.025=5532$.

Since there are $13, \mathrm{I} 78$ Class $I$ trees, a surplus of $13, \mathrm{I} 78-5,532$ $=7,646$ trees exists.

The cut for the period over which it is desired to distribute the surplus will be: The present Class I trees, plus the total number of trees reaching Class $I$ in the period, minus the growing stock, all divided by the period.

A modification may be made by calculating the annual yield on the basis of only the upper classes (the first three or four) instead of on all classes. The sum of these classes is then divided by the number of years which the lowest class used will take to become Class I instead of by the rotation.

(c) Value and Application.-Practically the only place 
where the single tree method is used is in India. There it is used almost to the exclusion of all other methods. It is particularly well adapted to mixed tropical forests in which only one or two of the many species found is merchantable.

The disadvantages of the method are its lack of elasticity, its complexity, and liability to error; it also requires as many data as better methods. Hence it should be used only in exceptional cases.

12. BY VOLUME.-BASED ON DIAMETER CLASSES. DIAMETERCLASS METHOD_(HUFNAGL).

(a) Description of Method.-I, yield in volume only; II, yield in volume and in number of trees.

I. For uneven-aged (selection) forests the yield can be determined if all stands or trees more than $\frac{r}{2}$ years old are known and their increment. This presupposes the fixation of the rotation age (Chapter I, Section 3, "Rotation"). By means of ringcounts on stumps of average diameter it is then determined at what diameter breast high the trees have an age equal to $\frac{r}{2}$. All trees of this diameter and over are next estimated-preferably in three-inch diameter classes - and their volume and current annual increment determined (see Chapter I, Sections I and 2).

$Y$ then equals volume of trees or of diameter classes $\frac{r}{2}$ years and over, plus increment thereof in $\frac{r}{4}$ years; this sum divided by $\frac{r}{2}$. (For underlying theory see Formula Methods above.)

II. Going a step further, diameter can be substituted for age. After determining at what diameter, and upwards, the trees. are most merchantable, it follows that all trees of this diameter and larger are merchantable and should, other things being equal, be cut in the near future, i.e., during a period of years required 
for the next lowest diameter class or classes to produce an equal number of merchantable stems. But since the lower diameter classes contain more trees than the higher classes, therefore more than replacing those cut in the higher class, proportionately more of the oldest stems can be cut.

To express this numerically, the period of years separating the diameter classes must be known, i.e., the average age of the average tree in each diameter class. Let this value equal $a_{1}$, $a_{2}, a_{3}$, etc. The volume of the average tree in each diameter class must also be known (volume tables, measurement of representative trees, etc.). Let this value equal $v_{1}, v_{2}$, $v_{3}$, etc. Let, finally, the number of trees in each diameter class equal $n_{1}, n_{2}, n_{3}$, etc., and the formula follows:

$$
Y=\frac{n_{4}}{a_{4}-a_{3}} v_{4}+\frac{n_{3}-n_{4}}{a_{4}-a_{3}} v_{3}+\frac{n_{2}-n_{3}}{a_{3}-a_{2}} v_{2}+\frac{n_{1}-n_{2}}{a_{2}-a_{1}} v_{1}
$$

Hufnagl further advocates the comparison of $y$ obtained by this method with $y$ obtained by current annual increment (method No. 4 above) and, if necessary, the use of only the first one or first two of this series of expressions so as to make the results correspond, and also periodic revisions of the data on which the method is based.

Since the method is particularly intended for selection forests it is Hufnagl's theory that the cutting cycle shall equal approximately $a_{4}-a_{3}$ years, i.e., the time required for the highest nonmerchantable diameter class to become merchantable.

(b) Example.-A certain uneven-aged forest of Western yellow pine is to be managed on a 200-year rotation. Stump analyses show that at the age of $\frac{r}{2}=$ Ioo years the average diameter breast high equals 18 inches. ${ }^{*}$ The estimate of all trees over 18 inches diameter breast high equals $I, 085,200$ feet board measure, divided as shown below. The current annual increment is assumed at .7 per cent.

* Adapted from Bulletin IoI, Forest Service, U. S. Dept. of Agric. 
$y$ then $=\left(\begin{array}{c}\mathrm{I}, 085 ; 200+\left(7,596 \times \frac{200}{4}\right) \\ \frac{200}{2}\end{array}\right)=14,650$ feet board measure $=$ annual cut.

Substituting diameter for age (variation II) and assuming the diameter classes to be as follows*:

\begin{tabular}{|c|c|c|c|c|}
\hline $\begin{array}{l}\text { D. B. H. H. } \\
\text { inches }\end{array}$ & $\begin{array}{l}\text { Average Volume } \\
\text { feet } \mathrm{b} . \mathrm{m} \text {. }\end{array}$ & No. of Trees & Total Volume & $\begin{array}{l}\text { Intervening Years } \\
\text { (from diameter } \\
\text { growth tables) }\end{array}$ \\
\hline $10-12$ & 60 & 240 & 14,400 & ........ \\
\hline I $3-$ I 5 & I IO & 440 & 48,400 & $\ldots \ldots \ldots$ \\
\hline I6-I 8 & 190 & 770 & 146,300 & ........ \\
\hline $19-2 I$ & 310 & 720 & 223,200 & $\cdots \ldots$ \\
\hline $22-24$ & $480(v !)$ & $580\left(n_{1}\right)$ & 278,400 & $45\left(a_{2}-a_{1}\right)$ \\
\hline $25^{-27}$ & $7 \mathrm{IO}\left(v_{2}\right)$ & $4 \operatorname{IO}\left(n_{2}\right)$ & 291,100 & $47\left(a_{3}-a_{2}\right)$ \\
\hline $28-30$ & $\mathbf{I}, 020\left(v_{3}\right)$ & I90 $\left(n_{3}\right)$ & $-93,800$ & $48\left(a_{4}-a_{3}\right)$ \\
\hline $3 I-33$ & $\mathrm{I}, 4 \mathrm{IO}\left(v_{4}\right)$ & $70\left(n_{4}\right)$ & 8,700 & $\ldots \ldots$ \\
\hline
\end{tabular}

Now, having determined that the trees are most merchantable at a diameter of 22 inches and upward, it follows that the last four diameter classes are ripe for cutting. Applying the formula:

$$
\begin{aligned}
& Y=\frac{n_{4}}{a_{4}-a_{3}} v_{4}=\quad \frac{70}{48} \quad \times \text { I410 }=2,059 \text { feet b. m. } \\
& +\frac{n_{3}-n_{4}}{a_{4}-a_{3}} v_{3}=\frac{190-70}{48} \times 1020=2,550 \text { feet } \mathrm{b} . \mathrm{m} . \\
& +\frac{n_{2}-n_{3}}{a_{3}-a_{2}} v_{2}=\frac{410-190}{30} \times 710=5,204 \text { teet b. m. } \\
& +\frac{n_{1}-n_{2}}{a_{2}-a_{1}} v_{1}=\frac{580-410}{20} \times 480=4,080 \text { feet b. m. } \\
& Y=\mathrm{I}_{3}, 893 \text { feet b. m. }= \\
& \text { annual cut. }
\end{aligned}
$$

Comparing this with the results obtained from similar data by method No. 4 equals 15,428 feet board measure, the annual cut does not appear excessive. If, however, the result were appreciably higher than that by method No. 4, the formula

* Adapted from Bulletin Ior, Forest Service, U. S. Dept. of Agric. 
should be cut down to the first one or two expressions of the series; e.g., if to expressions I and 2 it would be $y=\frac{n_{4}}{a_{4}-a_{3}} v_{4}$ $+\frac{n_{3}-n_{4}}{a_{4}-a_{3}} v_{3}=2,059+2,55^{\circ}=4,609$ feet b. $\mathrm{m}$.

The cutting cycle equals $a_{4}-a_{3}=48$ years, or, roughly, 50 years.

(c) Value and Application.-This method, first published by Hufnagl in $1893{ }^{*}$ is excellently adapted, especially in its second variation, to the irregular and over-mature selection forest which is so commonly encountered in all parts of America. It is especially well suited to virgin stands, tending to cut the excess growing stock (of overmature timber) within the first cutting cycle, and yet providing ample material for a second cut at the end thereof (in 50 years from first cut).

The data which are required are those of every thorough reconnaissance preliminary to a working plan, namely, data on diameter-class distribution, on number of trees in each (in representative stands), of volume, and of diameter growth or, in the first variation, of increment (current annual). If it is not feasible to tally diameter classes for the tract, carefully chosen, fully stocked sample plots of varying site classes will suffice, but when applied to the total stand must be reduced to correspond with the varying density of stocking.

When accompanied by a plan of cutting (distribution of yield) for the next decade, the method is perhaps the most practical yet invented for irregular selection forests. Indeed, it is intended for just such conditions in the more remote parts of Austria.

I3. BY AREA AND VOLUME.-FOR ENTIRE FOREST. RUSSIAN METHOD.

(a) Description of Method. $\nmid$-This method is primarily adapted to forests managed under the shelterwood or shelter-

* “Oesterreichische Vierteljahrschrift für Forstwesen," I893, pp. I77 and following.

$\dagger$ From a translation by Mr. Raphael Zon of the Forest Service. 
wood-selection system (see Chapter I, Section 3) wherein the timber is cut off gradually and regeneration stretches over a period of years known as the "regenerative period." The method is described as follows:

"The area is taken for the measure of the annual cut, although it is generally admitted that in such forests the area is less appropriate measure than in forests with clear cutting. In selection forests there cannot be any annual cutting area, but an area which is to be cut over during the number of years which is contained in the regenerative period, since during that period the entire forest area must be cut off. Instead of an annual cutting area in selection forests there must be taken a periodic area, the size of which is obtained by dividing the area of the forest by the quotient resulting from division of the rotation by the regenerative period. In order to obtain an equal annual cut each year it is necessary to determine the amount of standing timber on the periodic area which is to be cut over and then aim to cut annually only an equal part of that amount. Of course this tendency to cut every year an equal amount of the standing timber may be disturbed at the time of a good seed year, when it will be desirable to cut over a larger area, and cut less during the years when there is no seed. Since, however, the regenerative period is always of some length, it will always be possible to equalize to some extent the amount to be cut within that period. On a large area which is being cut over within a given regenerative period it is possible to increase during poor seed years, the so-called preliminary cuttings, which allow more light into the stand, while in good seed years such cuttings may be suspended and stress laid chiefly upon so-called regenerative cuttings, which secure natural reproduction. If the area which is being cut over consists of several different types containing different species, the chances are that the seed years will not occur in all the species at the same time. This again may help to equalize the cuetings from year to year. Finally, even if it is impossible to equalize the amount of timber to be cut every year, this 
drawback will be more than offset by the advantages of this method.

"Properly speaking, not only the entire stand over the area which is to be cut over within the regenerative period should be taken into account in determining the annual cut, but also the increment that will take place within the regenerative period. This, however, is a very complicated undertaking, and it is best to determine the annual cut within the regenerative period merely on the basis of the actual standing timber, leaving the future revisions of the working plan to take account of the increment."

(b) Example.-A thousand-acre forest of Western yellow pine, containing $3,500,000$ feet board measure, is to be managed by the shelterwood-selection system with a regenerative period of approximately 50 years. The rotation is set at 200 years.

The periodic cutting area $=\frac{\mathrm{I}, 000}{\frac{200}{50}}=250$ acres. The cutting plan (distribution of yield) shows that the 250 acres selected for cutting in the next 50 years contain not $\frac{3,500,000}{4}=875,000$ feet board measure, but, since this part of the stand is somewhat overmature, $\mathrm{I}, 000,000$ feet board measure. $y$ then $=\frac{\mathrm{I}, 000,000}{50}=$ 20,000 feet board measure $=$ the annual cut for the next 50-year cutting period.

(c) Value and Application.-This method is exceedingly simple and applicable only under very rough conditions, as is shown by the fact that it dodges all calculations of increment. It has the advantage of simplicity and the disadvantage of being too ironclad. It is, however, a primitive recognition of the important interrelation of volume and area in the determination of the yield. 
14. BY AREA AND VOLUME.-BASED ON AGE CLASSES. DIRECT METHOD (HUFNAGL*).

(a) Description of Method.-If the volume and the area of the oldest stands which, presumably, will be cut in the next ten or twenty years, is known, the average volume per acre equals $\frac{v}{a}$. This volume multiplied by the allowed annual cut in area equals the allowed annual cut in volume.

(b) Example.-Referring to example of method No. I above: Variation I. Area not reduced. Annual cutting area equals 62.5 acres. The volume of the oldest stands to be cut in the next twenty years (oldest age class) equals $\mathrm{I}, 000,000$ feet board measure, their area is $25^{\circ}$ acres.

Then the average volume per acre $=\frac{v}{a}=4,000$ feet board measure.

The volume of the annual cut $=4,000 \times 62.5=250,000$ feet board measure.

Variation II. Area Reduced. Using the figures given in the example of Variation II, Method No. I above: Annual cutting area reduced to terms of Site Quality I equals 6.64 acres. The stands ripe for cutting in the next twenty years (oldest age class) show an average stocking of .7 and an average site quality III, and hence (from yield tables or from measurements of sample plots of mature fully stocked stands of varying site qualities) an average volume of $68,000 \times \cdot 7=47,600$ feet board measure per acre. 6.64 acres of site quality I are to be cut per annum. This is equivalent (see example, method No. I, Var. II) to Io acres of site quality III. Hence the annual cut $=47,600 \times 10=$ 476,000 feet board measure.

Variation III. Hufnagl. Using the figures in the example under method No. I, and the example under Variation I of the present method:

*Hufnagl, "Praktische Forsteinrichtung," is the source of this and the subsequent method (No. I5). 
The average volume per acre $=\frac{v}{a}=4,000$ feet board measure.

The volume of the annual cut $=4,000 \times 29=1 \mathrm{r} 6,000$ feet board measure.

(c) Value and Application.-As noted under similar heading in method No. I, the method has all the disadvantages of a fixed value for the rotation, instead of a naturally adjustable one, and allows none of the free play so necessary for the best silviculture. Variations I and III are exceedingly simple, and hence quite well adapted to forests with fairly uniform conditions, i.e., coppice and coppice with standards. Variation II is too complex for all but the most intensive conditions, and requires all the data, while possessing none of the advantages of other and better methods. Obviously the method presupposes an ageclass table, and hence a forest composed of fairly even-aged stands. It is therefore essentially not a method for selection forests. Furthermore, it is applicable only to forests wherein the oldest age class does not average more than $r+5$ years, i.e., is not more than 5 years older than the rotation. This condition is seldom attainable in American high forest, and for high forests, aside from its occasional use to check other figures, the method therefore lapses into merely historical interest and as the basis of the stand method (No. I6) and the various period methods (No. I7) discussed below.

\section{BY AREA AND VOLUME.-BASED ON AGE CLASSES. HUF- NAGL'S METHOD.}

(a) Description of Method.-Hufnagl's premise is that the sustained yield can be determined directly if the volume and the increment of the stands now more than $\frac{r}{2}$ years old is known. This method presupposes a stand table containing the volume and area of all stands of over $\frac{r}{2}$ years. To this volume is to be added, also, the increment of these stands in the next $\frac{r}{2}$ years; 
for since the area of these stands diminishes each year, and in the year $\frac{r}{2}=O$, the increment can only apply, on an average, to half the area.

As to the increment, Hufnagl distinguishes two variations of his method according as I the current, or II the mean annual increment is used.

I. The current annual increment of each stand over $\frac{r}{2}$ years old having been determined (by yield tables or by field measurements, Chapter I, Section I), the sum of these increments is used in the formula which follows.

II. The mean annual increment equals $\frac{V}{r}$. It can be determined from yield tables or, empirically, by measuring average stocked stands of average site quality whose age approximates $r$ years. $\frac{V}{r}$ then equals the mean annual increment.

Hufnagl's formula then follows: (letting $V$ equal the volume of stands $\frac{r}{2}$ years and over, $A$ their area, $i$ the increment in board feet per acre per annum, current or mean):

$$
Y=\frac{v+a \cdot i \cdot \frac{r}{4}}{\frac{r}{2}}
$$

If $i$ equals mean annual increment it will usually be Io-2o per cent less than the current annual increment. This makes its use the more conservative of the two.

(b) Example.-In a forest of 2,I60 acres with a rotation of 80 years, the stands 40 years and older have a volume of 3,2 I I,000 feet board measure on $I, I 20$ acres. The mean annual increment for the $r$ th (80th) year equals $\frac{3,2 \mathrm{II}, 000}{\mathrm{I}, \mathrm{I} 20} \times .007=2,867 \times$ 
$.007=20.069=20$ feet board measure. Then by the formula:-

$$
Y=\frac{v+a \cdot i \cdot \frac{r}{4}}{\frac{r}{2}}=\frac{3,2 \mathrm{II}, 000+(\mathrm{I}, \mathrm{I} 20 \times 20) 20}{40}=
$$

$\frac{3,2 \mathrm{II}, 000+448,000}{40}=9 \mathrm{r}, 475$ feet board measure $=$ annual cut.

(c) Value and Application.-Hufnagl's method shows much originality and is applicable to even-aged stands of only moderate regularity, the very conditions encountered in many American forests. Its age-class differentiation is very simple, as is also the volume and increment determination. The latter had best be the mean annual increment, and can readily be calculated from sample plots if yield tables are lacking.

A disadvantage of the method is the rigid fixation of the rotation age, which should really be a flexible quantity; but if this is offset by frequent revisions at regular intervals the method will pass muster, especially in the irregular stands common to most parts of America. If this method of calculating the yield is adopted, it must always be supplemented by a careful cutting plan (distribution of yield) (see Section 2).

16. BY AREA AND VOLUME.-BASED ON AGE CLASSES. THE STAND METHOD (JUDEICH'S "BESTANDSWIRTSCHAFT ").

(a) Description of Method.-Judeich* bases his method on the undoubted fact that no method of determining the yield for a period of years in advance-some even attempting to do so for the whole rotation or a substantial part thereof-is accurate without frequent revisions which recognize the unexpected changes inevitable in every stand no matter how carefully managed. He therefore makes no attempt to regulate the yield for more than a decade in advance, but prescribes not only a revision, but a new plan at the end of the decade. Vol. III.

* Adapted from Lorey, "Handbuch der Forstwissenschaft," 2d edit., 
In order to secure a sustained yield the annual cut is calculated with the following three regulating factors:

(a) The normal yearly cutting area or volume;

(b) The distribution of the age classes;

(c) The results of previous cuttings.

The more the results of previous cuttings, especially with regard to their effect on the distribution of the age classes, are available, the greater is the justification in regulating the yield for only a decade in advance. Where there has been no previous working plan nor adequate record keeping (with especial respect to volume, area, and distribution of age classes) the yield must be determined two, three, or at most four decades in advance.

Judeich does not give any certain method of ascertaining the yield-either in volume or in area-but adapts this to the peculiar exigencies of each forest. The object of the working plan is the attainment of normality in the distribution of the age classes; this is secured by a correct cutting series (see Section 2) and cutting policy.

The cutting policy selects for the next decade or two, or, at most, three or four, all the stands or groups of stands which require cutting for one or more of the following reasons:

I. Administrative necessity.

2. Disease and decadence (overmaturity).

3. Maturity.

4. Inferiority, slow growth.

The sum of stands ready to cut for reasons $\mathrm{I}-4$ gives in area and volume the cut for the next period, subject to the following regulating factors:

(a) The normal yearly cutting area or volume.

(b) The distribution of the age classes.

(c) The results of previous cuttings.

(a) Can be determined by any of the methods already described, by area if the distribution of the age classes is not too abnormal (e.g., method No. I), by volume, preferably, if the distribution of the age classes is far from normal and there is a preponderance of overmature timber (e.g., method No. 9). 
Judeich expressly states that his method is not restricted to a financial rotation, but is equally well adapted to rotations on other bases (see Chapter I, Section 3, "Rotations"), e.g., that of greatest volume or of technical production.

(b) Example.-Assuming a general stand table such as that given in Chapter I, Section 2, from this it appears that the following stands* are in need of cutting during the next ten years:

\begin{tabular}{|c|c|c|c|c|c|}
\hline Reason & $\begin{array}{l}\text { Compt. } \\
\text { No. }\end{array}$ & $\begin{array}{l}\text { Subcompt. } \\
\text { Letter }\end{array}$ & $\begin{array}{l}\text { Area } \\
\text { acres }\end{array}$ & \multicolumn{2}{|c|}{$\begin{array}{l}\text { Stand } \\
\text { Species and M. ft. b.m. }\end{array}$} \\
\hline 1. Administrative necessity & $\ldots$ & $\ldots$ & $\ldots$ & \multirow{2}{*}{ Spruce 900} & $\ldots$ \\
\hline 2. Disease and decadence.. & 9 & $\mathrm{~b}$ & $6 \mathrm{I}$ & & $\ldots$ \\
\hline \multirow{3}{*}{ 3. Maturity............ } & 10 & $\ldots$ & 50 & $\ldots \ldots$ & Fir 100 \\
\hline & 6 & $\ldots$ & 100 & " $\mathrm{I}, \mathrm{IOO}$ & “ 75 \\
\hline & 8 & $\ldots$ & 40 & “ 440 & “ 60 \\
\hline Total. & 2, & feet. & $25^{x}$ & Spruce 2,440 & Fir 235 \\
\hline
\end{tabular}

The distribution of the age classes (see age class table, Chapter I, Section 2) shows a considerable abnormality, as follows:

\begin{tabular}{|c|c|c|c|c|}
\hline & $\begin{array}{l}\text { nature } \\
0+1\end{array}$ & $\begin{array}{l}\text { Mature } \\
\text { (8I-I60) }\end{array}$ & $\begin{array}{l}\text { Young } \\
(I-80)\end{array}$ & $\begin{array}{l}\text { Restockable } \\
\text { blanks. }\end{array}$ \\
\hline .....acres & $6 I$ & 266 & 300 & 103 \\
\hline Normal. & . . & 355 & 355 & $\ldots$ \\
\hline Deficit. & .. & 89 & -55 & $\ldots$ \\
\hline Surplus. . & 6I & $\ldots$ & $\ldots$ & 103 \\
\hline
\end{tabular}

The rotation is 160 years; the total area 7 Io acres exclusive of natural blanks, and the protective belt of all-aged forest (see foot-note).

Despite the abnormality, the annual cutting area is here calculated for the sake of an example, e.g., by method No. I, variation I, the annual cutting area $=\frac{A}{r}=\frac{7 \text { IO }}{\text { I60 }}=4.432$ I 5 acres. For ten years $=44.3$ I 25 acres.

The cutting for the next ten years would, therefore, be confined entirely to compartment $9 \mathrm{~b}$.

But if variation II were to be used (assuming the same

* The all-aged selection forest of the protective belt is necessarily omitted since it obviously requires a different method of computing the yield. 
values as in the example under method I, Variation II) the reduced area would be, reduced to terms of site I:

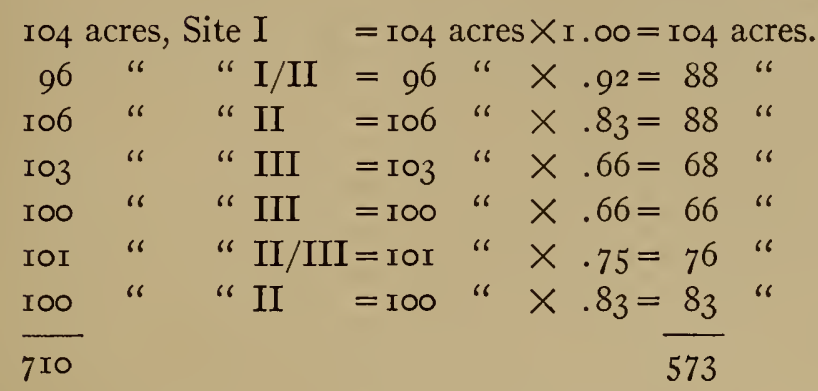

The annual cutting area $=\frac{\text { reduced area }}{\text { rotation }}=\frac{573}{\mathrm{I} 60}=3.58125$, for ten years equals 35.8 I 25 of Site $I$ or equivalent. The $6 \mathrm{I}$ acres in $9 \mathrm{~b}$ are Site II/III. It requires $\mathrm{I} .35$ acres of Site II/III to equal one acre of Site I. Hence 35.8 I $25 \times$ I. $35=48.35$ acres of permissible cutting area in $9 \mathrm{~b}$ during the next ten years. The volume can then be determined by multiplying the average stand per acre for the site determined from yield tables or from local measurement by the per cent of stocking and then by the reduced acreage (see example under Variation II, method No. I4).

But where stands are so irregular in age classes, site quality, and density of stocking, it is not well to resort to area as the regulating factor, but rather some volume method, such as Heyer's, of comparison with the normal growing stock (method No. 9).

This would give:

$i$ (increment $)=5,840 \mathrm{M}$. feet of spruce $\times($ say $) .007=40,880 \mathrm{ft}$. b.m. $970 \mathrm{M}$. feet of fir $\quad \times \quad .0 \mathrm{I}=\underline{9,700 \mathrm{ft}} . \mathrm{b} . \mathrm{m}$.

$r=\mathrm{I} 60$

Total, 50,580 feet.

$n v=\frac{r i}{2}=4,046,400$ feet $\mathrm{b} . \mathrm{m}$.

$v=6,8 \mathrm{Io,000}$ feet $\mathrm{b} . \mathrm{m}$.

$\therefore v>n v$ by $\overline{2,763,600}$ feet b. m. 
Let $x$ (the period of distribution) $=\frac{r}{4}=\frac{\mathrm{I} 60}{40}=40$ years. Then by the formula :

$y=\frac{v+i \cdot x-n v}{x}=\frac{6,810,000+(50,580 \times 40)-4,046,400}{40}=$ I 9,670 feet board measure.

The annual cut therefore equals I 19,670 feet board measure.

The cut for the decade equals $1,196,700$ feet board measure.

There is within compartments $9 \mathrm{~b}$, Io, and part of 6 and 8 ample $(2,675 \mathrm{M}$. feet) for the cutting within the next decade. Compartments 6 and 8 need scarcely be touched, which is just as well, since they are barely mature now. If, however, in view of the proportionately large amount of mature and overmature timber it is desired to reduce the period of distributing the surplus to ten years, the result would be:

$$
\frac{6,810,000+(50,580 \times 10)-4,046,400}{10}=326,940 \text {. }
$$

The annual cut therefore equals 326,940 feet board measure.

The cut for the decade equals $3,269,400$ feet board measure.

There are within compartments 9, 10, 6, and 8 only 2,675,000 feet, hence the management must either be conservative and content itself therewith or add compartment 4, with 945,000 feet to the cutting areas for the decade, which would make $3,620,000$ feet board measure, or ample whereon to draw for the 3,269,400 feet board measure to be cut.

(c) Value and Application.-This method is without doubt the most rational of all the methods of determining the yield; for it attempts no iron-clad rule or framework-such as the "period methods" next to be considered-but depends entirely on the silvicultural and economical requirements of the forest. By means of frequent revisions the amount cut can never endanger the continuity of the forest's productiveness, while it allows full play to the skill of the officer in charge of the management of the forest. The forest moves steadily toward a normal distribution of the age classes, but this very desirable goal is attained without undue sacrifices. 
It is a method of great freedom and adaptability. Freedom in so far as the cutting of certain stands is not prescribed far in advance for a certain time, but entirely according to the exigencies of the situation. It is adaptable to all methods of high forest which result in even-aged or fairly even-aged stands, i.c., to all but the selection system.

The method in its simple application is well suited to American conditions where it is often of prime importance to dispose of the overmature and decadent timber within the reasonable check of a sustained volume yield aided by the corrections of decennial redetermination of the yield and striving toward the distant goal of a normal age-class distribution.

77. BY AREA AND VOLUME.-BASED ON PERIODS ("FACHWERKSMETHODEN " *).

(a) Description of Method.-The rotation is divided into a number of equally long periods of time. Usually these periods comprise twenty years. Every stand or subcompartment is assigned to a period corresponding with its age, so that each part of the entire area of the working figure, with the exception of certain areas reserved for selection forest, protective belt, or other special purpose, is used once during the rotation.

The sums of the individual periods must be approximately equal, or somewhat higher for the later periods. If this is not the case, adjustment is necessary, by transferring certain stands or subcompartments to an adjacent period. According as this adjustment emphasizes equality of area, or equality of volume, or equality in both, different kinds of period methods are recognized as: I. Area-period method ("Flächenfachwerk"); II. Volume-period method ("Massenfachwerk"); III. Area-andvolume-period method ("Kombiniertes Fachwerk").

I. In the area-period method ("Flächenfachwerk") the areas are assigned to various periods either as actual areas or as

* The name "Fachwerksmethoden" comes from the German "Fächer" or pigeon-holes into which the various parts of the forest are placed by these methods. A "Fächerwerk" or "Fachwerk" is, therefore, a framework consisting of many pigeon-holes, and these methods are "Framework" methods. 
reduced areas (see method No. I above) of equal productivity. The method aims to cut each year, or each period, an equally productive area containing an approximately equal volume. The age-class table is the basis of the assignment to periods, however these must then be shifted to secure equality of utilization in each period. Knowing the area to be cut in the first (immediate) period and (from yield tables or empirical measurements) the volume yield thereof, the annual cut is found by dividing this volume by the number of years in the period. This volume calculation is usually confined to the first period. Final cuttings are restricted to this period.

In a rotation of $\mathrm{I} 20$ years there are, e.g. $\frac{\mathrm{I} 20}{20}=6$ periods. Were the age-class distribution normal, the periods and the age limits of the stands comprised therein would be as follows:

\begin{tabular}{|c|c|c|c|c|c|c|c|}
\hline \multicolumn{3}{|c|}{ I Period. } & \multicolumn{5}{|c|}{ Age of Stands I0o-120 years } \\
\hline II & " & & $\because$ & “ & “ & $80-100$ & “ \\
\hline III & “ & . & “ & “ & “ & $60-80$ & “ \\
\hline IV & “ & $\ldots \ldots \ldots \ldots \ldots \ldots \ldots \ldots$ & “ & “ & “ & $40-60$ & “ \\
\hline V & " & $\ldots \ldots \ldots \ldots \ldots$ & " & “ & " & $20-40$ & " \\
\hline VI & " & $\ldots \ldots \ldots \ldots \ldots \ldots \ldots$ & “ & ' & “ & $0-20$ & " \\
\hline
\end{tabular}

In practice this method is restricted to simple, regular conditions with artificial regeneration after clear cutting.

The area "framework" has the advantage of simplicity and ease of application. Within the rotation, if no unforeseen disturbances occur, the normal age-class distribution is attained. But the method has the great disadvantage that no due regard is paid to existing conditions (age-class distribution, growing stock, increment). In the case of an overmature, broken stand more should be cut than a strict period method permits; in the case of immature stands, less should be cut than this period method provides. Equality of periods is secured, often, only at a tremendous sacrifice.

II. In the volume-period method ("Massenfachwerk") the aim is to have an equal yield in each period. The various periods are, therefore, given approximately equal volumes, although the younger periods are sometimes endowed with slightly higher 
volumes ("Massen") than the older periods. The annual cut is found by dividing the volume of the first period by the number of years therein (usually twenty).

The individual stands (compartments and subcompartments are not requisite in this method, nor even the formation of working circles) are assigned to the periods corresponding to their age. Their volume is then prorated by means of yield tables or, at least, increment tables so as to determine the volume they will have at the time of reaching the middle of the I period (i.e., the cutting period). These volumes are then compared and the necessary adjustments made; the stands are shifted from one period to another, e.g., if the II period were deficient, the IV period excessive, some stands would have to be shifted from the IV into the III period, and from this into the II period, until the proper balance was secured. Since this "shiftuny" carries with it a recalculation of the final yield because of changed increment, the method involves an enormous amount of calculation.

This method was founded by G. L. Hartig in I795. It finds no application in practice to-day.

It has the advantage over the area "framework" of cutting an equal volume each year, and hence more nearly approaches the desires and needs of timber owner and timber buyer. But it has the glaring disadvantage of attempting to regulate the cut for a whole rotation. The future treatment of stands must depend on eventualities which cannot be foreseen in the present. Nor can the method be used in the extensive, irregular conditions for which it is intended because of the lack of adequate volume and increment data. Furthermore, an equal annual cut may disregard overmature stands in need (financial and silvicultural) of cutting, or, conversely, cut stands which are not yet mature. It is an unnecessarily narrow concept of sustained yield; it does not even secure normality, for (Chapter I, Section I) volume, i.e., growing stock, alone is no criterion of normality.

III. The area-and-volume period method ("Kombinierte Fachwerk") aims to combine the area "framework" and the 
volume "framework" so that each period will contain approximately equal areas and volumes.

Theoretically this distribution of volumes is for the whole rotation and is achieved for the I period by means of valuation surveys, for the other periods by means of yield tables. Areas and volumes are then adjusted as in the area "framework" and the volume "framework." The annual cut is then obtained by dividing the area and the volume of the I period by the number of years contained therein (usually twenty) and letting the two factors of area and volume act as a mutual check.*

In practice the difficulty of predicting volumes for a whole rotation and of equalizing volumes and areas, led to an important modification whereby the volumes are calculated for only the I period or, at most, the I and II periods; the areas, however, delineated, roughly, for the whole rotation so as to insure a sustained yield.

This method was founded by Heinrich Cotta in 1804 . The important modification of restricting the volumes to the $I$ or I and II periods dates from von Klipstein in 1823 and von Grebe in 1867 . With this modification the method is to-day used in Prussia, Hesse, Württemberg, and in Austria (see Part Two, Chapter I).

This method possesses the combined advantages of the area and the volume "framework"; it secures a greater regularity of volume yield than does the former and a quicker approach toward normality than does the latter. Combined with a proper distribution of the age classes and a liberal interpretation of equality in the periods, the method secures good results. But with too strict construction it results in crass errors, such as the needless leaving of overmature stands simply because they

* A number of variations have been suggested, e.g., annual cut $=$ volume of period $\div$ years of period (Prussian practice); annual cut $=$ area of period $\div$ years of period (Auhagen); annual cut $=$ area of (I or I and II) periods $\div$ years and reduced to volume (von Stockhausen and von Grebe). In practice both factors are regarded ocal conditions demand. 
are in the sacrosanct II period and can't be touched, ${ }^{*}$ or the cutting of immature stands which were placed in the I period merely to "fill in."

(b) Example.-Since, from what has gone before and what follows (c) these methods are so obviously unsuited to American conditions, it would serve no useful purpose to elaborate them by examples. $\dagger$

(c) Value and Application.-In most of the German States the "framework" methods were the foundation of regulated management and thus exerted a mighty influence on German forestry. But under the conditions of modern times they have steadily diminished in importance for the following reasons:

(I) The silvicultural method of management, to which the method of regulating the yield must conform, is often in direct disagreement with the "framework" method. The latter demands that the cutting on a given parcel (e.g., compartment) be completed within the period (twenty years). This is often impossible without silvicultural mistakes and economic sacrifices. The natural regeneration of many species requires more than an arbitrary period of, say, twenty years. Even with artificial reproduction there are often unavoidable and unforeseeable events which make complete regeneration impossible within the period.

(2) The concept of sustained yield which endows each period with an equal area or volume, or both, is unnecessarily narrow. For practical purposes it suffices that the area or volume, or both, of the next working period be in reasonable ratio to the total area or volume, or both, of the entire working circle. Modern economic conditions have greatly changed the concept of sustained yield (see Chapter I, Section 3). Present economic conditions often demand the cutting of other than the exact

* This has led to the growing demand for the "Opening of the II Period."

$\dagger$ These may be found in Judeich's or Martin's "Forsteinrichtung" (see Bibliography) or in Lorey's "Handbuch der Forstwissenschaft," 2d ed., Vol. III., pp. 4I I, 4I 5 , and 423 . 
period area; the zone of economic influence has extended tremendously.

(3) Cutting series (see Section 2 of present chapter) are not dependent on a period method; indeed the latter often resulted in cutting series of excessive length.

(4) The assignment of every compartment or other parcel of the forest to a certain period presumes a certainty of judgment on the part of the Forest Organizer amounting to prescience. As a result the cumbersome calculations are often valueless.

(5) These calculations of yield for the whole rotation in advance are the more unnecessary since, under proper administration, there are frequent revisions of the working plan at regular intervals.

Taking all these together, it is a just criticism of the "framework" methods to say that they are too hide-bound, adapted only to even-aged stands, to intensive conditions, and to methods of clear cutting with artificial regeneration. The realization of this has brought about a revulsion away from these methods. Most of the German States have definitely abandoned the "framework"; in others it still persists, but without any weight on the determination of yield for future periods (see Part Two, Chapter I).

\section{Review of the Methods of Determining the Yield}

No single one of the methods described above will be adapted to all varieties of conditions. The choice of method depends: I, on the intensity of management possible; 2, the kind of forest, and 3 , the silvicultural system adopted. In the light of these considerations, the methods may be valued as follows:

Method No. I is chiefly adapted to coppice and coppice with standards.

Methods Nos. 2 and 3 for provisional determination of the yield under rough conditions, and as a check on other methods. Method No. 4 as a check on other methods.

Methods Nos. 5-9 ("formula methods"): Of these all but 
No. 9 are restricted to rough calculations in irregular stands and as checks on other methods. No. 9 (Heyer's formula) finds a wide application in uneven-aged, virgin stands when supplemented with a careful cutting plan.

Method No. Io is adapted to high diameter limits and long rotations.

Method No. II is adapted to mixed tropical forests where only one or two of the many species are merchantable.

Method No. I 2 is excellently suited for irregular and overmature selection forests.

Method No. I3 is restricted to very crude conditions.

Method No. I4, variations I and III, for coppice and coppice with standards.

Method No. I5, for even-aged stands of only moderate regularity.

Method No. I6, the ultima ratio of fairly regular, evenaged stands.

Method No. I7, not adapted to American conditions.

It is always advisable to calculate the annual yield by a variety of methods so as to have a check on the figures.

It will often be the case that a crude working figure will contain both even-aged and uneven-aged stands. The yield must then be calculated separately for each and, when the plan is revised, the time may be ripe to make each of the two kinds of forest into a distinct working figure.

For the determination of yield the process should be as follows: First determine the allowed annual cut, in volume or in area, by means of one or several of the methods described.

Then choose the cutting areas according to silvicultural and economic necessities. To do this requires a careful cutting plan -or plan of distribution of the yield-which is next to be considered. 


\section{SECTION TWO}

\section{DISTRIBUTION OF YIELD}

To make the actual annual cut conform directly to the determined yield, i.e., to cut yearly the exact amount specified in the working plan, is neither possible nor desirable. Unforeseen contingencies, both silviculturrl and economic, often necessitate an overcut one year, ar undercut the following. If the working plan must be flexible sven under European conditions which allow the forester to decide the "where" and "when" of cutting, how much more is it necessary in America, where the "where" depends on profitable accessibility and the "when" on market conditions.

It therefore suffices entirely to keep within the allowed cut for the working period of ten or twenty years - the time before the next revision of the working plan-and to make no attempt to cut one-tenth or one-twentieth thereof each year. In other words: a periodic sustained yield rather than an annual sustained yield should be the aim.

For similar reasons, a great flexibility must be allowed in the selection of the actual cutting areas. The working plan properly lists certain areas to be cut within the working period of ten or twenty years-the time before the next revision of the working plan-but these cannot be rigidly adhered to, cannot in Europe, and much less so in America. European experience has brought about a great liberality in this regard-the executive officer in charge of the forest is given freedom of choice as to what areas he wishes to cut each year of the working period,* this yearly cutting plan is viséed and approved by his superior officers, otherwise he has carte blanche to exercise his judgment. No other course is possible in America, where conditions are far

* With due regard, of course, to supplying local needs for timber and to a proper distribution of classes of timber so as to keep values from fluctuating and to provide industries dependent on the forests with the timber they need. 
more extensive. The working plan designates certain areas, certain cutting series even; beyond this it cannot go. It must help and not hamper the managing officer. It is merely a frame within which he exercises his individual ingenuity.

\section{Selection of Stands to be Cut .}

The conditions which govern the selection of stands to be cut are: market, maturity, damage (insects, fungi, etc.), windfall, fire, and the like.

Under market are contained all the manifold considerations of logging accessibility, of profit in cutting and marketing, and the sizes and species which can be logged. For example, a spruce stand on top of an isolated mountain like Mt. Graham in Arizona may be fully mature and in need of cutting, but unless there are adequate logging devices which can market the timber at a reasonable profit, it is useless to designate this as the sole cutting area of the next working period. Similarly, there may be large amounts of fir (abies) in mixture with other species such as spruce and Douglas fir, but unless the fir is accepted as lumber and as ties it cannot be counted on the same basis with the other species. Finally, where material below a certain diameter cannot be marketed at a profit it should not be considered a part of the cut of the next working period. In other words, the cutting plan must deal first with actualities confronting the administrative officer and put hypothetical utilization in a subordinate place.

Other things being equal, the cutting plan provides for the logging of all mature and overmature stands, i.e., such as have attained or passed the rotation age. If the forest is even-aged or fairly so, these stands are those of the highest age class or classes.

Stands which show damage by insects, fungi, etc., should usually be cut; they are therefore included in the cutting plan for the next working period.

Stands which have suffered severe windfall must often be 7 
cut speedily so as to prevent further damage.* But, further than this, the lessons of past windfall must be applied in distributing the yield-e.g., to remove a certain stand may expose the one behind it and subject it to almost certain windfall. This can best be regulated by the formation of cutting series, described below. The windfall danger varies, of course, with species and character of stand, with soil and site, and with the prevailing wind direction. Spruce is exceedingly subject to windfall and often requires especial precautions.

Stands damaged by fire enough to necessitate regeneration, but not enough to be rendered unmerchantable, must be disposed of speedily before further deterioration.

\section{Mapping of Stands to Be Cut}

The type and stand map of the forest is of the greatest value in deciding on the areas to be included in the cutting plan for the working period, especially when supplemented by complete and reliable forest descriptions of each unit. Referring to the map given above under Chapter I, Section 2, "Maps and Tables," and presuming that it is possible to log and market where, when, and what one wishes, but that the windfall danger is great, making many "points of attack" preferable to extensive, consecutive cutting areas, the following stands would be chosen:

$4 \mathrm{a}, 7 \mathrm{e}$, and $8 \mathrm{a}$ can be cut without in the least endangering any other stands.

$6 e$, however, though it is sixty-five years old, cannot be cut before the larger, but only sixty-year-old $6 \mathrm{a}$, because this would immediately subject $6 \mathrm{a}$ to heavy windfalls. Hence $6 \mathrm{e}$ must wait until $6 \mathrm{a}$ is cut. This involves a balancing of whether it is the more desirable to cut $6 \mathrm{a}$ and $6 \mathrm{e}$ now or to wait until $6 \mathrm{a}$ is fully mature. Other things being equal, 6e must wait, since it is the smaller.

The stands or blocks in which it is intended to cut during

* In the spruce stands of the Black Forest, Germany, it is not uncommon to have the entire annual cut taken up by unexpected windfalls. 
the coming working period should be indicated on the working map either by color, or shading, or symbol. The kind of cutting intended, e.g., shelterwood, can also be indicated by using the symbols given in the "General Stand Table," Chapter I, Section 2, above.

\section{Cutting Series}

When one cutting area is purposely joined to another and this to a third, etc., they form a cutting series. Cutting series always progress from some initial "point of attack" against the prevailing wind direction. They are shown on the map by arrows. The formation of cutting series is a tremendous safeguard against windfall, especially where at the point of attack a forest mantle has formed on the edge of the stand to leeward. This mantle consists of the persisting middle and lower branches of the trees on the edge of the stand. It is artificially stimulated during the youth of the stand by the cutting through of compartment lines or "Schneisen" (see Chapter I, Section 2, "Boundaries of Divisions"), or forms naturally along a road, stream, or other topographic interruption. It can also be created by heavy thinning along the edge of a stand or compartment whereby the crowns remain deep and hence the trees windfirm.

Cutting series can seldom be arranged without some minor sacrifices. For example, in the map the small, forty-eight-year old stand $7 \mathrm{~d}$ lies in the midst of the nearly merchantable seventytwo-year old stand $7 \mathrm{e}$ : $7 \mathrm{~d}$ would be sacrificed to the cutting series, the lesser good to the greater. Only if the borders of $7 \mathrm{~d}$ were liberated so as to form a mantle, could it be left after $7 \mathrm{e}$ has been cut. This would be done in the case of $7 \mathrm{~g}$, since it is a much younger stand.

Cutting series must be decided upon by the Forest Organizer during the progress of the field work in order to gauge the sacrifices properly. They can be provisionally entered on the working map by using dotted arrows.

Theoretically the cutting series are like steps, actually they 
are always somewhat irregular even under favorable conditions. In the map, $5 \mathrm{~d}$ and $\mathrm{h}$, and $5 \mathrm{e}, \mathrm{f}, \mathrm{g}$, and $\mathrm{i}$ obviously belong to two cutting series. But $5^{\mathrm{l}}$ is a separate proposition because it must be cut before $5^{\mathrm{h}}$ since it is more than twice as old $\left(5^{\mathrm{h}}=\right.$ 23 years, $5^{\mathrm{l}=} 5^{2}$ years).

Cutting series must be planned decades in advance, and require careful thought and accurate judgment. The cutting of such a series may require many years; early mistakes are difficult to correct.

Cutting series are necessary only in even-aged stands of shallow-rooted species, but there they are of tremendous importance.* Their regular adoption in America is still of the future, but the principle can be utilized now.

\section{Plan of Cutting}

Having determined "how much" and "where" to cut during the ensuing working period, this is reduced to a documentary plan of cutting or "felling budget."

Two kinds of cutting plans should usually be drawn up: I, a general one for the entire working period-i.e., for the number of years to elapse before the next revision of the working plan, generally ten years; and II, a specific plan for the ensuing year.

I. The general cutting plan provides cutting areas sufficient to yield (if the working period is ten years) at least ten times the volume of the allowed annual cut or ten times the area, as the case may be. It should, however, provide for somewhat more, so as to provide additional cutting areas in case of unforeseen contingencies making the cutting of certain areas impractical or allowing a higher cut than was originally intended. Under fairly regular conditions the cutting plan may cover the next twenty years, or even forty years, but under average Amer-

* By this means windfall is checked and controlled in the spruce forests of Saxony; the lack of cutting series is largely accountable for the tremendous windfall in the spruce stands of the Black Forest in Baden. 
THE THEORY AND PRACTICE OF WORKING PLANS 101

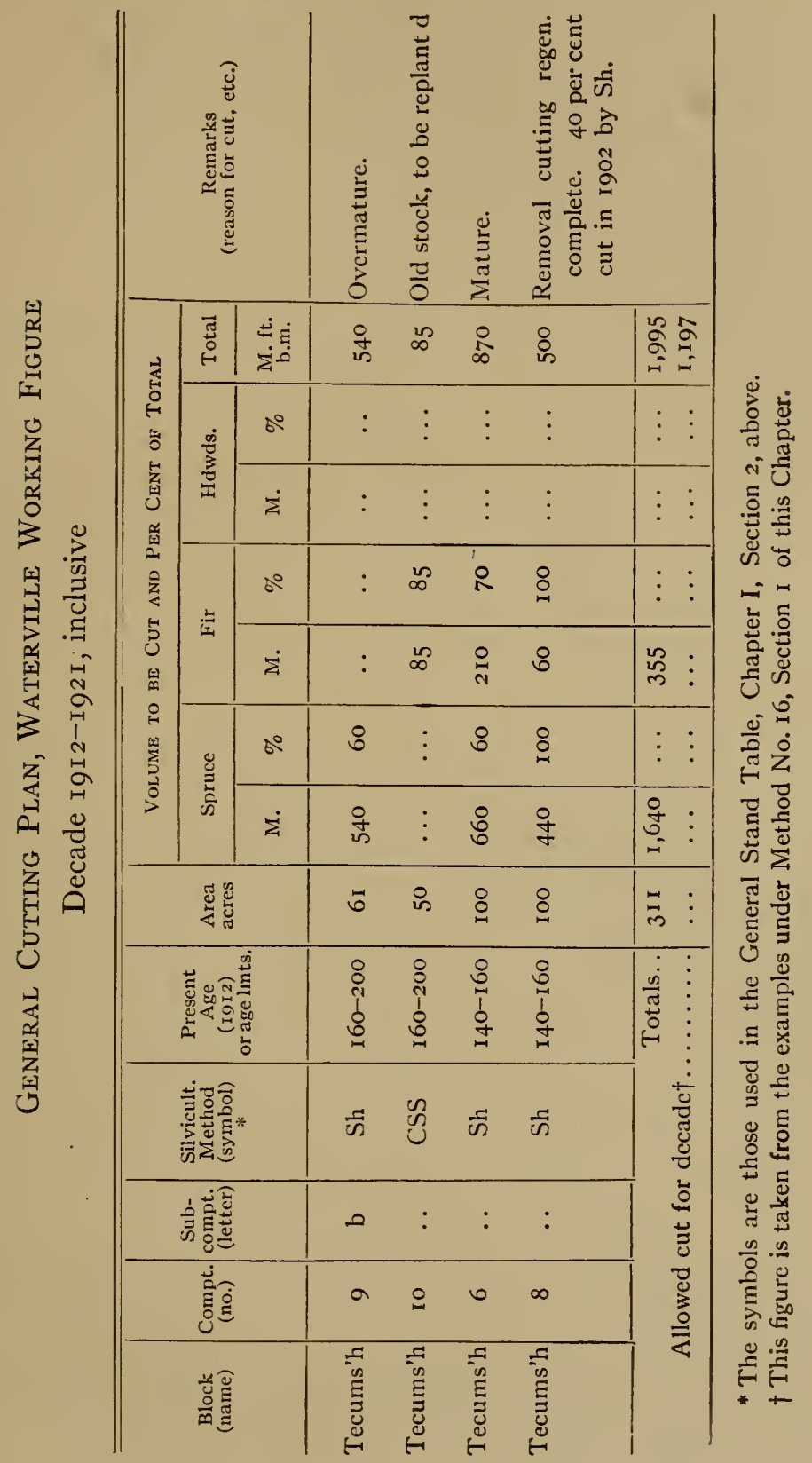


ican conditions this is little better than a useless play. Nor, under most American conditions, is it necessary or advisable to prorate the increment to the middle of the cutting period. Such corrections had best be left to frequent revisions of the working plan at regular intervals.

The general cutting plan should take the form* on preceding page:

II. The specific cutting plan for the ensuing year, calendar or fiscal, is drawn up by the administrative officer in charge of the forest and submitted by him to his superior officers (if he has any) for approval. Thus it is really a part of administration and not of forest organization, yet it is closely linked thereto. The administrator, through his intimate knowledge of the forest and of the exact status of local conditions of logging, market, etc., selects from out the general cutting plan those areas which in his judgment should be cut during the ensuing year. On large forests he usually consults each ranger on the subject. $\dagger$ A convenient form for the annual cutting plan is as follows. This can be printed or otherwise manifolded and serve as a permanent record. (See next page.)

In the following table, column 4 contains the estimated volume to be cut during the year. If instead of compartment Io, compartment $9 b$ had been chosen, with its $540 \mathrm{M}$. of spruce, the value in column 4 would have been set as directly equal the allowed annual cut, or I 20 M. Column 5 is always the volume actually cut. Column 6 is merely for convenience in checking the results of estimates as a guide to their accuracy. When column 4 contains only part of a compartment, column 6 must be deferred until the entire compartment has been cut over.

Where conditions are sufficiently intensive the table may include areas as well as volumes.

\footnotetext{
* The figures are taken from the General Stand Table, Chapter I, Section 2, above.

$\dagger$ In Prussia the Oberförster (supervisor) calls on each Förster (ranger) for an annual cutting plan for his district. These he then combines for the whole forest.
} 
THE THEORY AND PRACTICE OF WORKING PLANS 103

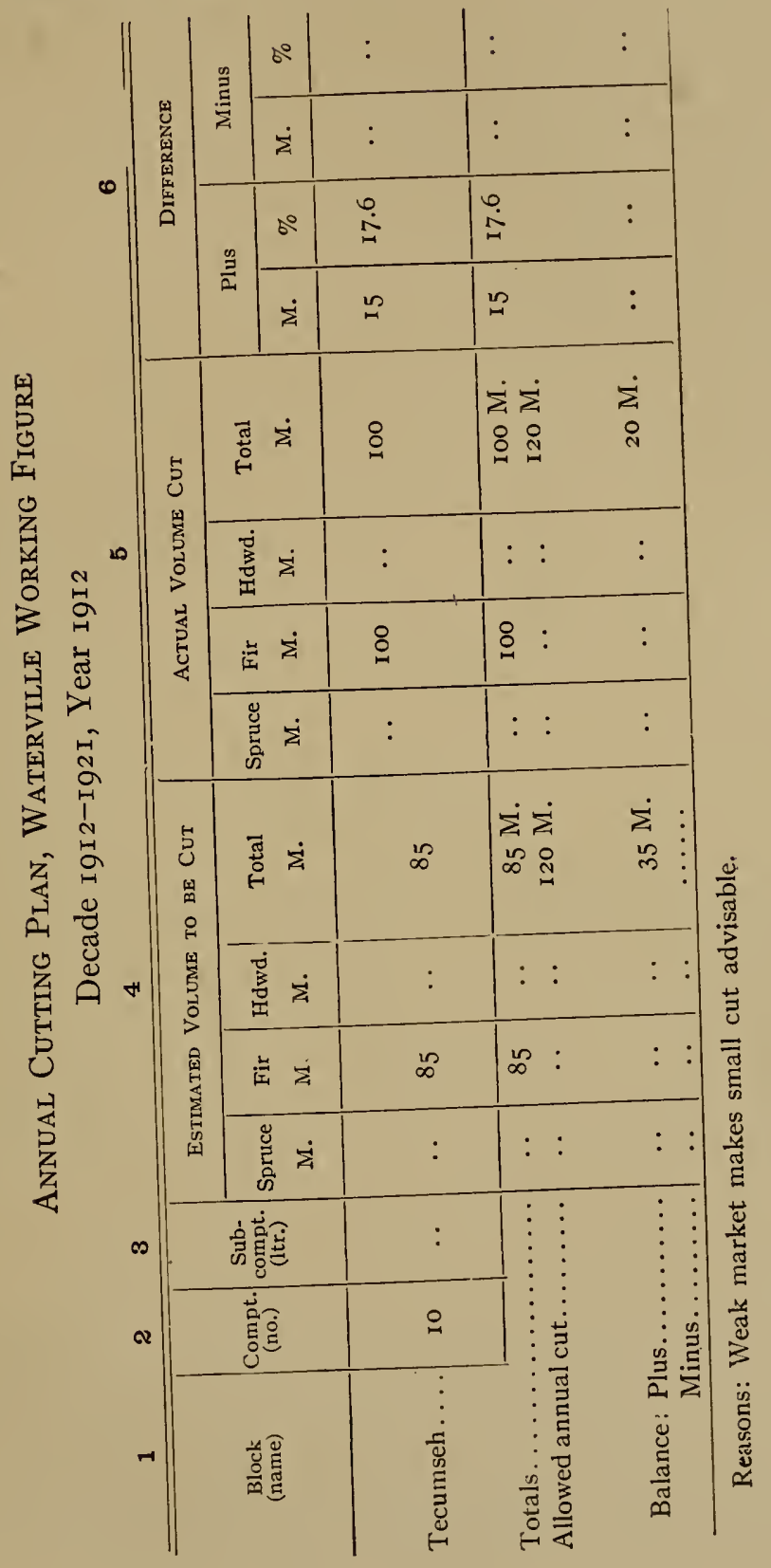


Descriptions and further explanations can always be added if advisable for clearness.

It is obvious that the cutting plan proper consists only of columns I, 2, 3, and 4 and the comparison of column 4 with the allowed annual cut. But for purposes of convenience columns 5 and 6 are added, thus making the record complete, though they cannot be filled until after the cutting is finished. Based on this record, the cutting plan for $\mathrm{I}_{9} \mathrm{I} 3$ is computed. Having saved $20 \mathrm{M}$. in I9I2, the administrator would not hesitate to cut $\mathrm{I} 20+20=\mathrm{I} 40 \mathrm{M}$. in I9I3. Indeed, considerable leeway is customary in this respect, so as not to tie the administrator's hands.*

At the end of the decade, if that is the working period, the annual cutting plan sheets are added up and the results compared with the general cutting plan; they then serve as most valuable data for the revision of the working plan (see Chapter III below).

\section{SECTION THREE}

\section{REGULATION OF YIELD IN SPECIAL CASES}

This section considers the methods of regulating the yield in special cases, such as, I abnormal forests, II transition forests, III wood-lots, and IV turpentine forests. Much of what has gone before will apply directly; it is only necessary here to note the exceptions and departures.

\section{Regulation of Abnormal Forests}

Strictly speaking all forests are abnormal which do not have a normal growing stock, a normal increment, and a normal distribution of the age classes (Chapter I, Section I). But in

* In Prussia the Oberförster (supervisor) may exceed the allowed cut by Io per cent without first seeking permission from his superiors. 
current usage the term "abnormal" is restricted to those forests which show striking irregularities-e.g., a very sparse, patchy stocking, or a marked excess of a single age class. In the latter case it is sometimes possible, if the entire stand is mature or past maturity, to cut it all off at once, invest the resulting capital, and let the interest thereon take the place of the sustained timber yield.

But ordinarily the timber owner needs timber rather than money wherewith to supply his saw-mills, pulp-mills, etc. In the case of the government it is obviously the correct political economy to be able to supply without undue interruption the necessary raw material to the timber-using industries dependent on the national or State forests. Furthermore, it is usually to the interest of the private owner to lumber conservatively and to plan for a second cut rather than to slash and abandon. By so doing he may, under average conditions, reasonably expect a five or six per cent return upon his investment and, if the shortage of lumber becomes as great as is freely predicted, stumpage values will increase prodigiously and profits proportionately.

Assuming, therefore, that the abnormal forest of a single age class is not to be exploited, but to be managed with a liberal construction of sustained yield, the regulation is as follows:

If the age is less than $\frac{r}{2}$ only thinnings are possible.

If the age is more than $\frac{r}{2}$ cutting is permissible, usually less than the allowed annual cut up to the age of $3 / 4 r$, usually more than the allowed annual cut beyond the age of $3 / 4 r$.

The object is to replace the excess of slow-growing mature and overmature stands by young, thrifty stands of rapid increment. This reduction of excess growing stock must never be brought about at the expense of glutting the timber market and forcing down prices. In America the silvicultural needs must, for the present at least, be subordinate to the economic demands. "In spite of the loss from deterioration, the country 
as a whole may be benefited more by reserving a considerable portion of these stands against the time of critical need than by cutting them off too rapidly, under present market conditions, in order to put the growing power of the soil to work." *

\section{Regulation of Transition Forests}

Forests in transition from high forest to coppice or, which is more frequently the case, from coppice to high forest, or from crude selection to even-aged forests, require special regulation.

The transition from coppice to high forest involves the replacing of sprouts by seedlings. The process of conversion is, briefly, as follows: Instead of cutting the coppice at the thirtieth year or thereabouts, as is usually done, it is allowed to grow until the sixtieth year or thereabouts. If the coppice does not already contain sufficient seedling trees in mixture, these must be supplied artificially. During the last decades, it is necessary to free the crowns of the seed-bearing standards from the encroaching coppice. This is done by means of preparatory cuts at intervals of about ten years.

When the coppice is about sixty years old, the regeneration cutting begins. This aims to open up the stand by cutting most of the coppice, allowing the seed from the standards to regenerate the area. The regeneration cutting is repeated four or five times at intervals of about five years, and gradually changes from cuts to seed up the area (or plant, if artificially) to cuts giving light to seedlings obtained, and at last to final removal cuttings. The last two cuts (light giving and final removal) operate not only in the coppice, but also in the seedbearing standards which may be present (coppice with standards).

The period of transition is thus thirty years' additional coppice plus twenty years of regeneration cutting if the coppice

*W. B. Greeley in "National Forest Sales on the Pacific Coast," "Proceedings of the Society of American Foresters," Vol. VII., No. I, p. 46. 
contains standards; otherwise extensive planting is necessary. The transition from coppice with standards to high forest is cheaper and easier than is the transition from straight coppice. Fifty years is the usual transition period, or about one-fourth to one-third the high-forest rotation. Even by planting the seedlings the time can only be shortened by greatly heightened annual expense unless the area to be transformed is small. There is also the danger of creating large areas of even-aged stands if too much is planted each year.

The forest regulation consists of a general cutting plan (Section 2, this chapter) for the whole period of transition. This cutting plan designates for each of the stages of transformation the approximate amount to be cut and how the cut is to be conducted. Where the seedlings have to be introduced artificially, this must be supplemented by a careful planting plan (Chapter III), showing species, kind of stock, spacing, etc., and the amounts and areas to be planted in each stage of the transformation.

It is obvious that the sustained yield suffers temporarily because of the cessation of coppice yields and the delay in securing high-forest yields. To minimize this delay it is often advisable to plant species of fairly rapid growth and hence low rotation age, such as chestnut, ash, pine, European larch, etc.

The transition from selection (all-aged) forest to even-aged forest is comparatively simple, but requires one or two rotations. The object is secured by a change in the silvicultural system employed, and can be brought about in a variety of ways.

The quickest and most useful is by means of shelterwoodselection cuttings (see Chapter I, Section 3), whereby the period of regeneration is reduced from the entire rotation to 30 to 50 years. With the next rotation the method can still further approach the shelterwood system, if conditions are favorable, and the period of regeneration reduced to from to to $\mathrm{I}_{5}$ years, resulting in virtually even-aged stands.

Where the selection forest is already very group-wise (evenaged in groups), the transition can take advantage of this by 
employing the shelterwood-group system (see Chapter I, Section 3 ).

The forest regulation consists in modifying the general cutting plan to meet the changed conditions-i.e., a high cut during the regeneration period followed by a cessation of cutting until the young growth is merchantable, instead of the more frequently recurring cutting cycles of the selection forest. The general cutting plan is also extended so as to cover the entire period of regeneration ( 30 to 50 years) instead of merely a decade or so.

\section{Regulation of WoOD-LOtS}

Wood-lots are seldom managed by a technically trained forester, hence the prescribed regulation must be so simple, clear, and direct that any layman can carry it out. The owner of the wood-lot is interested chiefly in having a sustained yield. This feature should, therefore, be emphasized by determining the allowed annual and periodic cut as exactly as possible by area or volume, or both. This should be incorporated in a detailed general cutting plan and the cutting areas for the next working period indicated on a map of the wood-lot.

Where frequent revisions are possible, the prescriptions can be confined to the next decade or so, but where frequent revisions are out of the question the progress of management should be sketched for the whole rotation as a guide to the owner.

The regulation of yield in wood-lots must conform primarily to the wishes and desires of the owner, but it can usually accomplish these without the waste incident to haphazard management, and hence it is of the greatest value to draw up simple working plans even for small wood-lots. The realization of this has led to compulsory working plans for private tracts, large and small, in several of the European States, notably Prussia.

\section{Regulation of Turpentine Forests}

The imminent dearth of timber available for naval stores emphasizes the urgent necessity of abandoning wasteful, destruc- 
tive methods of turpentining in favor of a more conservative utilization and a regulated yield.

The field data necessary for the regulation of the turpentine yield are, besides a thorough acquaintance with the general and local turpentine business:

(I) The distribution of the diameter classes on each management or survey unit.* This need not be by inch classes, but according to the cupping limits, explained below. Strip valuation surveys, two chains wide, are excellent for this purpose.

(2) The local turpentining quality of each stand, gauged by the number of cups per acre.

(3) The amount and character of young growth below the minimum turpentining diameter for each management or survey unit, supplemented by detailed figures from sample areas more carefully measured, i.e., calipered instead of estimated ocularly.

(4) The board measure contents of stands. The cord-wood contents of undergrowth, etc.

(5) The silvical characteristics-maturity, height, thriftiness, etc.

(6) Diameter increment tables showing time required to grow from one-inch class to the next.

For conservative turpentining, the use of a system of cupping is basic. Scarcely less so is the cupping to a diameter limite.g., no cups on trees below eleven inches in diameter, and never more than three cups on any tree. Furthermore, in order to prolong the productivity of the tree and minimize the injury, the chipping must be shallow and light.

A definite rotation must be adopted for the working of the crops $\dagger-e . g$., by shallow and light chipping the first faces can be chipped for three years, when the faces will be about 45 to 50 inches in height, the cups being moved up each year. Then the faces are worked with a "puller," a chipping tool svith a long handle, for another three years, which makes the faces from seven to eight feet

*E.g., blocks, compartments, subcompartments, or townships, sections, quarter-sections, etc.

† A "crop" is commonly considered as containing 10,000 cups 
high. The tree is then allowed to recuperate for three years, when "back cups" are placed between the old faces and worked for three years. The final period of three years' working is secured from the high-face back cups. Thus each tree is worked for twelve years, extending over a period of fifteen. When the trees have been completely worked, they are cut for saw-timber, ties, or other material.* Certain of them are left as seed trees (Chapter I, Section 3), if that form of regeneration is sought, or else the seeding is from the side by the strip system (Chapter I, Section 3). In case of artificial regeneration, the worked and logged area is resown or replanted. When the young growth has reached sufficient size, the larger trees are turpentined, and thus the cycle is completed.

The following illustration is taken from management of the Choctawhatchee Division of the Florida National Forest:

Cupping to a diameter limit: No cups on trees ten inches or less in diameter (outside the bark at $21 / 2$ feet above the ground $\dagger$ ):

I cup on trees II-I 5 inches inclusive.

2 cups " " $16-20$ " 3 cups " " $2 \mathrm{I}$ "

Not more than three cups on any tree.

The width of the face varies from 9 to $I_{4}$ inches, according to the size of the tree, hence room is always left for the future back cups, especially since the "bars" between the faces are at least 4 inches wide. However, to get 10,000 back cups nearly twice the area must be used as for virgin cups, because none of the three-cup trees, and but very few of the two-cup trees, can be back cupped, and never more than one back cup can be placed on a cupped tree.

Working of Crops in Rotation.--Under the system outlined, an average stand of one acre on which cupping was begun in timbers.

* The turpentined trees of France are highly prized in England as mine

$\dagger$ If measured at breast high $(4 \mathrm{~T} / 2 \mathrm{ft}$.) the diameter classes must be reduced, say, one inch; e.g., the two-cup class becomes from $15^{-19}$ inches inclusive. The exact taper is found by means of local measurements. 
Igro with a yield of twenty virgin cups will have, according to the present plans of management, the following turpentining history:

\begin{tabular}{|c|c|c|c|c|}
\hline $1913-1915$ & “ & 3 & " & 20 high-face cups \\
\hline $1916-1918$ & " & 3 & " & resting period \\
\hline $1919-1921$ & “ & 3 & $"$ & Io back cups \\
\hline I922-I924 & “ & 3 & $"$ & Io high-face back cups \\
\hline Total, & & & & 60 cups \\
\hline
\end{tabular}

Method of Regulating Yield.--This method of working the crops in rotation has been applied to the whole Choctawhatchee Division. Under the unfavorable conditions of slow growth and small timber, it appears necessary to wait roo years before obtaining a second cupping equal to the first. On this basis about six and two-thirds new crops (66,000 cups) can be worked each year for the next 100 years with a probable increase of from ten to fifteen crops annually thereafter. This does not mean six and two-thirds virgin cups each year, but includes the highface, back cups, and high-face back cups, since, according to the estimates, there are on the whole Division:

$$
\begin{array}{lll}
220 & \text { crops of virgin cups } \\
220 & \text { " } & \text { high-face cups } \\
\text { I IO “ } & \text { back cups } \\
\text { IIO " } & \text { high-face back cups }
\end{array}
$$

Total, 660 crops, or $6,600,000$ cups

However, in order to reduce the forest to normal and to fully utilize merchantable timber, the annual permits for the decade I9Io to I920 have not been restricted to six and two-thirds new crops. The following diagram (Fig. 2) shows the number of crops (I0,000 cups each) operative annually for the period Igro to I920. "First permit" means virgin cups, "second" means high-face cups, "third" means back cups, and "fourth" means high-face back cups.

At the end of the ten years the Choctawhatchee Division will practically be producing normally and should continue to do so during the remainder of the hundred-year cycle which must elapse before a second cupping is possible. 
It should be remembered, in this connection, that any regulation by number of cups must be approximate, since the area required for a crop of cups is so variable. Therefore, it is the

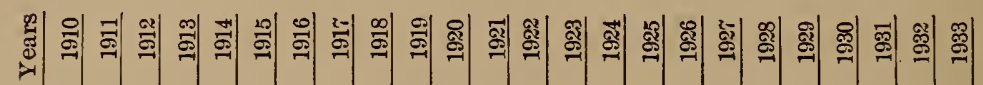

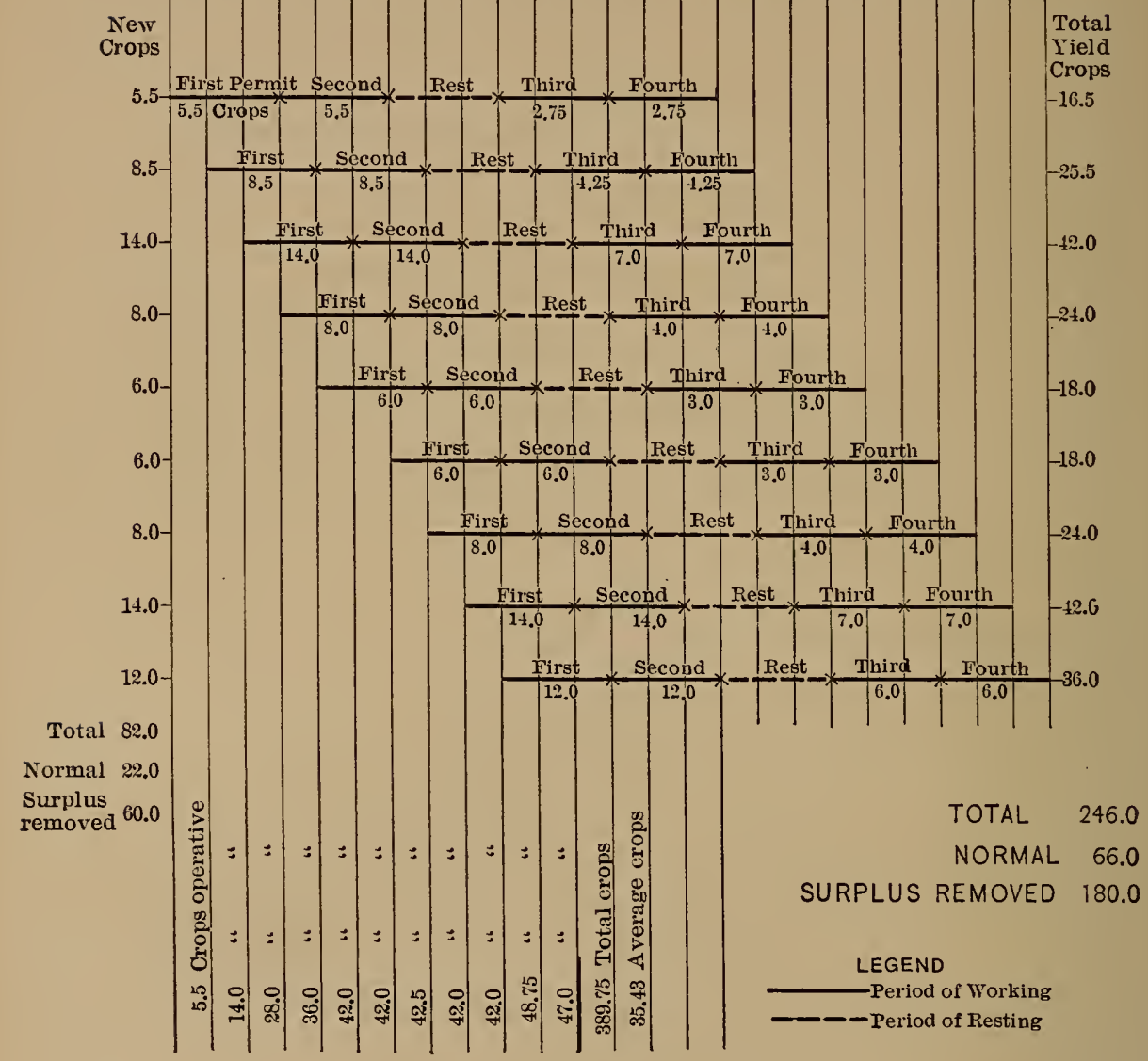

FIg. 2.

practice of the government to place on the market each year a certain area (by legal subdivisions) which the estimates show to contain approximately the scheduled number of cups. 


\title{
CHAPTER III
}

\section{THE WORKING-PLAN DOCUMENT}

\author{
SECTION ONE
}

\section{CONTENTS AND FORM}

THE working-plan document is the vehicle for recording the salient features of a forest bearing on its organization and the detailed prescriptions of that organization for the next working period. Simplicity and brevity are the key-notes. The descriptive portion is usually confined to such short statements as suffice to bring to the trained forester's eye the picture of the forest as it is in its essentials, but, occasionally, a more detailed description is warranted so as to make the plan comprehensible to a layman, e.g., where the plan is to be executed by a laymanowner (see previous chapter, Section 3, "Wood-lots").

In the interests of clearness and brevity data should be tabulated wherever possible, e.g., estimates, stand tables, ageclass tables, etc. Maps, also, are a powerful aid in graphic presentation of the data.

The working-plan document may be confined to the silvicultural management, or it may cover all the activities of a forest such as general administration, grazing management, permanent improvements, forest protection, and use of forest land (see Introduction); in other words, be a complete forest plan. The desirability of including these sundry subjects depends on their importance and the purpose of the plan. National forests usually require complete plans (see Part Two, Section 2). Where other subjects than that of silvicultural management are to be included, the descriptive data preceding the plan proper must be amplified accordingly (see Typical Outline for America, next section). 
The essential contents of a working plan confined to silvicultural management are (I) Orientation, i.e., location, size, history of forest with important changes, salient physiographic, social, and industrial features, time, method, and personnel of reconnaissance and work of organization, period for which made (working period), digest of working-plan conference, if had; (2) Foundation, i.e., growing stock (estimates) and increment, and (if even-aged) distribution of the age classes, general stand table, maps, forest description, division of area; (3) Recommendation: methods of management, past, present, and proposed, i.e., governing conditions, object of management, silvicultural system, rotation, etc.; (4) Regulation, i.e., yield determination and distribution, general and annual cutting plan, corresponding general and annual planting plans (Section 3).

These essentials may be presented in various forms, some of which are given in the following section, varying with the needs and desires of the administrative officers. The form of the working-plan document is comparatively unimportant. It may be typewritten or not, bound or unbound. If typewritten it can be manifolded more easily; if plainly bound it resists handling better, and the working-plan document is meant to be used constantly, not put away on a library shelf for the admiration of visitors. To facilitate this use a two-inch margin should be left at the side of the text throughout the document, excepting tables, for the purpose of allowing notes to be made from time to time by officers charged with the execution of the plan. This simple device keeps a plan alive and up to date and greatly facilitates the work of revision (Section 4).

The field work in connection with forest organization often results in the collection of many interesting and valuable silvical and other data which, while germane to the working plan, are not a cognate part thereof. Such data, including volume, growth, and yield tables, silvical notes, notes on climate, geology, soil, etc., should be placed in the appendix or elsewhere convenient, in order that everything in the plan may be confined 
to the actual scheme of management for the forest. These as already stated are:

I. Orientation.

2. Foundation.

3. Recommendation (silvicultural treatment).

4. Regulation.

The first three of these were largely covered in Chapter I, the last in Chapter II. It is, therefore, only necessary here to consider them from the documentary standpoint.

\section{Orientation}

(a) Location and Size.-The briefest mention suffices.

(b) History of Forest with Important Changes.-Past and present ownership and administration, boundaries, past object of management, past revenues and expenditures.

(c) Salient Physiographic, Social, and Industrial Features.The physiographic features include topography, drainage, geology, soils, and climate. Detailed observations and statistics should be reserved for the appendix, and only the salient characteristics which influence the forest organization stated briefly.

The social and industrial features include population, labor supply, local industries such as lumbering, grazing, mining, agriculture, etc., all in their bearing on the problems of forest organization. For it is evident that without adequate labor no forest resources can be developed, without lumbering facilities no regulation of the cut can be maintained or executed, and the very term "accessible" is modified by the degree of skill exercised in logging and the kinds of appliances used to get the timber. Again, the need of the local population for timber is the root of the theory of sustained yield. These fundamental phases require no detailed discussion, but brief statements of conditions in explanation of the plan proper.

(d) Time, Method, and Personnel of Reconnaissance and Organization.-These statements should be exceedingly brief- 
a tabular form is advisable for time and personnel, since they are of purely historical interest. The method used should, however, be set forth in sufficient detail so that there can be no question as to how much weight attaches to the accuracy of maps and estimates.

(e) Digest of Working-Plan Conference.-If a conference was had between the forest organizer and the owner or administrator of the forest, as suggested in Chapter I, Section I, this should be digested and added to the working-plan document with the names of the participants.

\section{Foundation}

(a) Growing Stock (Estimates).-The estimates should be in form of a table by species and classes of timber, either separate or as part of the general stand table. The details of this estimate table depend on the intensity of the entire plan. It will usually suffice to give the totals by compartments (if any) and blocks, or else by survey units such as sections, or even townships. The estimate for the entire working figure must always be given. It must also be stated to what minimum diameter trees were estimated and, if available, what average deduction must be made for defect. Estimates in greater detail, e.g., section sheets showing the stand on each "forty," should be reserved for the appendix (see Chapter I, Section 2).

(b) Increment.-The increment, either current or mean annual, or else both, is given, and is expressed either in increment per acre or as a per cent (Chapter I, Section I). Growth and yield tables on which the calculation of increment may be based should be included in the appendix.

(c) Distribution of the Age Classes.-If the stand is evenaged or approximately so, a table of age-class distribution, like the example given in Chapter I, Section 2, should be included. Not only does such a table show at a glance the relation of young, mature, and overmature timber, but, in the revisions of the 
working plan, it shows by means of graphic curves or blocks (Chapter I, Section I) what progress has been made toward the attainment of normality in this direction (see Section 4 ).

(d) General Stand Table.-A table approximating, as far as possible, the example in Chapter I, Section 2, should be included as a convenient tabular summary of areas, volumes, and conditions of timber.

(e) Maps can be elaborated to almost any extent according to the kind and importance of the data to be shown thereon. The following are the most important:

(I) A topographic map showing topography in contours, seldom hachures; roads, trails, railroads, saw-mills, and all other "culture"; drainage. This map is the "base" and should be of a convenient scale, such as $1 / 2, I, 2,4$, or even more inches to the mile, depending on the size of the tract and the amount of detail to be shown. It should be drawn so as to permit of being manifolded in order that all officers charged with the administration of the forest and the execution of the working plan may be furnished with copies. On this "base" can be added any or all of the following special data in so far as the wealth of detail will not confuse the whole.

(2) Boundary map showing the ownership (status), the forest boundary or boundaries; survey lines, if any; boundary or boundaries of the working figures, blocks, compartments, and subcompartments (stands) (see Chapter I, Section 2).

(3) Forest-type map, showing the various forest types (Chapter I, Section 2), also cut-over areas, burns, open "parks," etc.

(4) Age-class map, showing the distribution of the various age classes.

(5) Site-quality map, showing the distribution of the various site qualities.

(6) Soil map, showing the various soils and geologic formations of the forest.

(7) Reproduction map, showing areas of good, fair, and poor reproduction (Chapter I, Section 2).

(8) Cutting map, to accompany the general cutting plan, 
showing areas to be cut over within the next working period (Chapter II, Section 2).

(9) Planting map, to accompany the general planting plan, showing areas to be restocked artificially during the next working period (Chapter III, Section 3), and areas already planted or sown, all nurseries and proposed nursery sites.

If the plan is to be a complete forest plan, and not confined to the silvicultural management, there may be the following additional maps:

(1o) Fire map, to accompany the fire plan (see Introduction), showing all lookout points, watch towers, lines of patrol, ranger headquarters, fire-guard stations, location of fire-fighting tools, and places whence assistance in fighting fire may be obtained. The base should be maps I and 3 combined.

(II) Permanent improvement map, to accompany the permanent improvement plan (see Introduction) showing all improvements, existing or proposed, such as ranger stations, fire cabins, telephone lines, etc.

(I2) Grazing map, to accompany the grazing plan (see Introduction), showing the grazing types, condition of the range, the portions grazed (and by what class of stock) or ungrazed, the winter, summer, or yearlong range, corrals, pastures, drift fences, water tanks, etc.

Lest too many data be placed on one map, it is better to have separate maps than to combine too much and cause confusion. For ordinary purposes, however, the following maps may well be combined:

Nos. I, 2, 3, and 4. Topography, boundaries, types, ageclasses.*

Nos. I, 2, 3, 7, and 8. Topography, boundaries, types, reproduction, cutting.

Nos. r, 2, 3, and 9. Topography, boundaries, types, planting.

Various methods of regulating the yield (Chapter II, Section I) require special data on the map, e.g., if the regulation is

* If even-aged or approximately so. 
to be by area reduced according to site classes (method No. I, variation II; method No. I4, variation II; method No. I6, variation II, also method No. I7, Nos. I and III), then a siteclass map (No. 5) is necessary.

Detailed maps of survey units or of small areas which it is desired to show in greater detail should be placed in the appendix, as should also special maps showing areas of insect or fungus attacks, etc.

f. Forest Description.-Must be concise and free from burdensome details. These had better be placed in the appendix. The forest description of the entire working figure should be a careful summary of the descriptions for each block* (see Chapter I, Section 2). The aim is to present a lucid picture of the forest as it is in the essential silvical factors bearing on the plan of management adopted. The description must be ample reason for the provisions of the working plan. The description is the premise; the recommended management the logical deduction from that premise.

g. Division of Area.-On the basis of the forest description, the division of area should be so evidently logical as to require very little special justification. However, it is well to explain briefly what considerations governed in the choice of working figure, block, compartment, and subcompartment (Chapter I, Section 2), in so far as this was not already covered in the digest of the working-plan conference. Since the working figure is the unit of sustained yield, its adequacy from this viewpoint should be considered along the broad lines laid down in Chapter I, Section 3 .

\section{Recommendation}

The recommended management should be the logical sequence of the data given under "Orientation" and "Founda-

* These, together with the estimate and map sheets of the survey unit (see "Reconnaissance," Chapter I, Section 2), should be placed in the appendix or else filed conveniently for future reference. 
tion." The basic considerations of silvicultural method of management, object of management, and rotation are contained in Chapter I, Section 3. This part of the working-plan document should review the governing conditions which determine the recommended management. These are:

(a) Object of Management-i.e., the wishes and purpose of the owner (in so far as not already contained in the digest of the working-plan conference).

(b) Practical Restrictions of market, logging accessibility, fire danger, erosion danger, etc.

(c) Silvicultural Method of Management which can best fulfil the object of management with the given silvical conditions and under the practical restrictions imposed. Past management and its mistakes and lessons should be reviewed and the proposed method of management given in detail. The best silviculture is not always possible under existing conditions, and the organizer must seek to combine the three divergent factors of object of management, practical restrictions, and silvical requirements into a harmonious scheme of management. This should cover:

(I) Silvicultural system Ior each type (Chapter I, Section 3) with brief description thereof.

(2) Rotation (Chapter I, Section 3) choser, with reasons for its adoption. The period of regeneration, cutting cycles, etc., should be given and made entirely clear.

(3) Marking rules to be followed in the execution of the cuttings for natural regeneration. They should be clear and concise, simply put so as to be readily intelligible to the nontechnical man charged with their execution, sufficiently elastic to cover all cases. Good marking rules will do much towards insuring the actual execution of the silvicultural system decided upon, especially when backed by sample areas marked by the forest organizer as a concrete illustration.

(4) Brush disposal rules are a necessary concomitant of the marking rules. Here too actual examples of what is desired should reinforce the written rules. 


\section{Regulation}

As the recommended management (3) is the logical outgrowth of the data given under Orientation (I) and Foundation (2), so the regulation of the yield itself is but the carrying out of the Recommendations (3).

The chief phases of yield regulation are:

(a) Yield Determination by one or more of the methods described in Chapter II, Section I.

(b) Yield Distribution.-Selection of stands to be cut, formation of cutting series, etc., with concise reason for the choice, in accordance-with the principles given in Chapter II, Section 2. Cutting policy in so far as not covered already in the digest of the working-plan conference.

(c) General Cutting Plan for the next working period according to the example in Chapter II, Section 2. It should contain in addition recommendations in regard to stumpage rates, methods of logging, rules of cutting to prevent waste, and other features of practical utilization such as probable purchasers, uses and markets, etc. An annual cutting plan for the ensuing year is usually drawn up by the administrative officer in charge of the forest, and does not as a rule form a part of the workingplan document (Chapter II, Section 2).

(d) General Planting Plan for the next working period according to the example given below in Section 3. A description of the methods and cost of nursery, planting, and seeding practice to be employed. An annual planting plan for the ensuing year is usually drawn up by the administrative officer in charge of the forest, and does not, as a rule, form a part of the working-plan document (Chapter III, Section 3). 


\section{SECTION TWO \\ OUTLINES FOR WORKING PLAN}

Three typical outlines for working-plan documents will be given. A. The Prussian outline, typical of forest organization in countries based on forest-rent.* B. The Saxon outline, typical of forest organization in countries based on soil-rent, ${ }^{*}$ and, $\mathrm{C}$, an outline typical for the average extensive conditions existing in America. This last includes all the phases of a complete forest plan.

\section{A. Prussian Outline}

Introduction. Working period (two decades). Revision (every decade). Name of forest organizer and assistants.

I. Letter of minister (secretary) putting plan into effect.

2. Plan of management.

Digest of working-plan conference.

Introduction. Time and scope of work.

General position and history of the forest.

The measurements.

a. Maps.

(I) Special maps (large scale).

(2) Location map (small scale).

(3) Map of servitudes (proscriptive rights).

b. Record of measurements.

(4) Boundaries.

(5) Table of measurements (survey notes).

(6) Record of changes in area.

(7) Record of changes in servitude

Division of area.

(8) Ranger districts and blocks

(9) Compartments.

(Io) Subcompartments.

* See Part Two, Chapter I, for details. Also Series "American Aspects of European Forestry" in "F. Q.," Vol. XI. 
Condition of stand.

(II) Site.
(a) Exposure.
(b) Soil.

(I2) Stand.
(a) Species.
(b) Relation of the age classes.

(I3) Injuries.
(a) Fire.
(b) Storm (wind).
(c) Frost.
(d) Drought.
(e) Fungus.
(f) Insects.

(I4) Market conditions.

(I5) Labor conditions.

(I6) Servitudes.

Regulation of yield and plan of management.

(I7) Former management.

(I8) Basis of present regulation of yield.
(a) Rotation.
(b) Plan of yield.
(c) Calculation of yield.

(ig) Method of cutting.

(20) Method of regeneration.

Miscellaneous.

(2I) Financial yield.

(22) By-products.

(23) Hunting and fishing.

(24) Forest protection and policing.

(25) Fiscal matters.

(26) Communal relations, i.e., with communal-owned forests.

(27) Other matters of interest.

3. Boundary register (status).

4. General stand tables. 
5. Area tables.

6. Table of servitudes.

7. Plan of thinnings.

8. Résumé of communal conditions.

\section{B. Saxon Outline}

Part One. Introduction. Working period (one decade). Revision (every five years).

General stand tables (areas and volumes).

Site-quality* table and comparison of increments.

Comparison of age classes and volume (growing stock). Table of age-class distribution in per cents and area. $\dagger$

Stand-quality table. $\neq$

Results of past management.

(I) Final cuttings.

(2) Intermediate cuttings.

(3) Total yield.

(4) Yield by cutting areas.

(5) Money yield from cuttings.

(6) Plantations, also care of plantations and of the stand.

(7) Road and trail building.

(8) Summary of net soil rent (Reinertrag).

Yield determination.

General rules of management.

Part Two. General cutting plan.

Part Three. General planting plan.

\section{AMERican Outline (suggested)}

I. Orientation.

a. Location and size of forest (working figure).

b. History of forest with important changes.

(I) Past and present ownership (status).

* "Standorts bonität."

† Diagrammatically by means of blocks. See Chapter I, Section I.

†"Bestands bonität." 
(2) Boundaries. Interior surveys.

(3) Past object of management and general administration.

(4) Past revenues and expenditures.

c. Physiographic features.

(I) Topography.

(2) Drainage.

(3) Geology (formation).

(4) Soils (depth, fertility, etc.).

(5) Climate (maximum, minimum, and average temperature, rainfall, prevailing wind direction).

d. Social and industrial features.

(I) Population. Dependence on forest for work and fuel and timber supply.

(2) Labor supply.

(3) Local conditions-lumbering, grazing, mining, agriculture, etc. Interrelation with forest.

e. Digest of working-plan conference.

f. Time, method, and personnel of field work. Cost, if desired.

\section{Foundation.}

a. Growing stock (estimates). Tabulation.

b. Increment per acre or per cent.

c. Distribution of the age classes. Tabulation.

d. General stand table. Tabulation.

e. Forest description.

g. Division of area. Working figure, block, compartment, subcompartment (stand).

3. Recommendation.

a. Object of management. Production of cord-wood, sawtimber, turpentine, etc.

b. Wishes and purpose of the owner (policy if national or State forest).

c. Practical restrictions. Market, logging accessibility, special danger from fire, erosion, avalanches, etc.

d. Method of management. 
(I) Silvicultural system or systems, their proposed application.

(2) Rotation (period of regeneration, cutting cycle, etc.).

(3) Marking rules.

(4) Rules for brush disposal.

4. Regulation.

a. Determination of yield.

b. Distribution of yield. Formation of cutting series, etc.

c. General cutting plan for working period.

d. General planting plan for working period.

5. Administrative plan.

a. Scheme of field administration.

(I) Administrative districts and area.

(2) Field and office force, yearlong and temporary.

6. Grazing plan.

a. Description of forage types and condition of range.

b. Protection and development of range.

(I) Range improvements. Watering facilities.

(2) Treatment of overgrazed and partly stocked areas.

(3) Measures for fuller use of range.

(4) Control and eradication of poisonous plants.

(5) Control and extermination of predatory animals, prairie dogs, and other pests.

c. Grazing control. Capacity of range. Grazing districts and allotments.

7. Permanent-improvement plan.
a. General.
b. Telephone.
c. Look-out towers.
d. Fire cabins and tool-boxes.
e. Roads and trails.
f. Ranger stations.

8. Forest-protection plan.

a. Fire control.

(I) Nature of fire problem.

(2) Past fires. Bearing on the plan. 
(3) Hazards. Danger zones, extra fire risks, necessity of special measures.

(4) Coöperation. Desirable and proposed coöperation.

(5) Scheme of protection.

(a) Primary control by look-outs.

(b) Secondary control by patrol and actual combat.

(6) Organization. Look-outs and patrolmen. Action in case of fire.

(7) Mobilization.

(a) Fire-fighters, regular and volunteer, available.

(b) Transportation. Logging railroads, pack trains, teams, etc.

(c) Tools, equipment, and supplies. Location of tool-boxes. Bases of supplies.

(8) Improvements. Additional headquarters, telephone lines, trails, etc., required.

b. Insect control $\{$ and other special problems warranting

c. Funguscontrol

9. Uses of forest land.

a. Settlement.

(I) Classification of lands, whether of relatively greater value for agriculture or for forest purposes.

(2) Sale prices of land. Comparative land values.

(3) Cost of clearing land for agriculture and probable

b. Special uses. profits of agriculture thereon.

c. Water-power sites. Present and future development.

Stream measurements.

ıo. Appendix (observations not properly a part of the main working plan).

a. General data-geology, soils, climate, occurrence and protection of fish and game.

b. Silvical data.

(I) Volume, growth, and yield tables.

(2) List of component species.

(3) Silvical characteristics of component species. 
(a) Soil and moisture requirements.

(b) Influence of elevation and aspect

(c) Tolerance.

(d) Reproduction.

(e) Injuries: fire, storm, frost, drought, fungus, insects, etc.

c. Detailed estimates, maps, and forest descriptions of survey units or other units, unless filed elsewhere for greater convenience.

I1. Maps.

\section{SECTION THREE}

\section{THE PLANTING PLAN}

This is properly an integral part of every working plan, but in order to avoid confusion, and not to encumber the subject of timber regulation, detailed mention has been reserved for this section.

Some planting operations are necessary in every well-regulated. forest, whether it be to eke out a too scanty natural regeneration or to restock former forest areas where natural regeneration is out of the question.

Just as a general cutting plan is drawn up for the intended cuttings in the ensuing working period (Chapter II, Section 2), so a general planting plan is drawn up to cover all the operations. of artificial regeneration which are contemplated during the ensuing working period. From out this general planting plan the administrative officer in charge of the forest selects those areas whose restocking he deems of the most immediate importance and incorporates them into an annual planting plan which, with the approval of his superior officers, becomes the planting schedule for the ensuing year.

As a preamble to the general planting plan should come a general discussion of the areas needing artificial regeneration, the extent to which it is expedient to go in replanting com- 
mensurate with the results to be obtained, and other phases of the policy to be pursued in the choice of areas. In general, it is advisable to restock first those areas on which success seems most assured, leaving for the future with its greater experience and presumably greater capital those areas where immediate success is less certain. For most administrations profit by making a good initial "showing" and once the way is paved the more difficult operations can be undertaken even though they fail to make so good a "showing." Other things being equal, the money return from a planting is surer, larger, and sooner the easier the site and the quicker the success of the operation.

This should be followed by a full discussion of the methods of regeneration to be employed. First the results of past plantings and sowing, accentuating the reasons for failure or success, and then the policy for future planting and sowing. The source of plant material-seeds, seedlings, and transplants should be considered; the seed should be shown to be from reliable and appropriate sources (sources suitable to the climatic and site conditions), and the planting stock preferably grown in nurseries on the forest or else secured from outside nurseries whose site corresponds approximately to that of the intended planting site. If there are to be nurseries on the forest, the preamble of the general planting plan gives full provisions for their location, creation, and maintenance, and should contain the area thereof in seed-beds and their capacity, the area thereof in transplant beds and their capacity, and the proposed annual production by species and classes of stock.

The area which it is intended to plant or sow during the coming working period should be indicated on the working map of the forest either by color, or shading, or symbols.

The annual planting plan may conveniently take the forms on pages I3O and I3I, a separate head being used for plantings and sowings.

The general planting plan may conveniently take the form shown on page 132 . 


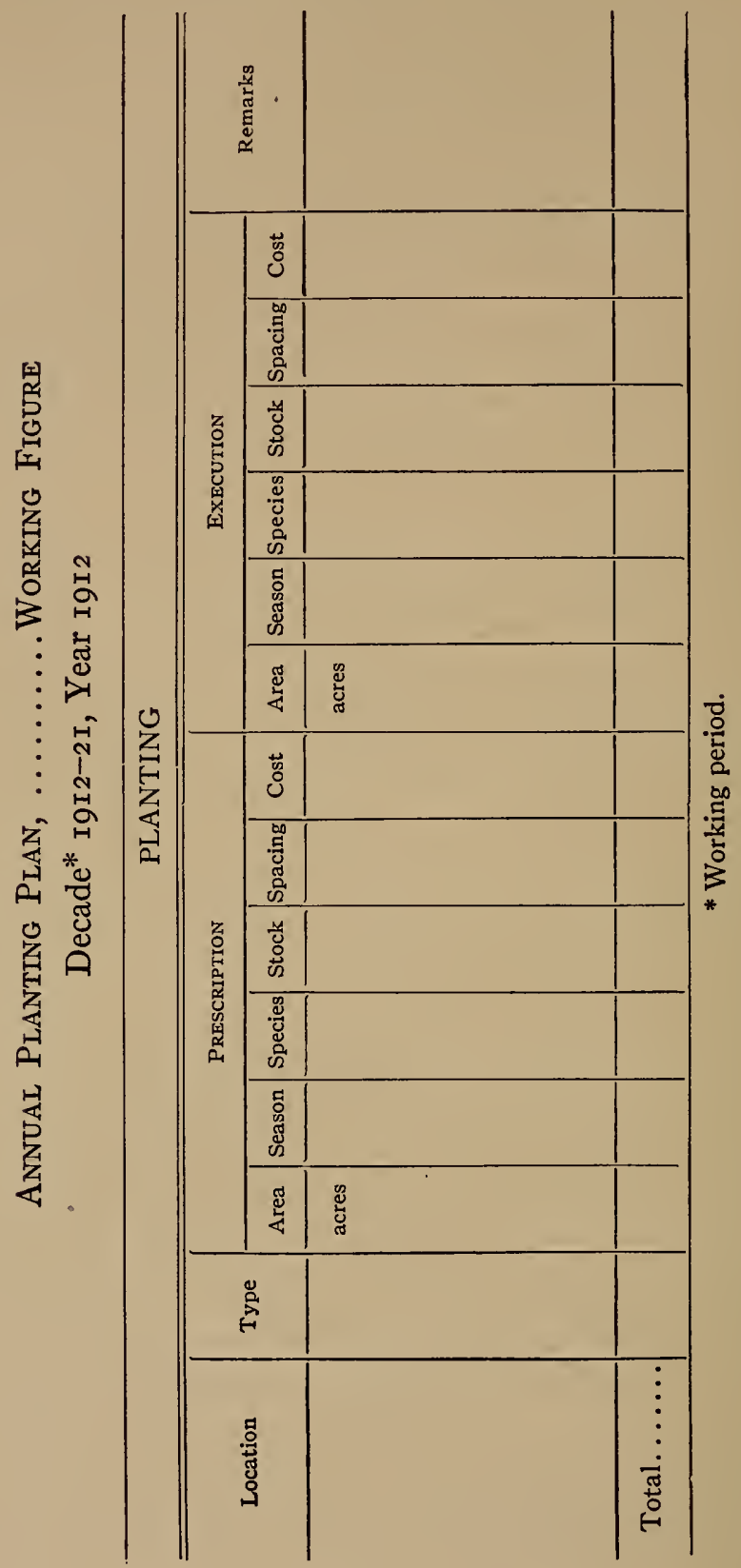


THE THEORY AND PRACTICE OF WORKING PLANS

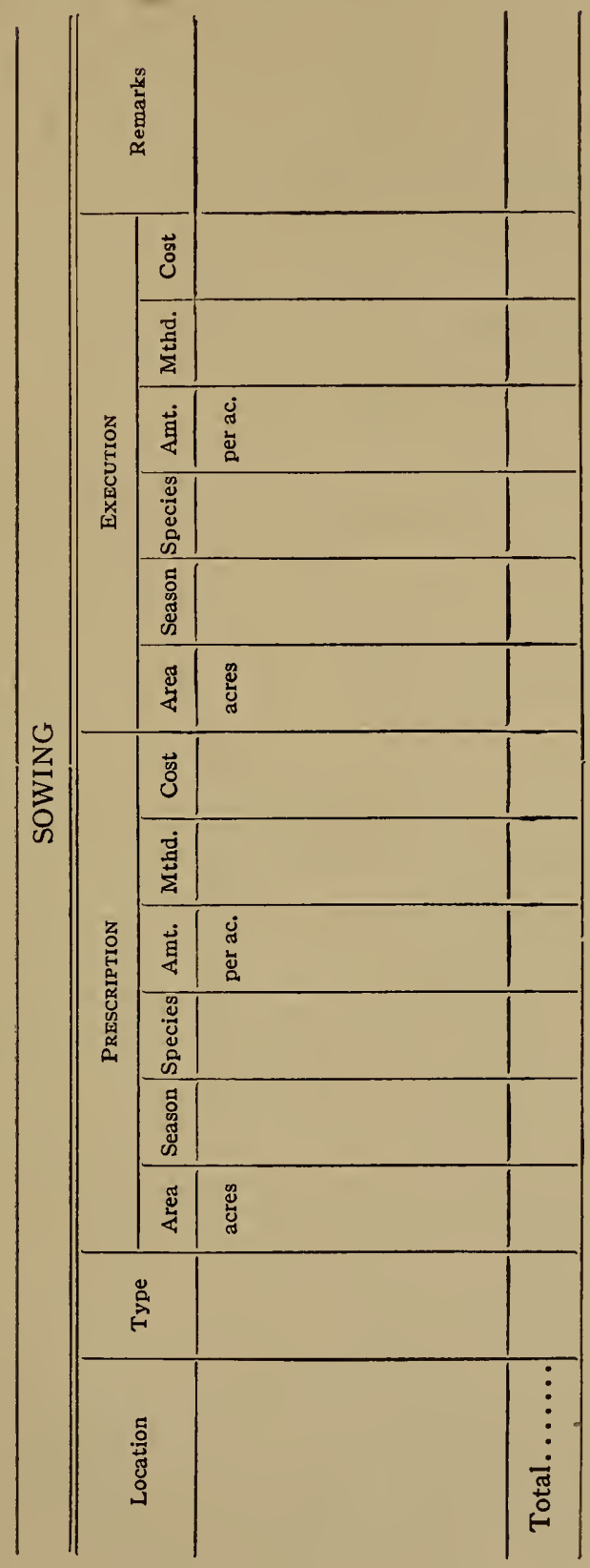




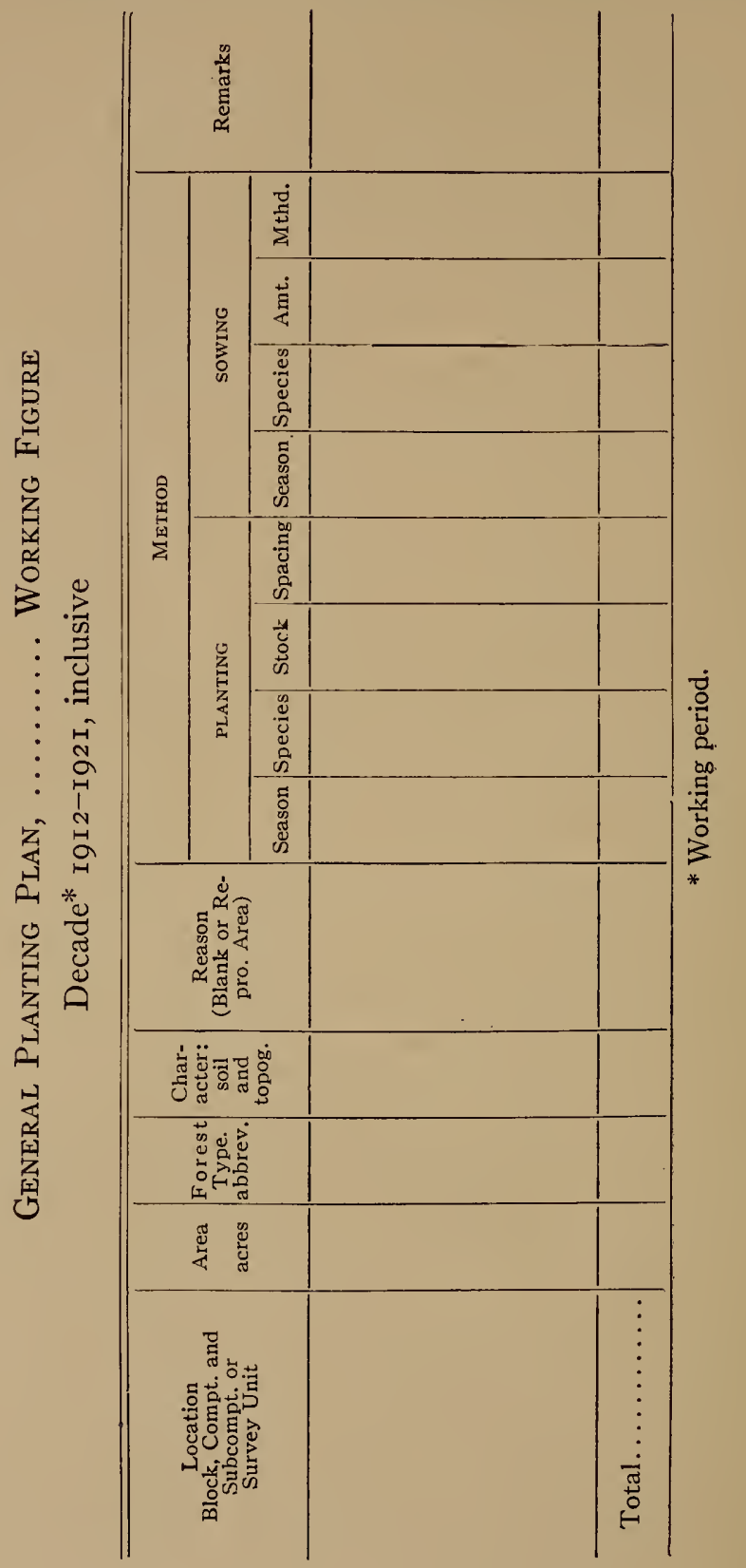




\section{SECTION FOUR}

\section{CONTROL AND REVISION OF WORKING PLAN}

No working plan can remain alive and useful unless it is revised at frequent, regular intervals. These revisions incorporate all the changes which have taken place during the working period.

Since the working period is usually ten years, the workingplan document is usually revised every decade. But under very intensive conditions more frequent revision may be justified, even to the extent of every five years (see Example of Saxony, Part Two, Chapter I). On the other hand, a plan should not, ordinarily, go without revision for more than a decade, or perhaps twelve years, even though the working period be longer, e.g., two decades, or even four, as in Prussia and Austria, respectively (see Part Two, Chapter I).

Especially under the kaleidoscopically changing conditions in most parts of America is it desirable to have frequent revisions so that the working plan may really "work" and not become obsolete within the working period. Special revisions before the end of the working period are, of course, necessitated whenever, through storm, purchase, or the like, a substantial change is caused in the size, character, or composition of the forest.

The record of the progress of the forest under the working plan is called the control book. This book is conveniently in two parts: I, the cutting and planting record; II, the general or "history" book. The former may conveniently take the following form (page I34).

It is obvious that this part I of the control book is built up from the annual cutting and planting plans. It embodies their essentials in convenient form as a permanent record. It can, of course, be extended to cover all the activities of the forest besides "timber," e.g., grazing. A column for areas can also be added between columns 3 and 4 if desired. 
134 THE THEORY AND PRACTICE OF WORKING PLANS

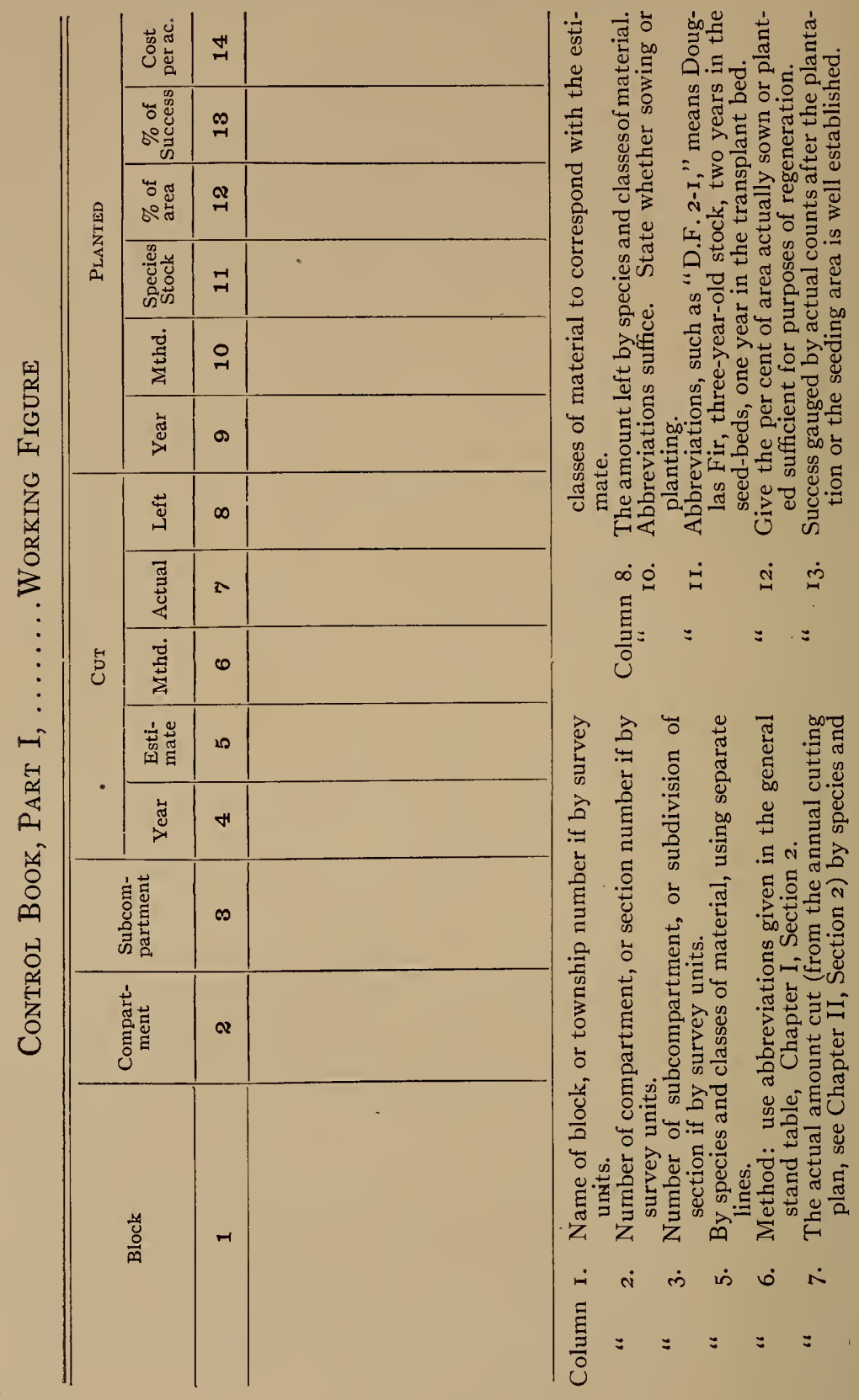


A separate page is kept for each convenient unit-be it block or compartment, township or section, depending on the needs of the administration.

All areas cut or planted are to be entered on the map of the forest.

Part Two, the "history" book, contains convenient headings for a general record of the various forest activities. Such are:

ᄃ. Reconnaissance and boundaries: a running record of the reconnaissance done and proposed, be it for timber, grazing, or what not, and of the changes in boundaries and the demarcation in the field of the boundaries.

2. Methods of cutting and planting: a running record of silvical observations in natural and artificial regeneration.

3. Forest protection: a running record of all important forest menaces; the method and success of the combat with them. Such are:
(a) Fire.
(b) Storm.
(c) Frost.
(d) Drought.
(e) Fungi.
(f) Insects, etc.

Chapters can be added at will for the other forest activities covered in a forest plan (see Section 2), such as:

4. Administration.

5. Grazing.

6. Permanent improvements.

7. Uses of forest land.

8. Utilization of forest products.

(a) Methods of logging.

(b) Methods of saw-milling.

(c) Markets and prices of stumpage and lumber.

(d) Utilization of by-products.

(e) Impregnation of wood (wood preservation), etc., ad $l i b$.

9. Game and the chase. 
Io. Money returns of management.

(a) Gross income and expense.

(b) Net income.

II. Personnel relations.

I2. Miscellaneous data.

Such a control book, together with the summarized annual cutting and planting plans, corrected maps, and the marginal notes and corrections in the plan itself, forms a perfectly adequate basis for undertaking the periodic revision.

The thoroughness of the revision depends on the correctness of the original plan. Only rarely should it be necessary to rewrite the entire plan. Those portions which come under "Orientation," such as physiographic features, social and industrial features, and under "Foundation," such as forest description, division of area, etc., can either be incorporated directly in the new working plan, or else reference made to the original working plan covering these portions in detail.

In matters of yield determination and distribution as embodied in the general cutting and planting plans, the revision is essentially a recalculation and reallotment.

The preliminary of every revision should be a working-plan conference to review the plan for the working period just passed and to make suggestions for the ensuing period. The digest of this conference should be incorporated in the revised working plan.

If the forest is essentially even-aged, the revised working plan should contain under "Orientation": "History of forest with important changes," a diagrammatic presentation of the distribution of the age classes, showing graphically the gradual approach (presumably) towards normality in this respect. This may be shown either by means of a curve or by means of proportionate blocks (see Chapter I, Section r, "Distribution of the Age Classes"). 


\section{PART TWO}

\section{PRACTICE OF WORKING PLANS}

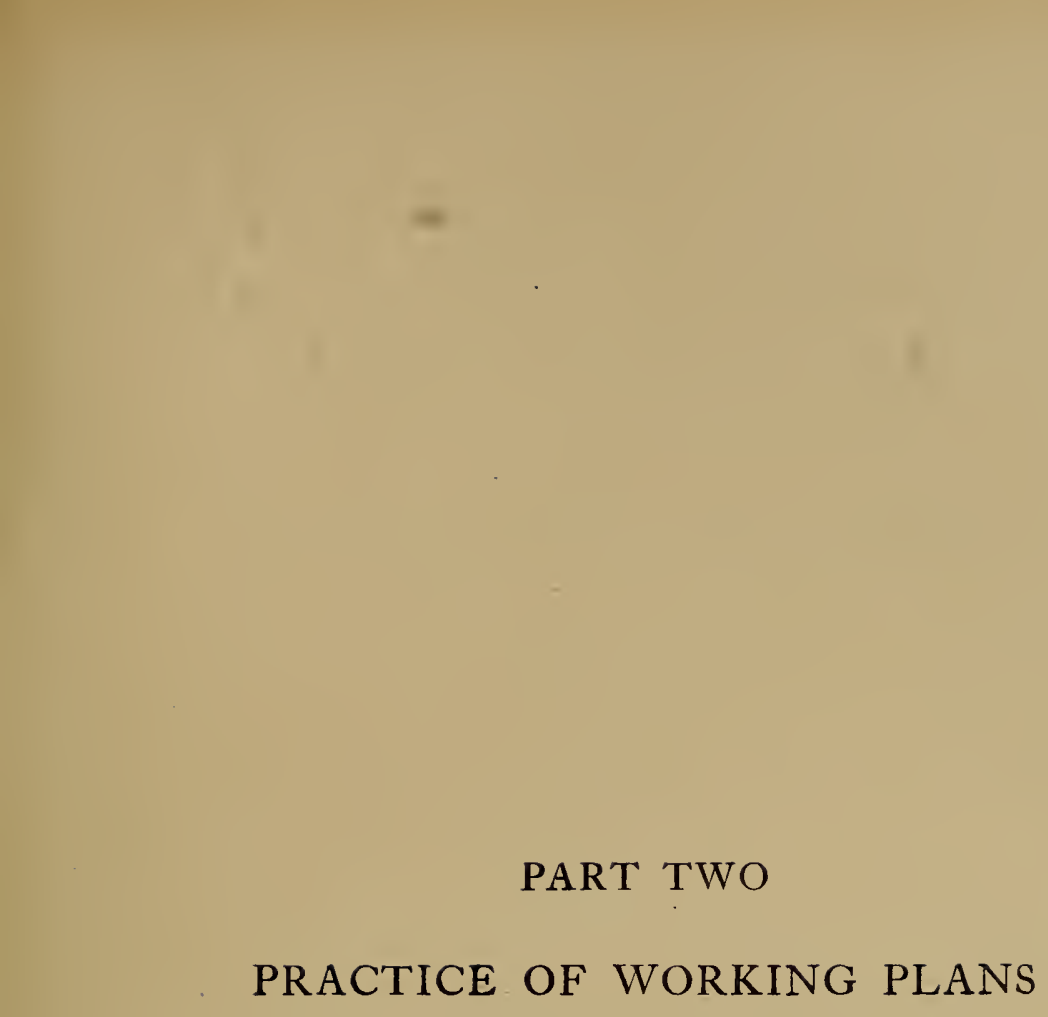





\title{
PRACTICE OF WORKING PLANS
}

\section{CHAPTER I}

\section{IN EUROPE}

\author{
SECTION ONE
}

\section{GERMANY}

THE chief States of Germany from the standpoint of forestry are: Prussia, Bavaria, Saxony, Württemberg, Baden, and Alsace-Lorraine. For each of these will be given, after a summary of the salient conditions, such as size of country and forests, topography, species, markets, etc., a brief review of the history of working plans, the chief foundations of plans, the methods of regulating the yield, and the prescriptions for control and revision of the working plan. The same scheme will be followed for the data about France and Austria (Sections 2 and 3 ).

\section{PRUSSIA}

Prussia is by far the largest of the German States, with 86, I 18,526 acres, or about 65 per cent, of the total German Empire. Of these $86, \mathrm{II} 8,526$ acres, $20,427, \mathrm{I} 79$ acres, or 23.72 per cent, are in forest.

Prussia contains widely varying topography, from the very characteristic plains of the northeast to the lesser ranges along the Austrian frontier (Riesengebirge) and in the east-central pcrtions (Harz, Teutoburger Wald, Taunus, etc.). 
If one considers Germany as roughly divided into three main forest regions by a line from the corner of Bohemia, at Eger, northward through Hannover into Lübeck on the Baltic, and another line from Hannover westward to Amsterdam, the large northeast block may be called the pine region, the small northwest block the heath region, and the remaining southwest block the hardwood-spruce-fir region. Practically all of the pine region is contained within Prussia, and this explains the preponderating percentage of Scotch pine-6o per cent as against I 2 per cent of spruce and fir, 5 per cent of oak, $x_{5}$ per cent of beech, and 4 per cent of birch and alder-in Prussia.

The markets for Prussian forest products are so excellent as to admit of the profitable placing of all classes of timber with only minor exceptions.

During the nineteenth century the period method of regulating the yield ("Fachwerksmethoden," i.e., "Framework Methods"-see Part One, Chapter II, Section 3, Method No. I7) predominated in Prussia. At first, owing to the influence of G. L. Hartig, it was a strict volume-period method ("Massenfachwerk," i.e., volume framework). The official instructions of $18 \mathrm{Ig}$ provide a detailed allotment by volume and classes of material for each of the six periods of the I20-year rotation. The impracticability of such calculations without adequate bases soon brought a change from Hartig's strict method, the more so since such slow progress was being made toward the goal of having working plans for each forest. Therefore, in 1836 , after a provisional regulation of the yield had been accomplished between 1826 and 1835 , a new order for regulating the yield was issued which remained in force almost to the end of the century. Though still based on the volume-framework method, the calculation of yield was simplified, and the equality of area was also taken into consideration together with a correct distribution of the age classes and the formation of cutting series. With the introduction of the factor of area, the volume-period method (Massenfachwerk) fell into abeyance and the combined period method (Kombinierte Fachwerk) came to be used for less 
regular stands, the straight area-period method (Flächenfachwerk) for the more regular conditions.*

Of late the calculation of yield has been more and more confined to the ensuing period (the I period), paying little or no attention to the periods following (periods II, III, IV, V, and VI).

The general stand table is combined with the general cutting plan, and takes the following form:

Column ra Block and compartment.

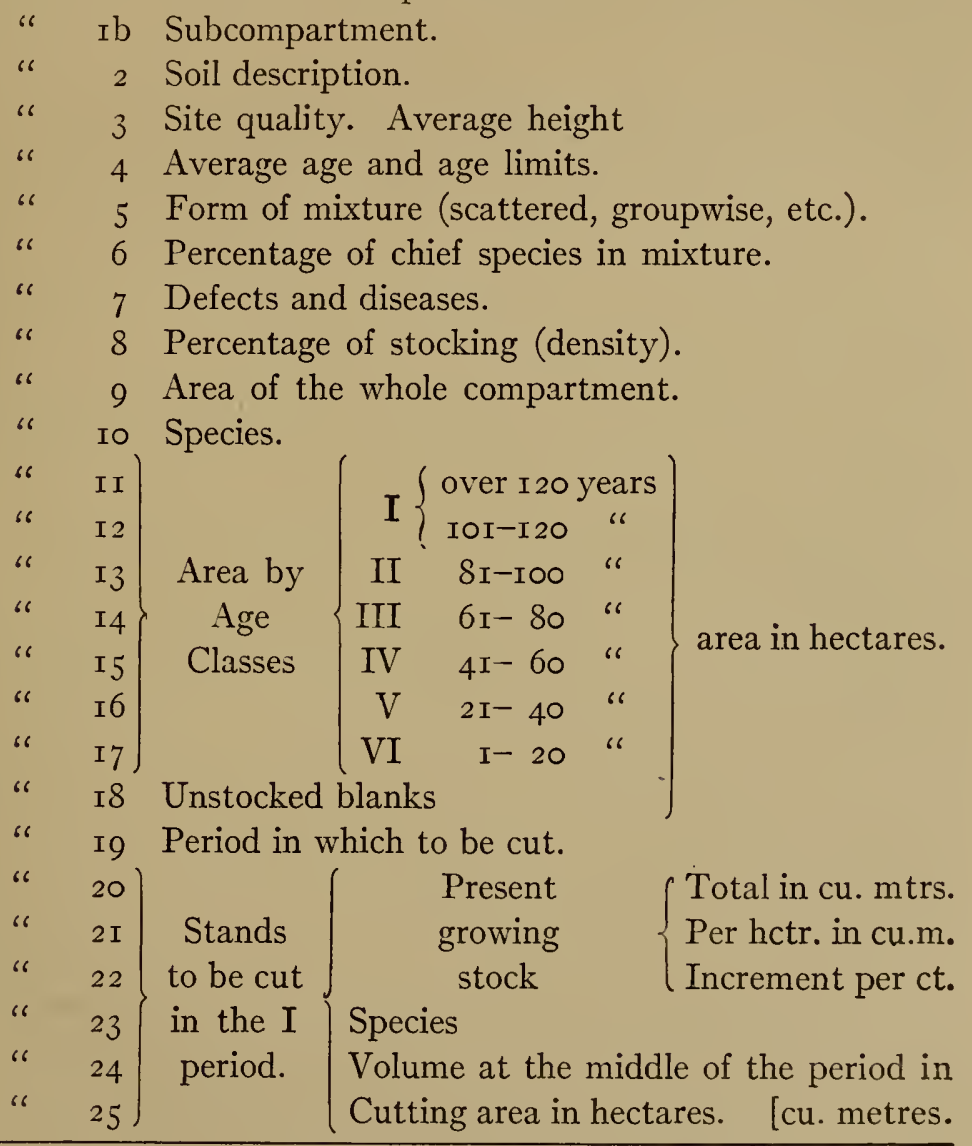

* For outline of Prussian working plan, see Part One, Chapter III, Section 2. 
Column 26 Cutting area of the II period in hectares.

" 27 Silvicultural system of cutting.

" 28 Species to be planted.

" 29 Area to be planted (of that given in columns 18 and 25).

" 30 Remarks and necessary additional details.

The block and the ranger district usually coincide. Working figures (working circles, "Betriebsklassen") are segregated whenever there are salient differences in species, rotation, or method of management.

The block is subdivided into rectangular units called "Jagen" ("hunts") in the plains, "Distrikte" ("districts") in the mountains. The boundaries are roads or topographic features (ridges, streams, etc.). The average size in pine stands is from 49.4 to $74 . \mathrm{I}$ acres; in spruce stands, from 24.7 to 49.4 acres.

Subcompartments are not segregated for minor lifferences, and never for less than 2.47 acres (I hectare).

To insure continuity of records the numbers and boundaries of blocks, compartments, etc., are not changed except for urgent reasons.

The soil and rock description is usually taken directly from the geological survey maps.

The site quality is usually gauged by means of the yield tables published by the experiment station. The average height is determined by hypsometer measurements of representative trees in the main stand.

In uneven-aged stands in which the age classes blend one into the other, the age limits and average age are indicated; where the age classes are widely divergent (e.g., very young and mature) they are entered separately. Great weight attaches to the age class and area table. The area is reduced according to per cent of stocking, i.e., stands whose density is less than .8 are reduced proportionately in area. The areas of each species, in pure stands, are entered separately; this is why column ro immediately precedes columns i I to I 7 .

The criterion of cutting the sustained yield is the normal 
area of the period. This is determined by the proportion of the period to the rotation which is usually $\frac{20}{120}=\frac{1}{6}$. An annual sustained yield is not required, but, under regular conditions, the periodic yield must be sustained even for the individual blocks; under irregular conditions more than the normal area can be cut if there is an excess growing stock, and vice versa. With species requiring a long period of regeneration (e.g., natural regeneration by shelterwood-selection method requires often forty years) the areas are allotted in detail for the I and II periods, but not the volumes.

The cutting is virtually restricted to the stands indicated for the I period. The manifest impossibility of selecting such stands twenty years in advance and then barring all the others has led to a universal demand for the "Opening of the II Period."

The choice of stands for the I period, i.e., the stands to be cut during the next twenty years, is prescribed as follows: Mature stands and defective stands are chosen first. Without undue sacrifices the object to attain is the equalization of the age-class distribution by smoothing out the age differences between subcompartments (unless they are extreme), but not by having too large adjacent areas of the same age class, because of the increased danger from fire, insects, windbreak, etc., in coniferous stands especially. Cutting series are, therefore, advised and so many points of attack that each cutting area will have become stocked with young, thrifty growth before the adjacent area is cut. This usually means a wait of twenty years.

The rotation for the chief species is determined for all Prussia, hence only departures therefrom need detailed explanation and justification.

The yield or allowed cut for the twenty-year period is the growing stock on the cutting areas of the I period plus the increment thereon during ten years (half the period). This growing stock is estimated by calipering, either all the trees, or a certain per cent thereof, if conditions are sufficiently uniform. 
The volumes are then calculated from volume tables. The volume of stands of the younger age classes is, if sufficiently regular, taken directly from yield tables, or by means of sample areas.* The increment per cent is usually taken directly from the yield tables.

The allowed annual cut is then found by dividing the volume of the entire I period by twenty.

A separate cutting plan for thinnings is drawn up. The yield in thinnings is approximated from past experience. This includes the accidental yield through drought and windfall.

The regulation of yield in selection forests is purposely simplified, since these all-aged stands are primarily intended for protection. The division into subcompartments is usually waived; the age classes are only approximated, and the calipering of every single stem is not necessary. The allowed cut for the I period is estimated for each working figure according to the ripeness for cutting. Where the selection forest is a distinct unit of sufficient size (e.g., a block) the average annual increment of the whole is determined and taken directly as the allowed annual cut in so far as there is not a marked excess or deficiency in the growing stock or the condition of the forest or other cogent reasons demand a heavier cutting or vice versa. Where the selection forest has been under regulated management for some time past, experience will dictate the approximately correct annual cut.

Control and revision of the working plan are provided for

* The field-work is done by younger members of the Service (forest assessors, etc.), sent out by the Office of Forest Organization in Berlin (where also the maps are made and the necessary clerical and computing work done), but working under the direction of the supervisor. It is preceded by a workingplan conference between the district officer, the supervisor, and the forest assessor. This body is called the Taxations Commission. This conference discusses ways and means, is digested and incorporated in the working-plan document (called the "Abschätzungswerk," a bound volume of some 125 pages, manuscript or typewritten, with ample margins for additional notes). The working plan must be submitted first to the Commission and then, through regular channels, to the Minister of Agriculture, whose letter putting the working plan into effect is incorporated in the bound volume. 
by means of the control book, the chief note-book (Hauptmerkbuch), and the area register.

The control book serves the double purpose of checking the estimate and the allowed annual cut. For the allowed cut must be adjusted according as the estimates are shown to be just right, or too high, or too low. If too high, there will be a deficit at the end of the period; if too low, there will be a surplus. The allowed annual cut is not strictly maintained; silvicultural or market conditions may necessitate a higher or lower cut.* Of course this must be offset by reducing or increasing the cut in the years following.

Each cutting is entered in the control book, Part A, where for each Jagen, or District (compartment), there is a page whereon to show the time and kind of cutting, the species, and the amount obtained by classes of material.

When the cutting of a stand is finished the result is compared with the estimate and the difference entered in control book, Part AI, which is arranged as follows:

Column I. Block.

" 2. Compartment.

"3. Subcompartment.

"4. Year in which cutting is completed.

"5. Estimate in cubic metres by species.

"6. Actual cut in cubic metres by species-from control book, Part A.

"7. Plus difference in cubic metres between columns 5 and 6.

" 8. Minus difference in cubic metres between columns 5 and 6.

At the end of each yeart a balance is struck, and the result of this comparison between the estimate and the actual cut is

* An Oberförster (supervisor) may not exceed the allowed annual cut by more than five per cent without the consent of the district office; over ten per cent requires the consent of the central office in Berlin.

$\uparrow$ Formerly every three years. 
applied to the allowed cut as entered in control book, Part $\mathrm{C}$, which is arranged as follows:

\begin{tabular}{l|l|l|l|l|l}
\hline \hline Year & & & \multicolumn{3}{|c|}{ Cut by Species, in Cubic Metres } \\
\hline $\begin{array}{c}\text { Allowed } \\
\text { Actual } \\
\text { Balance } \\
\end{array}$ & & & & & \\
\hline
\end{tabular}

This balance, be it a plus or a minus sum, is carried forward and used as the basis of the cutting plan for the year following, taking into account the plus or minus divergence of the estimate. At the same time Part $\mathrm{C}$ serves as a current record of the annual cuts. It is customary to add brief marginal explanations of the cuts larger or smaller in amount than the calculated yield.

The chief note-book (Hauptmerkbuch) is a running history of the forest showing the occurrences, management, measures taken, observations made, etc., to form the basis for a new organization of the forest $\dagger$ and as a guide to new administrative officers just taking charge of the forest. It is divided in two parts - the first, a general part, divided into various headings for the recording of events connected with the history of the forest, observations, and also recommendations, under the following headings:

* Part B has long since been abandoned.

$\dagger$ This is sometimes supplemented by a "Taxatorische Notizbuch," i.e., a note-book containing data especially concerning the field-work and operation of the working plans. 
I. Surveying and estimating.

2. Methods and results of cuttings and plantings.

3. Forest protection.

4. Status and servitudes.

5. Miscellaneous: markets, utilization, by-products, the chase, money returns, personnel, etc.

The second part of the chief note-book is specific, and contains a page for each compartment whereon to record the events and changes affecting it. It is in tabular form, as follows:

Column I Compartment.

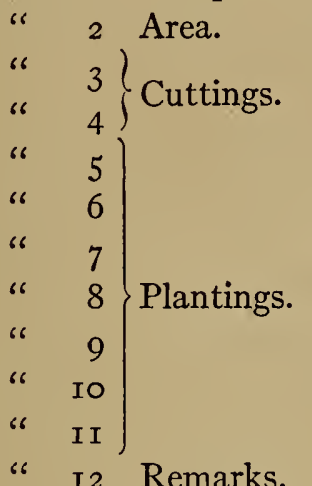

As a supplement to this, all changes in boundaries, soil utilization, in the character of the stands through cutting or planting, new constructions such as roads, etc., are entered on a map of the forest.

The register of area consists of four parts:

(A) The index to all extant maps, estimates, and working plans for the forest.

(B) A record of all changes in area.

(C) A record of all changes in ownership, servitudes, etc.

(D) A record of the changes in the area devoted to the growth of timber.

Since the year $185^{2}$ there have been detailed instructions for the revision of working plans. Until recently this included not only the regulation of the yield, but also the actual admin- 
istration of the forest. With the advent of frequent statistical reports and inspection trips, this last fell into abeyance.

The work of revision is similar to that of a new working plan; the degree of revision necessary depends on the changes which have occurred. Preparatory to the revision, each portion of the forest is carefully gone over to determine its present condition as compared with the condition at the time the estimate was made, in order to form an adequate basis for judging the effectiveness of the measures of the working plan, their further usefulness, and extent to which they require revision. The results of this examination are presented in brief-oftentimes tabularform, especially as concerns cuttings, plantings, financial results, changes in area, servitudes, and the like.

Simple revisions are made by the Oberförster (supervisor) himself, more complicated ones by men especially detailed, as in the case of the original estimates. All revisions are based on a conference between the officials concerned, following the precedent of the working-plan conference; this conference decides upon the further usefulness of the working plan as it stands, just what revisions are to be undertaken, and along what lines.

The following are given as the chief considerations in the revision of a working plan:

(I) The correction of the surveys and estimates. The area register and the second part of the chief note-book together with the forest maps posted to date are aids in this.

(2) Review of the accomplished cutting and regeneration. The bases of this are the control-book and the chief note-book. As an index to the results of management, the cut is totalled for the period; in addition there is compiled from Part A I of the control-book a comparison of the estimated cut with the actual cut; the areas planted or sown during the period are also summarized.

(3) Review of the silvicultural method of treatment, the rotation, division of area, etc.

(4) Review of the regulation of the yield both in determina- 
tion and distribution. This may involve a partial or even complete revision of the estimates.

(5) The drawing up of new general cutting and planting plans according to the revised regulation.

(6) The correction or even redrafting of the forest map.

\section{BAVARIA}

Bavaria is the second largest of the German States. Of its I8,739,890 acres, $32 \cdot 5^{I}$ per cent $(6,072,386$ acres) are in forest.

Bavaria presents widely varying topographic and forest. conditions, from the rugged spruce and fir-clad northern ranges of the Alps along the southern boundary, through the varied spruce, fir, and Scotch pine stands mixed more or less with hardwoods, of the central and northern portions, to the extensive stands of pure spruce on the east-the famous "Bohemian woods," low ranges not exceeding 5,000 feet elevation, which form the boundary with Austria - and the magnificent oaks of the Spessart in the north-west corner.

The market for timber in Bavaria is very variable. In the more remote localities, such as the Alps on the south or the "Bohemian woods" on the east, utilization is still, necessarily, incomplete. In the northern and central portions of the kingdom intensive agriculture has brought with it the profitable possibility of complete utilization.

Systematic forest organization in Bavaria dates from 1830 , when the combined period method (see Part One, Chapter II, Section I, Method No. I7) was adopted by a governmental order.* The period was taken as 24 years instead of the customary 20 years. The yield was regulated for three periods72 years-in advance.

The end of the nineteenth and beginning of the twentieth century witnessed a revolution in the forest policy of Bavaria, away from the often excessive conservatism of the early days, towards a more liberal interpretation of the State's economic

* "Instruktion für Forstwirtschaftseinrichtung," June 30, I 830. 
duty, especially in regard to the increasing tendency to manage the State forests for profit as well as for a future timber supply.

This change in general policy has manifested itself in the new instructions for forest adjustment.* These are the most recent of the working-plan instructions for any of the major States, and because of their absolute modernity deserve somewhat detailed mention.

The objects of forest organization are given as:

(I) To give a clear conception of existing conditions in the forest.

(2) To deduce from these conditions and the purposes which the forest is to serve the object and methods of management and the determination of the yield.

(3) To regulate the yield in detail for the ensuing working period.

(4) To control the execution of the plan and to secure statistical data thereon.

The working-plan unit (working figure) usually coincides with the administrative unit (forest), but this is not essential; if conditions on two or more adjacent forests are sufficiently similar one working plan may suffice.

The working-plan unit (working figure, "Betriebsverband") is divided into districts, and these into compartments. This division is primarily for the purpose of orderly arrangement and easier orientation.

The basis of division into districts (blocks) is usually topographic; sometimes, however, matters of status and of servitudes cause the segregation of a district.

The basis of division into compartments is chiefly silvicultural, i.e., differences in elevation, exposure, opening of logging means, formation of a forest mantle against windfall, etc. The actual boundaries are usually topographic--ravines, ridges, etc.with artificial boundaries-roads, trails, cut-out lanes, etc.-as

* "Anweisung für die Forsteinrichtung in den Königlich Bayrischen Staatswaldungen," Munich, I9I0, Verlagsbuchhandlung Oskar Beck. 
needed. For mere division of area a width of 3 metres $(9.84 \text { feet })^{*}$ suffices; where protection from fire or wind also comes into play (formation of windmantles), the width must be increased accordingly.

The determination of existing conditions (the first task of forest organization) begins with the division of each compartment into forest and non-forest soil; the latter includes not only those areas unsuited for forest, but also those suited for forest but used otherwise. Where accurate measurements are impossible, as in the Alpine zone, estimates of the relative area suffice.

Of the forest areas, those are to be distinguished whose yield is naturally very slight (Alpine type) or, for reasons of protection, cost of logging, etc., do not permit of complete, regular utilization.

The compartment is divided into subcompartments. The basis of this division is the individual stand. On the stand as the ultimate unit is built up the entire management.

The stand, or subcompartment, must be a unit as regards site, soil quality, species, age, and character (growth, density, health, etc.). A stand must differ in at least one of these features in order to be made into a subcompartment. However, all minor differences are to be disregarded. The minimum size of a subcompartment is usually I hectare (2.47 acres).

In coppice and in selection forest the segregation of stands (subcompartments) is often impossible, and the compartments must suffice.

Wherever possible the subcompartment boundaries are to be topographic features or roads, trails, etc. Where these do not suffice, lines are cleared to a width of $\mathrm{I}-2$ metres $(3.28$ to 6.56 feet) and rings of white paint put on the border trees.

In uneven-aged stands the average age as well as the age limits is to be given. Throughout the greatest attention is given

* In Saxony the main compartment lines running north and south (W'irtschaftsstreifen) average 9 metres (29.52 feet); the secondary compartment lines running east and west (Schneisen) average $4 \% 2$ metres (I $4.76 \mathrm{feet}$ ). 
to the presentation of the age classes in their relation to area by I, species, singly and in mixture; 2, site qualities; and 3 , density of stocking. These are shown graphically by means of diagrams. The reason of this attention to the age-class relation is that in even-aged high forest it is made, in conjunction with data on the thriftiness of stands and their suitability to the chosen site, the basis of regulating the yield and of judging the progress towards a normal forest. In coppice with preponderating standards ("Oberholzreichen Mittelwald") and in selection forest a presentation of the age classes is seldom practicable; the most that could be done would be a summary of the area occupied by each age class within. the same (uneven-aged) stand, and this gives no adequate basis for judgment.

Detailed estimates are confined usually to those stands intended for cutting during the ensuing working period of ten years. Ocular estimates suffice if conditions are regular and there are available data on cuttings of, or yield tables for, similar stands. In all other cases caliper measurements either of sample plots or of every tree, as the irregularity of the stand may necessitate, are required.

The increment is to be determined for the next twenty years, because it is a fundamental principle that, at the end of twenty years at the latest, the working plan is to be completely revised, growing stock, increment, and yield redetermined. However, only half the increment for the twenty years is to be added to the present volume of the stands to be cut, since at the end of the first decade half of the stands so designated will have been cut and be without further increment (see diagram, Part One, Chapter II, Section I).

The increment is taken either from suitable normal yie,d tables or as the current annual. The former is simple; the latter, in irregular and overmature stands, more reliable. The mean annual increment can be used if, by investigation, it has been determined what relation with increasing age and on different site qualities the current annual increment bears to the mean annual. 
A peculiarity of Bavarian forest organization is the "Character Index" ("Charakterzahl") of the stand; $\frac{N}{d}$ or the number of stems per hectare divided by the average diameter. This index figure is determined separately for each stand.

In the description of existing conditions, special attention is paid to the methods of getting out the timber and suggestions for the development of roads, and other logging methods. Forests only partially accessible demand a plan of logging which includes portions now inaccessible as well as those already opened to management. This plan is usually indicated on a contour map.

The real and the normal growing stock are determined (the latter from yield tables), since they show whether there is an excess or a deficit. The relation of normal increment to normal growing stock gives the normal yield by which the actual yield can be judged (see Hundeshagen's formula, Part One, Chapter II, Section I, Method No. 7).

On the basis of conditions as they exist, the general rules of management are then formulated according to the objects which the forest is to serve. A decision must therefore be reached as to species, form of stands desired, silvicultural systems, working figures ("Betriebsklassen"), and the rotation to be adopted. Finally the cutting area for the next working period must be fixed.

A working figure ("Betriebsklasse") is that portion of one or more administrative units ("Betriebsverbande," forests) varying sufficiently from conditions on the rest of the area to warrant a separate age-class table and calculation of the yield. These variations can be in silvicultural system; in different age of maturity in the species (i.e., different rotations); in marked difference of increment, especially in widely varying elevations; and in important servitudes which influence the course of management.

It is to be remembered, however, that too many working figures make the plan unwieldy and difficult of execution, hence 
only considerable differences are to be taken into account in forming working figures.

The instructions for determining the rotation age are a declaration of principles for the new Bavarian forest policy. The rotation age is to be governed by the objects of management: "Without violating the sustained yield and with due regard to rights of user, to secure the highest possible production of those classes of timber best suited to the needs of the community and of the country as a whole. In addition, the administration is bound to manage the State property entrusted to it in an economic manner, and from the management to secure the highest possible money revenue.

"According, therefore, as a forest is not exclusively or preponderatingly intended to satisfy servitudes or to be a protection or a recreation forest, the management must aim at the largest possible production of most demanded timber and at the economic securing of a maximum money revenue."

The rotation age must be determined from this standpoint. This determination is not to be confined to the older stands, but must extend to the younger classes whose origin and growth are often different from that of the older timbers; ${ }^{*}$ for in fixing the rotation age, the period of years required for these younger stands to reach maturity is the most important.

The possible rotation period is bounded on the lower side by the merchantability of the sizes secured, on the upper side by the age at which the forest rent ceases to increase. The time of maximum forest rent is therefore the extreme rotation age. As a rule the rotation is to be fixed at that age which produces the maximum amount of timber of medium size, provided the site quality permits. On poorer sites the growth is slower, and

* This difference is well illustrated by the Western yellow pine. Measurements made by the author near Flagstaff, Arizona, in 1907, show that the mature yellow pine, when in the "blackjack" form, grew much slower than the present "blackjack" of the same size; e.g., at roo years of age the present "yellow pine" were $\mathbf{1} 3.2$ inches diameter breast high; the present "blackjack" I7.95 inches diameter breast high. See Forest Service Bulletin. Ior, "Western Yellow Pine in Arizona and New Mexico," tables 9 and ro. 
there the management must be satisfied with the production of smaller sized timber if the rotation is not to be unduly prolonged.

Some sacrifices, however, of mere income to the production of larger timbers is proper, since it is the duty of the state to provide for these. But where this can be secured only at the sacrifice of a satisfactory income per cent the prolongation of the rotation is unwarranted.

Besides the mathematical calculations of timber and money yield certain other factors come into play, e.g., the influence of the rotation age on the condition of the soil and on the capacity of the stand for natural regeneration, the increased danger of windfall, the decreased vigor with increasing years, the possibility of intensive thinnings, and other partly economic, partly silvicultural, partly administrative considerations.

Where there are several species with considerable variance in their rotation age, but working figures are not segregated, the rotation age is taken as the geometric mean of the respective areas and rotations.

In selection forest a rotation age is difficult of determination because of the widely varying conditions of growth. Diameter is a better guide, i.e., the diameter of greatest productivity determined by measurements of sample trees. Trees which have reached the diameter so determined are merchantable.

For every working figure the area must be determined which is to be cut over in the ensuing twenty-year working period. The fundamental consideration is to gauge the cutting areas so that overmature stands and cutting of immature stands are both avoided, but at the same time so that undue vacillations of area cut over do not occur with their bad effect on local market for and needs of timber, employment for men in the woods, and also delayed normality in the distribution of the age classes.

If the cutting areas are gauged properly and if, in addition, by means of prompt regeneration, care of soil and growth, the increment in volume and in value is furthered, then the demands of a sustained yield are fully met. 
In the normal forest the periodic cutting area is constantly equal to $\frac{\text { Total area }}{\text { Rotation }} \times 20$. Where the age-class distribution is abnormal this figure can serve only as a means of comparison. In such a case the periodic cutting area is the sum of the stands requiring cutting for silvicultural reasons ("hiebsbedürftig"), stands now mature ("hiebsreif") or becoming mature in the next twenty years.

Where the distribution of the age classes shows a marked departure from the normal, the progress of the cuttings must be gauged for several decades in advance, so as to foretell the progress which the cutting of the present working period will make towards a normal distribution of the age classes. This is to be done schematically according to the following form:

Premise. - Rotation $=100$ years. Area $=982.2$ acres.

Normal periodic cutting area $=\frac{982.2}{100} \times 20=196.4$ acres; for silvicultural reasons (overmaturity and poor growth) this has to be increased to 258 acres. This overcutting is then equalized in ensuing periods. (See table next page.)

The distribution of cutting areas for the ensuing working period is not confined to assigning half the periodic area to the ten years elapsing before the intermediate revision. The administrative officer in charge of the forest requires leeway in the choice of where to cut; for he must vary his points of attack, use to the full each seed year, secure a mixture of species by advance regeneration of certain ones (e.g., of fir in spruce-fir type; of beech in pine-beech type), take thought of the fluctuations in the demand for timber, aim to secure each year an approximately equal revenue, etc. This is possible only if the field of operations is larger than the mere ten-year cutting area. This is secured by allowing the administrative officer in charge of the forest to pick from the periodic (twenty-year) cutting area those areas for the cutting in the ensuing decade which he deems most expedient for reasons of silviculture, cutting sequence (cutting series), administration, and maturity. 
THE THEORY AND PRACTICE OF WORKING PLANS

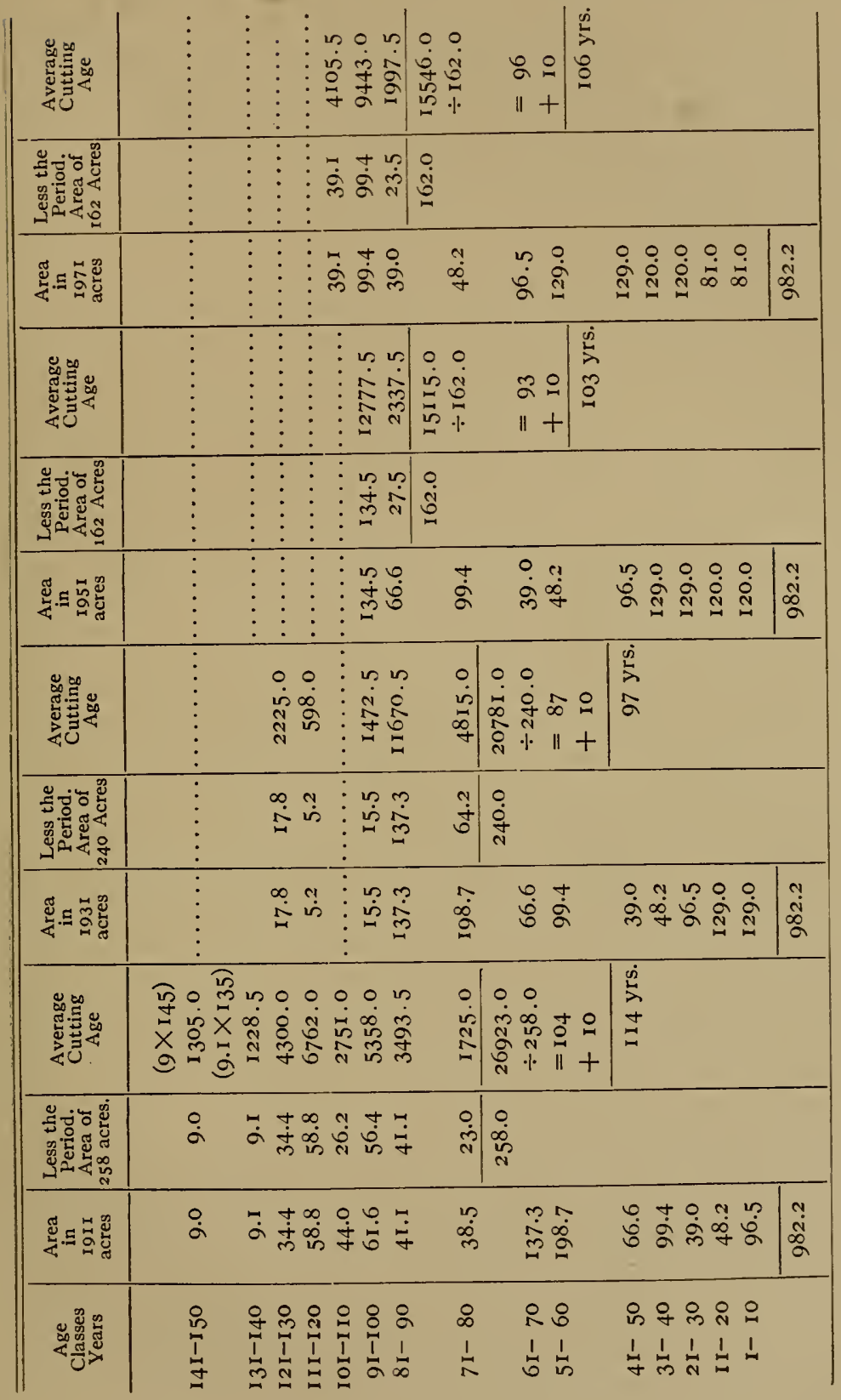


If the sum of the stands so chosen greatly exceeds the allowed ten-year cutting area, those stands are to be excluded and saved for a future decade whose growth is the most thrifty and valuable.

By dividing the entire periodic cutting area into the merchantable volume thereon, the cut per hectare is obtained. This multiplied by the annual cutting area gives the allowed annual cut in volume.

In coppice with preponderating standards and in selection forest regulation by area is not desirable, since it does not do justice to the complicated and varying needs of the tree in such uneven-aged stands.* In such stands the cut for the ensuing working period consists of all trees above a fixed diameter (determined as stated above), in addition the volume of those trees which during the next ten years will reach this diameter and such as have to be removed for silvicultural reasons ("wolftrees," "snobs," etc.). In the case of coppice with standards there is, also, of course, the volume of the coppice. A tenth of the total amount for the next decade is the annual yield; this is checked by the current increment per cent-the sum of the increment per cents of each diameter class, and by the result of past cuttings. Order and progress of the cuttings are insured by the observance of a cutting cycle.

The provisions for renewal of the working plan are as follows: Each plan is drawn up for a period of twenty years, but at the end of the first decade an intermediate revision-or review-is had; at the end of the twenty years a complete revision is had resulting in a new plan. Exceptional circumstances may necessitate a complete revision before that time, as when unforeseen changes have occurred in the very foundations of the plan. Often, however, it suffices in such cases to make provisional changes for the remainder of the working period. Natural calamities-wind, fire, etc--always require some time, as things are, before the measure of the catastrophe can be properly judged.

* Where the undergrowth is too dense to permit calipering, it may be necessary to regulate the yield, even of coppice with standards, by area. 
The intermediate revisions are to cover the following points:

$a$. Necessary corrections of the methods of determining the yield (checking of estimates, etc.).

$b$. Determination of the cutting areas for the past decade, comparison with the allowed area, and determination of the area for the ensuing decade which again is really that for a period of twenty years.

c. Emendation of the plan of management.

$d$. Determination of the volume yield of the next working period (based on $a, b$, and $c$ ).

$e$. The making of a new map of the forest.

In the main revisions the task is a similar one, but more exhaustive. The results of the management during the past period-2o years-are to be compiled and the whole structure of the working plan renewed as may be necessary.

Bavaria, in common with many of the German States, has a separate section of working plans in the central office at Munich. This section is charged with the field-work and the office preparation of the plans. The supervisor of the forest concerned is consulted in every feature of the plan; he and his subordinates are charged to assist in the preparation thereof.

The bases of the plan as well as the completed plan require the approval of the royal ministry of finance, forest section.

The procedure in working plans is as follows:

During the working period the supervisor is supposed to keep careful record of such results of management as aid in judging of the volume and value yield. The underlying field data can often be supplemented by him during slack periods of the year.

In the last year of the twenty-year working period the supervisor has to report about the execution of the working plan, the experiences gained thereby, and about the essential results of the management, the changes in the condition of the forest, to express himself about the fundamentals of the working plan and to base suggested changes on detailed data.

The district inspection officer has to express himself as to 
this report and these recommendations of the supervisor. The working-plans officer assigned for the task has then, in company with the district officer and the officers of the forest, to go over the forest in detail. On the basis of this trip over the forest, and after due consideration of the proposals made by the district officer and the supervisor, ${ }^{*}$ the working-plans officer draws up the fundamentals of the new working plan, and the scheme of field-work. Often, of course, some of these fundamentals must await, at least in part, certain investigations in the field; for such points a supplement is to be prepared.

The fundamentals as agreed upon at the working-plan conference and any supplement thereto, must be approved by the State ministry of finance.

In the last year of each decade, also, the supervisor must anticipate the intermediate revision or review by a report on the correctness and applicability of the methods of yield determination and of the rules of management.

A working-plan conference and consequent drawing up of the fundamentals of the proposed plan are not necessary in the intermediate revisions.

The field-work is done by assistants of the working-plans officer in so far as the forest force cannot be used therefor. The party may be divided into sections, each under the direction of a section chief versed in working-plans procedure. These section chiefs and their workmen are instructed (if necessary in writing) by the working-plans officer acting in conjunction with the administrative officers of the forest.

The supervisor has to keep in touch with the progress of the work and the manner of execution. The section chief, on demand, must report thereon to the supervisor.

The working up of the field data and the preparation of the working-plan document is the task of the section of working plans in the central office at Munich. As soon as the essentials of the plan are ready in rough draft, they are to be submitted

* If their advice is refused the reason for such refusal must be stated by the working-plans officer. 
to the supervisor of the forest for his review and written recommendations and memoranda. These last are to be incorporated in the working-plan document. Then the draft of the plan is submitted to the officers of the district and central offices, who must also record any divergent opinions in writing.

Finally, all new working plans or main revisions have to be laid before the ministry of finance for its approval, which puts the plan in force. In intermediate revisions it suffices to notify the ministry of departures necessitated from the original plan, before submitting the revised plan to the supervisor for execution.

A map of the forest forms an indispensable jart of every working plan.

No special document is necessary for the intermediate revisions; the existing plan is merely amended in the text, if necessary by the insertion of extra pages.

A part of every revision is a résumé of the management during the working period just concluded.

\section{SAXONY}

Although small in size- 3,703,27 I acres-Saxony is, because of its dense population and great industrial development, the state of third importance in Germany. Despite its dense population, $949,8 \mathrm{I}_{3}$ acres, or 25.65 per cent of the total area, is forested.

Saxony is a compact unit, roughly triangular in shape, the low mountains of the Erz Gebirge forming the base and the city of Leipzig the apex. The stands in Saxony are, overwhelmingly, pure spruce with Scotch pine stands in the northern, plains portion.

The Saxon markets are pluperfect, which explains the success of the Saxon spruce management with such a low rotation and resulting small diameter.*

Forest organization in Saxony is under the control of a cen-

* See "Management of Spruce in Saxony," Article V in the series. "American Aspects of European Forestry" in "Forestry Quarterly," Volume XI. 
tral bureau of forest organization (Forsteinrichtungsanstalt) in Dresden. This has worked well, since it has secured uniformity of methods and results and an experienced, well-drilled personnel. It also established for forest organization a definite and correct interrelation with the other branches of forestryadministration, experimentation, etc.

As in most of the German states, the regulation of yield was first by the period method. I Heinrich Cotta, who systematized the working plans for the Saxon state forests in the years I8II to I83I, endorsed both the area period and the combined period methods. Frequent, regular revisions soon obviated the necessity of determining the yield several periods of twenty years each in advance. The period method was therefore abandoned and the determination of yield confined to the next decade by means of the stand method ("Bestandswirtschaft") (Method No. I6, Part One, Chapter II, Section I).*

The division of area is as far as possible rectilinear, the boundaries being used as roads. Because of the imminent danger of windfall in spruce, the lines are run parallel with and at right angles to the prevailing wind direction.

Stands (subcompartments) are segregated down to a minimum area of half an acre. The prevalent uniformity of conditions permits of tabulated forest descriptions. Site quality is gauged both according to the intrinsic quality of the soil (Standortsbonität) and according to the quality of the stand growing thereon (Bestandsbonität). The two by no means always coincide; for the stand growing on a certain site is not necessarily the one best suited to it.

The age classes are in twenty-year gradations-each age class is again divided in half so that the age-class distribution is recorded by decades.

Owing to the great regularity of the stands, calipering is not ordinarily necessary. Stands less than half of the usual rotation of eighty years are estimated from yield tables; stands

* For outline of Saxon working plan, see Part One, Chapter III, Section 2. 


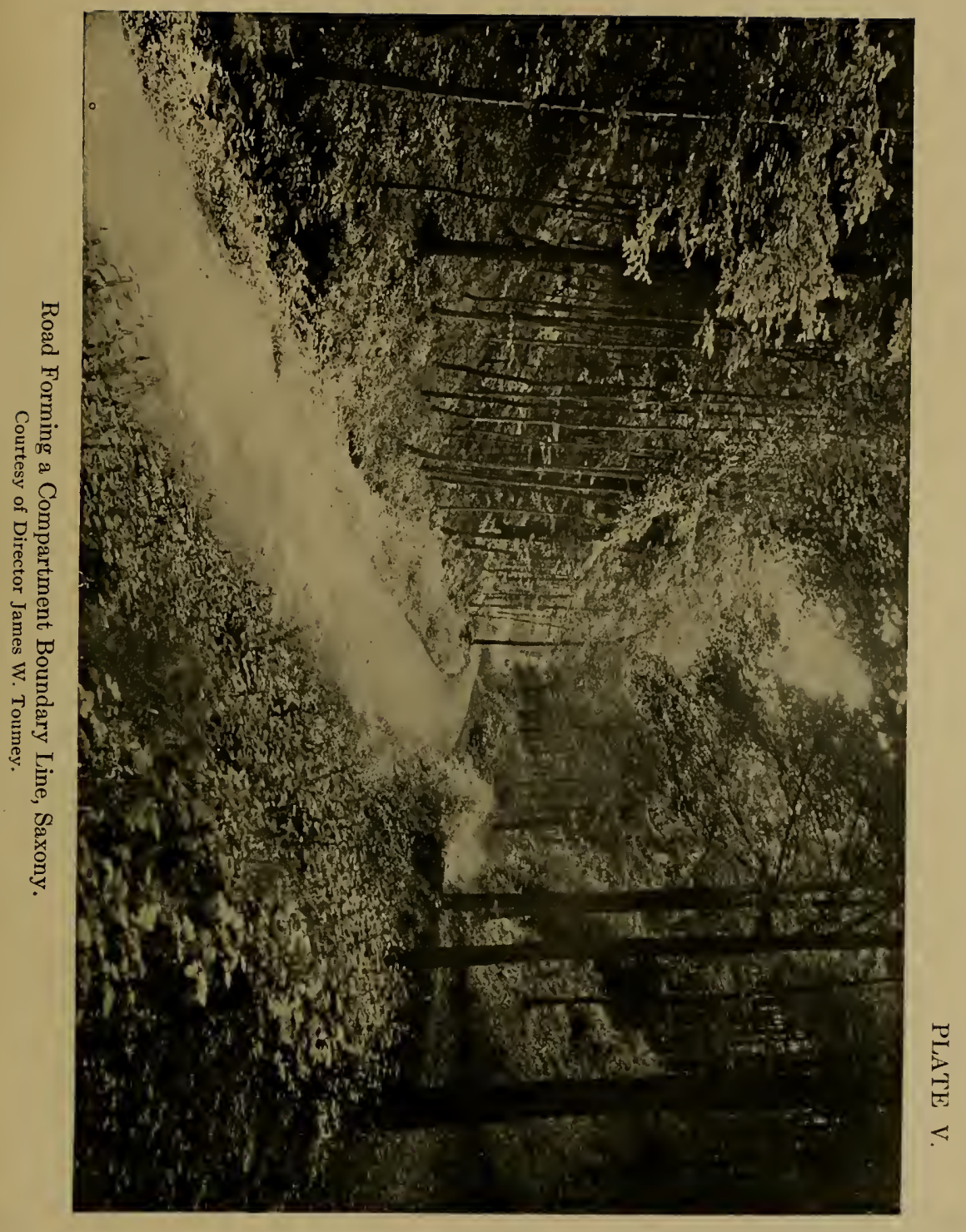



over forty years old are estimated ocularly and reëstimated at each ten-year revision.

Where clear cutting preponderates, the normal annual cut is taken roughly as the total area divided by the rotation. The proper rotation age is determined by applying the index per cent (Weiserprozent) to the individual stand, i.e., determining the maximum value increment (see Part One, Chapter I, Section 3). Tables of value increment have been prepared for the whole kingdom of Saxony, based on the prices secured in the open market for the various classes of timber.

Saxon forestry foots on the soil-rent basis. In order to show the profits of management on this basis, the net income for the whole forest is compared with the total cost of production. This is done for purposes of forest organization, by determining the timber and soil capital which the forest represents and then showing in tabular form the rate of interest returned thereon for each year by the forest management (Reinertragsübersicht).

The normal annual cutting area is maintained as nearly as may be. Under irregular conditions, departures therefrom are necessary. The table of age-class distribution serves as an index to the degree of departure necessary. If the higher age classes are in excess, the annual cutting area is increased; conversely, it is diminished. Hence, a careful exposition of the age-class distribution is of vital importance.

The Saxon system, of maximum money returns on the investment, demands that those stands whose index per cent is lowest be cut first. The next most important consideration is the cutting series; for the preponderance of spruce, the danger from windfall demands that the cutting areas progress towards the prevailing wind direction. Since the cutting strips are narrow and an interval elapses before the adjacent strip is cut, it follows, as a general rule, that the cutting series are short. However, in order to accomplish this and to avoid the joining together of large areas of practically equal age, it is necessary to have many points of attack. To secure these, the edge of a 
stand exposed by the removal of the sheltering stand to windward, must betimes be accustomed to the exposure by the formation of deep crowns-the so-called forest mantle or wind mantle (see Part One, Chapter II, Section 2).

The most important task of the forest organization, as regards arrangement of area, is the selection of these points of attack for the cutting series. The further development of the cutting series can, however, be only sketched, since it depends on circumstances which the organizer at the time of drawing up the plan cannot know.

The volume of the cut for the working period of ten years is found by ocular determination of the stand on the area to be cut over. The yield to be expected from thinnings is gauged according to the results of the decade past, aided by yield tables, and, of course, with special regard to the needs of the stands.

Stress is laid on the continuity of statistical records $r e$ ageclass distribution, volume of growing stock, yearly cuts in amount and classes of material, the gross income, the expenses, the net income (Reinertrag), the forest capital, etc. These records have been kept in Saxony since 1817 and are invaluable aids for purposes of forest organization.

In addition to the revisions at the end of the ten-year working period, there are, in Saxony, intermediate revisions in the middle of the working period. The most important features of revision are the entry of cuttings and plantings on the map of the forest; the comparison of the actual cut with the estimate; the necessitated departures from the prescriptions of the working plan, etc.

For purposes of forest organization the usual stand map (scale of I : 20,000 or I : I 5,000 ) showing species, age, classes, and cutting series is used as a base whereon to show the intended cutting areas of the next decade, special planting areas, the cutting series, etc. 


\section{WÜRTTEMBERG}

Württemberg and Baden between them contain the Black Forest, that long line of lesser ranges flanking the Rhine on the east. Württemberg has an area of $4,819,95^{8}$ acres, of which 30.77 per cent or $\mathrm{I}, 483,025$ acres are forested.

Württemberg is traversed by various lesser ranges which give to the whole kingdom a rolling topography. The species corresponding thereto are preponderatingly spruce and fir.

The splendid development of the timber market in Württemberg and of the road system necessary to get the timber on the market puts Württemberg on a par with Saxony as regards financially. profitable management.

Württemberg's systematic forest organization dates from the year 1878 . The experience gained during the years following led to a sweeping revision in 1898 . The period method was dropped, with its impractical endowment of areas in advance for each twenty-year period of the rotation. Attention was centred on the segregation of stand units, i.e., subcompartments and the regulation of yield based thereon rather than on the area of arbitrary divisions (compartments). The condition of the individual stand was made the criterion of regulation; the yield is no longer determined in advance for the whole rotation, but usually for only the first period of 20 years, exceptionally for the second period also.

Normally, the cutting area of the I Period $=\frac{\text { Area }}{\text { Rotation }}$ $\times$ 20. Exceptions are necessitated under abnormal conditions such as an excess or deficit of merchantable timber, etc. With thrifty stands and a proper distribution of the age classes (in tenyear gradations) the sum of the merchantable stands will automatically aggregate the periodic cutting area.

In the choice of stands for regeneration, great attention is paid to the formation of proper cutting series, just as in Saxony (see above).*

* See also Article VI of the Series "American Aspects of European Forestry," "Forestry Quarterly," Volume XI. 
The process of forest organization is summarized as follows: After rotation, silvicultural system, and species have been settled upon and the actual condition of each stand (subcompartment) accurately determined, the first period of twenty years is endowed with the proper area of subcompartments according to the principles outlined above. Then for the next decade the stands on half the period area are accurately estimated (calipered). Since there are always unlooked-for contingencies requiring cutting of areas aside from those provided for in the plan, an amount based on past experience is allowed for such emergencies.

A separate area plan is drawn up for thinnings.

Forest organization in Württemberg is in a state of transition from the period method to that by stands; it is not quite "off with the old" as yet nor "on with the new."

\section{BADEN}

The Grand Duchy of Baden is the neighbor state of Württemberg. It.has a total area of $3,725,007$ acres, of which I,402,454 acres, or 37.65 per cent, are forested, the highest percentage of any of the German states, only excepting the petty principalities c.t Waldeck and of Reuss.*

The Black Forest range traverses Baden from north to south like a backbone. The preponderating species are therefore spruce and fir (whence the name "Black Forest") except in the northeir plains and along the Rhine, where there are stands of hardwoods (mostly coppice) and of Scotch pine.

As in Württemberg, a magnificent road system makes accessible every portion of the forests; a ready market exists for almost every class of products.

In Baden, too, forest organization developed from the volume period method (Massenfachwerk). But under the prevailing forest conditions of the Grand Duchy, which is charac-

* These have 38.18 and 37.74 per cent, respectively. The average for the whole German Empire is 25.88 per cent. 
terized by splendid natural regeneration, ${ }^{*}$ especially of fir, the method did not prove feasible; for the process of natural regeneration requires a much longer time than the twenty-year period (usually from 30 to 50 years).

Since 1860 thoroughgoing revisions of the working plan are undertaken every ten years. They are based on the results of the past decade; the actual cut, as compared with the estimates; the effect thereof on the condition of the forest, etc.

The present working-plan procedure dates from 1869; its characteristic features are as follows:

Foundations.-Before the working-plan data are secured, the forest is carefully gone over by the officials who are concerned in the organization of the forest. This also involves the critical scrutiny of the existing working plan in all its parts. This examination lays stress on the division of area, the descriptions of site and of stands, the estimates of growing stock and of increment, the results of the previous management, and the basic provisions of the future proposed management.

The general forest description and other "Foundations" must set forth clearly the site conditions, the existing species, the silvicultural system, the rotation, the rules of management, etc. The special forest description gives briefly, for each compartment and subcompartment, the area, volume by species, the character and condition of the timber, and the increment.

The estimates of volume are most carefully executed by special measurements in those compartments undergoing regeneration, i.e., in the oldest stands; in the remainder the volume is usually determined roughly by means of yield tables, past experiences, and sample areas.

For the determination of the increment yield tables and past experiences are used; also increment borings on suitably chosen representative trees of the stand (see Part One, Chapter I, Section I).

Regulation of Yield.-The yield is determined according

* See "Natural Regeneration in the Black Forest," Article VI of the Series "American Aspects of European Forestry," "Forestry Quarterly," Volume XI. 
to Heyer's formula (see Method No. 9, Part One, Chapter II, Section I). The basis and gauge of the yield is the acutal increment. The regulations of 1869 prescribe this as the current increment "as it will probably be in the next decade." Recognizing the difficulty of an exact computation, and the restriction of application to the merchantable yield, it seemed expedient to substitute for the current increment the mean annual increment.

The normal growing stock is calculated by the formula $n v=n i \times \frac{r}{2}$. Similarly the actual growing stock of uncut stands is taken as the product of mean annual increment, age, and density of stocking (in decimals).

More than the increment is to be cut if the growing stock is in excess of the normal, and the cutting thereof is silviculturally and economically advisable. Less than the increment is to be cut if the growing stock is less than the normal. The more rapidly in the latter case the growing stock can be raised to normal by a saving of the increment, the better it is, provided that no substantial economic losses or silvicultural errors are caused thereby; in no case is the period of equalization to be longer than the rotation.

With due regard to these principles the annual cut is to be fixed according to the local economic and silvicultural necessities (emphatically including the wishes of the owner), not forgetting the desirability, especially in forests owned corporately or communally, of a steady annual yield: violent fluctuations in the yield react adversely on the owner's opinion of the working plan. A gradual augmenting of the yield will suit the owner far better than a sudden increase followed by a slump. Furthermore, it must be remembered that in almost every decade there are unforeseen contingencies and demands for timber which necessitate additional cuttings, in excess of the annual cut as fixed; wherefore, in case of doubt, the allowed annual cut should be set somewhat lower than is mathematically necessary. 
The allowed annual cut in coppice and coppice with standards is solely by area and not by volume.

Statistical Record has, since 1869 , been in intimate conjunction with forest organization so as to have systematic data on conditions and results, to simplify the working-plan documents and to be applied as precedents, good or bad.

The vital statistical records are: The history of the particular administrative unit (origin, composition, status, etc.); the description of the forest according to the subheads: forested area, topography, management, forest utilization, logging methods, forest protection, the chase, money returns, etc.

These data are compiled for the first time by the administrative officers of a forest, but the continuation and supplementing thereof is done by the forest organizer at revision of the working plan.

\section{Alsace-Lorraine}

These provinces conquered from the French in $1870-7 \mathrm{I}$ contain the major part of the Vosges Mountains, a long line of lesser ranges flanking the Rhine on the west. Together they have an area of $3,584,7$ I I acres, of which I,086,385 acres, or $30.3 \mathrm{I}$ per cent, are forested.

The topography is rolling, becoming mountainous in the southern portion of the Vosges. The species correspond closely to the topography: coppice hardwoods and Scotch pine in the more level portions; fir and beech and some spruce in the mountains, with oak on the foothills.

The road development and the timber markets of these provinces are rapidly approaching the same degree of perfection as already exists in the neighboring state of Baden.

When Germany gained control of these provinces in $187 \mathrm{I}$ it became necessary at once to have provisional working plans for each administrative unit. These were made by the administrative officer in charge of the forest, passed upon by the inspecting (district) officer, and finally approved by the minister. 
The essentials of these provisional plans are the division of area, plan for roads and trails, determination of the method of management and of the silvicultural system, fixation of the rotation, etc.

As soon as possible following thereupon, regular working plans were constructed, based on these provisional plans. Revised plans are also prescribed at the expiration of each twentyyear period, after substantial changes in area or growing stock, and in cases of transition as from high forest to coppice and vice versa.

The regulations of 1904 lay stress on the following features of forest organization.*

Division of Area.-The segregation of compartments is done in conjunction with the laying out of the logging and wagon roads and the trails. The area in coniferous stands is not to exceed 24.70 to 37.05 acres, in hardwood stands from 37.05 to 49.40 acres. For coppice and coppice with standards the forest is divided into annual cutting areas; for there the regulation is by area alone. In communal forests one-quarter of the area is set aside as reserve, dating from the ordinances of Colbert in 1669 , which provide that in forests owned by the church, or alienated in mortmain, or owned by communities or by parishes, one-fourth of the area is to be reserved from cutting; the balance to be divided into regular cuts ("coupes régulées").

There are no binding prescriptions for the division into subcompartments. In larger forests with various species the minimum size is to be 2.47 acres (one hectare). For segregation on the basis of age differences or differences in density of stocking, a minimum of 4.94 acres suffices. Subcompartments are segregated only if the area requires distinctive treatment. Stands in process of regeneration are to be segregated down to a minimum size of 2.47 acres.

The subcompartments are indicated on the ground by

\footnotetext{
* "Vorschriften für die Aufstellung und Revision der Forstbetriebseinrichtungswerke," Strassburg, 1904.
} 
means of stakes and ditches at the corners and are entered in the maps.

Maps: Field surveys are usually confined to interior lines, since reliable geodetic maps are available for both provinces. The forest map is usually on a scale of I : 25,000 and shows the species by different colors. The cutting areas are indicated on the map for the I and II period-i.e., for the next forty yearsby means of cross hatching, unbroken lines for the I period, broken lines and dots for the II period.

Forest Description is to be short and confined to the characteristic features such as status, boundaries, surveys, etc.; stand and site conditions; the occurrence and interrelation of the chief species; past management and results; future, intended management, especially species, silvicultural systems, rotations, formation of cutting series, regenerative methods, roads, markets, by-products, the chase, etc.

Regulation of Yield.-The criterion of yield is the normal periodic cutting area. If the same rotation applies throughout the forest this area $=$ the total area of the forest $\times 20 \div$ the rotation. Where there are several rotations, the normal periodic cutting area is determined for each species according to the ratio of the period to the rotation. The total cutting area is then secured by adding together those of each species.

Stands of the I period in which regeneration cuttings have begun are entered with reduced areas in proportion to the percentage of the stand removed. A distribution of cutting areas for the III, IV, V, and VI periods is obsolete; these stands and their areas are merely entered in the column headed "later periods." In deciding on stands for the I and II periot especial regard is paid to age and thriftiness, and, in coniferous stands, on the formation of small cutting series.

The period method, strictly speaking, is therefore no longer used in Alsace-Lorraine.

The long period of regeneration-often 30 to 50 years-requires the assignment of stands for two periods-40 years- in advance. The stands inte ided for cutting in the I and II 
period are usually calipered; those of the II period, if sufficiently uniform, may be estimated by means of sample areas; thereto must be added the increment calculated to the middle of each period.

The volume of the allowed annual cut is $\mathrm{I} / 20$ of the period volume calculated separately by species. In communal forests one-fourth of the allowed cut is to be subtracted (see above).

In selection stands the yield is determined from the actual increment and the relation of the actual to the normal growing stock according to Heyer's formula (Method No. 9, Part One, Chapter II, Section I). In order to determine the actual growing stock, all the trees above $3 \frac{1}{6}$ inches ( 8 centimetres) in diameter are calipered. The actual increment is determined by increment borings of trees of various diameter classes; the normal increment according to the formula $\frac{r i}{2}$, where $i=$ the mean annual increment. The number of years in which the excess or deficit of the growing stock is to be taken up is determined for each individual case according to the particular circumstances. The cutting cycle (period between cuts) is not to be placed too high: usually 7 to 9 years.

Planting and Road Plans are to form a part of every working plan. The planting plan embraces not only the methods of artificial planting, of nursery practice, and the source of plant material, but also the care of cutting areas and of young plantations.

Revisions of the Working Plan are to take place in the middle of the 2o-year period. The kind and degree of the revision to be undertaken follows from the demands made of the plans and the changes which, through the methods of management pursued or through outside influences, have occurred during the first half of the working period (Io years). At the end of the working period (20 years) an entirely new working plan is drawn up (see above).

The essential points to be considered in revision are: Changes 
in area, the actual annual cut as compared with the allowed annual cut as regulated, the comparison of the volume yield of stands cut over with the estimated volume thereof, the unforeseen cuttings not provided for in the plan, the yield from thinnings, the execution and cost of plantings and sowings, the changes in servitudes, the relation of by-products to the scheme of management, the completion of road and trail building, etc.

\section{SECTION TWO}

\section{FRANCE}

The total area of France is $132,49^{2}, 776$ acres, of which* I8.I 7 per cent are covered with forests: $5,187,000$ acres, or 77 per cent, hardwoods; I, 583,270 acres, or 23 per cent, conifers. Of these $6,770,270$ acres the State forests comprise only I 2 per cent; the communal forests under State management, 20.2 per cent.

The forests of France proper may be divided roughly into (I) plain and (2) mountain forests. Under (I) may be included the Parisienne zone, the Gironde, the Provençale; under (2) the Vosges, Jura, Alpes, Plateau Central, and the Pyrénées.t Corresponding to the topography the chief species are either oak, beech, birch, elm, chestnut, and pine, or, in the mountains, fir, spruce, pine, larch, and beech. La Savoie is the only region of France where the spruce dominates in the forests. In the Pyrénées and along the Mediterranean coast species are found distinctive of the region, such as hook pine, d'Alep pine, maritime pine, cork oak, live oak, etc.

The timber markets of France, while not so intensely developed as those of Germany, are still almost as omnivorous as

*From Hüffel: "Économie Forestière."

†For further details see Article: "European Study for Foresters" by A. B. Recknagel and Theodore S. Woolsey, Jr.; "Forestry Quarterly," Volume X., No. 3 . 
those of the neighbor State on the east because of the relatively smaller per cent of forest land.*

The methods of forest organization in France are in striking contrast to those in Germany. The conditions of forest ownership have strongly influenced French forest organization or "Aménagement," as it is called. Hitherto it has been generally assumed that privately owned forests are not suited to a sustained yield management. It was thought that the difficulty of foretelling future needs and the uncertainty of predicting yields were in contravention to the basic principles of forest management for private ends and that, furthermore, the growing of timber, especially of the larger sizes, is primarily the duty of the state and of the communities. These views coincided with the actual conditions of forest ownership: in the forests owned by the state high forest is the rule with a high rotation; $\dagger$ the forests owned communally are usually coppice with standards; and th 2 forests privately owned, straight coppice. But of late conditions have changed substantially: the increased prices of forest products and the decreased interest rate have made the growing of the larger sizes of timber profitable also for the private owner.

The chief features of French forest organization are the division of area, the methods of determining the yield, the distribution of the periodic cutting areas, and the determination of the allowed annual cut.

Division of Area.-The state forests and the forests under state control are divided into series. These series are adjacent forest areas with uniform market conditions and a sustained yield; they often coincide with the ranger district (triages). "By a series is understood a portion of the forest, intended to be covered by a special plan of utilization and consequently to furnish a series of annual cutting areas." $\ddagger$

The series are subdivided into sections. "By a section is

* In France I8. I 7; 25.88 per cent in Germany.

$\dagger$ I $40,160,200$, and even 240 years.

† Tassy: "Études sur l'aménagement des forêts." 
understood a portion of the forest distinct from the rest by the method of management" (coppice, regular high forest, selection high forest, etc.). Accordingly, the segregation into sections is based, preferably, on the method of management (régime) and on the silvicultural system (mode de traitement).

The series are further divided into periodic cutting areas called "affectations."

The division by silvical units, i.e., stands, is called the parcelle. These parcelles are the basis of the whole forest organization and of the course of the management. In each forest district (canton) those portions are to be segregated which differ in species or in age, or in site, exposure, growth or density of stand, in such a way that each portion or parcelle can be handled identically throughout. In the records the parcelles are classed as divisions if they are permanent, as subdivisions if only temporary. The parcelles are marked by stones at the intersections of the boundary lines; the boundaries themselves by narrow cleared lines or by signs.

The forest description of the individual parcelles is according to the following form.*

Column I. Cantons, i.e., forest district, or block.

"2. Divisions and subdivisions.

" 3 ? Volume Subdivisions.

" 4 C Contents of the $\{$ divisions.

"5. Site and elevation.

"6. Exposure.

" 7. Slope.

" 8. Soil.

"9. Percentage of each species in the mixture.

" Iо. Age.

" II. Character of the stand.

"I2. Growth.

“ I3. Remarks.

Method of Determining the Yield.-The yield is determined

* Called "État descriptif des divisions et subdivisions." 
by the area period method as appears from the following tabulated form for working plans.*

Column I. Number of the affectation.

"2. Names of the cantons.

"3. Divisions and subdivisions.

" 4 . 4.$\}$ Area in hectares of the $\left\{\begin{array}{l}\text { subdivisions. } \\ \text { divisions. }\end{array}\right.$

“6. Site, exposure, soil.

" 7. Percentage of each species.

" 8. Density and growth of the stand.

" $\left.\quad \begin{array}{r}9 \\ \text { " }\end{array}\right\}$ Age $\left\{\begin{array}{l}\text { present. } \\ \text { at the time of cutting. }\end{array}\right.$

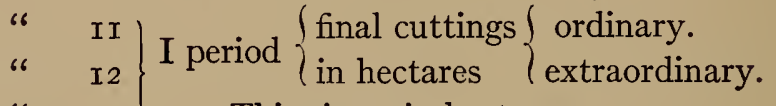

" I3 Thinnings, in hectares.

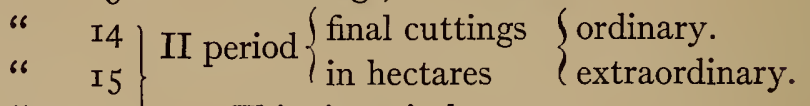

" I6 Thinnings, in hectares.

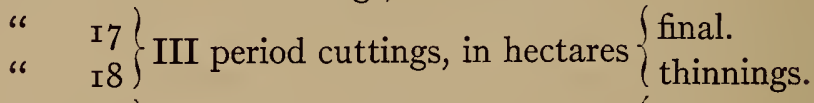

“ 19$\}$ IV period cuttings, in hectares final.

“ 20) IV period cuttings, in hectares thinnings.

“ $2 \mathrm{I}\} \mathrm{V}$ period cuttings, in hectares final.

“ 22$\}$ V period cuttings, in hectares $\left\{\begin{array}{l}\text { thinnings. } \\ \text { thal }\end{array}\right.$

" 23 "VI perinal.

“ 24$\}$

“ 25. Remarks.

The number and length of the periods vary with the species and the locality. For oak in central France eight periods of 25 years each are formed; for beech usually six periods of 20 years each; for fir four or five or more periods of 30 years each. The

* Règlement général des exploitations par période pendant la première révolution (révolution equals rotation). See also Méthode de Masson and Méthode de 1883 (French M-thod), Nos. 3 and Io, respectively, Part One, Chapter II, Section 1. 
approval of the period number and length requires the approval of the minister.*

The rotation age is only fixed tentatively "without attempting to fix it definitely by applying experiences whose value is often only specious." $\dagger$

For the state forests a rotation age is chosen which corresponds to the maximum possible yield of the most useful classes of materials. This has resulted in a conservative tendency showing itself in the present conditions of the forests of France and of Alsace-Lorraine. In general the adopted rotations are distributed as follows:

\begin{tabular}{l||c|c|c}
\hline \hline & \multicolumn{3}{|c|}{ Rotation Age } \\
\cline { 2 - 4 } & Under roo years & I00-150 years & 150-200 years \\
\hline & $35.7 \%$ of total area $43.1 \%$ of total area & $21.2 \%$ of total area \\
\hline $\begin{array}{l}\text { Reg. high forest } \\
\text { Select. high forest }\end{array}$ & $9.8 \%$ of total area & $43.7 \%$ of total area & $46.5 \%$ of total area \\
\hline
\end{tabular}

Distribution of the Periodic Cutting Areas.-This is the most characteristic feature of French forest organization. The periodic cutting areas are to be so arranged that they comprise the area of each period without a break or interrupting area of another period. This is in direct contradiction to the aim of the German forest organization, particularly of the Saxon. The reasons given for this distribution are simplicity in regeneration cuttings; of regularity of formation of the periodic cutting areas with their narrow side toward the prevailing storm direction and bounded wherever possible by roads. Tassy in his "Êtudes sur I'aménagement des forêts" lays especial stress on the undesirability of breaking up the periodic cutting areas into cutting series. $f$

This principle has been followed in the working plans for the

* Formerly of the Emperor himself by a decree.

† From a French working plan.

$\ddagger$ Tassy, troisième étude, Chapter IV, Section 3, "formation des affectations conformément aux régles d'assiette." 
state and communal forests. The periodic cutting areas are systematically grouped in the maps and on the ground. The immediate consequence is that many stands are cut not at the time of their maturity, but too soon or too late; furthermore, the reproduction cuttings become very large and thus, in the future, there will be extensive stands of even age. Both consequences are attended with drawbacks of management (increased danger of windfall, fire, insects, fungi, etc.), even though these are less in France by reason of the prevalence of the natural regeneration and the predominance of hardwoods than they would be, for example, under German conditions.

Determination of the Allowed Annual Cut is both by volumes and by values. For the cuttings of the first period a special cutting plan or felling budget is drawn up (Règlement special des exploitations pour la première période), in which the cutting areas and volumes are entered, arranged according to the divisions and subdivisions and according to final cuttings (Coupes principales) further divided into Coupes ordinaires and Coupes extra ordinaires, and thinnings (Coupes intermédiaires).

The volume of the Coupes principales is determined first by caliper measurements entered separately by species; the volumes are then computed from volume tables based on the contents of sample trees of the various diameter classes.

The increment for the years elapsing between the estimate and the cutting is disregarded in the computation.

Thinnings are regulated by area; their volume is taken from the experience of the preceding decade.

To the determination of the allowed annual cut by volume is added one by values (Évaluation en argent de la possibilité). This is based on the estimate of the classes of timber which is made for each species and for each class on the value according to the prevailing prices (prix sur pied par nature de marchandises). Adding the values of each class gives the total value of the felling budget.

The regulation of yield in coppice and in coppice with standards is by area. Coppice systems have reached a point of de- 
velopment in France far in advance of that in other European countries. The regulation of coppice dates from the ordinances of Colbert in r669. The division of area depends on the rotation age of the coppice under the standards. In the state forests $5 \circ$ per cent have a coppice rotation of 20 to 30 years; 46 per cent have a rotation of over 30 years; in the communal forests 77 per cent have a rotation of 20 to 30 years, 20 per cent a rotation of over 30 years. ${ }^{*}$ The standards are arranged by age classes and distributed equally on the area. These standards are either two, three, or four times the rotation age (baliveaux de l'âge, modernes, and anciens, respectively). The yield of standards is determined by the number of stems of each class and is usually accomplished with the utmost regularity.

\section{SECTION THREE}

\section{AUSTRIA}

Austria, exclusive of Hungary, $\uparrow$ contains 74, IOI,976 acres, of which $24, \mathrm{I} 25,888$ acres or 32.6 per cent are forested. $\ddagger$ This puts Austria fourth in the rank of timbered countries of Europe, preceded only by Sweden with 49 per cent forest area, Finland with 46 per cent, and Russia with 39 per cent. The ownership of Austrian forests, which has profoundly influenced the development of forestry there, is as follows: State forests II per cent of the total area, communal forests 44 per cent, church forests 17 per cent, private forests 59 per cent. $\$$

Austria can be conveniently divided into five great districts;

* For straight coppice 56 per cent of the state forests and 76 per cent of the communal forests have a rotation age of 20 to 30 years.

$\dagger$ The differences of race and language have resulted in all but the political separation of the two countries.

$\$$ In Hungary It is 27.8 per cent; in Germany 25.88 per cent; in France I8. I 7 per cent.

$\S$ Data from "Die Holzproduktion Oesterreichs," K. K. Ackerbauministerium, 1907 .

12 
these, with their percentage of forested area and the per cent of timber tracts over 2,500 acres in size, are as follows:

\begin{tabular}{|c|c|c|}
\hline District and included Provinces & $\begin{array}{l}\% \text { of } \\
\text { forest area }\end{array}$ & $\begin{array}{l}\text { \% of tracts } \\
2,500 \text { acres } \\
\text { and over }\end{array}$ \\
\hline $\begin{array}{l}\text { Danube (Niederösterreich, Oberösterreich)....... } \\
\text { Alps (Salzburg, Tirol, Steiermark, Kärnten, and }\end{array}$ & $34 \cdot 2$ & 44.6 \\
\hline Krain) $\ldots \ldots \ldots \ldots \ldots \ldots \ldots \ldots \ldots \ldots \ldots \ldots \ldots$ & $4 \mathrm{r} .8$ & $4 \mathrm{I} \cdot \mathrm{I}$ \\
\hline Coast (Küstenland, Dalmatia)........... & 29.6 & $37 \cdot 7$ \\
\hline Northwest (Bohemia, Mähren, Schlesien).... . & $29 . I$ & $65 \cdot 7$ \\
\hline Northeast (Galicia, Bukowina)............. & 27.7 & 69.6 \\
\hline Totals...... & 32.6 & $54 \cdot 3$ \\
\hline
\end{tabular}

of which nearly one-half are tracts of 7,500 acres in size or more; nearly one-quarter, or half, of the half are tracts of 25,000 acres or more.

This division corresponds fairly well with the general topography and the forest conditions. The Alps and the northeast districts (Carpathians) comprise tremendous mountain ranges; the Alps continue in diminished form through the coast district to the southeast and break down northward into the rolling plains and foothills of the Danube district, this foothill character is preserved through most of the northwest district adjoining thereon, grading gradually into the main ranges of the Carpathians, the divide of which forms the boundary between the Northern Districts of Austria and Hungary.

The coniferous species in Austria cover over 60 per cent of the total forest area; 2I per cent are hardwoods; the balance of I9 per cent are mixed stands. Spruce predominates with 44 per cent of the total forest area, it occurs at almost all elevations from the plains up to timber line, only in Dalmatia is it lacking. Scotch pine is next, with 7 per cent of the total forest area, chiefly occurring on the plains. The remainder of the 60 per cent of coniferous stands are mixtures of various speciesfir, Austrian and other pines, and larch.

Of the hardwood stands which cover 2 I per cent of the total forest area, beech leads the list with Io per cent, the remaining I I per cent are stands of oak with beech, or hornbeam with beech, or of aspen, alder, birch, etc. 
The I9 per cent of mixed stands are admixtures of larch, Pinus Cembra ("Zirbe"), ash, elm, maple, chestnut, etc

Austria shows within its boundaries the greatest variety of forest conditions.* All phases of vegetation are encountered from the semi-tropical shores of the Adriatic grading through the sandy and often rocky coastal plains, through the mounting foothills to the dolomitic or archaic fastnesses of the Alps and Carpathians, where all tree growth is dwarfed and even the lower stands are constantly threatened with rock slides and avalanches. The forest products vary accordingly from the finest timbers with high rotations down to mere fuel woods with the shortest of coppice rotations. Similarly, some forests are in immediate proximity to dense centres of population-as, e.g., the Wienerwald just outside the gates of Vienna-permitting almost perfect utilization because of a voracious market; some forests, on the other hand, are still virgin and as yet out of profitable reach of the lumberman's axe. Gradually, though, the increasing prices of timber are making accessible at a profit even the stands most remote from centres of population, and soon there will be no virgin forests in Austria. $\dagger$

Again, the task of forest management is, sometimes, 'as in Salzburg, burdened by servitudes; elsewhere no such restrictions exist. As a result the market varies greatly, but in general it is developing rapidly, especially in the export trade to Germany and Italy and other European or Oriental countries.

Eighty-five per cent of the Austrian timberlands are managed as high forest, of which one-third is selection forest

* See "Methods of Natural Regeneration in Austria" and "Methods of Artificial Regeneration in Austria," Articles VIII and IX, respectively, in the series: "American Aspects of European Forestry," "F. Q.," Volume XI.

$\dagger$ The Austrian government now constructs its own logging devices, sawmills, railroads, chutes, flumes, etc.; these are used by the purchaser of the stumpage for which use he pays a proportionately higher stumpage price. Formerly stumpage was sold as in America, and the purchaser put in his own improvements; as rapidly as possible these improvements were then bought up by the government and paid in cash or in timber. 
mostly in the "high" protection zone of the Alps; I2 per cent are managed as coppice; 3 per cent as coppice with standards.

Forest organization in Austria has reached a remarkable state of perfection despite the exceedingly irregular conditions as portrayed. The Austrian Kameraltaxe (Austrian formulasee Method No. 5, Part One, Chapter II, Section I) dates from I 788 ; in the Tirol a volume period method was in use in the sixteenth century. From these early beginnings a systematic forest organization has been built up and extended even to the most remote regions, ${ }^{*}$ comprising not only the State forests but also the large tracts privately owned. Practically half of the forested area of Austria is under working plans.

The salient features of Austrian working plans as contained in the government code of I90 $\dagger$ are as follows:

Division of Area begins with the setting aside of protection forest wherever necessary; it is usually divided from the lower

* For example, the remote Bukowina, lying between Russia and Roumania on the extreme eastern border of Austria, shows 73 per cent of its I, I I 3,970 acres of forest covered by detailed working plans in perfect operation. When this province was acquired by Austria in 1775 from Turkey it was largely-nearly 50 per cent of the total area-in trackless virgin forest. The first work of forest organization, that of making provisional working plans, was completed in 1818 . About 1850 the preparation of final working plans was begun on the basis of period area method; failing of systematic revisions thesa soon became mere waste paper, the more so since it was impossible, for lack of markets and of logging facilities, to carry out the cuttings as planned. In 1875 a thorough reorganization of the forest administration in the Bukowina was begun looking to the opening up of the hitherto inaccessible timber resources. A section of forest organization (Einrichtungsabteilung) was created in the Bukowina district similar to that already existing in all the other district offices of the empire. A thorough reconnaissance (Durchforschung) was made and on this basis new provisional working plans prepared, beginning, of course, with the more accessible forests. As the data and utilization warranted it, these were transformed into regular plans with frequent revisions, on the model of those prescribed for the rest of Austria, with emphasis on regulation by area rather than by volume, as befits the more extensive conditions.

$\dagger$ "Instruktion für die Begrenzung, Vermessung und Betriebseinrichtung der Oesterreichischen Staats und Fondsforste," 3d edition, I90I. 
slopes by a trail following the appropriate contour. This protection belt is always managed as strictest selection forest. The management for the rest of the area is then decided upon and the area divided according to working figures (Betriebsklassen), cutting series, compartments, and subcompartments.

An area with a uniform, silvicultural system and rotation, uniform market and constituting a single logging unit is called a Betriebsklasse; it is further divided into cutting series, whose formation depends on the topography, the species, and the method of regeneration. A single cutting series does not usually comprise more than three compartments. The boundaries of the cutting series are topographic or artificial-roads, compartment lines, etc. These boundaries are to be cleared of timber to a width of from 16 to 26 feet, in order that a wind resisting forest mantle may form along the edges of the stands. Cutting series are shown on the maps by arrows.

The compartments (Abteilungen) are units of convenience; their shape is quadrangular, 2,600 to 3,300 feet long and about two-thirds as wide. The boundary lines are topographic, cultural (roads, railroads, etc.), or else artificial. The last are either "Schneisen" and are usually made $61 / 2$ feet wide ( 2 metres), or are "Wirtschafts Streifen," with the regular width of I6 to 26 feet (5-8 metres). (See Part One, Chapter I, Section 2, "Division of Area.")

The division into subcompartments (Unterabteilungen) is based ( $\mathrm{I}$ ) on differences in required treatment of which the following are distinguished: High forest with clear cutting; high forest with shelterwood cutting; high forest with selection cutting; straight coppice; coppice with standards; forest burdened with servitudes; protection forest, voluntary or enforced by law: or (2) on differences in species if the stands are pure: or (3) on substantial differences in percentage of mixture if the stands are mixed: or (4) on differences in average age exceeding ro years in young, 20 years in old high forest, 5 years in coppice forest: or (5) on marked differences in site quality or yield quality as shown by substantial differences in the height growth 
of equal-aged stands: or (6) on marked differences in the density of stand: or (7) on need of artificial regeneration.

The minimum size of a subcompartment is $1 / 2$ acres. The boundaries are marked with stencilled numbers painted in oil paint on the corner trees or else by means of symbols made with a bark scratcher; in young stands narrow alleys are cleared.

Estimates and Forest Description.-As a general rule yield tables are constructed for the various silvicultural systems of management, species, and site classes, based on sample areas measured during the progress of the field-work. The following form is used:

Column I. Age.

"2. Number of stems per hectare.

" 3. Basal area at I.3 M. above ground, in square metres.

" 4. Average diameter at I.3 M. above ground, in centimetres.

" 5. Average height in metres.

"6. Average annual height increment in metres.

"7. Volume by timber classes, in cubic metres.

" 8. Increment-current annual, in cubic metres.

"9. Increment-mean annual, in cubic metres.

“ Io. Increment per cent-mean annual.

These yield tables are compared with the published yield tables of the International Association of Forest Experiment Stations.

The description of the individual stand covers the following phases:

(I) Soil and site.

(2) Species, percentage of mixture and general form of the stand. The percentage of mixture is expressed in tenths according to the area occupied by each species. Shelterwood cuttings are considered as preparatory if .8 of the original volume remains; as seed cuttings if .5 to .8 remains; as removal cuttings if less than .5 remains. 
(3) Both the average age and the age limits are given. The table of age-class distribution takes the following form:

Column I. Compartment number.

" 2. Subcompartment letter.

" 3. Site and stand quality.

" 4. Barrens and blanks.

“ 5. I I stands $\mathbf{I}^{-20}$ \{ partly stocked

“ 6. 6 years old fully stocked

“ 7. II stands $2 \mathrm{I}-40$ years old

" 8. III stands $4 \mathrm{I}-60$ years old

" 9. IV stands $6 \mathrm{I}-80$ years old

in hectares.

" Io. V stands $8 \mathrm{I}-\mathrm{ro0}$ years old

" II. VI stands IoI-r 20 years old

" I2. VII stands over 120 years old

" I3. Total area

"4. "Area in $\{$ of the areas under regeneration.

" I5. hectares $\{$ of the areas under selection system.

" I6. Remarks.

A separate age-class table is prepared for each working figure ("Betriebsklasse," see above).

Areas in process of regeneration are entered in full in Column 14. But, if the cutting is shelterwood the proper proportions of the areas appear also in the age class (Columns 4-I2) so as to show the existing proportion of old timber, young growth, and blanks.

Below the actual area of each age class, the normal area thereof is entered for purposes of comparison.

(4) As index to the yield the following factors are entered:

(a) The average height of the stand.

(b) The sum of the basal areas.

(c) The site quality and species occupying it.

(d) The present density in tenths of $1.0=$ fully stocked. Stands are to be considered fully stocked if the actual volume per hectare corresponds to the volume given in the yield table for the same age, site quality, species, and silvicultural system. 
(5) The volume of those stands which are to be cut in the next two decades.

(6) The mean annual increment prorated to the end of the rotation.

The data on volume and increment of the younger stands is taken from yield tables; in stands approaching maturity exact measurements in the field are required. Stands of varying density, and all under 5 acres in size are to be calipered completely. In very irregular stands (e.g., mixed species, all-aged, etc.) sample plots are measured to cover from 5 to ro per cent of the total area. The volume is calculated from the calipered diameters by measuring average trees, so chosen that in height and diameter they represent the stand in miniature.

These data are combined in a tabular forest description which takes the following form (stand table):

Column I. Locality (corresponds to "Block," Part One, Chapter I, Section 2).

"2. Compartment-number.

"3. Subcompartment-letter.

"4. Soil and slope.

" 5. Species, per cent of mixture and general form of stand.

"6. Age of stand-years.

"7. Average height of stand-metres.

" 8. Total basal area-square metres.

" 9. Site quality.

" Io. Density of stand in decimals of r.o.

" II. Area in hectares.

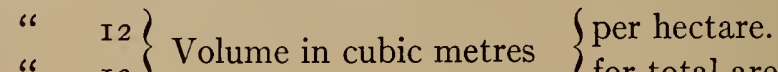

66 
This is supplemented by a general forest description for the entire area, covering all of the forest conditions-natural, legal, political, economic, commercial, financial, and administrative, including personnel.

Determination of the Yield is for a decade in advance. The allowed cut is divided into final cuttings, thinnings, and accidental cuttings. The basis of regulation is the normal periodic cutting area. If the conditions are regular this is adhered to as strictly as possible. Often there are large amounts of overmature timber, as, e.g., in the virgin forests of the Bukowina mentioned in foot-note preceding, where with a 120 -year rotation the stands over roo years old aggregated $\mathrm{rr} 6,592$ hectares instead of the normal (based on age-class relation) of $33,22 \mathrm{I}$ hectares; an excess of 83,37 hectares. ${ }^{*}$ In these overmature stands the increment merely offsets the decay and their interest yield on the investment is nil. To substitute for them young, thriftily growing stands was axiomatic but required cutting in excess of the normally allowed area. The amount of excess permissible was fixed on the following three considerations: (I) Not so great that regeneration, natural or artificial, cannot keep pace with the cutting, and so imperil the continuity of the forest; (2) not so great as to depress prices by glutting the market and thus losing all the financial advantage gained by stimulated increment; (3) not so great as to cause too serious disturbances of the sustained yield. These considerations were met by a sliding scale of area gradually approaching the normal as follows: In the I period of 20 years 1.5 the normal area can be cut (sometimes $\mathrm{r} .6$ in the first decade, $\mathrm{r} .4$ in the second decade); in the II period of 20 years I. 3 of the normal area can be cut; in the III period of 20 years I. 2 of the normal can be cut, and thenceforth approximately the normal amount only is to be cut. During the decade ending rgro the average annual cutting area in the Bukowina was 3,008 hectares, or approximately I.5 the normal of 2,03 I hectares.

* "Die Forstwirtschaft und ihre Industrien ... im Herzogthume Bukowina," by E. Guzman, Vienna, I90I. 
The rotation age is determined on the basis of highest net income (Forstreinertrag) unless there are cogent reasons, such as legal constraints, logging or market conditions, for keeping a higher rotation. Stands are therefore considered mature, i.e., of proper cutting age, whose index per cent has sunk below the adopted interest per cent on the investment an 1 whose cutting will not interfere with the proper development of the cutting series.

In addition to the stands thus mature, the cuttings of the ensuing working period are to include all very open stands and stands with unsatisfactory increment whose regeneration is obviously desirable; and also such stands as must be sacrificed to the proper progress of the cutting series.

The aim is, obviously, to approach a normal distribution of the age classes. The length of time required in this approach to normal is fixed tentatively. To aid in this and in the fixation of the decade cutting area the results of past cuttings are reviewed, especially in their effect on the development of the proper age-class distribution; this last is shown graphically for decades past.

Based on these considerations the decade cutting area is finally fixed and the volume thereon, increased by the current increment to the middle of the decade, constitutes the allowed cut for the decade.

In the selection forest of the protective belt, everything is subordinated to the protective function and hence no sustained annual cut is determined, but the allowed cut merely approximated from experience.

Control and Revision of the working plan which is documented in bound form and called an "Operat."-The following current records are kept:

(I) The memoranda book ("Gedenkbuch") wherein all changes other than those of changes resulting from the cuttings prescribed in the working plan are entered. Changes in surveys; in logging methods; substantial injuries to the forest by man, climate, fire, etc.; the progress of the hunt and of fishing; 
personnel; statistics of volume yield and money returns; forest experiments, etc. It corresponds closely to the general part of the Prussian "Hauptmerkbuch" (see Section I, above).

(2) The management book corresponds to the Prussian : control book, together with the specific part of the Prussian "Hauptmerkbuch." It is divided in two parts: The first gives for each subcompartment (figure of control-"Kontrollfigur") the yield of cuttings by classes of material and area, the completed sowings and plantings, and the early care of the stands. The second part contains the total annual cut of the whole forest (Wirtschaftsbezirk) compared with the estimate.

(3) Index of changes in status, comparison of the total, annual, actual with the allowed cut in volume and area; summary of accidental-i.e., unforeseen-cuttings, of plantings, of receipts and expenditures, of income, etc.

Regular revisions are made in the last year of the ten-year working period; revisions may be necessary between times if unforeseen contingencies occur, such as large windfall, insect damage, change of area, etc. The most important tasks of the revision are: First, the determination of whether the provisions of the working plan just terminating were observed in every detail; whether and to what extent the departures therefrom were justified; and whether the prescriptions of the working plan proved correct, singly and collectively. Second, the correction of the existing maps and estimates which may necessitate the collection of additional field data. Third, the preparation of the working plan for the next ten years.

\section{SECTION FOUR}

\section{RESUMÉ}

A review of the practice of working plans in Europe shows that forest organization developed very differently in the various countries. The differences consist in the form of the work- 
ing-plan document; in the length of the working period; in the methods of estimating, forest description, mapping; in the principles and nomenclature of the divisions of area. These differences arose primarily out of differences in the forest conditions to which the methods of forest organization were adapted; in part also because the various practices developed independently of one another. Many of the rules and regulations for working plans remained practically unknown outside of their immediate sphere of application.

Despite these differences, the various existing methods of forest organization are very similar in the essentials of working plans. For all, the most important task is recognized to be the designation of the areas which are to be regenerated. For this the character and composition of the individual stands is scrutinized. The more unfavorable the condition of the stands is in regard to growth, density, etc., the more is their early cutting indicated. At the same time, however, all the existing methods demand that the stands are not to be considered by themselves alone, but in conjunction with the whole area of which they form a part and their treatment decided upon accordingly. In general agreement are, furthermore, the methods of determining the allowed cut. At first, regulation was by volume alone, as fitted the irregular conditions encountered; as management progressed, area came to play a more and more important part in regulation. Area and volume combined are now the basis of yield regulation in all intensively managed forests. In Prussia, Austria, Saxony, and other countries, the criterion of yield is the normal periodic cutting area wherever the conditions are sufficiently regular. This area is increased or diminished according to the distribution of the age classes. The volume on the periodic cutting area constitutes the allowed periodic cut and affords, by volume regulation, a check on the sustained character of the yield.*

The consequent progress of forest organization is also very

* However, under fairly regular but rather extensive conditions it is considered sufficient to regulate the cutting by area alone. 
similar. In the formula $\frac{a}{r}$ or $a \frac{20}{r}$, which represents the annual or the periodic cutting area, respectively, $r$, the rotation, is set as a definite figure, as indeed is necessary for the execution of a working plan during a definite working period. As a matter of fact, however, the rotation age is not a fixed quantity, when considered for a longer period of time, but a varying quantity influenced by the changing conditions of management. To recognize these conditions and to set forth clearly their influence is the common task of all methods of forest organization, a task more important than the form of the working-plan document and the method of determining the yield. The rotation age, i.e., the age of physical, silvicultural, financial, or other maturity, whichever may be chosen, is dependent on all the conditions of site, silviculture, utilization, and economics, which influence the increment of the stands and the value of the timber. 


\section{CHAPTER II}

\section{IN AMERICA}

\section{SECTION ONE}

\section{EARLY BEGINNINGS}

WORKING plans are almost coincident with the beginnings of American forestry. Before the control of the national forests passed over to the Forest Service of the Department of Agriculture in 1905 , the then Bureau of Forestry, through its offer of coöperation with private owners, prepared many working plans for timber tracts in the Eastern and Southern States. Since these plans were for very irregular, extensive conditions and were generally intended for execution by laymen who had little or no conception of the purposes of forest management, it was inevitable that they exceeded the confines of mere forest organization and often consisted chiefly of elaborate forest descriptions and estimates, emphasizing the silvical characteristics of the more important species, of logging methods and rules to prevent waste. Actual calculation of the yield was confined to a rather crude diameter-limit method which emphasized the possible periods of return for an equal or approximately equal cut. Little or no attempt was made to distribute the cut according to the needs of the individual stands; the regulation was by volume alone.

As working plans these were, probably, with rare exceptions, failures; for no plan can hope to live that is made from the outside without an adequate understanding of the silvicultural and economic conditions. It was a precocious attempt to make a plan on European models without the basis of exact knowledge which is the fruit of decades of European experience. 190 
The plans, as such, were valuable chiefly for the estimates, maps, and other field data which they furnished to the owner, and for the volume, growth, and other silvical data which they furnished to the Bureau, together with a splendid field training for the men concerned in the work.

It is doubtful if any of the plans were ever maintained; for no adequate provisions were made for their control and revision and, though drawn up for decades in advance, they soon lapsed into desuetude.

Some were published as bulletins of the Bureau, and are now chiefly valuable for the volume and growth tables, and other silvical data which they contain, and as landmarks of the progress toward an American forest management.

\section{SECTION TWO}

\section{THE NEW RECONNAISSANCE}

On February I, I905, the Forest. Service of the Department of Agriculture took over the charge of the then forest reserves. The tremendous task of organizing the administrative machinery over an area of over 100 million acres absorbed all the energies of the forest service, and although the need of working plans was repeatedly recognized by those in authority and a few sporadic plans were actually made, ${ }^{*}$ nothing systematic was done until the winter of $1907-08$, when for the first time rough estimates of the timber standing on the various national forests were compiled.

The section of reconnaissance in the office of forest management was reorganized and its activities diverted from a study of the distribution, existing volume, utilization, and management of the more important commercial species (so called "Commer-

* For the details of this development see article "The New Reconnaissance, Working Plans that Work," in Proceeding Soc. Am. Foresters, Volume IV., No. I. Reprinted Yale Publishing Association, 1909. 
cial Tree Studies") to the far more pressing task of systematizing and controlling the estimates, allowed annual cut, marking rules, stumpage rates, and sale policy of the national forests which then aggregated about $\mathrm{r} 75$ million acres.

The compilation of estimates from the various national forests were so glaringly inadequate that steps were immediately taken to secure reliable estimates of all the forests, beginning with those where the cutting was heaviest and threatened to exceed the proper allowance. The method of estimating developed was that described above in Part One, Chapter I, Section 2, "Estimates," and, with minor changes, has continued in use to this day. This method aims to strike the mean between the rough guesses of supervisor and rangers and the accurate but far too slow strip valuation surveys.

By the placing of several parties in the field each season good progress has been made* towards securing fairly reliable estimates and forest descriptions and usually excellent maps.

Based on these field data, insufficient though they are, simple working plans have been prepared in accordance with standard outlines. The outline now in effect (I9I2) is as follows:

\section{General Description}

(General data which relates to two or more sections of the plan, or which can be treated more logically here than under other sections. Under most headings the discussion will be a summary of important points treated in detail in other sections of the plan.)

Creation. Area, past and present. Totals of alienated lands by classes. (Tabulated form.)

Physical features. (Concise. Include the information which has a distinct bearing upon or forms the basis for the provisions of the plan.)

Climate. (Data not of direct application may be placed in the Appendix.) Topography. (For use in the division of the forest into working circles, as well as its bearing upon use, development, and administration of the forest.)

Geology. (As it affects soils, etc.)

Soils. (In such form that statement made may be appl:ed directly in silvicultural practice, settlement, policy, etc.)

Land classification. Forest, agriculture, grazing, barren, etc. (Tabulated. Brief discussion, if necessary.)

* See "The Progress of Reconnaissance," "Forestry Quarterly," Volume VIII., No. 4. 
Transportation. (Railroads, water, etc., only as it affects the administration or the development of the forest.)

Settlement. Present and probable future. (As it affects the forest and the plan.)

Industries. Mining, grazing, ranching, lumbering, etc. (Only as they have a bearing on the plan.)

Timber:

\section{Silviculture}

Estimates and detailed descriptions of timber. Estimates by species, separately by divisions, blocks, and other natural or artificial subdivisions. Quality and condition of timber, age classes if stand is even-aged, accessibility, information on logging, etc., as necessary, cut-over areas. (Tabulation.)

Forest Types. Composition, occurrence, distribution of age classes, and condition of timber. (Concise general descriptions, and the fundamental silvicultural requirements and principles which form the basis for the choice and application of silvicultural systems.)

Species. (Concise. Treat, from the standpoint of the type and the stand rather than the individual tree, the characteristics and requirements upon which will be based conclusions regarding the species to be favored and the relation in the management of each species to the others in the stand or type.)

Climatic, soil, moisture, and light requirements.

Growth, form, volume, ctc. (Tables to be included in the plan if they will be used frequently, otherwise in the Appendix.)

Reproduction. Advance reproduction present. Conditions necessary to secure it.

Value of wood. (Properties. Comparative values.)

Causes of injury. Fire, insects, fungi, mistletoe, smester fumes, weather, animals, etc. (Control under protection.)

Increment. Yield tables or other data, or the method used to determine increment. Effect of thinnings on growth, etc.

Timber operations.

Markets.

Consumption and demand, local and general, past, present, and future. Relation to surrounding forests if any. Cut, by years, sales, and free use. (For use in the determination of working circle boundaries and in regulation.)

Prices. (To aid in stumpage appraisals.)

Methods and utilization. (Methods in relation to preservation of proper silvicultural conditions, also as a basis for costs. Reasonable possibilities in utilization.)

Costs. (As a basis for stumpage appraisals.)

Objects of Management. Watershed protection, species of timber and classes of material, sustained annual or periodic yield, etc. (State specifically in order of importance the objects which materially affect the provisions of the plan.)

Silvicultural Systems and their application. For each type. (Concise descriptions of the systems adopted and provisions for their specific application. Include brush disposal.)

Regulation of yield:

Rotation, cutting cycles, etc. (Rotation of maximum volume production. Cutting cycles as short as practical considerations will allow.)

Division of the forest into necessary divisions (working circles), areas within which sustained yield, annual or periodic, is now or will ultimately be desirable, based upon markets, transportation, and to- 
pography. (This may be done elsewhere in cases where such action will simplify treatment.)

Blocks and chances only when they are actually needed to assist in regulation. (Blocks-main logging units or groups of logging units. Chances - single logging units or the subdivision of blocks necessary to carry out the management.)

Annual or periodic cut. The limitation of cut including sales and free use. Accurately for ten years, and approximately for the periods of the rotation. (Include in the plan only the essential features of the method used, and cover necessary details in the Appendix. Blank table for tabulation of limitation and amounts actually cut. Sales and free use.)

Sales. (By divisions, if advisable.)

Policy. Restriction and encouragement and location. (The plan of cutting and specific application to actual conditions of the preceding conclusions and of the service policy and regulations. Past management to be treated only as it will help in an understanding of that proposed.)

Stumpage appraisals. Maximum and minimum rates.

Administration and other features. Special force needed. Costs. (Summary for use in obtaining total forest expenditures in Section VII.)

Free Use. (Principles applying specifically the general free use policy, especially where it is more or less vague and general. By divisions, if advisable.)

Present and prospective annual demand by classes of users and of forest products.

Policy, restriction, or encouragement by districts and classes of products.

Administration. Free use areas. Blanket or year long permits. Other measures to promote economy. Special force needed. Costs. (Summary for use in obtaining total forest expenditures in Section VII.)

Map or maps showing topography, types, classification of timber, boundaries of divisions, blocks, etc., free use areas, cut-over areas, etc.

\section{Forestation:}

General relation to ultimate timber management.

Areas requiring forestation. By types. (Brief description. Tabulated.)

Methods and species. (Concise. Base upon results of past work. In addition to sowing, planting, etc., include seed collection, poisoning rodents, etc.)

Detailed plan. (Five years, or if impracticable, omit and provide for annually.)

Areas, methods, and costs. (Tabulated.)

Administrative features. Special force needed. (Regular and Nursery. special work such as seed collecting, etc.)

Ultimate production, species, and numbers.

Methods. (Essential features.)

Detailed plan. (Five years.)

Species, numbers, and costs. (Tabulated form.)

Administrative features. Special force needed.

Map showing areas to be reforested, classified as above, etc.

Investigations: (Which can be conducted inexpensively in connection with the regular administration of the forest and which should result in practical information needed in the administration. Brief.) 
Kange Management:

\section{GraZING}

Types. (Concise descriptions of each.)

Names of important and characteristic forage plants.

Accurate data on seasons of growth.

Accurate data on forage value.

Acreage. With forage. Waste. (Tabulated.)

Carrying capacity. Present. Possible. Brief descriptions. By allotments or divisions. (Tabulated.)

Demand and other local conditions in the live-stock industry which affect grazing on the forest. Relation to silviculture.

Allotments.

Arrangement. (Division of the range between cattle and sheep, grazing districts, and individual allotments to be shown on map. Guiding principles, or necessary comment in the discussion.) To secure Best division between cattle and sheep.

Full and equal utilization.

Best division of types and early and late ranges.

Best division of watering places.

Proper silvicultural and watershed protection.

Number and kind of stock grazed. By allotments or divisions. Number of permits by classes.

Seasons. (To secure full utilization of the forage without seriously interfering with the natural requirements of plant growth, each portion of the range should occasionally, every few years, be grazed only during the last half of the natural growing period in order to keep the plant constitutions strong and allow some actual reseeding. So far as is consistent with this principle, the green tender feed should be available for the stock during as much of the season as is practicable. This is essential, especially for sheep. This plan may be considered a variation of seasons or a division of allotment.)

Fees. By classes of stock and season. (Tabulated.)

Methods of handling stock.

Cattle. (Salting and necessary riding by permittees to secure equal utilization of range and prevent congregation along streams and water holes, with resulting destruction of plant growth and poor Sheep. development of stock.)

Size of bands.

Herding. (Develop open quiet herding and avoid driving back to camp.)

Salting. (Encourage abundant use of salt, it means easier herding, less danger from poison and disease, and less damage to the range.)

Other stock. (When special provisions are required.)

\section{Range improvements:}

(Permanent improvements in the improvement section.)

Reseeding either with cultivated plants or by restricting grazing for natural reseeding, posting poisonous areas, changes or improvement in stock driveways, extermination of predatory animals, prevention of erosion by proper handling of stock.

Policy and administration.

General principles of policy not already covered. Protective and maximum limits, new owners, advisory boards, etc.

Administration. Extermination of predatory animals, counting stock, or other special phases of the work. Special force required. Costs. (Summary for use in obtaining total of forest expenditures in Section VII.) 
Investigations:

Proper seasons, carrying capacity, poisonous plants, artificial reseeding, demonstration tests of proper utilization, effect of grazing upon reproduction, and most efficient systems of grazing management to eliminate damage. Herbarium with necessary notes.

Map or maps, showing types, water, fences, corrals, topography, grazing districts, allotments, reserved areas, driveways, or other factors or features which influence or illustrate the handling of the stock.

\section{Settlement:}

\section{LANDS}

Soils. (Classification with brief description and a statement of comparative agricultural and forest value of each class based upon land values, forest expectation values, etc.)

Demand for agricultural lands. Past, present, and future.

Policy. (In I, 2, and 3 order, application of policy based upon the preceding classification, results of past policy, service policy, and any other principles as a guide to examiners. Practicability of detailed classification of certain districts in advance of application.)

Map, showing soil classification, if data is available.

Uses and Easements:

Resources.

Demand. Past, present, and future.

Policy. (Special features which are important by kinds of uses or easements. Include charges compared with value to users.)

Water-power:

Resources. Streams, sites, power. Cost and market data and stream measurements. (Tabulate.)

Demand. Past, present, and future.

Policy. (Special features.)

Administrative sites:

Sites, rights of way, etc., withdrawn, or still néeded and to be withdrawn. Include comprehensive plan of rights of way needed for future sales and other uses as well as sites and rights of way required in administration. (Tabulate or show on map.)

\section{Administration:}

Special force needed. Other administrative questions.

Costs. (Summary for use in obtaining total forest expenditures in Section VII.)

\section{Investigation:}

Map or maps showing status, location of uses, easements, water-power projects, administrative sites, etc.

\section{Protection}

Fire: (By divisions or geographical subdivisions, if advisable.)

Liability. Statement of value of destructible resources by classes, and for districts or regions.

Timber, expectation value of young growth, forage.

Arbitrary value per acre of watershed protection. (Possible money damage. Tabulate.)

Hazard or risk. Statement by types or regions based upon character of stand, danger of fires starting, and difficulty and cost of suppression. (Should be based in part upon a study of past experience.)

Protection required. (Principles which sum up on the basis of liability and hazard the relative amount of protection needed in specified parts of the forest.) 
Control.

Improvements available. By districts. (Brief description, tabulate if map is not sufficient.)

Communication. Telephone, etc.

Transportation. Railroads, roads, trails, pack trains, etc.

Fire lines.

Look-out stations.

Supplies and tools. (Distribution or how they are to be purchased. etc. Tabulate.)

Coöperation.

Adjoining forests, between ranger districts, State associations, corporations, individuals, etc.

Organization and administration.

For look-out stations and patrol. Numbers of men and duties by districts. (Tabulate so far as possible.)

For fighting fires. (Tabulate if possible.)

Regular and temporary force.

Coöperation, labor, including users.

Outside labor.

Costs. (Summary for use in obtaining total of forest expenditures in Section VII.)

Specific and detailed instructions to rangers based on the above, and resulting in its direct application should be issued to all forest officers engaged in fire protection.

Map showing types, topography, improvements, and as much of above information as is possible and advisable. Copies to accompany letters of instruction.

Insects:

Extent of infestation and damage.

Control, administrative measures, methods. Special force needed. Costs. (Summary for use in obtaining total of forest expenditures in Section VII.)

\section{Other damages:}

Extent. Amount of damages.

Control, administrative measures. (As under Insects.)

\section{Game:}

Policy and administrative measures.

\section{Investigations:}

\section{IMPROVEMENTS}

Improvements. Comprehensive plan of the improvements needed. Location, brief description, estimated costs, indicate those which should be undertaken within the next five years. (Tabulated form.)

Roads, trails, telephone lines; fire lines, administrative fences, stock fences, including the fencing of poisonous areas and bog holes, bridges, corrals, dwellings, other buildings, water development, steam improvement, dams to prevent erosion, other projects.

Maintenance, as above.

Policy and administration.

Improvement policy of the forest. (Concisely by lines of work such as silviculture, grazing, protection, general administration, etc.)

Administrative provisions. Special force needed. Costs, exclusive of the costs of individual projects.

Map showing all improvements constructed and planned, with a sufficient amount of other data to make intelligible. 


\section{Administration}

Administrative districts. Number, area, and relative importance or amount of work. (Tabulate.)

Force. Office and field and assignment. Salaries.

Also a brief forecast of future requirements. (Tabulate.)

Permanent, statutory.

Semi-permanent and temporary.

General administrative policy of forest. (General relation of important lines of work. Include also points not already covered; fully and briefly in 1,2 , and 3 order.)

Receipts and expenditures and results. By lines of work for fiscal years, past and estimated future.

Administrative provisions for increasing receipts or reducing expenditures.

Map, boundaries of administrative, or other districts.

\section{Appendix}

Material which should be preserved in connection with the plan, but which will be used infrequently in actual forest administration.

List of species.

Details of methods used in the collection of data, costs, and areas covered. (Reconnaissance.)

Tables, growth, volume, etc., when it is reasonably certain that they will be used infrequently.

Details of method for regulating yield.

Detailed silvical discussions upon which conclusions and principles outlined in the plan are based, if preservation seems necessary or advisable.

General notes upon which the conclusions in the plan were based.

Inventory of existing improvements, if desired. (Tabulate.)

The first attempts to determine the allowed annual cut for each national forest, necessarily in advance, often, of any regular working plan, were very crude. Nevertheless, though based on insufficient data, the attempt recognized the fundamental principle of a sustained yield.

For each national forest the annual yield has been fixed since I908. At first this was taken, roughly, as equal to the current annual increment, a crude calculation based on often faulty estimates and insufficient growth data, but giving at least a working basis.

The allowed cut so calculated was not distributed on the ground, since this would have been a useless play, but instead a definite sale policy was drawn up for each forest by dividing the forest into areas where ordinary sales, i.e., of large size, are desirable, areas where small sales (for local industries) only are 
desirable, areas for free use of inhabitants only, and areas reserved as protection forest.

This rough division of area, indicated on forest and district maps, was further supplemented by general notes on areas requiring cutting because of overmaturity, insect damage, disease, fire, and the like.

Minimum stumpage rates for each species and class of material were also fixed for each national forest so as to prevent the wide variation in prices obtained.

It had been the custom to draw up special marking rules for each timber sale of larger size. To avoid constant repetition these began to be combined into a set of marking rules for all the various forest types contained within a certain national forest and these rules made standard for all sales within that forest.

These rules by forests were then combined into general marking rules for the various silvical regions of the West. This work was completed in November, I908, and the mimeographed marking rules as sent out to all forest officers represented the best information then available on the very important question of marking trees for cutting in timber sales. They have been revised from time to time and have been aptly supplemented by actual examples of properly marked areas as an ocular demonstration of how to do it.

Although the section of reconnaissance had brought together all the data stored in the files of the service and built thereon the first crude beginnings of a systematic forest organization, further progress would have been impossible except for the active coöperation of the men in the field. Realizing the inadequacy of the existing estimates and the time which must elapse before each forest could be covered by detailed reconnaissance, a circular letter was sent to all the supervisors in the spring of Igo8 requesting them to make every effort to correct and amend existing estimates during the approaching field season and to segregate the estimates by blocks (i.e., by watersheds), by species, and by classes of material. 
A similar letter was sent asking the supervisors to draw up, each for his forest, a plan of sale policy, indicating those areas on which cutting should be restricted or encouraged according to economic and silvicultural conditions, etc.

The first crude regulations of the yield (allowed annual cut), sale policy, and minimum stumpage rates were also sent to each of the six inspection districts and the chief inspector requested to revise and amplify them according to his local information.

In the Southwestern district (No. 3) Acting Chief Inspector Woolsey availed himself of this splendid opportunity to draw up a complete, far-sighted limitation of cut and sale policy for each forest and for the district and also minimum stumpage rates by forests, species, and classes of material. His sale policy was by far the most complete of any prepared, the more so as he proceeded to determine the allowed annual cut for each forest, separately for saw timber and cord-wood, by Von Mantel's Method (see Part One, Chapter II, Section I, Method No. 2). Crude as this method is, it was a marked step in advance and the regulation of yield on the national forests has only in the last year or so advanced from Von Mantel's "beautiful simplicity" to some of the higher methods, such as the Austrian formula, Heyer's formula, and the like (see Part One, Chapter II, Section I).

When the six Western administrative districts were created in December, I908, the office of management, and with it the section of reconnaissance, ceased to exist. So enormous had been the undertaken task of systematizing and controlling the estimates, allowed annual cut, marking rules, stumpage rates, and sale policy that only the foundations of a correct forest organization were turned over to the districts whereon to build.

The office of silviculture in each of the districts took over the task and the manual of procedure in the district offices provided for annual revisions of the estimates, sale policy, allowed annual cut, minimum (later standard) stumpage rates, and marking rules, to be submitted by the supervisors, combined by the district forester and in the case of the allowed annual 
cut, forwarded by him to Washington for review by the forester and approval by the secretary. The limitation of annual cut as fixed by the secretary-based, of course, on reasons of sale policy-could not be exceeded without his consent. However, this was seldom required; for inaccessibility and competition with private timber restricted the bare possibility of national forest sales to a point far below what the forests would support. Thus in rgr I the annual cut which the national forests were estimated to be able to sustain permanently, totalled 3,274.$\infty, \infty, \infty \circ$ board feet. The actual cut under both timber sales and free use permits was $498,000,000$ board feet, but little over I 5 per cent of the actual yield of the forests.

\section{SECTION THREE}

\section{PRESENT PROCEDURE}

The decentralization of working-plans control resulted in a most unequal progress in forest organization. Starting with the same foundations in December, I908, there were, in matters of working plans, much confusion and wasted effort. This unfortunate condition was relieved by the issuance, late in rgr I, of the forest plans section of "The National Forest Manual" * which restores system and purpose to the work of forest organization and is a big step in advance towards unifying the workingplan procedure of the various districts.

The essentials of the manual are given below, together with its proposed application in the Southwestern district. It is significant to note that the manual calls for preliminary plans to be prepared immediately, to be followed, as data warrant, by a regular working plan. This continues the work begun by the

* "The National Forest Manual: Instructions to forest officers, relating to forest plans, forest extension, forest investigations, libraries, coöperation, and dendrology. Issued by the Secretary of Agriculture to take effect November I, I91 I." Washington, Government Printing Office, 191 I. 
former section of reconnaissance and emphasizes the fact that "the completion of any plan is but the beginning of systematic management."

There follows, in somewhat condensed form, the Forest plans portion of The National Forest Manual:

\section{FOREST PLANS}

The object of the forest plan is to systematize and control the management of each forest upon a definite basis which shall represent the cumulative experience and information which the service has acquired.

Three different kinds of plans, differing only in scope and intensity, will be used in developing the management of the respective forests, namely, preliminary plans, working plans, and annual plans.

A preliminary plan is simply a systematic statement, prepared from the best information now available, of the resources of the forest, the conditions governing their use and development, and the administrative measures to be followed in their management.

A working plan is a similar statement, more complete and final in character, based upon thorough investigation and accurate data, and including a definite scheme of management devised for a period of years.

The annual plan is covered by the various periodic estimates and reports. It constitutes a periodic revision of the preliminary or working plan, together with the specific application of these plans to the business of the forest for the ensuing year.

The subjects to be covered in all forest plans are:

I. General administration.

2. Silvicultural management.

3. Grazing management.

4. Permanent improvements.

5. Forest protection.

6. Uses of forest land. 
Each forest plan will provide for the management of a whole administrative unit or forest. No plan should include more than one forest. Where conditions in adjacent forests are similar, or the forests supply the same markets, these facts will be considered, particularly in the location of cutting area and limitation of the annual cut. Such considerations will also be necessary in grazing and protection.

Where necessary, because of important market or topographic considerations, the forest may be divided into areas, each of which will be managed with the idea of sustained yield. If necessary to assist in regulating the cut, a subdivision of the above areas may be made; this should be on the basis of logging units or groups of logging units, the boundaries depending entirely upon topography. Unnecessary divisions will not be made, since they complicate administration. Where possible the lines of administrative subdivisions and those for the technical management of the forest will be coördinated.

Final responsibility in the preparation of all forest plans rests with the supervisor. He should, in submitting the plan for approval, transmit any recommendations of the officer in direct charge of its preparation which differ materially from the plan as submitted.

Since the completion of any plan is but the beginning of systematic management, every effort should be made to improve plans which have been prepared and to obtain the additional data needed for more efficient administration.

\section{PRELIMINARY PLANS}

A preliminary plan should be prepared as soon as practicable on each forest from the data now available. The compilation of such data in the form of a definite plan of management will systematize and strengthen the administration of the forest and furnish a basis for further extension and improvement. The following points should be covered:

Under "General Administration" should be given:

I. The forest force, based upon the men required to transact 
economically the business of the forest and furnish adequate protection during the fire season.

2. Division of the forest into administrative and patrol districts to be shown on a map.

3. A record by classes of past receipts and expenditures and an estimate of future receipts and expenditures.

Under "Silvicultural management" should be given:

I. Divisions and subdivisions, if any, with reasons.

2. Approximate estimates of timber by convenient, technical, administrative, or legal subdivisions.

3. The silvicultural systems which should be used, by types, and by divisions if modification of the system on different divisions is necessary. Principles to govern marking drawn from the best silvical data available. The object of management for the forest, as far as available information makes it possible, or for divisions, classes of material to be produced, species to be favored, and rotation desirable.

4. A rough classification of the timber on the forest, or parts of the forest, in accordance with its age and condition, showing the bodies of mature timber, of thrifty timber not yet in need of cutting, and of young growth; together with a plan of cutting, showing the order in which the various areas should be logged. Areas of protection forest where no cutting is recommended should be indicated. The approximate periods in which immature stands will reach merchantable size should be shown.

5. Recommended limitations on the annual cut* for the ensuing four or five years.

6. Data on methods of logging, accessibility of merchantable bodies of timber, costs of logging and manufacture, markets and market conditions, demand, prices, etc.

7. The policy for the whole forest, or divisions if advisable, which should be followed as to sales, reservations for local industries, and free use, together with the opportunities for desirable sales.

*I.e., determination of the yield-see Part One, Chapter II, Section I. 
8. Tentative stumpage rates for the entire forest, or divisions.

9. Improvements needed to facilitate the sale or protection of timber. (To be incorporated in the permanent improvement plan.)

Io. The approximate areas on which artificial reforestation will be necessary in whole or in part, together with the species to be used, and, broadly, the plan to be followed during the ensuing four or five years, plans for nurseries, outline of desirable experiments, etc.

II. The order in which the various parts of the forest should be covered by complete reconnaissance, ${ }^{*}$ desirable silvical studies leading toward better management, etc.

This part of the plan should be accompanied by a map showing topography in as much detail as data available will allow, roads, trails, forest types, age classes, if necessary, nursery sites, and areas proposed for artificial regeneration. Much of the other data called for may be shown either on the map or in concise tabulations with explanatory notes.

Under "Grazing" the essential point is to compile all available information on the range conditions in the forest as a basis for systematic range protection, development, and improvement. The following outline is intended only as a guide:

I. Classification of grazing lands and estimates of carrying capacity, including:

(I) Determination of characteristic ecological types or groups of forage plants, each of which includes certain combinations of grasses, weeds, and browse. The types should be mapped on a base map of the forest. Groups containing poisonous plants may demand particular attention.

(2) Concise descriptions of each group or type including notes on individual species, the seasons when the plants may be used, the relative grazing value of the types, and the class of stock for which they are best suited.

(3) A record in tabulated form of the kind and amount

* I.e., estimates as described, Part One, Chapter I, Section 2. 
of stock at present grazed on the land, with an estimate of its present grazing capacity, and if overgrazed or poorly stocked with forage plants the capacity to which it may be brought by proper treatment.

2. Range improvements: Map record of present and needed watering facilities, including wells, streams, springs, natural and artificial ponds and tanks, drift fences, and other improvements necessary for the best use of the range. (To be incorporated in the permanent improvement plan.)

3. The plan of management should include, with necessary maps, notes, and explanatory data, provision for:

(I) The control and eradication of poisonous plants.

(2) Improvement of overgrazed or poorly stocked areas, including reseeding, the use of a rotation scheme of excluding stock from areas for a part of the year to allow seeding of native plants, etc.

(3) Fuller use of the range by the class of stock for which it is best suited, including areas not now used.

(4) Exclusion or reduction of stock or the change of grazing seasons when necessary for silvical reasons or the protection of watersheds for irrigation or municipal water-supply. Reduction to prevent overgrazing, or erosion caused by grazing.

(5) The better handling of stock, including salting, bedding, the prevention of concentration to the injury of the range, improved herding methods, etc.

(6) Improvement in range districts, range allotments, etc.

(7) The extermination of predatory animals, based upon the kind and amount of damage done.

(8) The extermination of prairie dogs, based upon the area occupied and the damage done.

A systematic plan for the Permanent Improvements on the forest should be steadily developed, extended, and improved.

The improvement plan will take the form of a map, and such additional notes as may be necessary for its proper understanding. Rough estimates of cost should be included wherever obtainable. The following kinds of work will be considered: 
Roads, trails, bridges, telephone lines, signal systems, permanent and temporary headquarters, pastures, look-out towers, fire lines, tool boxes, improvements necessary for range development or making timber accessible, and areas in which the blazing and posting of trails is urgent.

Under "Forest protection" provision will be made for protection against fire and insects, and the protection of nurseries and plantations against rodents.

A plan for fire protection, as complete as is now practicable, should be formulated and put into effect on each forest.

The fire plan will consist of a map showing detailed topography, forest types, all permanent improvements which will be of any value in fire protection, look-out points, lines of fire patrol, camping sites, places where assistance in fighting fire may be obtained, areas of particular menace and areas in particular need of protection, and detailed directions to rangers concerning fire patrol, and coöperation with other districts and forests.

Under "Uses of Forest Lands" data should be collected showing:

I. Sale prices of agricultural lands within or near the forest, including stump lands, unimproved non-timbered lands, and improved ranches.

2. Cost of clearing and stumping timbered lands

3. Comparative value of timbered land for agricultural and forest purposes.

The location of all uses which have been granted should be recorded on a base map of the forest. Any information secured as to tracts desirable for particular uses should be similarly recorded, especially reservoir and dam sites, as part of the inventory of the resources of the forest.

The water-power possibilities of the forests, including stream measurements and the collection of cost and market data.

All administrative sites should be shown on the improvement map of the forest. Sufficient additional data will be recorded to show in concrete form the system of administrative 
sites devised for the forest, including patrol and look-out stations, nurseries, and sites required for logging facilities, and other uses in connection with the sale of timber.

\section{WORKING PLANS}

A working plan is simply an extension and development of the preliminary plan, based upon more ciact data. Such a plan should ultimately be prepared for every forest as the need for a more systematic basis of management becomes urgent. Reconnaissance work should, except in unusual cases, result in working plans.

Working plans will be prepared first on forests where the demand for timber is great as compared with the supply, and where large quantities of timber are evidently mature and it is reasonably certain that sales can be made if the proper data are secured. It may be advisable to prepare special working plans for forests on which large areas are in need of reforestation. Special grazing working plans may be prepared for forests where the use of forage resources is of importance. Special problems in any other phase of service work demanding careful study may require the preparation of working plans. Where conditions on a forest differ widely, it may be advisable to cover only the part of a forest to which the special administrative urgency applies.

Each working plan will outline the general management of the forest for a long period, usually a rotation in the recommendations on timber cuttings, and the management in detail for some such period as Io or 15 years.

The amount of detail in the working plan will depend upon the value of the forest products concerned, the need for intensive methods, and the certainty or possibility of large returns within the probable life of the plan. On forests or parts of forests where the demand for timber equals or exceeds the amount which can be cut with safety, the plan for silvicultural management must be in much greater detail than where the demand is comparatively small. The requirements of detail in 


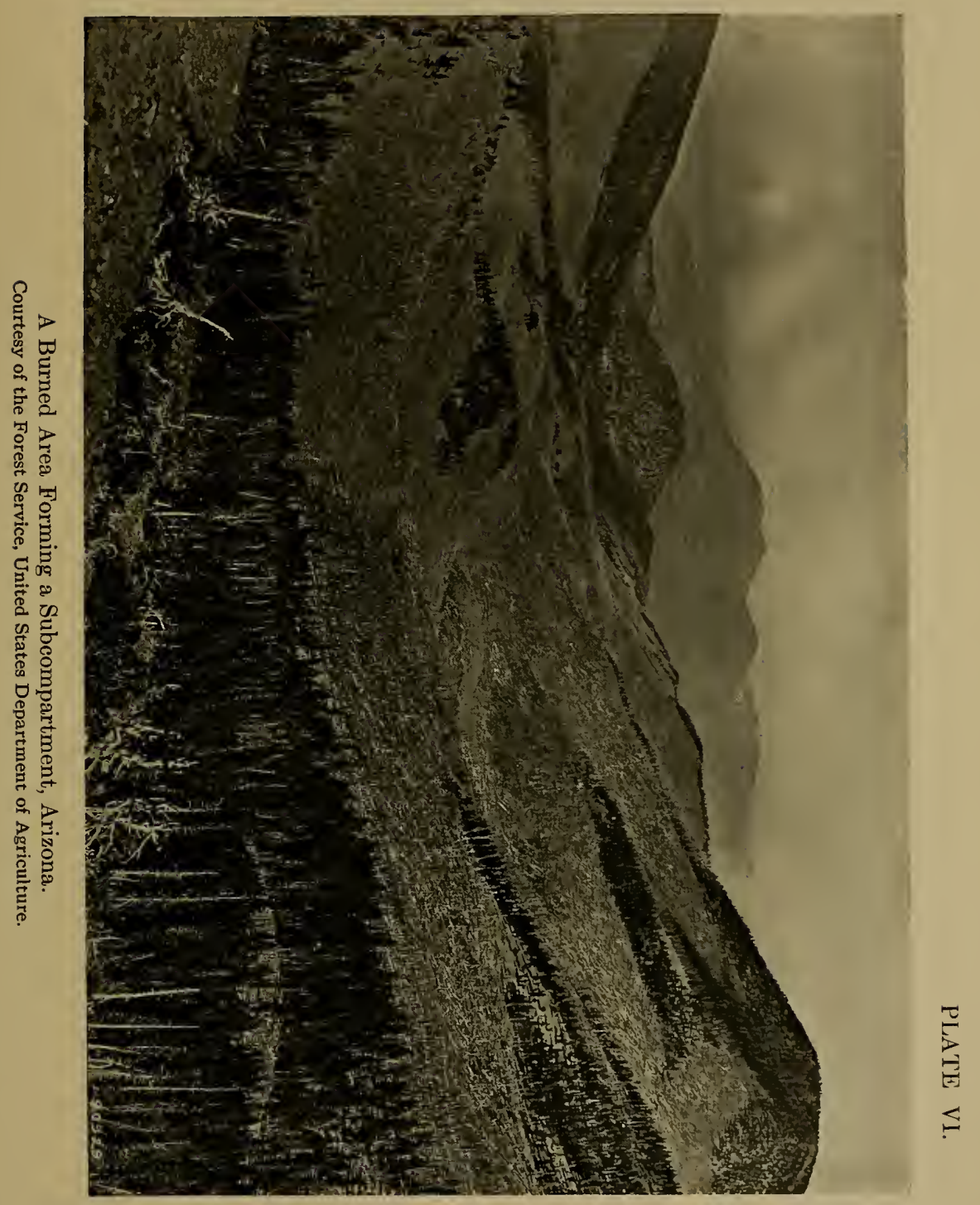



the different parts of the plan and in different working units must be adjusted to the administrative needs of the forest in all lines of work.

When it has been decided to make a working plan, its essential features and the field-work necessary should be outlined at a conference between the officer who will have charge of the field-work, the supervisor of the forest, the assistant district foresters concerned, and the district forester at his discretion. It is particularly necessary that the general system or systems of management be determined, and the methods for determining the yield of each unit be decided upon. Plans may then be made to secure the exact data needed and unnecessary work eliminated. The preliminary plan for the forest and working plans already prepared will form the basis for this discussion.

Field data will in general be obtained by special parties, which as far as possible should consist of experienced men. As far as possible, the data for all parts of the plan will be collected at the same time, if necessary by specialists temporarily assigned to the party. The data for planting or grazing features may be collected independently when the need justifies it. The work will be done under the direction of the supervisor.

As far as possible all data in the working-plan report will be tabulated with brief notes of necessary explanation. While working plans must be complete, every possible effort will be made to eliminate unnecessary discussion and to put them in concise form. All detailed data relating to climate, geology, soil, growth studies, silvical notes, etc., should be placed in the appendix of the working plan, and everything in the plan subordinated to the actual scheme of management for the forest.

Working plans will be approved by the forester.

The general ground to be covered by working plans is as follows:

Under "General Administration" the topics listed for preliminary plans should be discussed with such further detail as more intensive study makes possible.

Under "Silvicultural management" the topics listed for pre- 
liminary plans should be developed with much greater accuracy and in much greater detail.

To secure uniform data from the national forests in each district, the district forester will decide upon standard field methods. Standardization will include:

I. Methods of making estimates under specified conditions to secure results of uniform accuracy.

2. The unit for recording estimates in both surveyed and unsurveyed ground.

3. The minimum sizes to which timber will be estimated and a method of classifying reproduction and young timber below this minimum.

4. A scale for field and base maps and the conditions under which contour or hachure maps will be made.

5. The form and character of notes on silvicultural questions, forest descriptions, etc.

6. The principles upon which the silvicultural system, the rotation, the period for which management will be planned in detail, etc.

In each district, also, to insure reasonable uniformity under similar conditions, a careful study will be made of the methods of determining the limitation of annual cut under each silvicultural system which will be used, and standard methods established.

In the completed plan the data secured under each topic will be summarized and the conclusions stated. The following points are of special importance:

I. Silvicultural systems based on the most reliable silvical data available, and upon careful observations on the part of the working-plans officer (i.e., the forest organizer).

2. A carefully drawn set of marking principles (marking rules) designed to put into effect the silvicultural systems recommended.

3. The maximum annual cut to be allowed during the ensuing Io or 15 years, and the approximate cuts for each period of the rotation. 
4. The order in which the important bodies of merchantable timber should be sold.

5. The order in which areas needing artificial restocking should be sowed or planted, and the acreage to be covered during each year of the period for which detailed recommendations are made.

Under "Grazing," technical reconnaissance and special studies should be conducted, following the general ground covered under preliminary plans, but with more detail and greater exactness; it should be directed as far as practicable by grazing experts.

The permanent improvement plan, protection plan, and plan. for uses of forest land for the forest should be considered and developed as far as may be practicable in connection with the intensive timber estimates and other investigations conducted by working-plan parties.

\section{ANNUAL PLANS}

The annual reports, estimates, and recommendations submitted on the various lines of forest work should be based upon the preliminary or working plan for the forest and should refer specifically to the portions of the plan dealing with the subject in question. They should show how far it is feasible to apply the plan to the work of the forest during the current or ensuing year, the specific action proposed to put its provisions into effect, and the changes which appear advisable.

Annual recommendations on maximum and minimum stumpage prices and limitation of yearly cut should be submitted to the district forester. These and the planting and nursery reports should refer to the portion of the plan dealing with silvicultural management and indicate any necessary changes in its application. Revisions of the cutting methods advocated in the plan and of other features of its silvicultural management should be submitted whenever they appear advisable, together with any additional data secured on estimates, logging costs, market conditions, etc. 
The annual grazing report and recommendations constitute a concise restatement of the preliminary or working plan and its application to the business of the ensuing year. Additional data should be reported and necessary changes from the plan noted.

In submitting the annual improvement estimates a copy of the improvement map of the forest, showing the plan as revised and extended to date and indicating the work of greatest urgency, should be furnished.

In connection with the annual fire report, the fire plan for the forest should be checked over and necessary modifications noted. The annual planting and nursery reports should inslude a current revision and application of the portions of the protection plan dealing with rodents. Special reports and revisions of the forest plan as regards protection from insects and diseases will be submitted from time to time on forests where this work is of importance.

In connection with the current business and periodical reports relating to uses of forest land, the preliminary or working plan should be steadily revised and extended.

The application of the foregoing instructions has been worked out by each of the districts. The proposed outline for the plan of silvicultural management, as worked out in the Southwestern district, follows. This outline is in skeleton form, so as to give an idea of the bulk and character of the plan in its final form. It is to be used in the preparation of both preliminary and final working plans. When all, or the majority, of the chapters have been completed in satisfactory final form, the plan will be submitted to the forester for approval as a forest working plan. The outline follows the instructions of the manual (see above) that a plan should consist just so far as possible of tables and maps. Most of the tables provide for the entry of records in future years. A two-inch margin will be left at the right of all text throughout the plan for the purpose of allowing notes to be made from time to time. Tables will, however, extend the width of the page. 
The entire plan for each forest is to be bound in a cover and will contain only the strictly necessary information; all supplementary or basic data will be filed in a separate file for forest plans. The forest plan thus bound will serve as a hand-book of the forest. Two copies are prepared: one for the supervisor's office; the other for the district forester. It is aimed to keep the plans up to date by penned notes in the blank spaces which may, as a rule, simply refer to correspondence or reports which alter the plan or supplement it. Every few years the plan may be typewritten and all of these changes incorporated in the text or tables.

\section{OUTLINE FOR PLAN OF SILVICULTURAL MANAGEMENT}

TIMBER ESTIMATES BY DIVISIONS

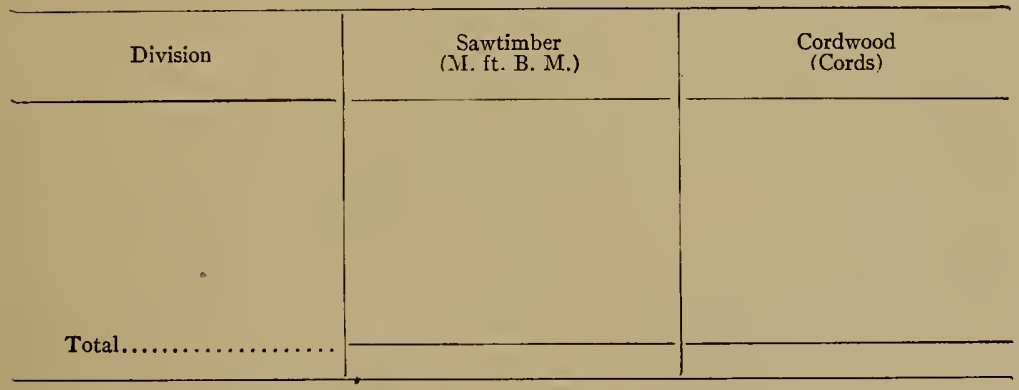

Notes.-Explain above divisions. Make reference to townsbip or section sheets if available. Tabulate estimates by natural divisions, technical division (or compartment), Ranger districts, or watersheds, according to data available and with view to homogeneous units of management. 


\section{THE THEORY AND PRACTICE OF WORKING PLANS}

\section{TIMBER ESTIMATE IN DETAIL}

Division *

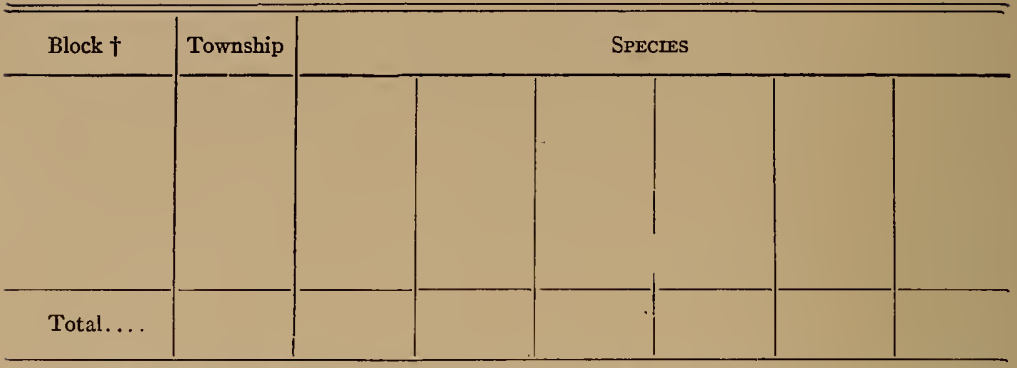

* Handle subjects under Silvicultural Management for each division in greater or less detail according to data available for each. A division which is a distinct unit and for which a sustained yield is desirable, independent of the remainder of the forest, may be treated separately so as to avoid confusion:

$\dagger$ Or watershed, or ranger district.

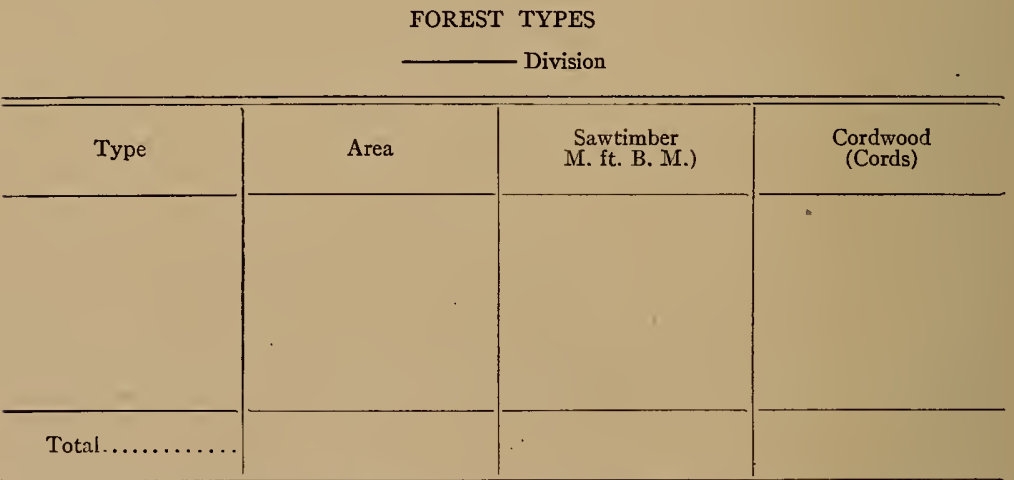

Notes.-Brief comments or descriptions of types where necessary because of unusual features. Refer to type map if there is one. 


\section{OBJECT OF MANAGEMENT •}

Timber Types: $\dagger$

Woodland Types:

\section{Description:}

\section{Application:}

\section{Marking Rules.}

* Separately for each division if desirable.

t State objects briefly, also species to be favored and classes of material to be produced.

$\ddagger$ By types, and by divisions if necessary. 
Rolation:

Division of Forest:

Annual or Periodic Cut.

\section{REGULATION OF YIELD}

\section{REGULATION OF CUT*}

Limitation of annual cut for first period.

Cutting plan for period by years, with proper references to cutting map.

Tabulate amount to be cut each year.

Unless forest or division has been covered by reconnaissance, it will probably be necessary to confine cutting plan to a few ensuing years -4 to ro.

Record of Regulation-Separately for Sawtimber and Cordwood.

\begin{tabular}{|c|c|c|c|c|c|c|c|c|}
\hline \multirow{2}{*}{ Year } & \multirow{2}{*}{$\begin{array}{l}\text { Total Merchant- } \\
\text { able Stand }\end{array}$} & \multirow{2}{*}{$\begin{array}{c}\text { Estimtd. } \\
\text { Annual } \\
\text { Yield }\end{array}$} & \multirow{2}{*}{$\begin{array}{l}\text { Limit'n } \\
\text { of Cut } \\
\text { (Secre- } \\
\text { tary's) }\end{array}$} & \multicolumn{3}{|c|}{ TIMBER Cut } & \multirow{2}{*}{$\begin{array}{l}\text { Surplus } \\
(+) \text { or } \\
\text { Deficit } \\
(-) \text { in } \\
\text { Allowed } \\
\text { Annual } \\
\text { Cut }(t)\end{array}$} & \multirow{2}{*}{$\begin{array}{c}\text { Accum- } \\
\text { ulated } \\
\text { Surplus } \\
(+) \text { or } \\
\text { Deficit } \\
(-)\end{array}$} \\
\hline & & & & Sale & $\begin{array}{l}\text { Free } \\
\text { Use }\end{array}$ & Total & & \\
\hline & & & & & & & & \\
\hline & & & & & & & & \\
\hline & & & & & & & & \\
\hline & & & & & & & & \\
\hline & & & & & & & & \\
\hline
\end{tabular}

* By divisions if desirable. This subject shuuld be handled in greater or less detail according to available data.

$\dagger$ Based on Estimated Annual Yield. 


\author{
POLICX \\ Protection: \\ Division \\ Importance of any special areas for protection. Refer to cutting map on which reserved areas \\ should be shown.
}

\title{
Free Use:
}

Brief notes on volume of free use business, past, present, and future; character of material used; localities, etc. Any exceptions to general policy, or special points of importance. Refer to cutting map for free use areas.

Sales:

Any necessary comments on sales policy. Opportunities for desirable sales.

STUMPAGE RATES

Rates recommended with brief statement of reasons. Provision for future increase.

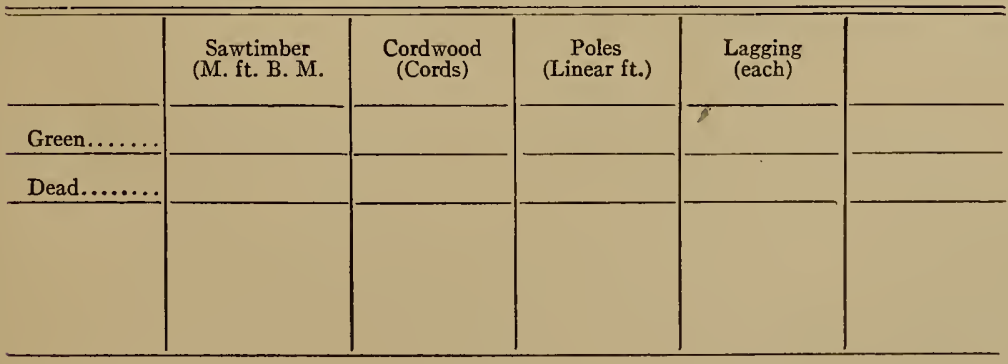




\section{THE THEORY AND PRACTICE OF WORKING PLANS}

\section{UTILIZATION *}

Cutting Prior to Creation of Forest:

Brief notes. Acreage cut over by types, if possible. Amount cut. Refer to map showing cutover areas.

Methods of Logging:

* Confine treatment of this subject to brief notes summarizing conditions. References to more detailed data should be listed in Appendix. 
Accessibility of Timber:

Include reference to improvements needed to open up timber stands.

Costs of Logging and Manufacture:

Markets, Market Conditions. Demand, Prices: 


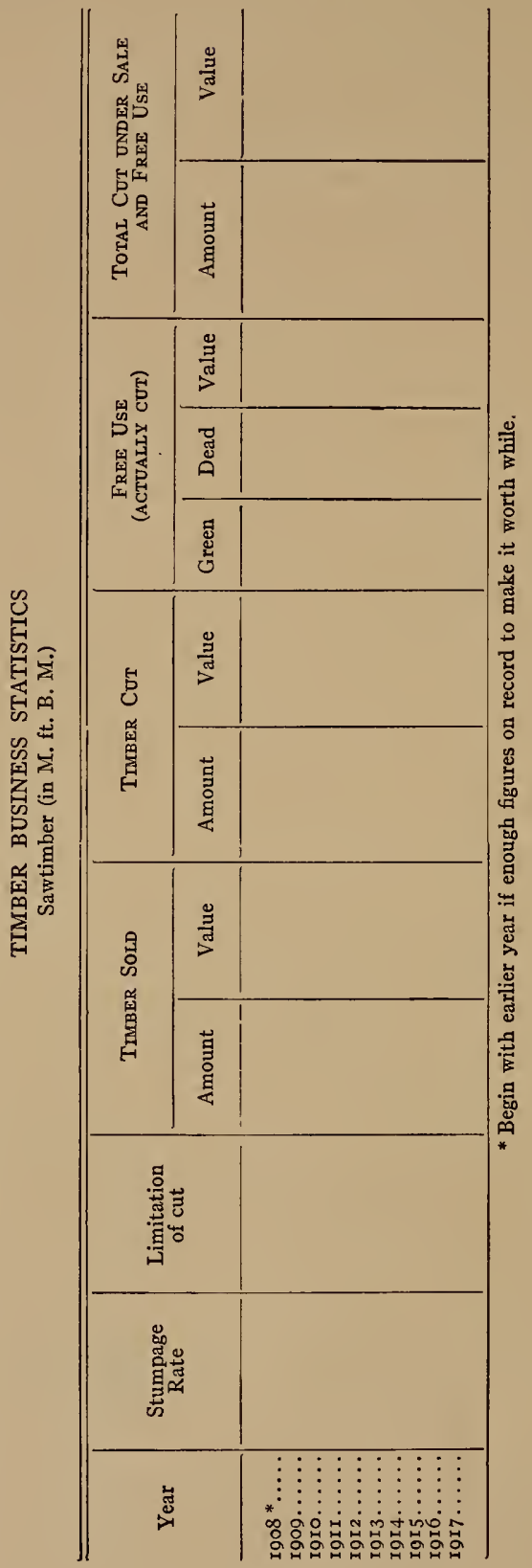


THE THEORY AND PRACTICE OF WORKING PLANS 221

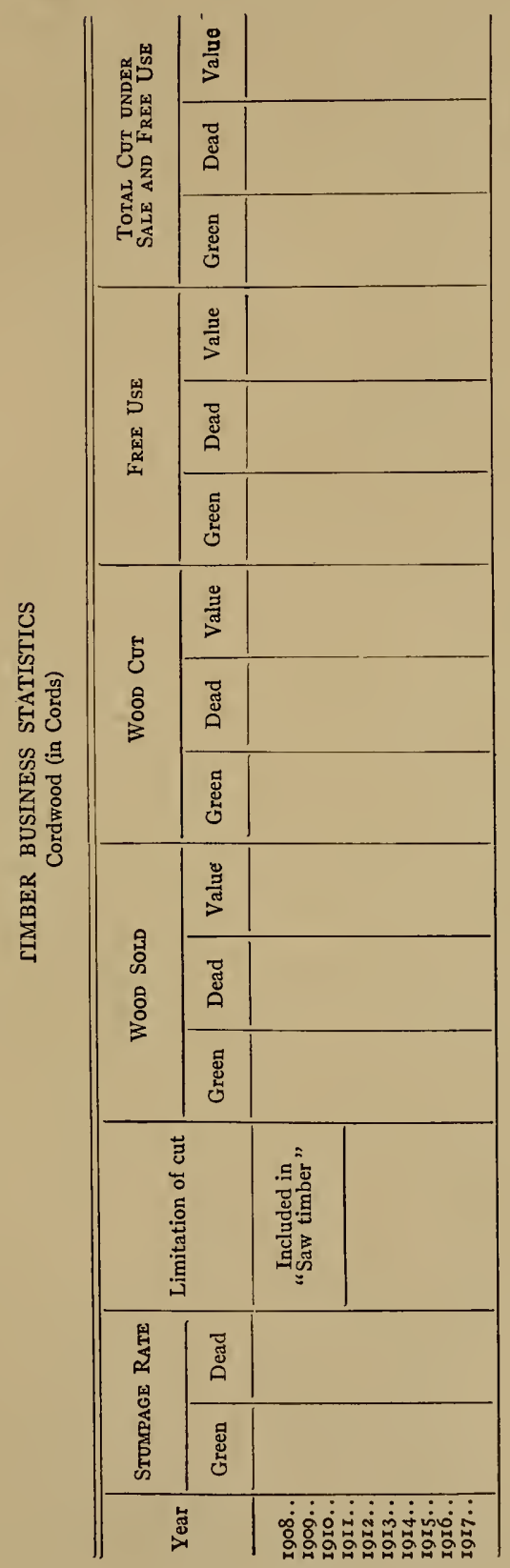


222 THE THEORY AND PRACTICE OF WORKING PLANS

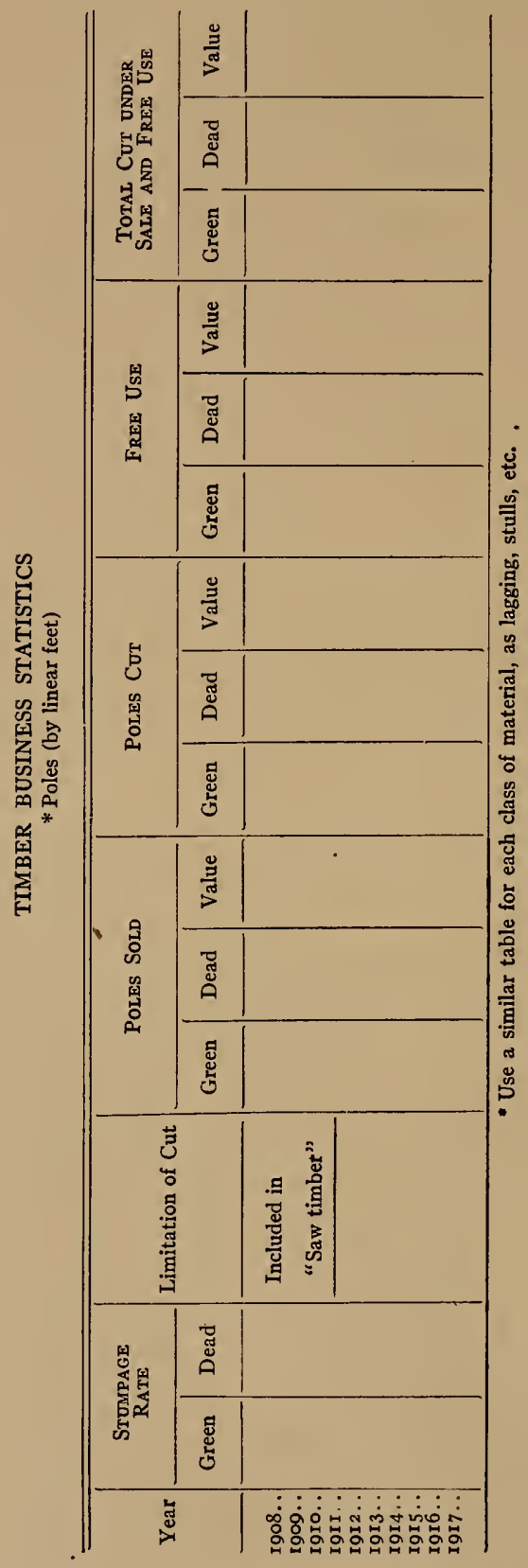


THE THEORY AND PRACTICE OF WORKING PLANS 223

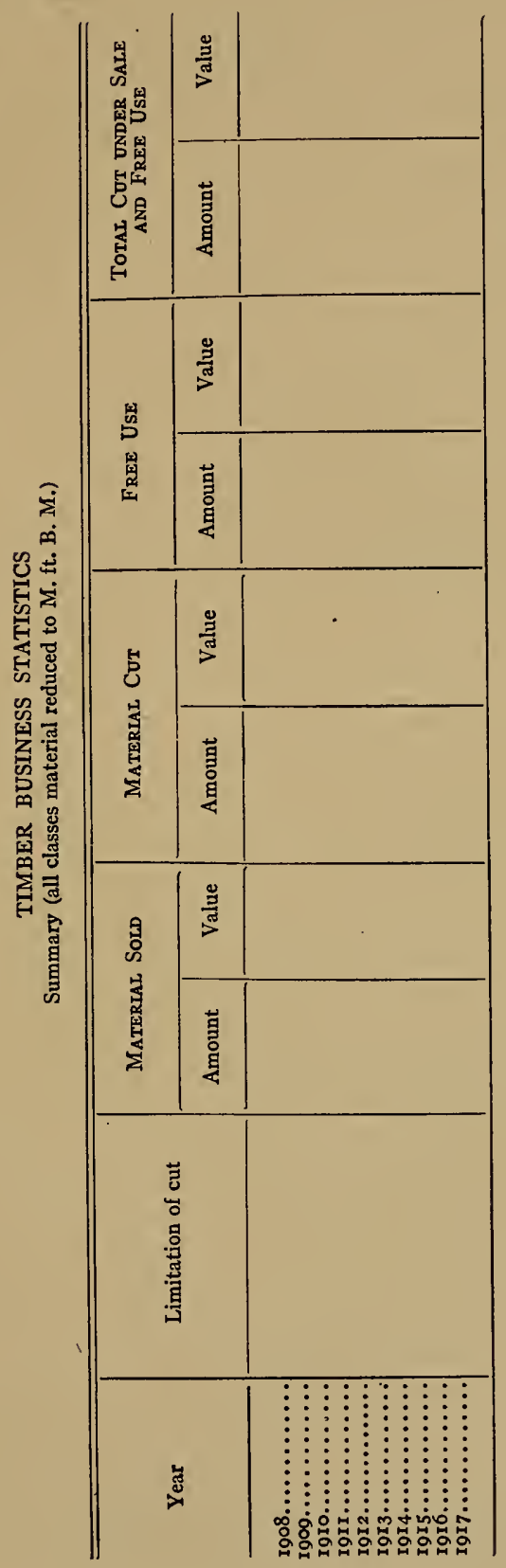




\section{PLANTING *}

Areas Needing Restocking:

\begin{tabular}{c|c|c|c|c|c|c|}
\hline Type & Area \\
\hline &
\end{tabular} \mid

NoTEs.-Make reference to proper map showing planting and sowing areas. Location of areas should usually be done by Timber Reconnaissance parties.

Summary of Results of Past Planting a:id Soxi: : :

\section{Policy:}

Brief statement of character of work proposed.

* Details of tabulated plan for a period of years not necessary. Operations for ensuing year will be covered in annual plan after plan for district is formulated. 
NURSERIES

Policy:

Equipment.

Arec in Seed Beds

Area in Transplant Beds

Tolal Arec

Capacity-Seedlings

Transplants

Proposed Anmual Production Species

Total 
TIMBER RECONNAISSANCE

Portions of Forest Covered:

\begin{tabular}{c|c|c|c|c|}
\hline Division & Block & Area & Year & $\begin{array}{c}\text { Timberland } \\
\text { or Woodland }\end{array}$ \\
\hline & & & \\
\hline
\end{tabular}

Portions to be Covered in Order of Importance:

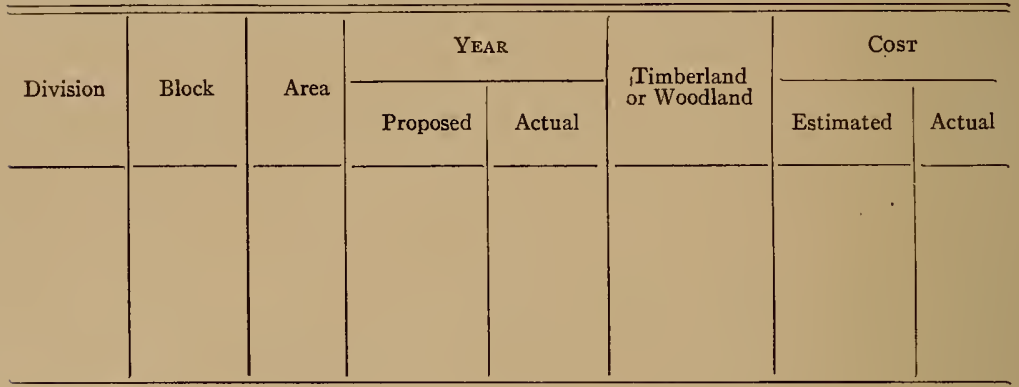

Notes:

Silvical Studies:

INVESTIGATIONS *

Past.

Proposed.

Reforestation Experiments $\uparrow$

* List studies and experiments approved by investigative committee and also any others which appear desirable for future attention.

$\dagger$ If covered under Planting, make suitable reference. 


\section{INDEX}

Abnormal forests, regulation of, 104

Administrative divisions, 25

Administrative plan, instructions for, 203, 209

outline for, 126, 198

Age classes, general classification, 5

in selection forest, 5

size of, 4

table of, 29

table of, in Austria, 183, 186

Allison, J. H., I5

Allowed annual cut (see regulation of yield)

Aménagement (see working plans, practice of, in France) (syn. forest organization)

Annual plans (see working plans, also cutting plan and planting plan) instructions for, in United States, 2 r $\mathrm{I}$

Area, determination of yield by, 44

Auhagen, 92

Austrian formula, determination of yield by, 52, 180, 200

Base lines (see also timber estimates), ro

Block (see also division of area), 20

Breymann's method, determination of yield by, $6 \mathrm{I}$

Brush disposal, place of in working plan (see also marking rules), I20

Bukowina, forest organization in, 180,185

Bureau of Forestry, 190

Collection of data (see also reconnaissance)

in Baden, 165

in Bavaria, 157

in United States, instructions for, 209

preliminary work, 8

survey of area, 9

Compartment (see also division of area), 20, $2 \mathrm{I}$

Control and revision (see working plans, control and revision of)

Cuntrol book, 133

in Austria, 187

in Prussia, 143

Cotta, Heinrich, 92, 160

Coupes (see also determination of yield, in France), 176

Cutting and logging rules, place of in working plan, I2 I

Cutting and planting record (see control book) 
Cutting cycle, record of in working plan (see also rotation), 120

Cutting plan, 97, 100

annual, 103, 121

general, IOI, I $2 \mathbf{I}$

in Bavaria, 155

in France, 174

in Prussia, $\mathbf{I} 39$

place of in revisions, 136

place of in working plan, I2I

Cutting series, 99

in Saxony, 162

Department of Agriculture, I90

Secretary of, 201

Determination of yield, 43

by area, 44

by area and volume by age classes, $81,82,84$

by area and volume by periods, 89

by area and volume for entire forest, 78

by volume on diameter classes, 66

by volume on growing stock, 47,49

by volume on growing stock and increment, 52, 55, 59

by volume on increment, 49

in Austria, 185

in France, 66, 172,176

in United States, 198

record of in working plan, I2I

review of methods, 94

summary of methods, 43

Diameter-class method, determination of yield by, 75

application to America, 78

Direct method, determination of yield by, $8 \mathrm{I}$

Distribution of the age classes, $\mathbf{I}, 4$

advantages of comparison between actual and normal, 7

graphic comparison of actual with normal, 7

record of in working plan (see also tables), I $16, \mathbf{2} 21, \mathbf{1} 36$

Distribution of yield, 96

in France, 175

District Forester, 200, 2I3

Division of area, 20

block, 20, 2 I

boundaries of, 23,25

coincidence with administrative divisions, 25

compartment, 20, 2 I

designations of, 23

in Alsace-Lorraine, I68 
Division of area in Austria, I80

in Bavaria, $148, \mathbf{r}_{5} \mathbf{I}$

in France, 172

in Prussia, I40

in Saxony, r6o

principles of, 20

record of in working plan, II

subcompartment (stand), 20, 2 I

working figure, 20

Estimates (see timber estimates)

Fernow, B. E., see Introduction, p. xii

Fire plan (see forest protection plan)

Forest adjustment (syn. forest organization)

Forest description, 17

essentials of, 17

in Alsace-Lorraine, 169

in Austria, 184

in France, 173

record of in working plan, I I9

unit of, 19

Forest organization

control of, in Austria, I8o

in Bavaria, 157

in Prussia, 142

in Saxony, 159

in United States, I9I, 200, 20I, 209, 212

definition of, see Introduction, p. xi

Forest organizer (see forest organization)

Forest plan, see Introduction, p. xi

section of National Forest Manual, 201

instructions in, 202 et seq.

issued, 201

Forest protection plan, instructions for, 202, 207, 209, 212

outline for, 126,196

Forest Service, 190

Forest types, record of in working plan, 2 I4

Forsteinrichtung (syn. forest organization, which see)

French method, determination of yield by, 66

Graves, Henry S., 2

Grazing management, plan of, instructions tor, 202, 205, 2 II, 212 outline for, 126,195

Greeley, W. B., 106

Growing stock, normal, I, 4 
Growing stock, actual (see reconnaissance and timber estimates) record of, in working plan, I 16

Guzman, E., 185

Hartig, G. L., I 38

Heyer's method, determination of yield by, 63

application to America, 65

Heyer, Carl, 65

Heyer, Gustav, 65

use in Alsace-Lorraine, I70

use in Baden, 166

use in United States, 200

Hufnagl's methods of determining yield, $2,49,75,8 \mathrm{I}, 82,83$

by age classes, $8 \mathbf{I}, 82$

by current annual increment, 49

by diameter classes, 75

formula for determining the yield, 83

application to America, 84

Hundeshagen's method, determination of yield by, 59

Increment, borer, use of, 2

current annual, 3

determination of, I

determination of yield by, 49

importance of, 43

mean annual, 3

normal, I

record of in working plan, 116

Indian method, determination of yield by, 72

Investigations, record of, in working plan, 226

Jagen (see working-plans practice, Prussia)

Judeich, Friedrich, 53, 58, 59, 64, 84

Kameraltaxe (see Austrian formula)

Karl's method, determination of yield by, 55

ILimitation of annual cut (see regulation of yield)

Logging unit (see also Block), 34

Management, object of, 33, 37

record of in working plan, 120,215

silvicultural, Introduction, p. xi

silvicultural method of, 33,35

record of in working plan, $\mathrm{I} 20,2 \mathrm{I} 5$

Manual of procedure, 200 
Maps and tables (see also tables), 28

in working plan, II 7

of stands to be cut (see also cutting plan), 98

sample sketch map, 27

Markets, influence of on sustained yield, 34

Market unit (see also working figure), 34

Marking rules, place of in working plan, 120, 2 I0, 2 I 5

general, 199

Martin, Heinrich, 43, 53, $5^{8}$

Masson, Méthode de, 2, 49

Méthode de 1883 (see French method)

Method of treatment, determination of, 33

Moore, Barrington, 52, 66, 72

National forest manual, $20 \mathrm{r}$

National forests, 190, 19r, 198

New reconnaissance, the, I9I

Normal forest, its attributes, I

Office of forest management, $19 \mathrm{r}$

Office of silviculture, 200

Organization (see forest organization)

Paulsen (see also Hundeshagen), 60

Period methods, determination of yield by, 89

area-period method (syn. area framework, "flächenfachwerk"), 89

area-and-volume-period method (syn. combined framework, "kombiniertes fachwerk"), 9I

in Alsace-Lorraine, 169

in Austria, 185

in Baden, 164

in Bavaria, 147

in France, I73, I74

in Prussia, 138

in Saxony, 160

in Württemberg, 163

volume-period method (syn. volume framework, "Massenfachwerk"), 90

Period of regeneration, record of in working plan (see also method of management, silvicultural), I20

Permanent improvement plan, instructions for, 202, 206, 21 1, 212 outline for, 126, 197

Plarting plan, I 28

annual, I28, I30, I3r

general, I28, I29, I32

place of in revisions, 135

place of in working plan, 12 I, 224 
Preliminary plans, in Austria (Bukowina), $\mathbf{1} 80$

in United States, 201, 203

Prussia, practice of working plans in, 137

Reconnaissance (see collection of data and timber estimates)

estimates, method of, 14

record of in working plan, I I 5, 226

section of, I9I, I99, 200

Regulation, in selection forest, Alsace-Lorraine, $\mathbf{1 7 0}$

in special cases, 104

of transition forests, 106

of turpentine forests, 108

of wood-lots, 108

of yield, defined, 42

record of in working plan, 121,216

unit of, 33

Revisions (see working plans, control and revision of)

in Alsace-Lorraine, 170

in Austria, 186

in Baden, 165

in Bavaria, 156

in Prussia, 142

in Saxony, 162

in United States, 213

Rotation, 33,38

choice of, 40

customary rotations in Europe, $4 \mathrm{I}$

financial rotation (syn. of highest soil rent), 39

in Austria, 186

in Bavaria, 152

in Prussia, I4I

latent rotation, 39

of greatest income (syn. of highest forest rent), 39

of greatest volume (syn. silvicultural rotation, economic rotation), 38

physical rotation, 38

record of in working plan, I20, 216

technical rotation, 38

Russian method, determination of yield by, 78

Sale policy, 198, 200

Schneider's formula, use or, 2

Section of reconnaissance, I9I, I99, 200

Silvicultural management, plan of, instructions for, 204, 209, 2 I I

outline for, I93, 2 I 2

system (see silvicultural method of management)

Stand (see also subcompartment), 20, 2 I 
Stand, basis of differentiation, 22

selection of stands to be cut (see also cutting plan), 97

Stand method, determination of yield by, 84

application to America, 89

table (see tables)

Statistics, record of in working plan, 220, 221, 222, 223

Strip surveys (see also timber estimates), I2, I92

Stumpage rates, minimum, I99, 200

place of in working plan, I2 I, 2 I 7

standard, 200

Subcompartment (see also division of area, and stand), 20, 2 I

Survey of area (see also collection of data), 9

Sustained yield, application of, 34

relation to increment, 43

total for national forests, $20 \mathrm{I}$

Tables (see also maps and tables)

age-class table, 29; examples of, 31,32 ;

alienation table, 29

area tables, 29

general stand table, example of, 29

in Austria, 184

in Prussia, 139

place of in working plan, II 7

instructions for tabulations, United States, 209

stanrl tables, 29

Timber estimates (see also collection of data and reconnaissance)

base lines, Io

cost of, 17

in Austria, 182

in Bavaria, 150

in United States, I9I, I92, 213, 214

ocular estimates (see also reconnaissance), I3

requisites, Io

size of crew, 12

the strips, 12

time of, 16

Transition forest, regulation of, 106

Turpentine forest, regulation of, 108 number of crops operative annually, II 2

Use per cent (see Hundeshagen's method)

Uses of forest land, instructions for, 202, 207, 2 I I, 2 I 2

outline for plan of, 127,196

Utilization, record of in working plan, 2 I 8 
Von Grebe, 92

Von Mantel's method, determination of yield by, 2, 47, 200

Von Stockhausen, 92

Wood-lots, regulation of, 108

IVoolsey, T. S., Jr., 200

Working block (see working figure)

Working circle (see working figure)

Working figure (see also division of area), 20, 33

Working period, I2 I, I33, 208

Working plans

conference, $8, \mathrm{I} 36, \mathrm{r} 5^{8}$

record of in plan, I 16, 136, 209

control and revision of, $\mathrm{I} 33$

documents, II3

contents and form, II 3

foundations of, I

outlines for, I22

American outline, suggested, 124

administrative plan, 126

appendix, contents of, 127

forest protection plan, 126

foundation, 125

grazing plan, I 26

maps, 128

orientation, 124

permanent improvement plan, I 26

recommendations, 125

regulation, 126

uses of forest land, 127

Forest service outline, 192

Prussian outline, I22

Saxon outline, I24

ractice of, 137

in Alsace-Lorraine, 167

in America, I90; instructions for, 202, 203, 208, 2 I I

in Austria, I77

in Baden, 164

in Bavaria, 147

in France, $I 7 \mathrm{I}$

in Prussia, 137

in Saxony, 159

in Württemberg, 163

résumé of, in Europe, 187

scope of, Introduction, p. xi

sphere of, Introduction, p. xii

value and need of, Introduction, p. xi 
Working plans officer (see forest organizer)

Yale forest school, Introduction, p. xii

Yield, determination of (see determination of yield)

Yield tables, use of in estimating, 17

Zon, Raphael, 78 



\title{
SHORT-TITLE CATALOGUE \\ OF THE PUBLICATIONS
}

\author{
OF \\ JOHN WILEY \& SONS \\ NEW YORK \\ London: CHAPMAN \& HALL, Limited \\ Montreal, Can.: RENOUF PUB. CO.
}

ARRANGED UNDER SUBJECTS

Descriptive circulars sent on application. Books marked with an asterisk $\left({ }^{\star}\right)$ are sold at net prices on!y. All books are bound in cloth unless otherwise stated.

\section{AGRICULTURE-HORTICULTURE-FORESTRY.}

ARMSBY-Principles of Animal Nutrition.................. 8 vo, $\$ 400$

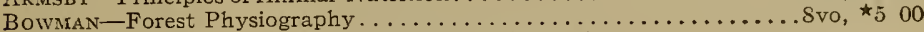
BUDD and HANSEN-American Horticultural Manual:

Part I. Propagation, Culture, and Improvement........... $12 \mathrm{mo}, \quad 150$

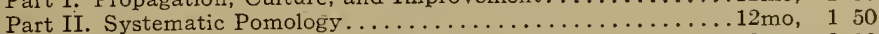

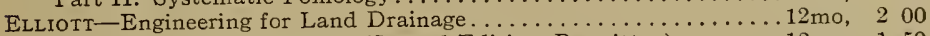

Practical Farm Drainage. (Second Edition, Rewritten)....... 12mo, 150

FUller-Domestic Water Supplies for the Farm............... Svo, ${ }^{1} 50$

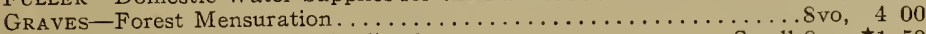

Principles of Handling Woodlands.................................................. 150

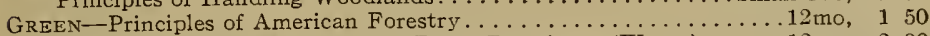

Grotenfelt-Principles of Modern Dairy Practice. (Woll.).......... $12 \mathrm{mo}, 200$

HAwLEY and Hawes -Forestry in New England. . . . . . . . . . . . 8 vo, 350

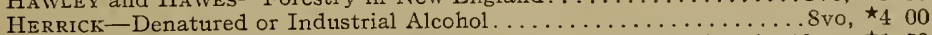

KEMP and WAUGH-Landscape Gardening. (New Edition,Rewritten)...12mo, ^ 150

LARSEN and WhITE-Dairy Technology........................... 8 vo, ${ }^{1} 50$

MCKAY and LARSEN-Principles and Practice of Butter-making. . . . . . 8vo, ${ }^{\star} 150$

Maynard-Landscape Gardening as Applied to Home Decoration. . . 12mo, 150

RECORD-Identification of the Economic Woods of the United States.. . Svo, ${ }_{1} 125$

RECKNAGEL-Theory and Practice of Working Plans (Forest Organi-

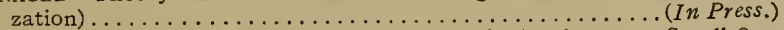

Sanderson- Insect Pests of Farm, Garden, and Orchard.......... Small svo, * 300

Insects Injurious to Staple Crops . . . . . . . . . . . . . 150

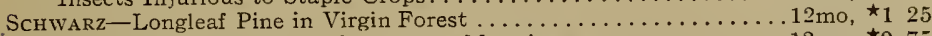

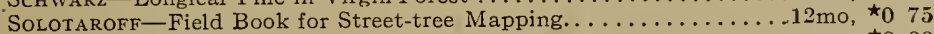

In lots of one dozen. . . . . . . . . . . . . . . . . . . . . . . . 00

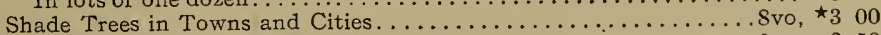

STOCKBRIDGE-Rocks and Soils............................. 250

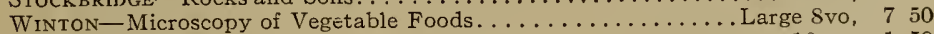

Woll-Handbook for Farme: 3 and Dairymen. . . . . . . . . . . . . 16mo, 150

\section{ARCHITECTURE.}

ATkinson-Orientation of Buildings or Planning for Sunlight........ 8 vo, $\star_{2} 00$ BALDwin-Steam Heating for Buildings.......................... 250 BERG-Buildings and Structures of American Railroads............. 500 
BIRKMIRE-Architectural Iron and Steel. ................. 8vo, $\$ 350$

Compound Riveted Girders as Applied in Buildings............ Svo, 200

Planning and Construction of High Office Buildings.......... 3 vo, 350

Skeleton Construction in Buildings................... 3 vo, 300

Briggs - Modern American School Buildings......................... 4 vo, 00

BYRNE-Inspection of Materials and Workmanship Employed in Construc-

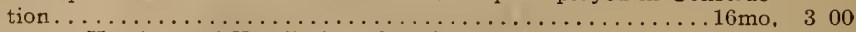

CARPENTER-Heating and Ventilating of Buildings.................

Corthell-Allowable Pressure on Deep Foundations............12mo, $\star_{1} 25$

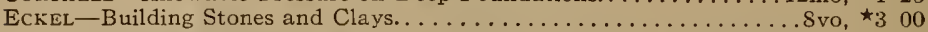

FREITAG-Architectural Engineering.................. 350

Fire Prevention and Fire Protection. . . . . . . . . . . . ${ }_{4} 00$

Fireproofing of Steel Buildings. . . . . . . . . . . . . . 250

Gerhard - Guide to Sanitary Inspections. . . . .

Modern Baths and Bath Houses........................................ 300

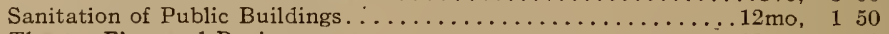

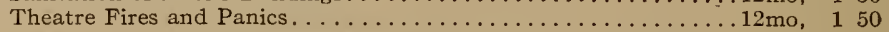

The Water Supply, Sewerage and Plumbing of Modern City Buildings,

8 vo, $\star 400$

GREENE-Elements of Heating and Ventilation............... 8 vo, $\star_{2} 50$

Johnson-Statics by Algebraic and Graphic Methods............... 8 vo, 200

Kellaway - How to Lay Out Suburban Home Grounds. . . . . . . . . . . . Svo, 200

KIDDER-Architects' and Builders' Pocket-book ............ 16mo, mor., 500

MERRILL - Stones for Building and Decoration...................... 500

Monckton-Stair-building. ................................ 400

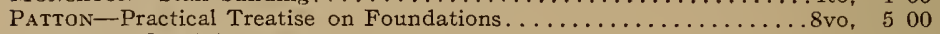

PEABody-Naval Architecture............................... 750

RICE-Concrete-block Manufacture................................. 200

RicheY - Handbook for Superintendents of Construction.......16mo, mor., 400

Building Foreman's Pocket Book and Ready Reference.....16mo, mor,, 500

Building Mechanics' Ready Reference Series: *

Carpenters' and Woodworkers' Edition..........16mo, mor., *1 50

Cement Workers' and Plasterers' Edition..............mo, mor., $\star 150$

Plumbers', Steam-Fitters', and Tinners' Edition......16mo, mor., ^1 50

Stone- and Brick-masons' Edition.............. $16 \mathrm{mo}$, mor., *1 50

Ries-Building Stones and Clay Products. ................

SABIN-House Painting (Glazing, Paper Hanging and Whitewashing).12mo, 100

SIEBERT and BIGGIN-Modern Stone-cutting and Masonry...........8vo, 150

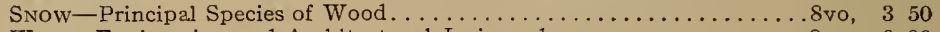

WAIT-Engineering and Architectural Jurisprudence . ...........8vo, 600

Sheep, 650

Law of Contracts............................ 300

Law of Operations Preliminary to Construction in Engineering and Architecture. . . . . . . . . . . . .

Sheep, 550

Wilson-Air Conditioning. . . . . . . . . . . . . . . $150 \ldots \ldots 12 \mathrm{mo}$

WORCESTER and ATKINSON-Small Hospitals, Establishment and Maintenance, Suggestions for Hospital Architecture, with Plans for a Small

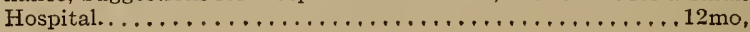

\section{ASSAYING.}

Betts-Lead Refining by Electrolysis.................. 8vo, 400 .

FLetCheR - Practical Instructions in Quantitative Assaying with the Blow-

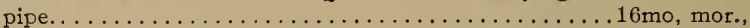
Furman and PARdoe-Manual of Practical Assaying....................... LODGE-Notes on Assaying and Metallurgical Laboratory Experiments . 8vo, Low-Technical Methods of Ore Analysis . . . . . . . . . . . . . . . 8 vo, Miller-Cyanide Process . . . . . . . . . . . . . . . . . . . . .

Manual of Assaying. . . . . . . . . . Minet-Production of Aluminum and its Industrial Use. (WALDo)... 12mo, PRICE and MEADE-The Technical Analysis of Brass and the Non-Ferrous

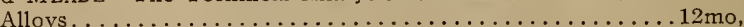

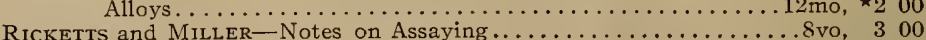

Robine and Lenglen-Cyanide Industry. (Le Clerc.) ............... SEAMoN-Manual for Assayers and Chemists.............. Small 8 vo, $\star_{2} 50$ 
ULKE-Modern Electrolytic Copper Refining. ................. 8vo, $\$ 300$

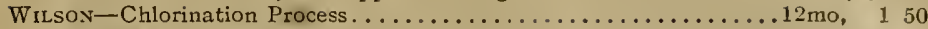

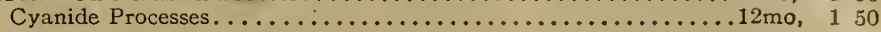

\section{ASTRONOMY.}

Comstock-Field Astronomy for Engineers................8vo, 250

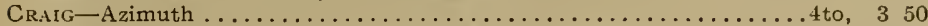

CRandall - Text-book on Geodesy and Least Squares............. 8vo, 300

Doolittle-Treatise on Practical Astronomy.................. 400

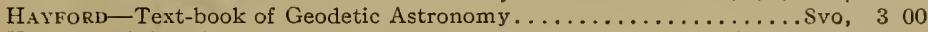

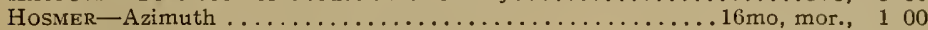

Text-book on Practical Astronomy......................... 200

Merrinian-Elements of Precise Surveying and Geodesy ......... 8vo, 250

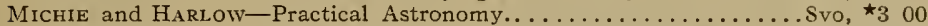

Rust-Ex-meridian Altitude, Azimuth and Star-Finding Tables...... Svo, 500

WhiTe--Elements of Theoretical and Descriptive Astronomy.......12mo, $\star_{2} 00$

\section{BIOLOGY.}

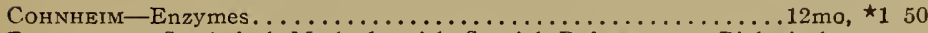
DavenPor - Statistical Methods with Special Reference to Biological

Variation................................. mor, 150

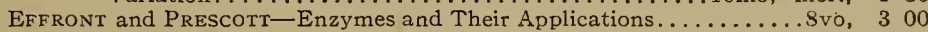

Euler and POPE-General Chemistry of the Enzymes.............. Svo, $\star_{3} 00$

MAST-Light and Behavior of Organisms................................ 50

PRESCOTT and WinsLOW-Elements of Water Bacteriology, with Special

Reference to Sanitary Water Analysis................... 150

WARD and WHIPPLE-Freshwater Biology ................ (In Press.)

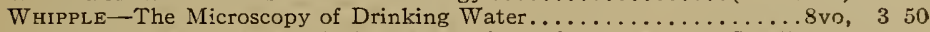

WinsLow-The Systematic Relationship of the Coccacea............... 8 vo, 250

\section{CHEMISTRY.}

AbDerhalden-Physiological Chemistry in Thirty Lectures. (HALl and

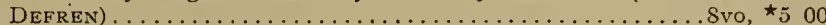

ABEGG - Theory of Electrolytic Dissociation. (von ENDE.)..................... 125 AlexeyefF-General Principles of Organic Syntheses. (Matiheivs.).. Svo, 300 ALLEN-Exercises in General Chemistry, Loose Leaf Laboratory Manual. Oblong 4to, paper, $\star_{1} 00$

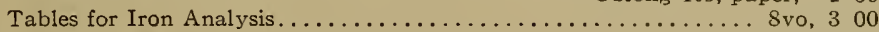

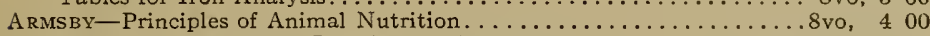
ARNold-Compendium of Chemistry. (MANDEL.)............. Association of State and National Food and Dairy Departments, Hartford Meeting, $1906 \ldots \ldots \ldots \ldots \ldots \ldots \ldots \ldots \ldots \ldots$. . . . 300

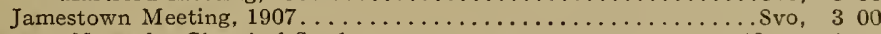

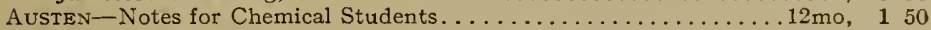
BERNADOU-Smokeless Powder.-Nitro-cellulose, and Theory of the Cellulose Molecule................................ 250

BILtz-Introduction to Inorganic Chemistry. (HALl and PHELAN.)... 12 mo, ${ }_{1} 125$

Laboratory Methods of Inorganic Chemistry. (HALL and Blanchard.)

Svo, 300
(1)

BinghaM and White-Laboratory Manual of Inorganic Chemistry... $12 \mathrm{mo}^{*}{ }^{*}{ }_{1} 00$ BlANCHARD - Synthetic Inorganic Chemistry. . . . . . . . . . . $12 \mathrm{mo} \star^{\star} 100$ BotTLER-German and American Varnish Making. (SABIN.)... Small Svo $\star_{3} 50$

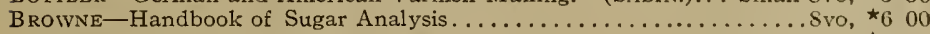

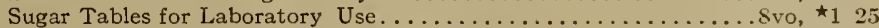

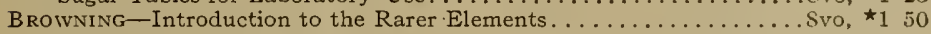
Brunsivig-Explosives. (MUNROE and KIBLER) .............. Small Svo, ${ }^{\star} 300$ ClaAssen-Beet-sugar Manufacture. (Hall and Rolfe.).................... ${ }^{3} 00$ Classen-Quantitative Analysis by Electrolysis. (H.All.)......... (In Press.) 
Cohn-Indicators and Test-papers.................... $12 \mathrm{mo}, \$ 200$

Tests and Reagents................................... 300

Cooper-Constitutional Analysis by Physico-chenical Methods (Inorganic),

(In Press.)

DANNEEL-Electrochemistry. (MERriam.).................

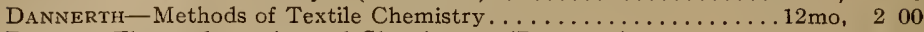

DuHem-Thermodynamics and Chemistry. (Burgess.)............ 4 vo, 400

EISSLER-Modern High Explosives........................ 4 vo, 00

EKELEY - Laboratory Manual of Inorganic Chemistry . . . . . . . . . . .

Fletcher-Practical Instructions in Quantitative Assaying with the Blow-

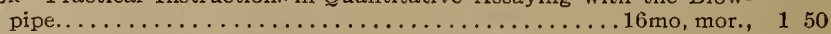

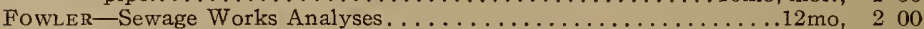

Fresenius-Manual of Qualitative Chemical Analysis. (Wells.)....8vo, 500 Manual of Qualitative Chemical Analysis. Part I. Descriptive.

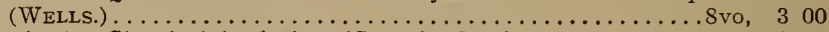

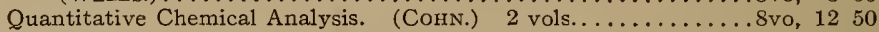
When Sold Separately, Vol. I, $\$ 6$. Vol. II, $\$ 8$.

Fuertes - Water and Public Health..................... 150

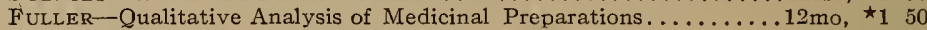

Furman and PARdoe-Manual of Practical Assaying.............. 3 vo, 300

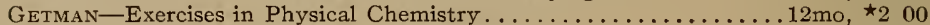

GiLL-Gas and Fuel Analysis for Engineers................. 125

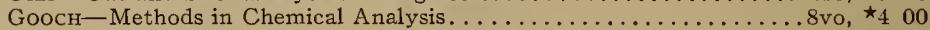

and BRownING-Outlines of Qualitative Chemical Analysis. . Small 8vo. ${ }^{\star} 125$

Grotenfelt-Principles of Modern Dairy Practice. (Woll.)......12mo, 200

Groth-Introduction to Chemical Crystallography. (MARSHall.)...12mo, 125

Hammarsten-Text-book of Physiological Chemistry. (Mandel.)....8vo, $\star_{4} 00$

HanaUsex - Microscopy of Technical Products. (Winton.)........ 8 vo, 500

Haskins - Organic Chemistry . . . . . . . . . . . . . . . . . . ${ }^{2} 00$

HERRICK - Denatured or Industrial Alcohol . . . . . . . . . . . . . . . . vo $^{\star_{4}} 00$

Hinds-Inorganic Chemistry.................................. 300

Laboratory Manual for Students ................................... ${ }^{1} 00$

Holleman-Laboratory Manual of Organic Chemistry for Beginners.

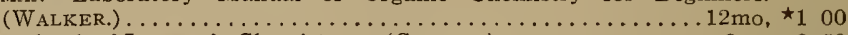

Text-book of Inorganic Chemistry. (COOPER.).............. 250

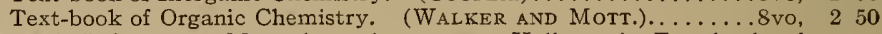

(Ekelex) Laboratory Manual to Accompany Holleman's Text-book of

Inorganic Chemistry.................................. ${ }^{\star} 100$

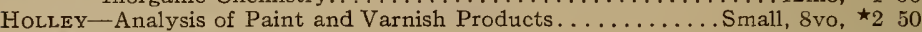

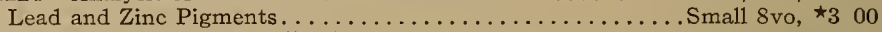

HopkINs-Oil-chemists' Handbook...................................... 300

JACKSON-Directions for Laboratory Work in Physiological Chemistry..8vo, 125

Johnson-Rapid Methods for the Chemical Analysis of Special Steels, Steelmaking Alloys and Graphite....................................... 300

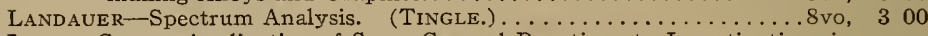

LASSAR-COHN-Application of Some General Reactions to Investigations in

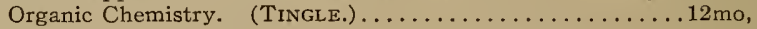

LEACH-Food Inspection and Analysis. . . . . . . . . . . . . .

Löв-Electrochemistry of Organic Compounds. (LoREnz.).........8vo,

LODGE- Notes on Assaying and Metallurgical Laboratory Experiments . .8vo,

Low-Technical Method of Ore Analysis. . . . . . . . . . . . . . 8vo

Lowe-Paint for Steel Structures. . . . . . . . . . . . . . . . . . . .

LUNGE-Techno-chemical Analysis. (CoHn.) . . . . . . . . . . .

MAIRE-Modern Pigments and their Vehicles....................... 200

MANDEL - Handbook for Bio-chemical Laboratory.................... I 50

MARTIN-Laboratory Guide to Qualitative Analysis with the Blowpipe.12mo, ${ }^{\star} 060$

MASON-Examination of Water. (Chemical and Bacteriological.)....12mo, 125

Water-supply. (Considered Principally from a Sanitary Standpoint.)

Svo, 400

Mathewson-First Principles of Chemical Theory............ 8 vo $^{\text {, }}{ }^{*} 00$

Matrhews-Laboratory Manual of Dyeing and Textile Chemistry.....8vo, 350

Textile Fibres................................ 400

Meyer-Determination of Radicles in Carbon Compounds. (TIngle.)

Third Edition........................................ 125

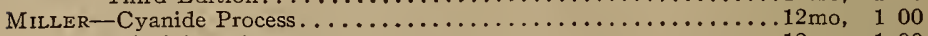

Manual of Assaying.............................. 100 
Minet-Production of Aluminum and its Industrial Use. (WALDo.). . 12mo, \$2 50 MittelstaEdT-Technical Calculations for Sugar Works. (BourBakis.)

IXTER-Elementary Text-book of Chemistry .............. $12 \mathrm{mo}, \quad 150$

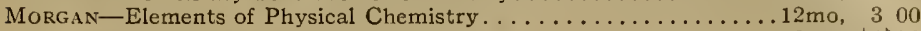
Physical Chemistry for Electrical Engineers.............

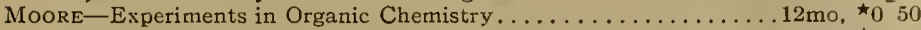

Outlines of Organic Chemistry............................ ${ }_{1} 50$

MORSE-Calculations used in Cane-sugar Factories..........16mo, mor., 150

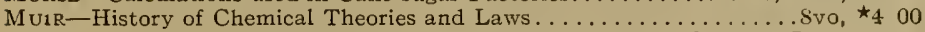

MULL1KEN-General Method for the Identification of Pure Organic Compounds. Vol. I. Compounds of Carbon with Hydrogen and

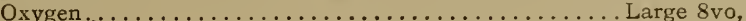

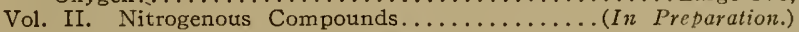

Vol. III. The Commercial Dyestuffs...................... 8vo, 500

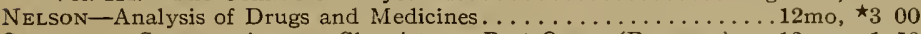

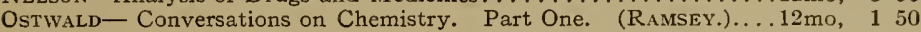
Part Two. (Turnbull.). $12 \mathrm{mo}, 200$

Introduction to Chemistry. (HaLl and Williams.)........ Small $8 \mathrm{vo}$, ${ }^{1} 50$ Owen and Standage-Dyeing and Cleaning of Textile Fabrics.....12mo, 200

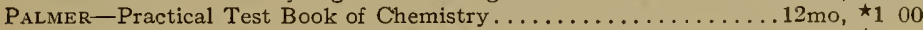
PAULI-Physical Chemistry in the Service of Medicine. (FISCHER.)..12mo, ${ }_{1} 125$ Pictet-Alkaloids and their Chemical Constitution. (Brddle.)......8vo, 500 PRESCOTT and WrNsLow-Elements of Water Bacteriology, with Special Reference to Sanitary Water Analysis................... 150

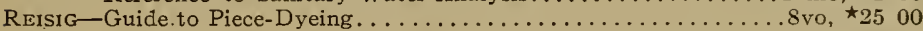
RICHARDS and WOODMAN-Air, Water, and Food from a Sanitary Stand-

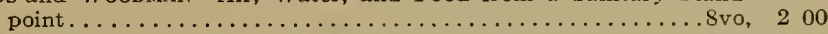

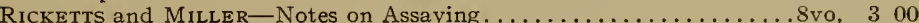

RideaL-Disinfection and the Preservation of Food.............. Svo, 400

Riggs-Elementary Manual for the Chemical Laboratory............ svo, 125

Robine and Lenglen-Cyanide Industry. (Le Clerc.).......... 8 vo, 400

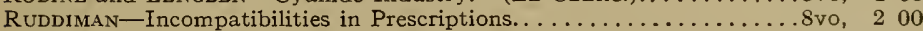

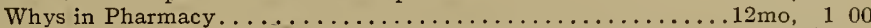

Ruer-Elements of Metallography. (MATHEwson.).............. $\mathrm{vo}^{\star} 300$

SABIN-Industrial and Artistic Technology of Paint and Varnish...... . 8vo, 300

SALkowski-Physiological and Pathological Chemistry. (Orndorff.).. 8vo, 250

ScHrmpF-Essentials of Volumetric Analysis.............. Small 8vo, $\star_{1} 50$

Manual of Volumetric Analysis..................... 5 \&o, 503

Qualitative Chemical Analysis. ................................. ${ }^{1} 25$

SEAMON-Manual for Assayers and Chemists............. Small Svo, $\star_{2} 50$

SMrth-Lecture Notes on Chemistry for Dental Students........... \&vo, $\star_{2} 50$

SPENCER-Handbook for Cane Sugar Manufacturers........16mo, mor., 300

Handbook for Chemists of Beet-sugar Houses..............mo, mor., 300

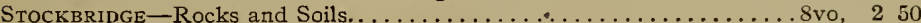

STone-Practical Testing of Gas and Gas Meters................

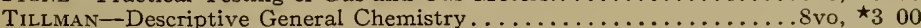

Elementary Lessons in Heat. ............................. ${ }_{1} 50$

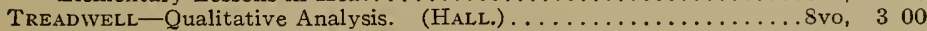

Quantitative Analysis. (Hall.)................... 400

Turneaure and Russell-Public Water-supplies.......................... 5 vo 00

Van Deventer-Physical Chemistry for Beginners. (Boltwood.) . 12mo, 150

VeNABLE-Methods and Devices for Bacterial Treatment of Sewage...8vo, 300

WARD and WHIPPLE-Freshwater Biology............... In Press.)

WARE-Beet-sugar Manufacture and Refining. Vol. $1 \ldots \ldots \ldots \ldots \ldots \ldots$. . . . . 400

Vol. II .................. 5 svo, 500

WASHington-Manual of the Chemical Analysis of Rocks............ Svo, 200

WEAVER - Military Explosives...................................... ${ }_{3} 00$

WELLS-Laboratory Guide in Qualitative Chemical Analysis.........8vo, 150

Short Course in Inorganic Qualitative Chemical Analysis for Engineering

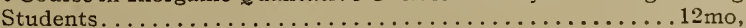

Text-book of Chemical Arithmetic......................... 125

Whipple-Microscopy of Drinking-water.................. 3 vo, 350

WILson-Chlorination Process............................ 150

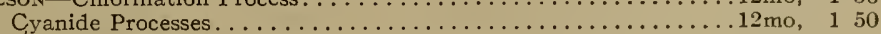

Winton-Microscopy of Vegetable Foods.................

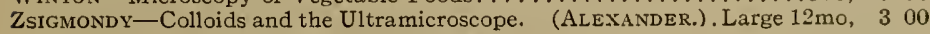




\section{CIVIL ENGINEERING.}

\section{BRIDGES AND ROOFS, HYDRAULICS, MATERIALS OF ENGINEER-}

ING. RAILWAY ENGINEERING.

American Civil Engineers' Pocket Book. (Mansfield Merriman, Editor-in-chief.) ........................ mor. $\star \$ 500$ BAKER-Engineers' Surveying Instruments . . . . . . . . . . $3 \ldots \ldots \ldots 12 \mathrm{mo}, \quad 3 \ldots$ BrxBy-Graphical Computing Table................................ $19 \frac{1}{2} \times 24 \frac{1}{4}$ inches, 025 BREed and Hosmer-Principles and Practice of Surveying.

Vol. I. Elementary Surveying...................... 3 vo, 300

Vol. II. Higher Surveying....................................... 250 BURR - Ancient and Modern Engineering and the Isthmian Canal...... . 8 vo, $\star_{3} 50$ Comstock-Field Astronomy for Engineers................ Cortilell-Allowable Pressure on Deep Foundations............ $12 \mathrm{mo}$, $\star_{1} 25$ Crandall - Text-book on Geodesy and Least Squares. . . . . . . . . . . . svo, 300 Davis-Elevation and Stadia Tables........................ 100 Ellior -Engineering for Land Drainage...................

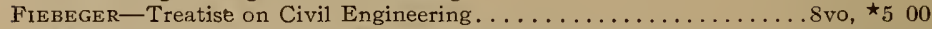
Flemer-Phototopographic Methods and Instruments........... 5 vo, 500 Folwell - Sewerage. (Designing and Maintenance.). .......... 8vo, 300 Freitag-Architectural Engineering. ............................ 350 HaUCH and Rice-Tables of Quantities for Preliminary Estimates. . 12mo, 1225 HAYFORD - Text-book of Geodetic Astronomy................. 300 HeRING-Ready Reference Tables (Conversion Factors.) ........16mo, mor., 250

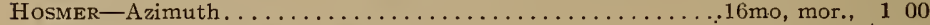

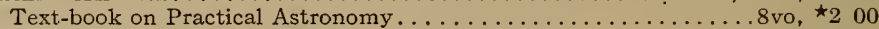

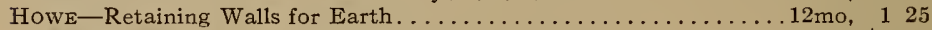

Ives-Adjustments of the Engineer's Transit and Level................. bds., ${ }^{\star} 025$ Ives and Hrlts-Problems in Surveying, Railroad Surveying and Geodesy................................... 150

Johnson (J. B.) and Smith-Theory and Practice of Surveying. Small $8 \mathrm{vo}, \star_{3} 50$ Johnson (L. J.) -Statics by Algebraic and Graphic Methods........ . 8vo, 200 Kinnicutt, Winslow and PRATt-Sewage Disposal.............8vo, * $_{3} 00$

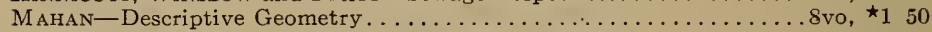

Merriman-Elements of Precise Surveying and Geodesy......... 250

MERriman and Brooks-Handbook for Surveyors........16mo, mor., 200

Nugent-Plane Surveying . . . . . . . . . . . . . . . . . . $3 \ldots \ldots \ldots$ svo, 50

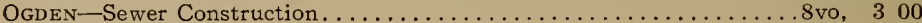

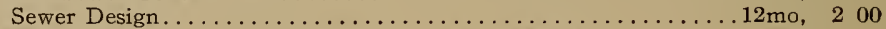

Ogden and Cleveland-Practical Methods of Sewage Disposal for Resi-

dences, Hotels, and Institutions. ...................... $\star_{1} 50$

Parsons--Disposal of Municipal Refuse................... 2 vo, 200

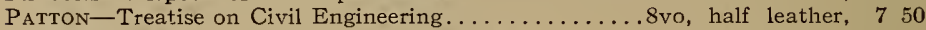

REED - Topographical Drawing arid Sketching.................. 500

Riemer-Shaft-sinking under Difficult Conditions. (Corning and Peele.)

8vo, 300

Siebert and Biggin-Modern Stone-cutting and Masonry...........8vo, 150

SMITH-Manual of Topographical Drawing. (McMillan.)......... 8 vo, 250

SOPER - Air and Ventilation of Subways.................

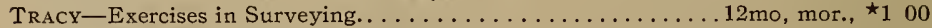

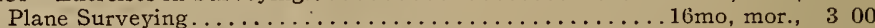

VENABLE-Garbage Crematories in America............... vo, 200

Methods and Devices for Bacterial Treatment of Sewage........... 3 vo, 300

WArT-Engineering and Architectural Jurisprudence............ 8 vo, 600

Sheep, 650

Law of Contracts. . . .

Law of Operations Preliminary to Construction in Engineering and Architecture.............................. 5 vo, 500

Sheep, 550

WARREN-Stereotomy-Problems in Stone-cutting............. WATERBURY-Vest-Pocket Hand-book of Mathematics for Engineers.

$2 \frac{7}{8} \times 5 \frac{3}{8}$ inches, mor., ${ }_{\star} 100$

Enlarged Edition, Including Tables . ..................mor., ${ }_{1} 50$

WeBB-Problems in the Use and Adjustment of Engineering Instruments.
$16 \mathrm{mo}$, mor.,

Wilson-Topographic, Trigonometric and Geodetic Surveying .......8vo, 350 


\section{BRIDGES AND ROOFS.}

Bishop-Structural Details of Hip and Valley Rafters... Oblong large 8vo ${ }^{\star} \$ 175$ Boller-Practical Treatise on the Construction of Iron Highway Bridges

Thames River Bridge..................... Oblong paper, $\star_{5} 00$

BURR and FALK-Design and Construction of Metallic Bridges....... svo, 500

Influence Lines for Bridge and Roof Compitations . . . . . . . . 8vo, 300

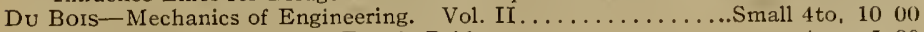

Foster-Treatise on Wooden Trestle Bridges............... 4 to, 500

Fowler-Ordinary Foundations. . . . . . . . . . . . . . . . . . 3 vo, 50

GREENE-Arches in Wood, Iron, and Stone....................... 250

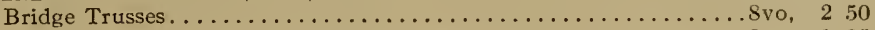

Roof Trusses...................................... 125

GRIMM-Secondary Stresses in Bridge Trusses............... 8 vo, 250

Helle - Stresses in Structures and the Accompanying Deformations. . 8vo, 300

Howv-Design of Simple Roof-trusses in Wood and Steel. . . . . . . . 8vo, 200

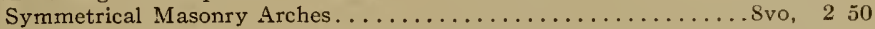

Treatise on Arches............................... 400

Hunsow-Deflections and Statically Indeterminate Stresses.. . . . Small 4 to, $\star_{3} 50$

Plate Girder Design........................................ ${ }^{\star} 50$

JACOBX-Structural Details, or Elements of Design in Heavy Framing, Svo, $\star_{2} 25$

Johnson, Bryan and Turneavre-Theory and Practice in the Designing of

Modern Framed Structures. New Edition.

Part I. Stresses in Simple Structures................. 8vo, 300

Part II. Statically Indeterminate Structures and Secondary Stresses

MERRIMAN and JACOBY-Text-book on Roofs and Bridges:

Part I. Stresses in Simple Trusses...................

Part II. Graphic Statics. . . . . . . . . . . .

Part III. Bridge Design.............................. 250

Part IV. Higher Structures........................................... 250

Ricker-Design and Construction of Roofs................

SoNDERICKER-Graphic Statics, with Applications to Trusses, Beams, and

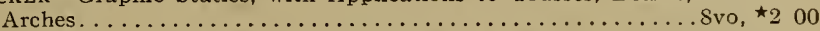

Waddel -De Pontibus, Pocket-book for Bridge Engineers. . . .16mo, mor., 200

Specifications for Steel Bridges....................

\section{HYDRAULICS.}

BARNeS-Ice Formation. . . . . . . . . . . . . . . . . . . .

BAzIN-Experiments upon the Contraction of the Liquid Vein Issuing from an Orifice. (TRaUtwine.) ........................... 200

Bovex - Treatise on Hydraulics............................. 500 CHURCh-Diagrams of Mean Velocity of Water in Open Channels.

Oblong 4to, paper, 150

Hydraulic Motors. ............................... 200

Mechanics of Fluids (5eing Part IV of Mechanics of Engineering). .8vo, 300

Coffrn-Graphical Solution of Hydraulic Problems...........16mo, mor., 250

FLATHER-Dynamometers, and the Measurement of Power.......12mo, 300

Folwell-Water-supply Engineering.................... 4 vo, 400

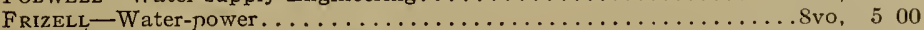

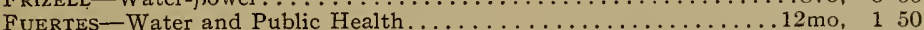

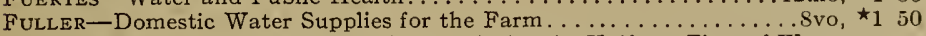

GANGUillet and KuTteR-General Formula for the Uniform Flow of Water

in Rivers and Other Channels. (HeRING and Trautwine.)...8vo, 400

HazeN-Clean Water and How to Get It................................. 150

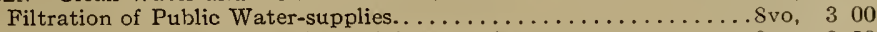

HAzElHuRst-Towers and Tanks for Water-works............... 250

HerscheL-115 Experiments on the Carrying Capacity of Large, Riveted,

Metal Conduits.................................. 200

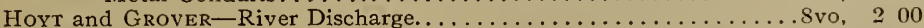

HuBBARD and KIERSTED-Water-works Management and Maintenance, 8 vo, 400

Lyndon-Development and Electrical Distribution of Water Power. .8vo, 300

MAsoN-Water-supply. (Considered Principally from a Sanitary Stand-

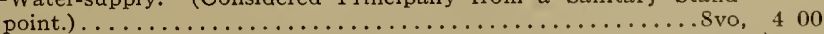

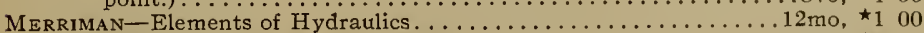

Treatise on Hydraulics. 9 th Edition, Rewritten................ ${ }_{4} 00$ 
MoliIOR-Hydraulics of Rivers, Weirs and Sluices.............. 8 vo, $\$ 200$

Morrison and Brodie-High Masonry Dam Design................ 8vo, ${ }^{1} 50$ SCHUYLER-Reservoirs for Irrigation, Water-power, and Domestic Water supply. Second Edition, Revised and Enlarged....... Large 8vo, 600 Thomas, and WAтt-Improvement of Rivers . . . . . . . . . . . . . TURneaUre and RUSSELL-Public Water-supplies.............. 8 vo, 500 Wegmann-Design and Construction of Dams. 6th Ed., enlarged.....4to, $\star_{6} 00$ Water Supply of the City of New York from 1658 to $1895 \ldots \ldots \ldots .4$ to, 1000

Whipple -Value of Pure Water................................. 100 Williams and Hazen-Hydraulic Tables............................ 150

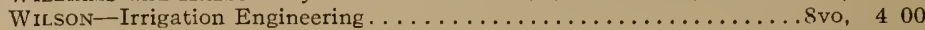

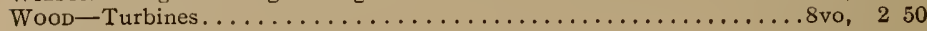

\section{MATERIALS OF ENGINEERING.}

Baker-Roads and Pavements. . . . . . . . . . . . . . . 5 . 00 Treatise on Masonry Construction................................. 500

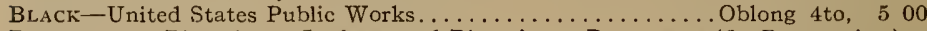

Blanchard-Bituminous Surfaces and Bituminous Pavements.(In Preparation.)

and Drowne-Highway Engineering, as Presented at the Second

International Road Congress, Brussels, $1910 \ldots \ldots \ldots \ldots \ldots \ldots$ vo, ${ }^{2} 00$

Text-book on Highway Engineering....................... (In Press.)

Bottler-German and American Varnish Making. (Sabin.)... . Small 8vo, ^3 50

BURR-Elasticity and Resistance of the Materials of Engineering.....8vo, 750

ByRne-Highway Construction. . . . . . . . . . . . . . . 5 . 00

Inspection of the Materials and Workmanship Employed in Construction.

$16 \mathrm{mo}, 300$

CHURCh-Mechanics of Engineering......................... 600 Mechanics of Solids (Being Parts I, II, III of Mechanics of Engineer-

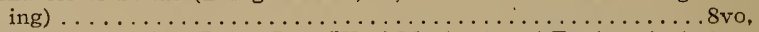
Mechanics of Fluids (Being Part IV of Mechanics of Engineering).8vo,

Du Bors-Mechanics of Engineering:

Vol. I. Kinematics, Statics, Kinetics.............. Small 4to,

Vol. II. The Stresses in Framed Structures, Strength of Materials and

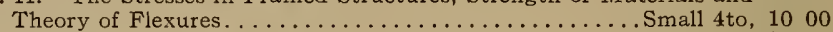

Eckel-Building Stones and Clays. . . . . . . . . . . . . . . . . . .

Cements, Limes, and Plasters. . . . . . . . . . . . . . . . . . . 8 vo, ${ }^{\star} 600$

FowLER-Ordinary Foundations.............................. 350

Fuller and Johnston-Applied Mechanics:

Vol. I. Theory of Statics and Kinetics................ (In Press.)

Vol. II. Strength of Materials......................... (In Preparation.)

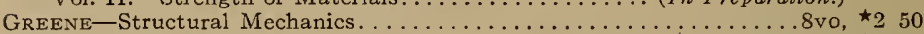

Holley-Analysis of Paint and Varnish Products............. Small 8vo, $\star_{2} 50$

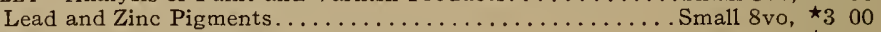

HubBaRd - Dust Preventives and Road Binders . . . . . . . . . . . 8 vo, $\star_{3} 00$

Johnson (J. B.) - Materials of Construction..................... 8 vo, 600

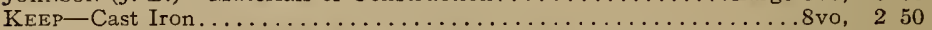

Krng-Elements of the Mechanics of Materials and of Power of Transmis-

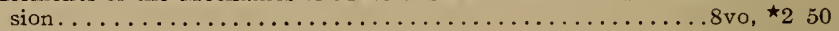

LANZA-Applied Mechanics....................... 8vo, 750

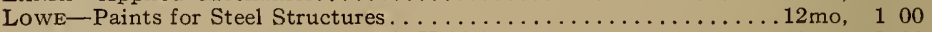

Marre-Modern Pigments and their Vehicles..................... 200

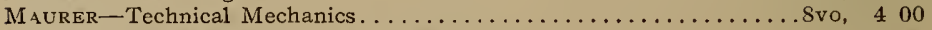

MERRILL - Stones for Building and Decoration. . . . . . . . . . . 5 . 00

Merriman-Mechanics of Materials.................... 500

Strength of Materials..................................... ${ }_{1} 00$

MetCAlf-Steel. A Manual for Steel-users................ 2 mo, 200

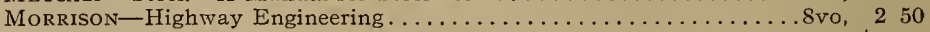

MURDOCK-Strength of Materials .....................

PAtron-Practical Treatise on Foundations................... 500

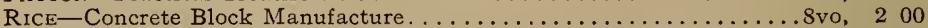

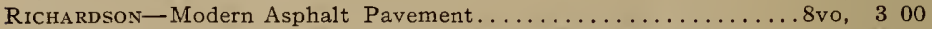

Richey-Building Foreman's Pocket Book and Ready Reference.16mo.mor,, 500

Cement Workers' and Plasterers' Edition (Building Mechanics' Ready

Reference Series $). . \ldots \ldots \ldots \ldots \ldots \ldots \ldots \ldots \ldots \ldots \ldots$.................. ${ }^{1} 50$

Handbook for Superintendents of Construction........16mo, mor., 400

Stone and Brick Masons' Edition (Building Mechanics' Ready Reference Series) . . . . . . . . 
Ries-Building Stones and Clay Products................ 8 vo ${ }^{\star} \$ 300$ Clays: Their Occurrence, Properties, and Uses................ and LeightoN-History of the Clay-working Industry of the United States....................................... 50

SABIN-Industrial and Artistic Technology of Paint and Varnish......8vo, 300

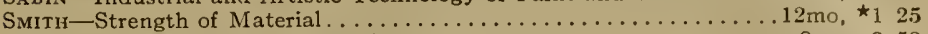

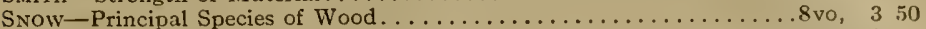

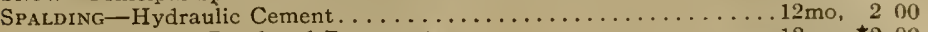

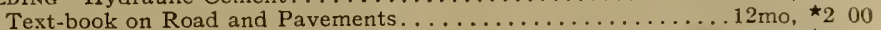

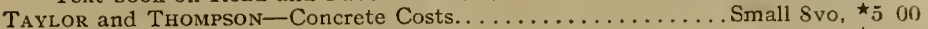

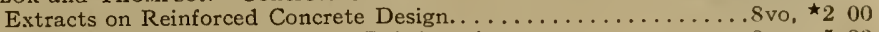

Treatise on Concrete, Plain and Reinforced..............8vo, 500

Thurston-Materials of Engineering. In Three Parts........... 8 vo, 800

Part I. Non-metallic Materials of Engineering and Metallurgy . . 8vo, 200

Part II. Iron and Steel. . . . . . . . . . . . . . . $5 \ldots \ldots \ldots$. 50

Part III. A Treatise on Brasses, Bronzes, and Other Alloys and their

Constituents.......................... 250

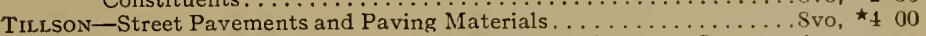
Turneaure and MaURer-Principles of Reinforce 1 Concrete Construction.

8 vo, 350

Waterbury-Cement Laboratory Manual................. $12 \mathrm{mo}, 100$

Laboratory Manual for Testing Materials of Construction........ $12 \mathrm{mo}$, 150

WOOD (DE V.) Treatise on the Resistance of Materials, and an Appendix on the Preservation of Timber.....................

(M. P.)-Rustless Coatings: Corrosion and Electrolysis of Iron and

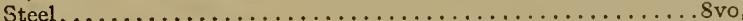

\section{RAILWAY ENGINEERING.}

BERG-Buildings and Structures of American Railroads. . . . . . . . 4 to, 500 Brooks-Handbook of Street Railroad Location. . . . . . . . . . . . . . . . . mor., 150

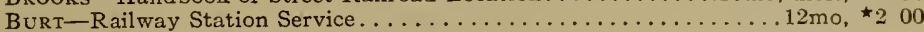

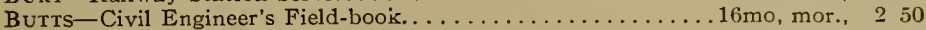

Crandal - Railway and Other Earthwork Tables................ Svo, 150

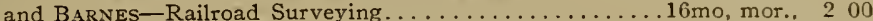

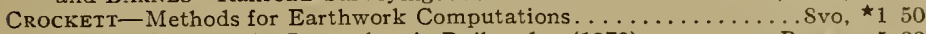

DREDGE-History of the Pennsylvania Railroad. (1S79) ...........Paper, 500

Fish-Earthwork Haul and Overhaul. ................. In Press.)

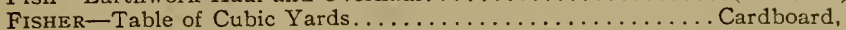

Gilbert, Wightman and Saunders-Subways and Tunnels of New York.

8vo, $\star_{4} 00$

Gonwin-Railroad Engineers' Field-book and Explorers' Guide..16mo, mor., 250

Hudson-Tables for Calculating the Cubic Contents of Excavations and

Embankments. ..........................8vo, 100

Ives and Hilts-Problems in Surveying, Railroad Surveying and Geodesy.

$16 \mathrm{mo}$, mor., 150

MOLITOR and BEARD-Manual for Resident Engineers...........

NAGLE-Field Manual for Railroad Engineers. . . . . . . . . . . . . . . . . mo, mor., 300

ORROCk-Railroad Structures and Estimates................. Svn, * 3 00

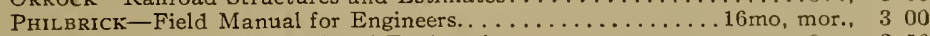

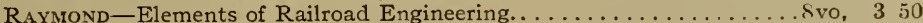

Railroad Engineer's Field Book.................. In Preparation.)

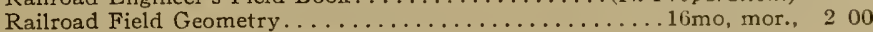

RoвERTS-Track Formulæ and Tables....................., mor., 300

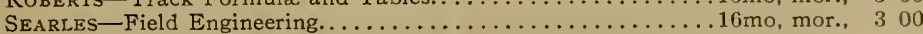

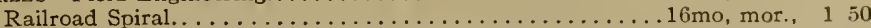

TAyLoR-Prismoidal Formulæ and Earthwork........................ 150

Wевв-Economics of Railroad Construction.......................... Svo, 250

Railroad Construction.................................. 5 00

Wellington-Economic Theory of the Location of Railways... . Small 8vo, 500

WiLsoN-Elements of Railroad-Track and Construction........., 12mo, 200 


\section{DRAWING.}

BARR and WooD-Kinematics of Machinery.......................... $\$ 250$

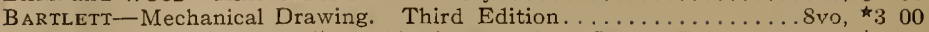
Abridgment of the Second Edition... . 8vo, * 150 and Jornson-Engineering Descriptive Geometry............8vo, ${ }_{1} 50$ Bishop-Structural Details of 'Hip and Valley Rafters... . Oblong large Svo, ${ }^{\star} 175$

Blessing and DaRLing-Descriptive Geometry . . . . . . . . . . . . 8 vo, 150 Elements of Drawing. ....................................... 150

Coolidge-Manual of Drawing................................. paper, 100 and Freeman-Elements of General Drafting for Mechanical Engineers

Oblong 4 to, 250

DURLEY-Kinematics of Machines.................... 8 vo, 400

EMCH-Introduction to Projective Geometry and its Application.......8vo, 250

French and Ives-Stereotomy............................. 250

Hill-Text-book on Shades and Shadows, and Perspective........8vo, 200

JAmison-Advanced Mechanical Drawing......................... 200 Elements of Mechanical Drawing...................... 250

Jones-Machine Design:

Part I. Kinematics of Machinery........................... 150

Part II. Form, Strength, and Proportions of Parts.......... 8 vo, 300

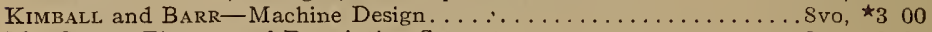

MACCoRD-Elements of Descriptive Geometry..............

Kinematics; or, Practical Mechanism................... 500

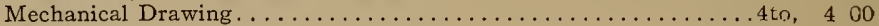

Velocity Diagrams.................................. 150

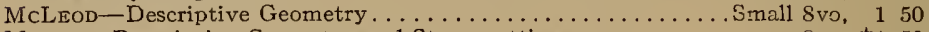

MAHAN-Descriptive Geometry and Stone-cutting............. 8 vo, ${ }^{\star} 150$

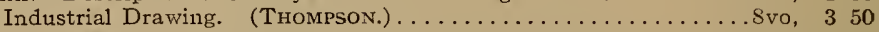

MOYER-Descriptive Geometry........................... 200

REED-Topographical Drawing and Sketching.................... 500

REID-Mechanical Drawing. (Elementary and Advanced.)......... 8vo, $\star_{2} 00$

Text-book of Mechanical Drawing and Elementary Machine Design.8vo, 300

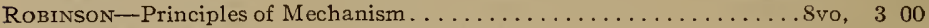

Schwamb and Merril.t-Elements of Mechanism................ 300

Smith (A. W.) and MARX-Machine Design..................... 300

(R. S.) - Manual of Topographical Drawing. (MCMillan.)....8vo, 250

Titsworth-Elements of Mechanical Drawing......... Oblong large 8vo, ${ }^{1} 25$

WARREN-Elements of Descriptive Geometry, Shadows, and Perspective.8vo, 350

Elements of Machine Construction and Drawing........... 750

Elements of Plane and Solid Free-hand Geometrical Drawing... . 12mo, 100

General Problems of Shades and Shadows................. Svo, 300

Manual of Elementary Problems in the Lincar Perspective of Forms and

Shadows.................................... 100

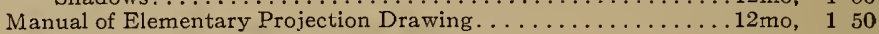

Plane Problems in Elementary Geometry................ 12mo, 125

Weisbach-Kinematics and Power of Transmission. (Herrmann and

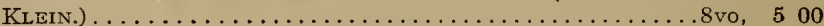

WrLson"(H. M.) - Topographic, Trigonometric and Geodetic Surveying. 8vo, 350

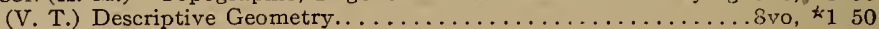

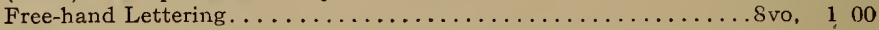

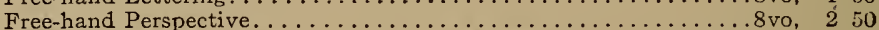

Woolf-Elementary Course in Descriptive Geometry.......... Large 8vo, 300

\section{ELECTRICITY AND PHYSICS.}

ABEGG-Theory of Electrolytic Dissociation. (von ENDE.).......12mo, ${ }^{\star} 125$

ANDREwS-Hand-book for Street Railway Engineers..... $3 \times 5$ inches, mor., 125

ANTHONY and BALL-Lecture-notes on the Theory of Electrical Measurements ...................................... 100

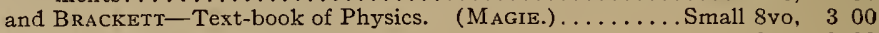

BeNJAMIN - History of Electricity . . . . . . . . . . . . . . . . $30 \ldots \ldots$ vo, 300

Betrs-Lead Refining and Electrolysis........................... 400

Burgess and Le Chatelier-Measurement of High Temperatures. Third

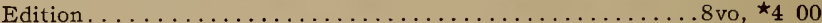

ClAsszn-Quantitative Analysis by Electro!ysis. (HALl.)........ (In Press.) 
Cozhrns-Manual of Wireless Telegraphy and Telephony. .

CREHORE and SouIER-Polarizing Photo-chronograph............. Svo, 300

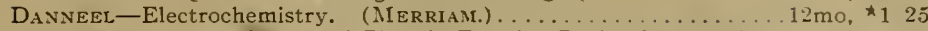

DAwsow- "Engineering " and Electric Traction Pocket-book...16mo, mor., 500

DOLEZALEK-Theory of the Lead Accumulator (Storage Battery). (Vo:

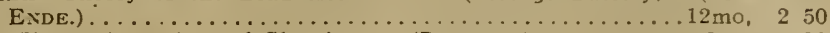

Duhem-Thermodynamics and Chemistry. (BURGess.).........8vo, 400

Flather-Dynamometers, and the Mleasurement of Power.......12mo, 300

Getmav-Introduction to Physical Science. . . . . . . . . . . . $12 \mathrm{mo}$, ${ }^{\text {I }} 50$

Gilbert-De Magnete. (Mottelay.)...................... 250

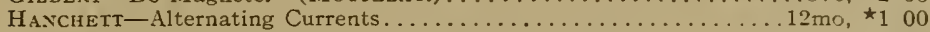

HeriNG-Ready Reference Tables (Conversion Factors)......16mo, mor., 250

Hobart and Elcis-High-speed Dynamo Electric Machinery........ \&vo, ${ }^{\star} 600$

Holmax-Precision of Measurements.................. 8vo, $2 \mathrm{G0}$

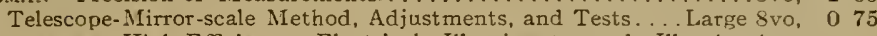

Hutchrnsos-High-Efficiency Electrical Illuminants and Illumination.

Small 8vo, 250

ToNes-Electric Ignition for Combustion Motors. . . . . . . . . . . . svo, ${ }^{\star} 400$

KARAPETOFF-Experimental Electrical Engineering:

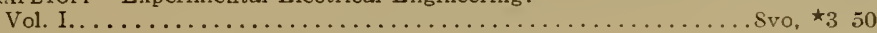

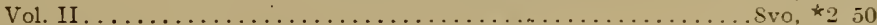

KinzbrunNer-Testing of Continuous-current Machines........... $8 v o, 200$

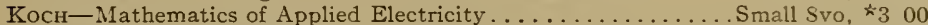

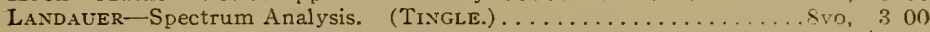

LAUFFER-Electrical Injuries . . . . . . . . .

LöB-Electrochemistry of Organic Compounds. (LoRExz.) . . . . . . Svo, 300

LyNDow-Development and Electrical Distribution of Water Power.... Svo, $\star_{3} 00$

Lyovs-Treatise on Electromagnetic Phenomena. Vols. I and II, \&vo, each, $\star_{6} 00$

Martin-Measurement of Induction Shocks................. $12 \mathrm{mo}$, $\star_{1} 25$

Michie-Elements of Wave Motion Relating to Sound and Light..... Svo, ${ }^{\star} \pm 00$

MorgaN-Physical Chemistry for Electrical Engineers.......... $12 \mathrm{mo}$, ${ }^{\star} 150$

Norris-Introduction to the Study of Electrical Engineerin . . . . . . . Svo, $\star_{2} 50$

Parshall and Hobart-Electric Machine Design........ 4to, half mor., ${ }^{\star} 1250$

REAGAN-Locomotives: Simple, Compound, and Electric........ Small Svo, 350

Rodenhauser and Schoenawa-Electric Furnaces in the Iron and Steel

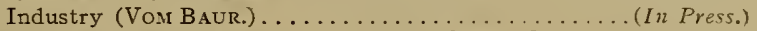

Rosenberg-Electrical Engineering. (HaLdaNF, GeE-KinzBruxiter.) . Svo, 200

Rya.N-Design of Electrical Machinery:

Vol. I. Direct Current Dynamos.............................. ${ }^{\star} 150$

Vol. II. Alternating Current Transformers........................ ${ }_{1} 50$

Vol. III. Alternators, Synchronous Motors, and Rotary Converters.

8 vo, ${ }^{1} 50$

SCHAPPER-Laboratory Guide for Students in Physical Chemistry... 12mo, 100

Tillman-Elementary Lessons in Heat. . . . . . . . . . . . . . . 8vo, ${ }^{\star} 1$

Timbie - Answers to Problems in Elements of Electricity . . . . . . 12mo, Paper, t:0 25

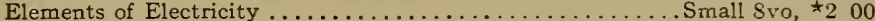

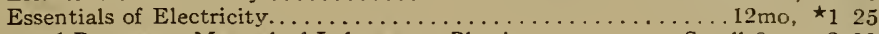

Tory and Pitcher-Manual of Laboratory Physics........... Small Svo, 200

Ulke-Modern Electrolytic Copper Refining. . . . . . . . . . . . . . Svo, 300 .

WAters-Commercial Dynamo Design.................................. $\star_{2} 00$

\section{LAW.}

BrenNaN-Hand-book of Useful Legal Information for Business Men. $16 \mathrm{mo}, \mathrm{mor}^{\circ} \star_{5} 00$

Davis-Elements of Law . . . . . . . . . . . . . . . . . . .

Treatise on the Military Law of United States....................... ${ }_{7} 00$

Dudley-Military Law and the Procedure of Courts-martial... Small 8vo, 250

Manual for Courts Martial............................ mor., 150

WAIT-Engineering and Architectural Jurisprudence. . . . . . . . . . 8vo, 600

Sheep, 650

Law of Contracts................................ 300

Law of Operations Preliminary to Construction in Engineering and

Architecture.................................... 500 


\section{MATHEMATICS.}

BAKER-Elliptic Functions. . . . . . . . . . . . . . . $\ldots \ldots \ldots$ svo, $\$ 150$ Briggs-Elements of Plane Analytic Geometry. (Bôculer.)............ 100 Buchanan-Plane and Spherical Trigonometry.............. $8 \mathrm{vo}^{\star}{ }_{1} 00$ BYerLy - Harmonic Functions. . . . . . . . ChandLeR-Elements of the Infinitesimal Calculus. . . . . . . . .

Coffin-Vector Analysis. . . . . . . . . . . . . . . . . . . . . . 50

Compton-Manual of Logarithmic Computations. . . . . . . . . . . . . . 12 mo, 150

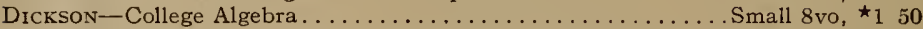

Introduction to the Theory of Algebraic Equations.......... Small $8 \mathrm{vo}$, $\star_{1} 25$

EMcH-Introduction to Projective Geometry and its Application......8vo, 250

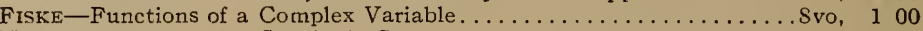

HALSTED-Elementary Synthetic Geometry................ 8vo, 150

Elements of Geometry.................................. 175

Rational Geometry.................................... ${ }_{1} 50$

Synthetic Projective Geometry...................... 100

HANCOCK-Lectures on the Theory of Elliptic Functions. . . . . . . . . 8 vo, $\star_{5} 00$

Hyde-Grassmann's Space Analysis....................... 8vo, 100

Johnson (J. B.) Three-place Logarithmic Tables: Vest-pocket size, paper, $\star_{0} 15$

100 copies, $\star_{5} 00$

Mounted on heavy cardboard, $8 \times 10$ inches, ${ }^{*} 025$

10 copies, $\star 200$

(W. W.) Abridged Editions of Differential and Integral Calculus. Small 8vo, 1 vol.. 250

Curve Tracing in Cartesian Co-ordinates................ $12 \mathrm{mo}, 100$

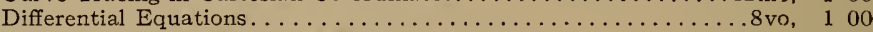

Elementary Treatise on Differential Calculus................... 8 vo, 150

Elementary Treatise on the Integ.al Calculus............ Small 8vo, 150

Theoretical Mechanics...................................... 300

Theory of Errors and the Method of Least Squares........... 12 mo, 150

Treatise on Differential Calculus........................... 8vo, 300

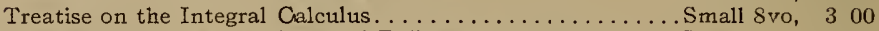

Treatise on Ordinary and Partial Differential Equations....... Small 8vo, 350

KARAPETOFF-Engineering Applications of Higher Mathematics:

Part I. Problems on Machine Design............... Small 8vo, $\star_{0} 75$

KocH-Mathematics of Applied Electricity............... Small 8vo, $\star_{3} 00$

LAPLACE-Philosophical Essay on Probabilities. (Truscotr and Emory.)

Le Messurier-Key to Professor W. W. Johnson's Differential Equations.

Small 8vo, ${ }^{\star} 75$
75

LudLow-Logarithmic and Trigonometric Tables............. 8 vo, ${ }_{1} 00$

and BASs-Elements of Trigonometry and Logarithmic and Other

Tables.................................. 8 vo, $\star_{3} 00$

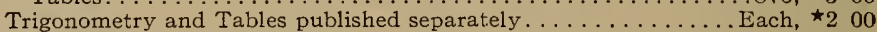

Macrarlane - Vector Analysis and Quaternions..............

MCMAHON-Hyperbolic Functions.......................... 100

MANNING - Irrational Numbers and their Representation by Sequences and Series................................... 125

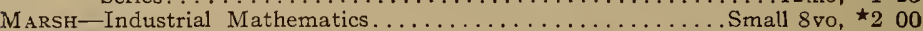

Mathematical Monographs. Edited by Mansfield Merriman and

ROBERT S. WOODWARD..................... Octavo, each, 100

No. 1. History of Modern Mathematics, by David Eugene Smith.

No. 2. Synthetic Projective Geometry, by George Bruce Halsted.

No. 3. Determinants, by Laenas Gifford Weld.

No. 4. Hyperbolic Functions, by James McMahon.

No. 5. Harmonic Functions, by William E. BYERLy.

No. 6. Grassmann's Space Analysis, by EDWARD W. HyoE.

No. 7. Probability and Theory of Errors, by RoBERT S. WOODWARD.

No. 8. Vector Analysis and Quaternions, by AlexANDER MACFarLANE.

No. 9. Differential Equations, by WILLIAM WOOLSEY JoHNSoN.

No. 10. The Solution of Equations, by MaNSField MERriman.

No. 11. Functions of a Complex Variable, by Thomas S. Fiske.

MaUrer-Technical Mechanics...................... 4 vo, 400

Merriman-Method of Least Squares..................... 2 vo, 200

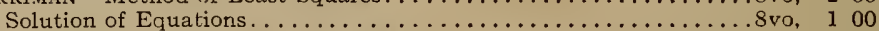

Moritz-Elements of Plane Trigonometry................ 8 vo, $\star_{2} 00$

High School Edition.................................. Small 8 vo, $\star_{1} 00$ 
RICE and JoHnson-Differential and Integral Calculus. 2 vols, in one.

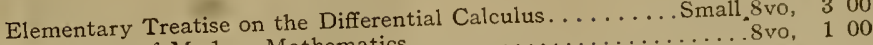
Smith-History of Modern Mathematics............................... On One VeBLEN and LenNes-Introduction to the Real Inf........... 8vo, $\star_{2} 00$ Variable..........................................................

Waterbury-Vest Pocket Hand-book of Mathematics $22_{5}^{7} \times 5 \frac{3}{8}$ inches, mor., $\star 100$

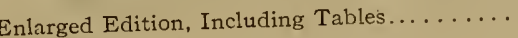

WELD-Determinants. . . . . . . . . . . . . . . . . . . . . 100

Woop-Elements of Co-ordinate Geometry.......................... 200

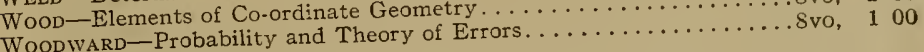

\section{MECHANICAL ENGINEER ING.}

MATERIALS OF ENGINEERING, STEAM-ENGINES AND BOILERS.

BACON-Forge Practice . . . . . . . . . . . . . . . . . . . . . . . . $12.12 \mathrm{mo}$

BALdwin-Steam Heating for Buildings. . . . . . . . . . . . . . . 12mo, 250

BARR and Wood - Kinematics of Machinery. ..................8vo, 250

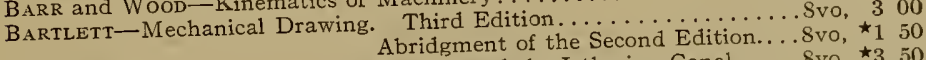

BurR-Ancient and Modern Engineering and the Isthmian Canal..... . 8vo, 350

ARPENTER - Heating and Ventilating Buildings...............8vo, 400

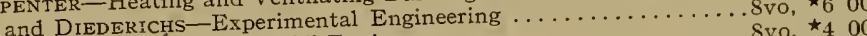

Clerk -The Gas, Petrol and Oil Engine. . . . . . . . . . . . . . . . . . . . . . . . . . . . . 4 . 40

Compton-First Lessons in Metal Working. . . . . . . . . . . . . . . . . . . . . . . . . . 12 . 12 .

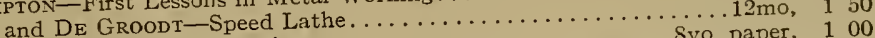

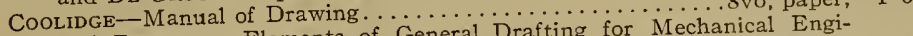

and FrEEMAN-Elements of General Drafting for M... Oblong 4to, 250

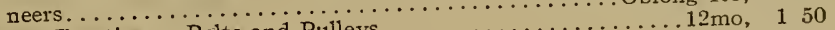

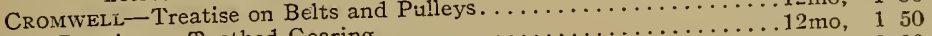

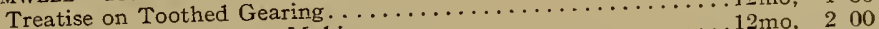

DiNGEy - Machinery Pattern Making. . . . . . . . . . . . . . . . . . . . . . . . 4 . 00

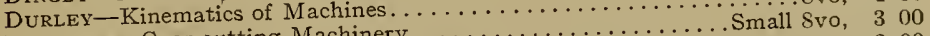

Flanders - Gear-cutting Machinery . . . . . . . . . . . . . . . . . . . 12mo, 300

FLATHER-Dynamometers and the Measurement of Power....................... 200

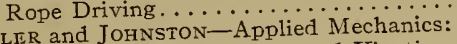

FULLER and Johnston-Applied Mechanics:

Vol. I. Theory of Statics and Kinetics................. (In Preparation.)

Vol. II. Strength of Materials................ In Preparation.)

Gill - Gas and Fuel Analysis for Engineers. . . . . . . . . . . . . . . . . . . . . . . . . . . 125

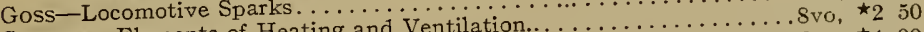

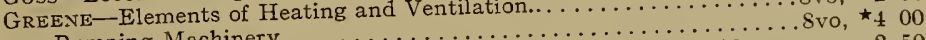

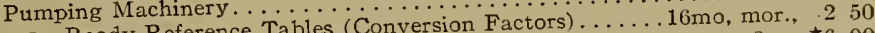

Hering-Ready Reference Tables (Conversion Factors) ....... . . . . Svo, ${ }^{\star} 600$

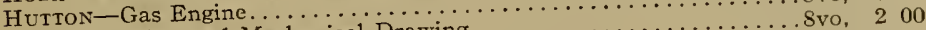

JAmIson-Advanced Mechanical Drawing. . . . . . . . . . . . . . . . . . . . . . . . 50

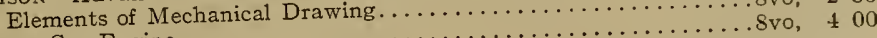

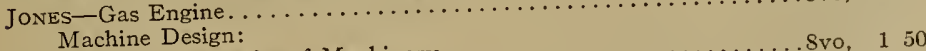

Machine Design:
Part I. Kinematics of Machinery. . . . . . . . . . . . . . . . . . . 8vo, 1 . 50

Part II. Form, Strength, and Proportions of Parts.............. Small Svo, $\star_{1} 25$

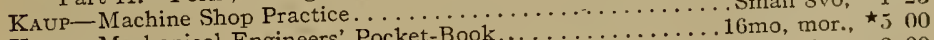

KENT-Mechanical Engineers' Pocket-Book..................................... 200

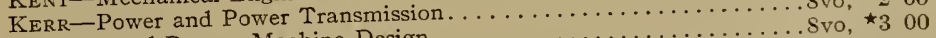

KIMLBAL and BARR-Machine Design . . . . . . . . . . . . . . . .

KING-Elements of the Mechanics of Materials and of Power of Trans- $\star 250$

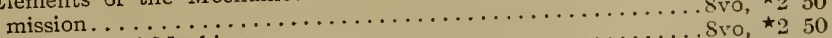

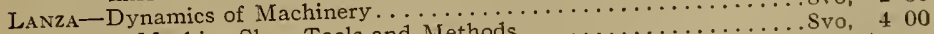

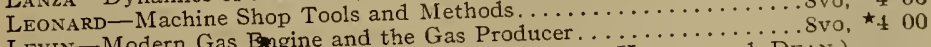

LeviN-Modern Gas Engine and the Gas Producer..................... (Pope, HAven, and DEAN.)

Lorenz-Modern Refrigerating Machinery. (Pope, Haven, and Dex.) $\star_{4} 00$ 
MACCoRD-Kinematics; or, Practical Mechanism $\ldots \ldots \ldots \ldots \ldots \ldots .8$ vo, $\$ 500$

Mechanical Drawing...................... 400

Velocity Diagrams................................ 150

MACFARLAND-Standard Reduction Factors for Gases...........

MAHAN-Industrial Drawing. (Thompson.).................. 350

Mehrtens-Gas Engine Theory and Design....................... 8vo, 250

OвERG-Handbook of Small Tools............................... 8 vo, 250

Parshall and HobarT-Electric Machine Design... Small 4 to, half leather, ${ }^{\star} 1250$

Peele-Compressed Air Plant. Second Edition, Revised and Enlarged. 8 vo, * 350

POOLE-Calorific Power of Fuels......................... 300

PORTER-Engineering Reminiscences, 1855 to $1882 \ldots \ldots \ldots \ldots \ldots \ldots$ vo, ${ }_{3} 00$

REID-Mechanical Drawing. (Elementary and Advanced.)......... 8vo, $\star_{2} 00$

Text-book of Mechanical Drawing and Elementary Machine Design. Svo, 300

Richards-Compressed Air........................... 150

RoBinson-Principles of Mechanism............................. 300

SCHWAMB and MERRILL-Elements of Mechanism.............

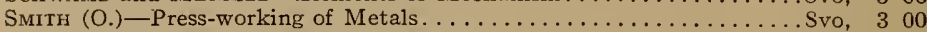

(A. W.) and MARX-Machine Design...............8vo, 300

SOREL-Carbureting and Combustion in Alcohol Engines. (WOODWARD and Preston.)......................................... $8 \mathrm{vo}, 300$

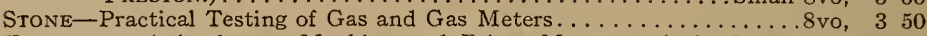

Thurston-Animal as a Machine and Prime Motor, and the Laws of

Energetics........................... 100

Treatise on Friction and Lost Work in Machinery and Mill Work. .8vo, 300

TILLSON-Complete Automobile Instructor................

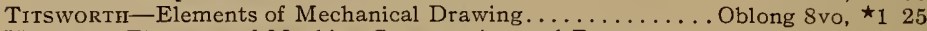

WARREN-Elements of Machine Construction and Drawing........8vo, 750

WATERBURY-Vest Pocket Hand-book of Mathematics for Engineers.

$2 \frac{7}{8} \times 5 \frac{3}{8}$ inches, mor., ${ }^{\star} 100$ Enlarged Edition, Including Tables............................ ${ }^{\star} 150$ WeISBACH-Kinematics and the Power of Transmission. (HERrManN-

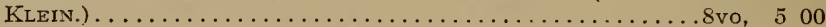

Machinery of Transmission and Governors. (HerRmann-Kiein.).8vo, 500

Wood-Turbines........................................ 250

\section{MATERIALS OF ENGINEERING.}

Bottler-German and American Varnish Making. (SABIN.)...Small 8vo, * 350 BURR-Elasticity and Resistance of the Materials of Engineering.....8vo, 750 CHURCH-Mechanics of Engineering...................... 600 Mechanics of Solids (Being Parts I, II, III of Mechanics of Engineering).

FULler and JoHnston-Applied Mechanics:

Vol. I. Theory of Statics and Kinetics. . . . . . . . . . . (In Press.)

Vol. II. Strength of Materials.................... Preparation.)

Greene-Structural Mechanics................................... $\star_{2} 50$

HoLLEy - Analysis of Paint and Varnish Products....................... 8 vo, $\star_{2} 50$

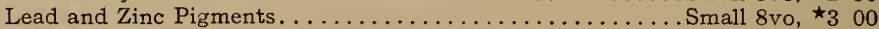

Johnson (C. M.) - Rapid Methods for the Chemical Analysis of Special

Steels, Steel-making Alloys and Graphite........... Small 8vo, 300

(J. B.) Materials of Construction.................... 6 vo, 60

KeEP-Cast Iron. . . . . . . . . . . . . . . . . . .

KING-Elements of the Mechanics of Materials and of Power of Trans-

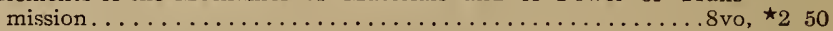

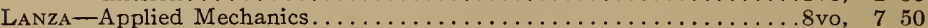

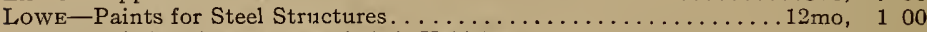

MAIRE-Modern Pigments and their Vehicles................ 200

MARIIN-Text-Book of Mechanics:

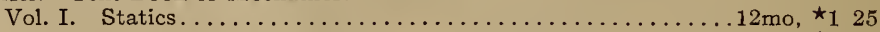

Vol. II. Kinematics and Kinetics............................. $\star_{1} 50$

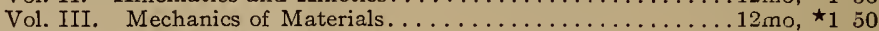

Vol. IV. Applied Statics. . . . . . . . . . . . . . . . . . . 12mo, $\star_{1} 50$

Maurer-Technical Mechanics............................. 400

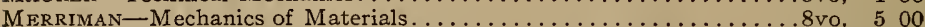

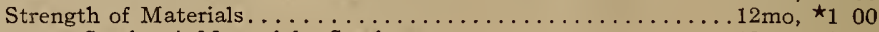

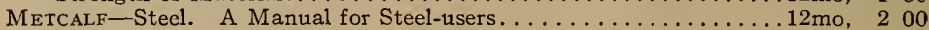

MURDOCK-Strength of Materials.......................... $\star_{2} 00$ 
SABIN-Industrial and Artistic Technology of Paint and Varnish......8vo, $\$ 300$ Smith (A. W.)-Materials of Machines................... 100

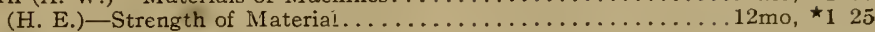

ThuRston-Materials of Engineering....................... 8 vols, 800

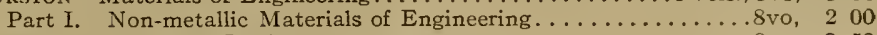

Part II. Iron and Steel. ......................

Part III. A Treatise on Brasses, Bronzes, and Other Alloys and their Constituents ............................... WAterbury-Laboratory Manual for Testing Materials of Construction.

Wood (DE V.) -Elements of Analytical Mechanics.............. 8vo,

Treatise on the Resistance of Materials and an Appendix on the Preser-

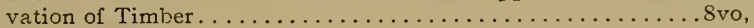

(M. P.) Rustless Coatings. Corrosion and Electrolysis of Iron and

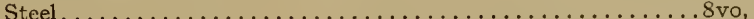

\section{STEAM-ENGINES AND BOILERS.}

ABRAHAM - Steam Economy in the Sugar Factory. (BAyLE.)... (In Press.) BERRY-Temperature-entropy Diagram. Third Edition Revised and EnJarged. . . . . . . . . . . . . . . . . . . . 12mo, Carnot-Reflections on the Motive Power of Heat. (Thurstox.)...12mo, CHASE-Art of Pattern Making...................... 12mo, Crerghton-Steam-engine and other Heat Motors. . . . . . . . . . . . . . . . . . . . . DAwson-" Engineering " and Electric Traction Pocket-book...16mo, mor., C. Steam Porver Plant Engineering ................ 8vo, 600

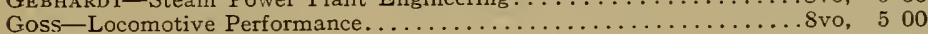
HEMENWAY - Indicator Practice and Steam-engine Economy.........12mo, 200 HIRSHIELD and BARNARD-Heat Power Engineering. ...........8vo, $\star_{5} 00$

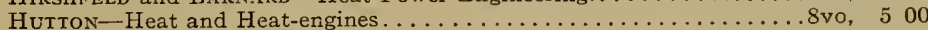
Mechanical Engineering of Power Plants ..................8vo, 500

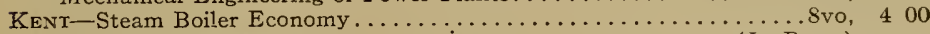
King-Steam Engineering. . . . . . . . . . . . . . . . . . . (In Press.)

KNEAss-Practice and Theory of the Injector . . . . . . . . . . . . . . . . . 150 MACCord -Silde-valves..............................8vo, 200 MEXER - Modern Locomotive Construction. . . . . . . . . . . . . . . . . . . . . . 4to, 1000 Miller, Berry, and Riley-Problems in Thermodynamics.... Svo, paper, 075 Moyer-Steam Turbines .................................8vo, 400 PEA Bodx-Manual of the Steam-engine Indicator . . . . . . . . . . . 12mo, 150 Tables of the Properties of Steam and Other Vapors and Temperature-

Entropy Table................................... 100

Thermodynamics of the Steam-engine and Other Heat-engines. . . .8vo, 500

Thermodynamics of the Steam Turbine..................8vo, 300

Valve-gears for Steam-engines. . . . . . . . . . . . . . . . . . . . . . . . . . 250

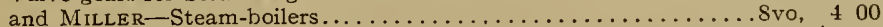

Perkins-Introduction to General Thermodynamics . . . . . . . . . . $12 \mathrm{mo}$, 150

PuprN-Thermodynamics of Reversible Cycles in Gases and Saturated Vapors. (OSterberg.) .................... 12mo, ReaGan-Locomotives: Simple, Compound, and Electric. New Edition. Small Svo

SINCLAIR - Locomotive Engine Running and Management. . . . . . . 12mo, SMART - Handbook of Engineering Laboratory Practice. . . . . . . . . 12mo, SNow-Steam-boiler Practice. . . . . . . . . . . . . . . . . . . . . . 8vo, SPANGLER - Notes on Thermodynamics . . . . . . . . . . . . . . 12 mo

Valve-gears . . . . . . . . . . . . . . . . . . . . . . . . . . . . .

GreEne, and MARshall-Elements of Steam-engineering ........

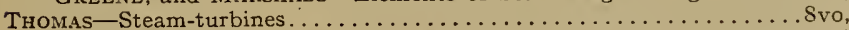
THURSToN-Manual of Steam-boilers, their Designs, Construction, and

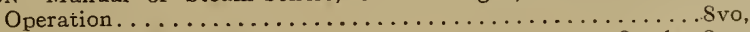

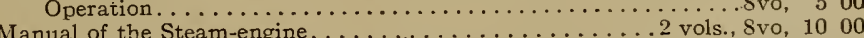
Part I. History, Structure, and Theory.............. 8vo, 600

Part II. Design, Construction, and Operation..................... 600 WeHRENFENNiG-Analysis and Softening of Boiler Feed-twater. (PATterson.) .................................... 4.00 WEISBACH-Heat, Steam, and Steam-engines. (DU Bois.) . . . . . . . . Svo, 500

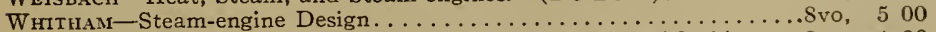
Woon-Thermodynamics, Heat Motors, and Refrigerating Machines...8vo, 400 


\section{MECHANICS PURE AND APPLIED.}

Church-Mechanics of Engineering.... . . . . . . . . . . . . Mechanics of Solids (Being Parts I, il, III of Mechanics of Engineering).

Mechanics of Fluids (Being Part IV of Mechanics of Engineering).8vo, 300 Mechanics of Internal Work ............................... 150

Notes and Examples in Mechanics........................... 200

DANA-Text-book of Elementary Mechanics for Colleges and Schools..12mo, 150 Du Bors-Elementary Principles of Mechanics:

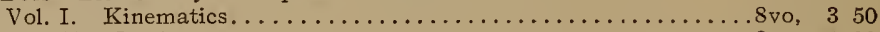

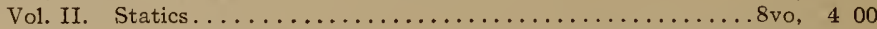

Mechanics of Engineering. Vol. I.......................... 4to, 750 Vol. II. . . . . . . . . . . Small 4 to, 1000

FUller and Johnston-Applied Mechanics:

Vol. I. Theory of Statics and Kinetics................. (In Press.)

Vol. II. Strength of Materials................ In Preparalion.)

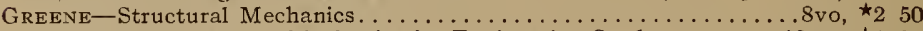
HARTMAnN-Elementary Mechanics for Engineering Students.......... JAMES-Kinematics of a Point and the Rational Mechanics of a Particle. Small 8vo, 200 Jorinson (W. W.) Theoretical Mechanics.......................... ${ }^{*} 300$ KING-Elements of the Mechanics of Materials and of Power of Transmission..................................... $\star_{2} 50$

Kоттсамp-Exercises for the Applied Mechanics Laboratory, Loose Leaf Laboratory Manual................... Oblong 4to, paper, ${ }_{1} 100$

LANZA-Applied Mechanics......................... 750 MARTIN-Text Book of Mechanics:

Vol. I. Statics........................................ ${ }_{1} 25$

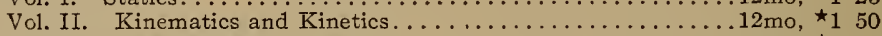

Vol. III. Mechanics of Materials........................... $\star_{1} 50$

Vol. IV. Applied.Statics.................................. 150 MAURER-Technical Mechanics........................... 400 MERRIMAN-Elements of Mechanics............................... ${ }_{1} 00$ Mechanics of Materials.......................... 500 Michie-Elements of Analytical Mechanics................. 8 vo, $\star_{4} 00$ RoBInson-Principles of Mechanism.............................. 300 SANBORN-Mechanics Problems.................................. 8 vo, ${ }^{1} 50$ SchwaMb and MerRILL-Elements of Mechanism.................. 300 Wood-Elements of Analytical Mechanics................ 3 vo, 300

Principles of Elementary Mechanics....................... 125

\section{MEDICAL.}

ABDERHALDEN-Physiological Chemistry in Thirty Lectures. (HALL and DEFREN.) . . . . . . . . . . . . . . . . voN BEHRING - Suppression of Tuberculosis. (Bolduan.)........... $12 \mathrm{mo}, 100$ BoldUAN-Immune Sera . . . . . . . . . . . . . . . . . . $12 \mathrm{mo}, \star_{1} 50$

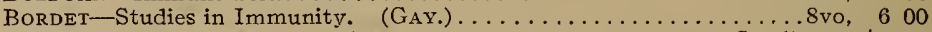
CHAPIN - The Sources and Modes of Infection. ......................... 8 vo, $\star_{3} 00$

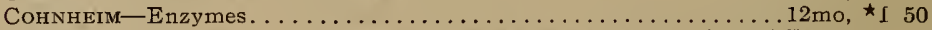
DAVENPORT-Statistical Methods with Special Reference to Biological Variations....................................... 150 Effront-Enzymes and Their Applications. (PREscott.).......... 3 vo, 300 Ehrlich-Studies on Immunity. (Bolduan.) ................... 600 Euler-General Chemistry of the Enzymes. (Pope.) . . . . . . . . . . . Fischer-Nephritis . . . . . . . . . . . . . . . . . . . . . . . . .

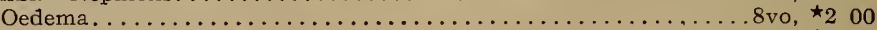

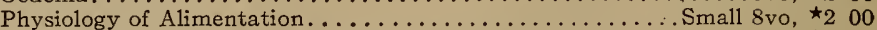
DE Fursac-Manual of Psychiatry. (Rosanoff and Collins.). Small 8vo, $\star_{2} 50$ Fuller-Qualitative Analysis of Medicinal Preparations.........12mo, ${ }_{1} 50$ Hammarsten-Text-book on Physiological Chemistry. (MANDEL.).... 8 vo, * 400 JAckson-Directions for Laboratory Work in Physiological Chemistry. Svo, 125 LASSAR-COHN-Praxis of Urinary Analysis. (LORENz.).........12mo, 100 LAUFFE R-Electrical Injuries. . . . . . . . . . . . . . . . . . . MANDEL-Hand-book for the Bio-Chemical Laboratory..........12mo, 150 
MARTIN-Measurement of Induction Shocks............... 12mo, ${ }^{\star} 125$

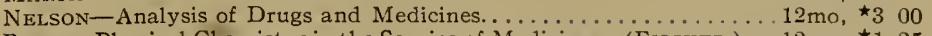

PaULI-Physical Chemistry in the Service of Medicine. (Frscher.)...12mo, ${ }^{\star} 125$

PozzI-Escot-Toxins and Venoms and their Antibodies. (COHN.)...12mo, ${ }_{1} 00$

RostoskI-Serum Diagnosis. (BolduAn........................ 100

Ruddrman-Incompatibilities in Prescriptions...................... 200

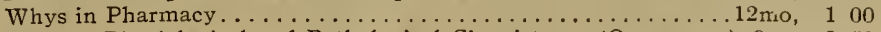

SALkowski-Physiological and Pathological Chemistry. (ORNDORfF.).8vo, 250

SAtTerlee-Outlines of Human Embryology ...............

Smrth-Lecture Notes on Chemistry for Dental Students...........

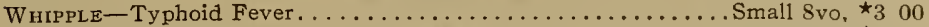

Woodhull - Military Hygiene for Officers of the Line.......... Small Svo, ${ }_{1} 50$

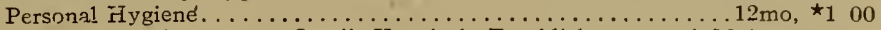

WorCESTER and ATKINSON-Small Hospitals Establishment and Maintenance, and Suggestions for Hospital Architecture, with Plans for a

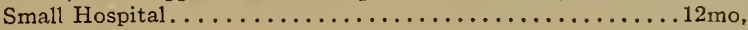

\section{METALLURGY.}

BETTS-Lead Refining by Electrolysis....................

Bolland-Encyclopedia of Founding and Dictionary of Foundry Terms used in the Practice of Moulding...................

Iron Founder. . . . . . . . . . . . . . . . . . . . . $12 \mathrm{mo}$ BURGeSS and LE CHATELIEK-Measurement of High Temperatures. Third

Edition. ............................

Douglas-Untechnical Addresses on Technical Subjects.........12mo, 100

Goesel-Minerals andjMetals: A Reference Book.........16mo, mor., 300

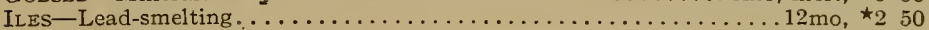
JoHnson-Rapid Methods for the Chemical Analysis of Special Stee!s, Steel-making Alloys and Graphite................................. 300 KeEp-Cast Iron..................................... 250 Metcalf-Steel. A Manual for Steel-users.................... 2 mo, 200 MINET-Production of Aluminum and its Industrial Use. (WALDo.)..12mo, 250 PALMER-Foundry Practice.................................... 8vo, $\star_{2} 00$

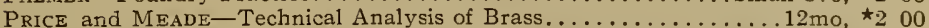
RODENHAUSER and Schoenatwa-Electric Furnaces in the Iron and Steel

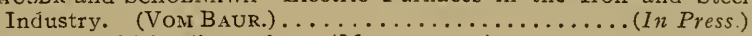

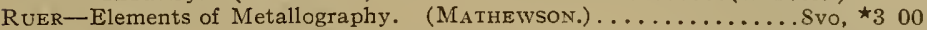

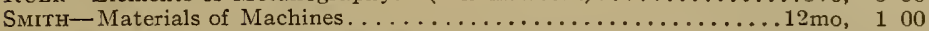

TAte and Stone-Foundry Practice.............................. 200

THurston-Materials of Engineering. In Three Parts............ 8 vo, 800

Part I. Non-metallic Materials of Engineering, see Civil Engineering, page 9.

Part II. Iron and Steel. . . . . . . . . . . . . . . . . . . svo

Part III. A Treatise on Brasses, Bronzes, and Other Alloys and Their

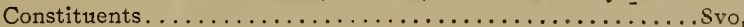

Urke-Modern Electrolytic Copper Refining. . . . . . . . . . . . . 8vo,

WEst-American Foundry Practice. . . . . . . . . . . . . . . . .

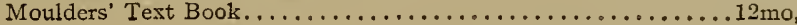

\section{MILITARY AND MARINE ENGINEERING。}

\section{ARMY AND NAVY.}

Bernadou-Smokeless Powder, Nitro-cellulose, and the Theory of the Cellulose Molecule.................................. 250

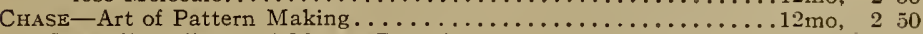
Screw Propellers and Marine Propulsion................. svo, 300

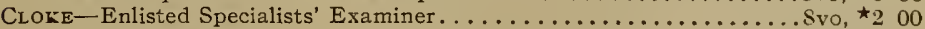
Gunner's Examiner.................................. 150

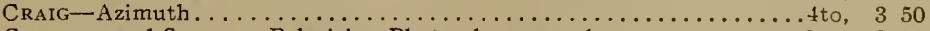
CREHORE and SQUiER-Polarizing Photo-chronograph................ Svo, 300

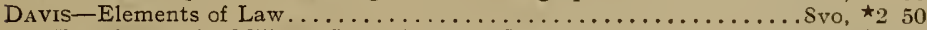

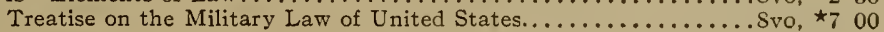


Dudley-Military Law and the Procedure of Courts-martial....Small 8 vo, $\star_{2} 50$

DURand - Resistance and Propulsion of Ships............... 500

DYER - Handbook of Light Artillery.................... $12 \mathrm{mo}^{\star} 300$

Eissler-Modern High Explosives........................ 400

FIEBEGER - Text-book on Field Fortification. . . . . . . . . . . . Small $8 \mathrm{vo}, \star_{2} 00$

Hamilton and Bond-The Gunner's Catechism............... $18 \mathrm{mo}, 100$

Howf-Elementary Naval Tactics. . . . . . . . . . . . . . . . . . 8 vo, 1150

Ingalls-Handbook of Problems in Direct Fire............... 4 vo, 400

Interior Ballistics........................................ ${ }_{3} 00$

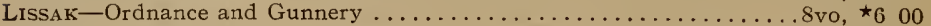

LudLow-Logarithmic and Trigonometric Tables............... svo, $^{\star} 100$

LyoNs-Treatise on Electromagnetic Phenomena. Vols. I. and II., 8vo, each, ${ }^{\star} 600$

MaHAN-Permanent Fortifications. (MERCUR) ........ 8 vo, half mor., *7 50

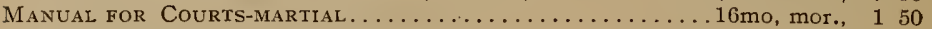

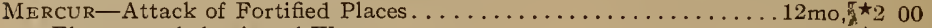

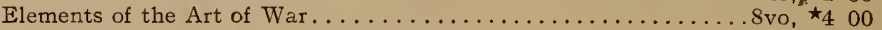

Nixon-Adjutants' Manual. ............................... 100

PEABODy-Naval Architecture............................ 750

Propellers..................................... 125

Phelps-Practical Marine Surveying. . . . . . . . . . . . . . . 50

Putnam-Natical Charts............................. 200

Rust--Ex-meridian Altitude, Azimuth and Star-Finding Tables...... 8 vo, 500

Selkirk - Catechism of Manual of Guard Duty ...............

SHARPE-Art of Subsisting Armies in War .............. mo, mor., 150

TAYLOR-Speed and Power of Ships. 2 vols. Text Svo, plates oblong 4 to, $\star_{7} 50$

TUPES and POOLE-Manual of Bayonet Exercise and Musketry Fencing.

$24 \mathrm{mo}$, leather, $\star_{0} 50$

WeAver-Military Explosives....................... 8 vo, $^{\star} 300$

Woodhull-Military Hygiene for Officers of the Line......... Small 8vo, ${ }^{\star} 150$

\section{MINERALOGY.}

BrownING-Introduction to Rarer Elements. . . . . . . . . . . . . 8vo, ${ }^{1} 50$

Brush--Manual of Determinative Mineralogy. (Penfield.).........8vo, 400

BUTLER-Pocket Hand-book of Blowpipe Analysis.............

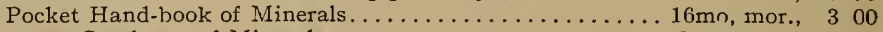

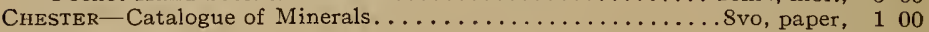

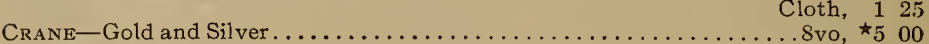

Dana-First Appendix to Dana's New " System of Minera!ogy.". Large $8 v o, \quad 100$

Second Appendix to Dana's New " System of Mineralogy." Large 8vo, 150

Manual of Mineralogy. (ForD.)....................... $\star_{2} 00$

Minerals, and How to Study Them.......................... 150

System of Mineralogy............................................... 1250

Text-book of Mineralogy.............................. 400

Douglas - Untechnical Addresses on Technical Subjects....................... 100

EAKLE-Mineral Tables...................................... 125

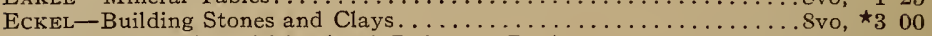

GoEsEL-Minerals and Metals: A Reference Book..........16mo, mor., 300

Groth-The Optical Properties of Crystals. (JAckson.)............

Introduction to Chemical Crystallography. (MARSHall.)....... 12mo, 125

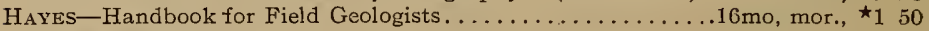

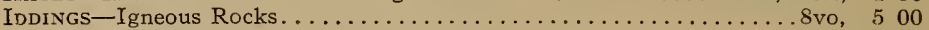

Rock Minerals............................... 5 vo, 00

JoHANNSEN-Determination of Rock-forming Minerals in Thin Sections, $8 \mathrm{vo}$,

With Thumb Index, 500

LEwIS-Determinative Mineralog. . . . . . . . . . . . . . Small Svo, $\star_{1} 50$

MARTIN-Laboratory Guide to Qualitative Analysis with the Blowpipe.12mo, ${ }_{0} 00$

Merrill-Non-metallic Minerals: Their Occurrence and Uses....... 8vo, 400

Stones for Building and Decoration..................... 5 vo, 50

Penfield - Notes on Determinative Mineralogy and Record of Mineral

Tests........................... svo, paper, $\star_{0} 50$

Tables of Minerals, Including the Use of Minerals and Statistics of

Domestic Production. .......................... 100

Prrsson-Rocks and Rock Minerals. ...................

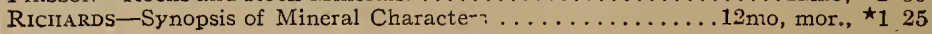


RIEs-Building Stones and Clay Products................. 8 vo, ${ }^{\star} \$ 300$ Clays: Their Occurrence, Properties and Uses.............. Svo, $\star^{\star} 500$ and LeIGHTON-History of the Clay-working Industry of the United

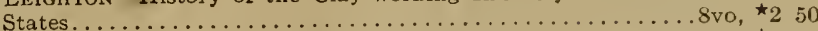

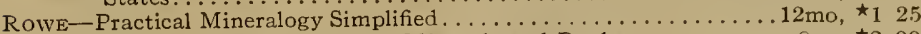
Tillman-Text-book of Important Minerals and Rocks...........8vo, ${ }^{2} 00$ WAsHington-Manual of the Chemical Analysis of Rocks..........

\section{MINING.}

BEARD-Mine Gases and Explosions........................... 8vo, ${ }^{3} 00$

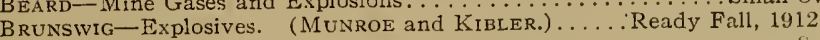

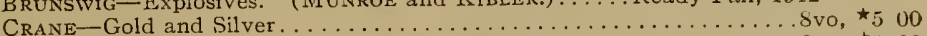
Index of Miring Engincering Literature, Vol. I. . . . . . . . . . . . $8 \mathrm{vo}^{\star}{ }_{1} 00$ $8 \mathrm{vo}, \mathrm{mor}, \star{ }_{5} 00$ Vol. II ............. 8 vo, $\star_{3} 00$ Svo, mor., $\star_{4} 00$

Ore Mining Methods................................. ${ }^{\star} 30$

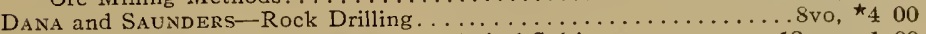
Douglas-Untechnical Addresses on Technical Subjects........... EisSLER-Modern High Explosives........................... 400 Gilbert, Wightman and Saunders-Subways and Tunnels of New York.

Goesel-Minerals and Metals: A Reference Book..........16mo, mor., 300

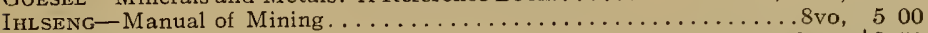
Iles-Lead Smelting. . . . . . . . . . . . . . . . . . . . 50

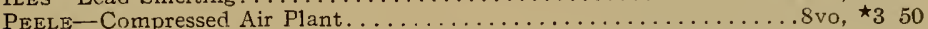
Riemer-Shaft Sinking under Difficult Conditions. (Corning and Peele.) Svo, 300

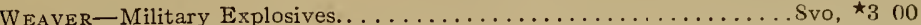

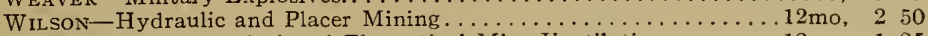
Treatise on Practical and Theoretical Mine Ventilation.......12mo, 125

\section{SANITARY SCIENCE.}

Association of State and National Food and Dairy Departments,

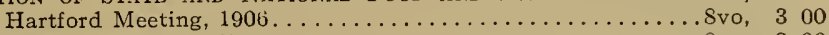

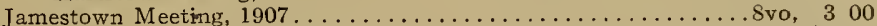

BASHORE-Outlines of Practical Sanitation. . . . . . . . . . . . . . Sanitation of a Country House....................... 100 Sanitation of Recreation Camps and Parks.................... 100

Folwell-Sewerage. (Designing, Construction, and Maintenance.)... Svo, 300 Water-supply Engineering............................. 400

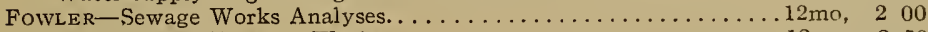

Fuertes-Water-filtration Works........................... 250

Gerhard-Guide to Sanitary Inspections...................... 150

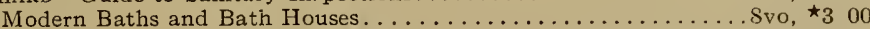

Sanitation of Public Buildings................... 150

The Water Supply, Sewerage, and Plumbing of Modern City Buildings.

HAZEN-Clean Water and How to Get It . . . . . . . . . . . Small Svo, 150

Filtration of Public Water-supplies.................

Kinnicutt, Winslow and Pratt-Sewage Disposal ..............

LEACH-Inspection and Analysis of Food witl Special Reference to State

Control. ............................... 750

MASON-Examination of Water. (Chemical and Bacteriological................... 125

Water-supply. (Considered principally from a Sanitary Standpoint.)

Svo, 400

MERRIMAN-Elements of Sanitary Engineering............... Svo, $\star_{2} 00$

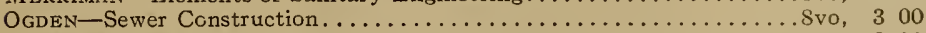

Sewer Design.............................................. 200

Ogden and Cleveland-Practical Methods of Sewage Disposal for Res-

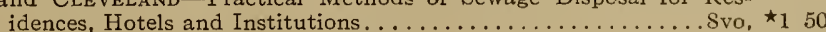

Parsons-Disposal of Municipal Refuse................... 
PRESCOTT and WinsLow-Elements of Water Bacteriology, with Special Reference to Sanitary Water Analysis........................ \$1 50

PrICE-Handbook on Sanitation. . . . . . . . . . . . . . . . 50

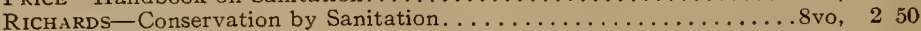

Cost of Cleanness. ................................... 100

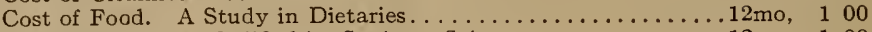

Cost of Living as Modified by Sanitary Science.................... 100

Cost of Shelter....................................... 100

Laboratory Notes on Industrial Water Analysis...............

RICHARDS and WOODMAN-Air, Water, and Food from a Sanitary Standpoint................................. 200

Richey-Plumbers', Steam-fitters', and Tinners' Edition (Building Mechanics' Ready Reference Series) .................16mo, mor., ^1 50

RiDfal-Disinfection and the Preservation of Food ...........8vo, 400

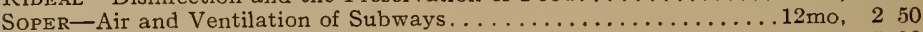

TuRnEaure and Russell_-Public Water-supplies.............. 5 vo, 500

Venable-Garbage Crematories in America......................... $\varepsilon 00$

Method and Devices for Bacterial Treatment of Sewage........8vo, 300

WARD and WHIPPLE-Freshwater Biology................. (In Press.)

WhIPPLE-Microscopy of Drinking-water ................... 3 . 30

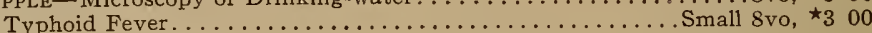

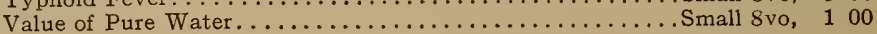

\section{MISCELLANEOUS.}

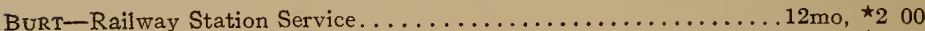

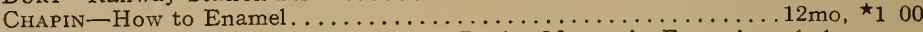

Emmons-Geological Guide-book of the Rocky Mountain Excursion of the

International Congress of Geologists.............. Large 8vo, 150

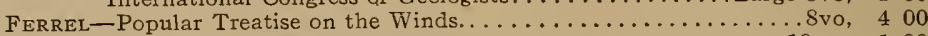

Fitzgerald - Boston Machinist ................................ 100

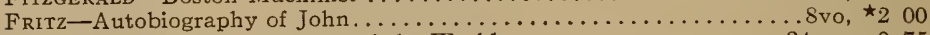

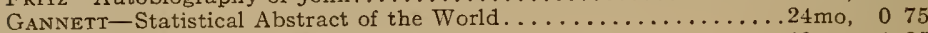

GreEN-Elementary Hebrew Grammar...................... 125

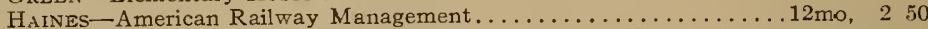

HANAUSEK-The Microscopy of Technical Products. (Winton.)...... Svo, 500

JACOBS-Betterment Briefs. A Collection of Published Papers on Organized Industrial Efficiency........................ 350

Metcalfe-Cost of Manufactures, and the Administration of Workshops.

Svo, 500

PARKhuRst-Applied Methods of Scientific Management ......... 8vo, $\star_{2} 00$

Putnam-Nautical Charts................................... 200

RICKETTS-History of Rensselaer Polytechnic Institute, 1824-1894.

Small 8vo, 300

Rotch and PALMER-Charts of the Atmosphere for Aeronauts and Aviators.

Oblong 4 to, $\star_{2} 00$

RotherhaM-Emphasised New Testament....................... 8vo, 200

Rust-Ex-Meridian Altitude, Azimuth and Star-finding Tables........

StANDAGE-Decoration of Wood, Glass, Metal, etc............12mo, 200

Westermaier-Compendium of General Botany. (Schneider.)...... . 8vo, 200

Winslow-Elements of Applied Microscopy ................ $12 \mathrm{mo}, \quad 50$ 

Whit 31913 


LIBRARY OF CONGRESS

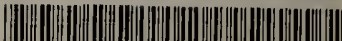

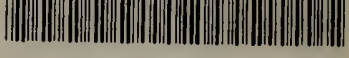

00009231055 